Final Report 275.03-72-11

on

-Survey - Compatibility of Materials with

High Pressure Oxygen Service

prepared for

National Aeronautics and Space Administration George C. Marshall Space Flight Centex Huntsville, Alabama

October 1972

NASA Order Number H-9 $2180 \mathrm{~A}$ Principal Technical Representative John G. Austin

Huntsville, Alabama

Prepared by

J. G. Hust and A. F. Clark Cryogenics Division Institute for Basic Standards National Bureau of Standards Boulder, Color ado 80302

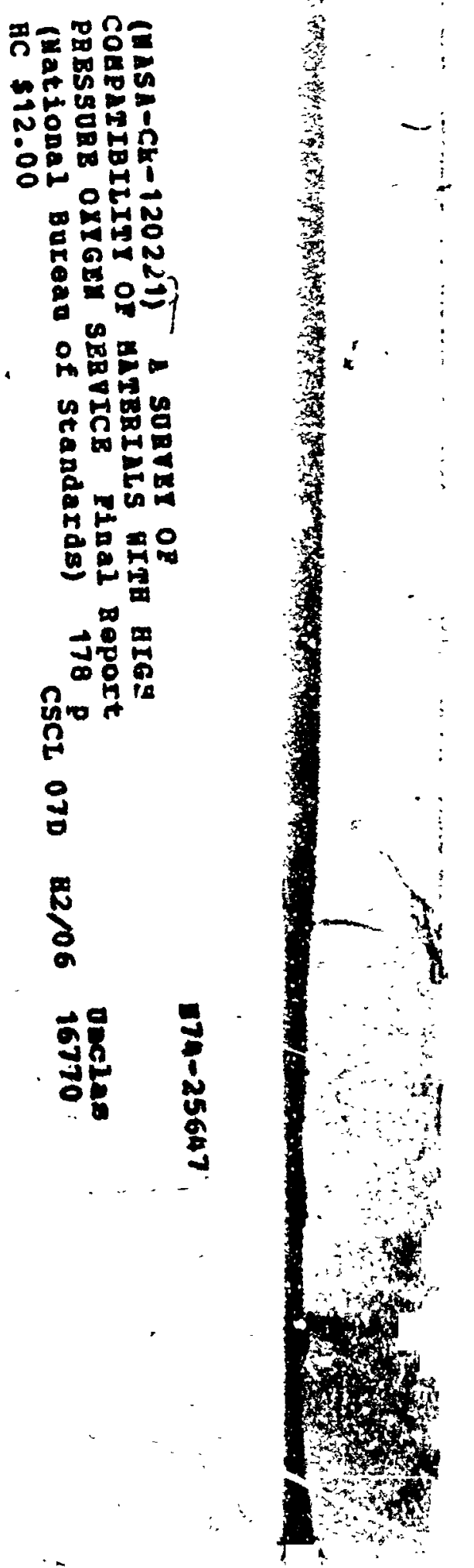




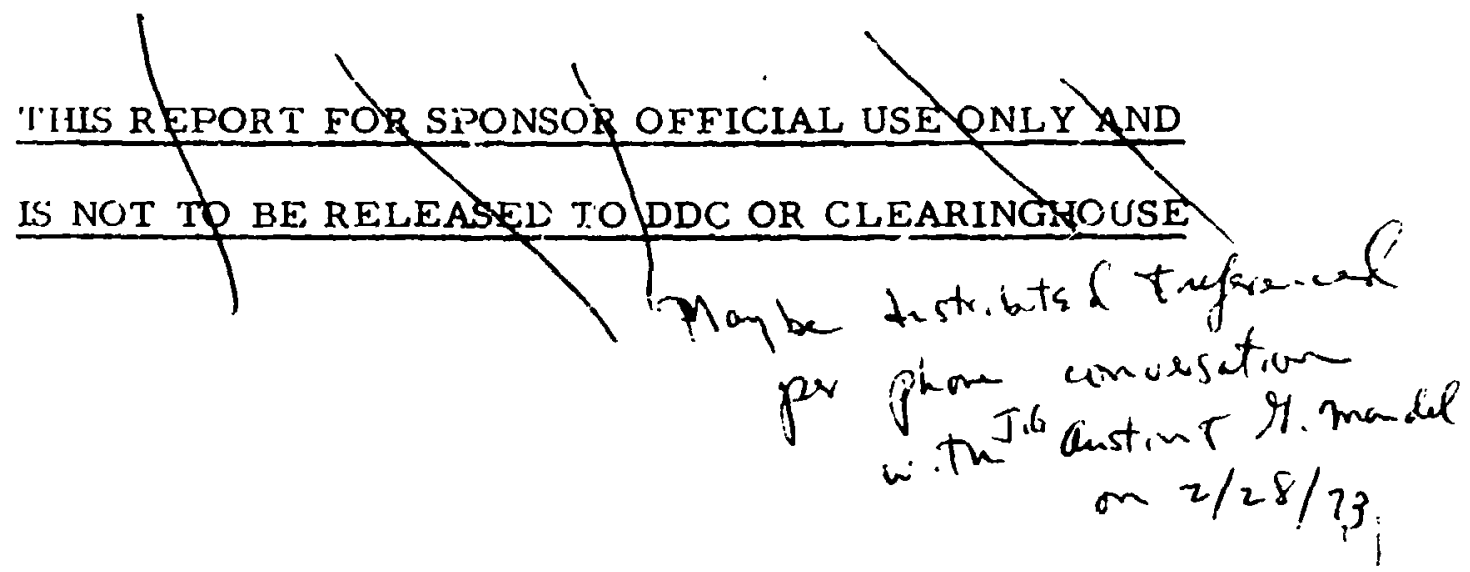

IMPORTANT NOTICE

The results of this report are not to be used for advertising or promosional purposes, or to indicate endorsement or disapproval of the uroduct(s) by the National Bureau of Standards.

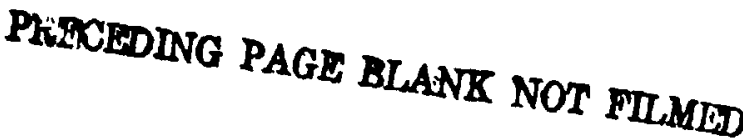


A Survey of Compatibility of Materials with

High Pressure Oxygen Service

Page

I. Introduction ..................... 1

II. Material Selection. ................... 4

A. Structural Considerations ............ 6

B. Chemical Reaction Considerations .........6 6

1. Reaction Sensitivity.............. 6

2. Reaction Inten sity ............. 7

3. Ignition Sources.............. 8

C. Recommended Selection Procedure........... y

III. Matc rial Compatibility Tests............... 13

IV. Material Compatibility Data ............. 19

A. Metals .................. 20

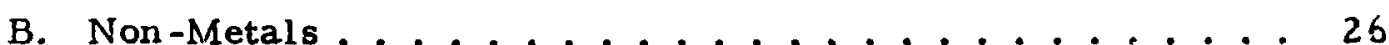

V. High Pressure Oxygen Equipment ............ 28

v1. High Pressure Oxygen Facilities ............ 32

VII. Recommendations ................ 34

vill. Summary .................... 38

IX. References ...................440

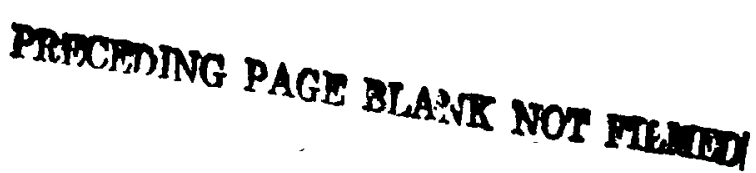


A Survey of Compatibility of Materials with

High Pressure Oxygen Service

I. Introduction

The Cryogenics Division of the National Bureau of Standards (NBS-CD) was recently requested by the Marshall Space Flight Center of the National Aeronautics and Space Administration (NASA-MSFC) to perform a survey and assess the existing state of knowledge regarding compatibility of materials with high pressure oxygen. Particular emphasis is to be placed on past practical operational and research experience.

Material compatibility, in general, implies a harmonious coexistence of all the materials of a system. The lack of such compatibility can lead to undesirable and sometimes disastrous results. For example, the chemical reaction of a combustible material with oxygen in a system results in corrosion, burning, or even explosion. It is clear that the general definition of incompatibility encompasses many phenomena. In this study, however, we have restricted ourselves to the consideration of materials exposed to high pressure oxygen. Because only high pressures are considered, any manrelated incompatibilities are ignored. The harmonious coexistence of materials in a high pressure oxygen system implies the physical containment of the oxygen as well as the lack of significant chemical reactions with the oxygen. Thus compatible materials are defined, in this study, as those materials or combinations of materials with sufficient mechanical strength to withstand the high pressures and whowe propertics are not significantly degraded by the presence of oxyger. We will pay particular attention to the ease with which any degradation is initiated (reaction sensitivity), the rate at which degradation progresees (reaction intensity), and the eurces of degradation 
initiation (ignition sources). The dependence sf these parameters on physical properties, such as thermal conductivity, specific heat, density, and heat of combustion, as well as system characteristics, such as pressiza, pipe wall thickness, total mass, radius of pife bends, and surface roughness, is considered. It is to be noted that the dependence on pressure is the primary consideration here; however, the interdependence of the effects of these characteristics makes it ess entially impossible to analyze any one separately.

The objective of this surrey is to gather the available information on the compatibility of materials with oxygen as applied to the production, transport, and applicaticrs experience of high pressure liquid and gaseous oxygen and to compile ihis material into a usable reference report. High pressure is here defined to be above about 2000 to $3000 \mathrm{psia}$. Since high pressure projections sometimes can be made from lower pressure data, some low pressure data are also included. Low pressure data are incluáed if they are considered helpful to a better understanding of the behavior at high pressures.

It is anticipated that this technical input to NASA-MSFC will assist in the establishment of practical and safe, but not stifling, guidelines in the future use of high pressure oxygen. It is hoped that such guidelines will eventual'y be commonly accepted throughout NASA, other government agencies, and the: commercial sector as well.

Recently, Clark (1971) of NBS performed a survey on oxygen compalibility of materials at ordinary pressures. Information from Clark's report whish is especially applicable to high pressure application will be repeated for convenience. Surveys of oxvgen related accidents have been conducted recently by Ordin (1971) and Johnson (1970) for NASA and by McQuaid and Ccle (1972) for the Navy. Each of these surveys indicate a surprisingly high rate of accidents caused by matorial incompatibility. The surveys by Ordin and Johnson covered 
NASA, some Air Force, and some related contractor records. O in reported $20 \%$ of the mishaps with Liquiu uxygen and $36 \%$ of the mis $\therefore$ s with gaseous oxygen involved material incompatibility. Johnson reported $56 \%$ were caused by the presence of oxygen incompatible materials. In many cases more than one factor was involved in the mishaps. For example, procedural erroxs were involved in $78 \%$ of the mishaps and design errors were present in $63 \%$ of the mishaps according to Ordin. Even though material incompatrbility with oxygen was present in fewer instances than procedural or design error, the percentage due $t:$ incompatibility is significantly large and it is expected to be even higher in high pressure oxygen systems. It is also noted that the accident rate due to material incompatibility in high pressure gas eous oxygen is almost twice that in liquid oxygen.

McQuaid and Cole's (1972) survey indicates an accident in a Navy compressed gas system due to spontaneous ignition every four weeks during the period January 1968 to May 1971. They do not indicate what proportion of these are due to material incompatibility, but do state that material failure accounts for about half of these accidents; the cause of the other half is unknown. No accidents are attributed to design failure or persunnel errcr. From this information one can not rule out that a sizable proportion may be due to material incompatibility.

F. f,cent trends in NASA, military, and commercial use of liquid (LOX) and gaseous (GOX) oxygen point toward use of higher pressures.' With this increased use to 10,000 psi and higher, compatibulty considerations are of paramount importance. Deep concern with safet; is rightfully prevalent throughout the field, both by the producer and the user. This survey will better define material incompatibility problems and huxards caused by the use of high pressure LOX and GOX. This report contains recommended guidelines in latex sections which will hopefully allow the necessary flexibility and compromise between cost - effectiveness and 
safety. Also included is a tabulation and assessment of available high pressure compatibility data and an indication of the availability of equipment. The next section is a discussion of the compatibility parameters affecting the selection of materials for high pressure oxygen service. Fo:lowing sections include discussions on structural integrity, chemical compatibility, and experimental tests and data which charac.erize the relative compatibility of different materials.

\section{Material Selection}

The selection of a given material to fulfill a specified function in high pressure oxygen service must be based both on its physical-mechanical properties as well as its chemical properties. The principal chemical property of interest here is its potential reactivity with oxygen. The relevant physical-mechanical properties axe primarily strength and plastic deformation properties. For example the plastic deformation of polytetrafuoroethylene may make it unusable for a valve seat material at sufíciently high pressure and copper may be too weak for a pressure chamber, even though they may be judged chemically compatible with oxygen. Also, the designer needs to consider that plastics and nearly all metals become more brittle at LOX temperatures. Other properties such as specific heat, thermal co'ductivity, density, and thermal diffusivity influence material compatibility. For exarnple, nickel-copper alloys are rapidly replacing stainless steel in high pressure oxygen systems because of the increased thermal cosductivity and diffusivity of the nickel-copper alloys. The higher thermal conductivicy results in lower reaction sensitivity. Also, mechanical properties may be altered in the presence of high pressure oxygen, e.g. crack propagation may be enhanced.

Several good reviews of lower pressure oxygen compatibility have been written. Many of these contain information basic to the understanding of the higher pressure phenomens. The most recent review is by Clark (1971); 
other noteworthy reviews and technical papers are by Felouch (1972), McQuaid and Cule (1972), McKinley (1971), Atwood and Allen (1971), Ordin (1971), Schwinghamer (1971), Keeping (1971), Blackstone and Ku (1971), Johnston (1970), Kimzey (1970), Guter (1967), Olson (1967), White and Ward (1966), Nihart and Smith (1964), Baum, Goobich, and Trainer (1962), Dean and Thompson (1961), Van Dyke (1959), and Grosse and Conway (1958). An assessment of the views presented by these authors along with our own views are described in this report.

Of particular interest is the work on oxygen safety by the Aerospace Safety Research and Data Institute (ASRDI) at NASA - Lewis Research Center. They will be publishing, soon, a series of NASA Special Publications entitled "ASRDI Oxygen Technology Survey: - . - ." covering the subject areas of metals and alloys, cleaning requirements, haröware, and contamination control. Of special interest for material selection is the report in this series by Pelouch (1972). Another pertinent report of this series is a state-of-the-art survey cn oxygen instrumentation, including a section on pressure measurement. This survey is being performed by the Cryogenics Division, NBS, Boulder. ASRDI has also collected a large amount of oxygen safety related information into a computerized data retrieval system called RECON. These reports and the readily accessible data bank should be very helpful for assessing specific problems.

An extensive treatise on the subject of material selection for arplication in manned spacecraft is NASA MSC-02681 (1972). T'his volume contains more general technical information and design guidelines regarding oxygen compatibility than any other single reference work. It is not addressed toward problems associated with. high pressures; however, as is stressed later, low pressure guidelines are directly applicable at high pressuse as well. 


\section{A. Structural Considerations}

Prior to chemical reaction considerations, one should be assured that the material selected for a given application is structurally adequate. If the material is not structurally adequate there is little point in assessing its chemical compatibility. The physical - mechanical properíies of interest for high pressure service are strength, hardness, mechinability, brittleness, thernial expansion, etc. Data necessary for structural design can be found in many sources. A few recent sources are Aerospace Structural Metals Handbook by Weiss (1966), Cryogenic Materials Data Handbook, Schwartzberg (1968), and Materials Properties Data Handbook by Aerojet Nuclear Systems Company (1970), NATO-AGARD (1959).

ASRDI recently contracted Linde Division of Union Carbide Corporation tc report on their vast experience in design and handling of oxygen systems. The resulting report, Linde (1971), includes a section on "Structural Compatibility" with emphasis on thermal expansion problems encountered with LOX equipment.

\section{B. Chemical Reaction Consideration}

Chemical reactions with system materials are important in that the material properties may be altered to the point of system failure. Material incompatibility here is generally synonymous with oxidation or burning. Important factors in the consideration of oxidation are reaction sensitivity, reaction intensity, and ignition sourses. The effect of high nressures on these factors and ultimately on equipment design is essentially the subject of this study.

\section{Reaction ensitivity}

Reaction sensitivity is a measure of how readily a mate:ial will react with oxygen. Most of the experimental test performed to characterise oxygen compacibility (described in a later section) are directed towurd obtaining a measure of reaction senuititivy. Examples of reaction sensitivity tests are those involving reactions initiated by impact, by heating, or by electric arc. The variable most important to reaction sensitivity is the 
igrition temperature of the material. However, this may be considerably altered by the presence of oxide coatings or contamination. It is to be noted that many of the materials tested include contamination or impurities. Oxide coatings on metals usually raise the apparent ignition temperatures; while contaminants generally lower the ignition temperature. Impurities such as cil or grease, rust, metal filings, etc. on metals usually drastically increase the probability of reaction. Other factors which are significant in the consideration of reaction sensitivity are specific heat, thermal conductivity, density, thermal diffusivity, and material configuration.

The ignition temperature is the most critical factor in determining a material's reaction sensitivity. As will be shown later, the ignition temperature of a solid generally decreases with increasing pressure up to about 2000 psia. Above this pressure the ignition temperature is relatively independent of pressure. Thus, the reaction sensitivity is not expected to change appreciably at higher pressures. However, the possibility of ignition at higher pressures is enhanced because the fossibility of the release of sufficient energy is greater.

\section{Reaction intensity}

Reaction intensity is a measure of the rate of energy release of the reaction once it is started. The importance of reaction intensity to material selection is discussed by Blackstone et al (1971), (1970), (1967) and Jamison (1971). Reaction intensity determines to a large extent the degree of damage done to a system, the speed with which the damage progresses, and the ability of the reaction to spread to other materials in the system. The factors which most influence reaction intensity are heat of combustion and oxygen availability. Oxygen availability is determined by temperature, volume, pressure, and rate of flow. Other lactors influencing reaction intensity are material density, configuration (e.g. the size $\rightarrow f$ the heat sink) and the properties of combustion products. Reaction intensity is expected to be greater in high pressure systems due to the increased availability of oxygen and concomitant increased burning potentiel. 


\section{Ignition Sources}

It is often stated that a reaction is only possible in the presence of a fuel, an oxidizer, and an ignition source. This statement is of little consolation in an oxygen system when one realizes that the fluid is the oxidizer, the system is the fuel, and ignition sources are everpresent in varied forms. Probably the most important source of igniticn in a high pressure sysiem is the heating due to rapid adiakatic compression. The use of materials with high thermal diffusivity and high heat capacity are most beneficial here since the most rapid rates of heating by compression are not appreciably faster than the effective surface cooling rate of good heat conductors.

Another important source of ignition is impact, such as by small particles or buj! pieces in a flowing stream of oxygen. Heating caused by friction and static discharges can also ignite system components. In high pressure systems the probability of ignition is greater because of increased likelihood of encountering high temperatures and possible lowered ignition temperatures. High pressures generally also result in greater flow velocities, increased impact energies, and frictional heating effects.

A chemical reaction of significance that is seldom considered is the fracture or crack propagation enhancement by an oxygen atmosphere. The fatigue behavior of a high pressure oxygen container is very critical, particularly if the pressure is cycled, yet very little work has been done [Linde (1971) and Baum, Goobich, and Trainer (1962)]. Crack growth enhancement has been reported for a titanium alloy by Jackwon et al (1963) and the absence of any enhancement for a nickel alloy has been reported by NASA (1970), This is an area of investigation that has been sorely neglected and, therefore, jrojections to high pressure are impossible. 


\section{Recommended Selection Procedure}

As indicated earlier, it is best to first select materials which physically fulfill the mechanical demands of the component considercd. These materials are then analyzed to select the most chemically compatible material. This selection process is often based upon the material ranking of a given compatibility test. Or it may be based upon the concensus of the material ranking recommendations found in the literature, as is also frequently aivocated. However, we believe that both of the se suffer from two serious drawbacks: (1) no consideration is given to the uniqueness of the particular demands of the application in question and (2) the materials ranking recommendations based upon the resuits of individual investigations often are highly contradictory. These contradictory results are frequen:ly due to the specialized nature of the test and the biased interpreiation of the results. A case in point is the vide disparity in the ranking of aluminum and stainless steel reported by various investigators: Dean and Thompson (1961), Kirschfeld (1961), (1965), (1967) and (1968), and Nihart and Smith (1964). We believe the material selection process should be accomplished by matching the particular demands of the equipment component with the materials best satisfying these demands. Material selection on this basis assumes the existence of several types of compatibility and physical properties data for these materials. For example, if a compcnent is likely to be impacted but noi likely to be in a ligh tempera'ure environment, materials with a low impact sensitivity should be considered regardless of their ranking according to ignition temperature. This proce' :re, apparently already used by NASA, is discusoed in the report NASA, MSC-02681 (1972). The importance of equipment design, as discussed in other parts of this report, should not be ignored. For example, the introduction of slow opening valves and heat sinks, whenever possible, will reduce the probability of ignition by adiabatic compression. 
The following is a priority sequence of guidelines that should be followed when selecting materials for oxygen use in the presence of ignition sources. Of course any considerations must include the effects of possible contaminants in the system.

1. Eluminate ignition - select a mater al which is least likely to ignite under the operational conditions.

2. Prevent continued reaction - select a material which tends to quench the reaction after ignition.

3. Reduce the rate of reaction - select materials which react as slowly as possible after ignition to permit the control of the reaction.

These recummendations encompass those suggested by McKinley (19?1) and recommended by NASA - Myers (1971). The first guideline is most likely satisfied by selecting the material with highest ignition temperziure but is also affected by the presence of oxide coatings or the possibility of intermaterial reactions. For example, it has been reported and discussed by Key (1968), (i964), Ordin (1971), and Keeping (1971) that chlorofiuoro compounds may react strongiy with aluminure under shear forces. This reaction may be sufficient to ignite aluminun in the presence of oxygen. Irc $\Omega$ rust according to Keeping (1971) significantly lowers the ignition re sistance of aluminum in oxygen. Materials with a high thermal diffusivity are better in dynamic sysiems since local energy impulses will result in les pronounced hot apots than with isw diffusivity materials. In a static system high thermal conductivity matexials are more desirable for essentially the same reason. Materials whose melting point is higher than the ignition temperature should be free of sharp edges. The presence of sharp edges may resuit in hot spots for ignition. If the ignition terr. rature is sufficiently above the melting point, sharp edges will probably be ...... hed by melting before ignition occurs. This has been reported to be t: case for aluminum Ly Keeping (1971). 
The second guideline, seiecting a material which tends to quench itself, is infucaced by several factors. The heat of combustion is the most important. If it is sufficiently low, the ne.at may be conducted away ra-idly enough to quench the burning. The reaction products may also interfere with continued oxidation. For example, slag biuldup has been reported to have a quenching effect in iron.

The materials portion of the third guideline, select slow burning materials, is affected by essentially the same factors. However, one can alsc utilize good design to slow down the reacticn. For example, one might insert a nickel-alloy pipe section in a predominantly stainless steel pipe. The nickel alloy section, having a lower reaction intensity, would either quench or slow a reaction propagating along the fipe. The shape and size of components at strategic points in a system can be significant in controlling a reaction. Thermal anchoring of potentially reactive components to a cold heat sink $c$ in also be liseful in curtailing a bura. A rapid operating system to shut down the oxygen supfly upon detecting a ralfunction inay prevent extensive damrge, unless the initial burn occurs with explosive violence. Limiting the oxygen availability by restricting oxygen flow where pcssible is dusirable for control purposes.

Material ranking lists are most useful for design purposes if they are clearly identified as to the experimental tests won which they are based. McKinley (1971) has compiled $x$ anking ljeis based upon irdividual past tests. These lists and the recommendations in NASA, MSC-02681 (1972) should be consulted for material siection. The results of various compatibility experiments along $\because$ ith fhysical property data, such as melting and vaporixation teisiperatures, thermal conductivity, specific heat, and heat of comburtion,' are sometimes combined to produce a weighted index of oxygen compatibility. Such an equation has been used by Linde Division of Union Carbide Coxporation [Carlson (1971)]. The critical point of setting up such an equation is the choice of the weighting factor for each parameter in the 

III. Material Compatibility Tests

A test to measure the compatibility of a material with oxygen basically consists of placing the material in oxygen in the presence of an ignition source and observing the sensitivity or intensity of the reaction. The tests may be conducted under different conditions, such as at different temperatures, pressures, or ignition energies, to determine any dependence on these variables. The kinds of tests possible are limited primarily by the number of possible ignition sources. However, most tests are quite realistic in sirnulating working conditions and common iguition zources. Somewhat arbitrarily, these tests are describer below by the following ignition categories: impact, thermal, electric arc, abrasive, and fracture. Also discussed ar environmental and configuration tests which involve various forms of ignition in simulation te:sts. There are also many experiments designed to measure spacific the rmodynamic properties, such as heat of combustion, thermal conductivity, specific heat, or melting point. Strictly speaking, these are not compatibility tests, but do provide a basis for understanding the results of compatibility tests. Most compatibility tests as concerned primarily with resistance to ignition (reaction sensitivity) but some also are designed to measure the burning rate or quenchant behavior (reaction intensity) after combustion is initiated.

One of the most probable ignition mechanisms is by impact in the presence of oxygen; be it by dropping a wrench in an oxygen spill (mechanical impact), by impinging a piece of weld slag on the bend of an oxygen pipeline (particle impact), or simply by rapidly opening or closing a high pressure valve (preumatic impact). Each of these conditions are simulated by a particular impact compatibility test method.

The most common version of an impact test is the Mechanical Impact Test developed by Lucas and Riehl (1960). This test has been used extensively and has resulted in an enormous number of datia, Key (1963), (1964), (1966), (1968), Jamieon (1970), and NASA, MSC-02681 (1972). It 
is one of only two ASTM standard tesio for oxygen compatibility, ASTM (1970). The test is conducted by imparting a known amount of energy from a falling plummet to a striker pin which is in contact with the specimen in the presence of liquid or gasersus oxygen and any reaction is noted. The test is relatively simple and readily adapted to variable pressure and temperature. Compatibility by this ASTM test is defined as no reactions out of 20 impacts with the plummet impact energy adjusted to $70 \mathrm{ft}-1 \mathrm{bs}$. Key (1968) indicated that this go-no-go test has been remarkably successful in rejecting incompatible materials. However, the arguments described in the next paragraph suggest that the poor repeatability inherent in the test may lead to the rejection of some compatible as well as the incompatible materials. Blackstone and $\mathrm{Ku}(1971)$ have gone so far as to suggest that this test has also passed some unacceptable materials.

The mechanical impact test procejure has undergone extensive criticism by Blackstone (1970), Blackstone and Ku (1971), Blackstone, Baber, and Ku (1967), Burmeistex, et el (1967), Reynales (1958), (1961), Staph et al

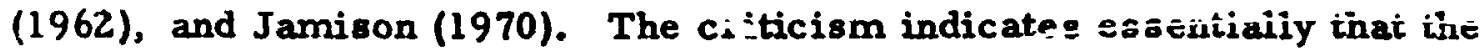
statistical procedure of the test is at fault rather than the test apparatus per se. Schwinghanier (1972) has refuted some of this criticism. A different statistical approach has been recommended by Jamison (1971) as a consequence of this criticism. Instead of accepting a material if it doesn't react in 20 tests at $\mathbf{7 0} \mathrm{ft}-1 \mathrm{bs}$, the test would be repeated 20 times at different energies to find the energy at whin. 50\% reactions are obtained. This energy (determined from the drop height of the falling weight) is used to indicate the relative impact seneitivity of the material. This method is referred to as the Bruceton or "up-and-down" method of mechanical impact testing. According to Jermison (1971) the "up-and-down" method of impact tenting, as an alternative to the go-no-go test, is brith efficient and repeatable. That the Bruceton method is more repeatable than the gono-go test is Intuitively reasanable; however, the go-no-go test is loss time consuming and the fofore is considered usaful 
as a screening test if the occasional rejection of an acceptabie material is pcrmissible. Blackstone and $\mathrm{Ku}$ (1971) and Janison (1971) give historical accounts of the development from the first impact testor described by Lucas and Riehl (1960) to current models. As a result of recent attempts to inprove the mechanical impact test it has been suggested that reaction intersity testing should also play a major role in material selection in conjunction with reaction sensitivity testing. Jamison (1971) has poiniad out that the improved repeatability of the Bruceton method of impict sensilivity testing shows that materials are not significantly different in sensitivity. However, he indicates that these materials differ widely in intensity since some of them react violently and are totally consumed while others are only slightly charred. It appears that further statistical considerations may be in order here to take advantage of both techniques rather than to reject either totally.

Another form of impact test which has been used considerably is the Pneumatic Impact Tast. The pneumatic impact test is designed to simulate the adiabatic compression resulting from a rapidly opening high pressure valve. It is usually performed in just that way wich a small specimen containing test chamber suddenly opened to a high pressure reservoir. The adiabatic compression test uses the highest pressures of all the ccmpatibility tests, except for a variation of this test using explosively generated shock $x$ aves.

Adi= batic compression tests involve the study of material ignition in the compressively heated oxygen gas. The absolute temperature, $T$, of an id al gas uncier adiabatic compression as a function of pressure, $P$, for ar. ideal gas is give: by

$$
T=I_{0} \frac{P^{\frac{n-1}{n}}}{P_{0}}
$$


where $T_{0}$ and $P_{0}$ are initial temperature and pressure, respectively and $n$ is the ratio of specific heat at constant pressure to specific heat at constant volume and is about 1.4 for oxygen. Nihart and Smith (1964) plotted values of J. versus $P$ for $T_{0}=273 \mathrm{~K}$ and $P_{0}=14.7$ psia. At 10,000 psia $T$ is $1900 \mathrm{~K}$ which is sufficiently high to ignite almost any structural material. Whether ignition actually occurs is determined by the temperature of the material and not just the temperature of the compressed gas. Thus the trarsient thermal characteristics of the system are important. The thermal diffusivity, heat capacity, and other factors such as tine existence of sharp edges, determine the peak temperature of the material. For these reasins an adiabatic compression test is most meaningful if performed on a system rather than on a specimen of material.

The Particle Impact Test is the least used of the impact tests; however, it.s importance should not be neglected especially in high pressure systems. This test is performed by impacting particles in a flowing oxygen stream with a test specimen and any resulting reaction is recorded. This test is conducted at various temperatures, pressures, flow $x$ ates (velocities), and particle size.

Thermal tests are those in which the ignition source is essentially the temperature of the specimen and its environment. In reality, all ignition sources are thermal in that a local rot spot must be created for ignition to occur. Classed as thermal ignition tests are bomb tests, promoted ignition tests, and hot wire tests. The Oxygen Bomb Test, described by Nihart and Smith (1964) and Guter (1967) is performed as follows: a specimen is placed in an oxygen filled bomb. The temperature of the contents of the bomb is gradually raised until ignition occurs, as indicated by a rapid rise in temperature, virible flash, or audible explosion. The temperature at which ignition oscurs is called the self-or auto-ignition temperature. The preasure in the chamber during the controlled temperature rise may be either conatant or allowed to rise with increasing temperature. In some caces the epeciman 
is exposed to oxygen only after equilibrium has been reached at each temperature and the specimen is changed after each such measurement. The Oxygen Bomb Test $c$ an be used to determine gaseous oxygen compatibility of metals or non-metals i: che solid, liquid or gaseous states. The Pot Test described by Guter (1967) is similar to the Bomb Test except the Pot Test is done at standard pressure and with flowing oxygen. It frequently is intended to simulate actual conditions of use and with it one can assess flow effects.

Promoted Ignition Tests are performed by burnirg an ignition promoting material in the presence of a specimen. Many materials have been used for promoters, however, the best materials are those that do not significantly effect the composition of the specimen surface as the promoter is burned. Contamination of the surface of the specimen by the promoter can change the specimen's ignition characteristics and thus produce erroneous results. The amount of specimen consumed by the burning of a fixed amount and type of promoter or the amount of promoter required to consume the entire specimen is used as a measure of its resistance to combustion.

The Hot Wire Test is conducted by heating a metai wire in a gaseous oxygen atmosphere. An electrical current is passed through the wire, resulting in $I^{2} \mathrm{~K}$ (or Joule) heating. The temperature is increased with increasing current, resulting eventually in the wire either igniting or melting. This test can only be used on metals below their melting temperatures and its only advantage is simplicity.

Probably the most tragic oxygen accidents have involved electrical ignition sources such as electrical arcing from associated electronic equipment. The Flash and Fire Point Test, used primarily on organic meteriale, is performed to simulate these conditions by using an electric arc to ignite a specimen in an oxygen filled chamber. The temperature of the chamber is raised and the electric spark is generated periodically near the specimen. The temperature at which a momentary ignition occurs is defined ax the 
flash point; the temperature at which sustained burning occurs is called the fire puint. At high oxygen pressures the lash and fire points are coincident. The relationship of flash and fire poirts ardato-i;nition temperatures (see oxygen bomb test) is not known specificaliy. Intuitively, one would expect that tie auto-ignition temperature is equal to or greater than the flash and fire temperature; the experimental data presented later indicate that at high pressures there is little difference between these temperatures.

Gailing caused by two pieces of metal rubbing was projected as one of the possible causes of an oxygen tank truck accident and there have tr:en a few Abrasive Tests to study such phenomena. Also the abrasive effect of fine particles in a flowing oxygen stream has been and is being studied.

A highly probable vel s :ldom observed accident source is Fracture. The exposure of a fresh clean surface of some metals to oxygen can cause a violent reaction. Various methods have been used from straight tensile tests to puncture by bullets or other projectiles, Jackson et al (1963). Even the effect of the projectilesize and mate ial has been considered.

Configurational - The final test of oxygen compatibility for any material 18 whether it will ignite in its final configuration, complete with adjacent materials and possible contaminants. Because of our lack of understanding of the ignitioss $\therefore$ ad combustion of metals, r $208 \mathrm{t}$ critical applications also undergo an environmental test. Artificial ignition of wire harnesses or clothing, hyperbaric testing of breathing apparatus, and overloading liquid oxygen pumps are all examples of this category. These tests will always be indispensable, especially where saiety is of prime concern.

In view of the controversies which exist regarding the value of various terting techniques, it is recommended that an independent group, such as NBS, study these methods and test resulte, using whatever exportise is necessary to eatablish standardized test procedures for liquid and gascous oxygen compatibility testing. Any recommendations should be flexible enough to laciude now 
methods or procedures as they are proven useful. As a consequence of the recent and thorough survey by Johnston (1970), it was concluded that there is censiderable concern for better and improved materials selection and testing methods and safety criteria. This plea has been repeated often since 1957 with apparent little effect. Recent activity in test development and reanalysis by NASA-ASRDI ray be a partial answer tis these recommendations.

IV. Material Compatibility Data

A not insignificant portion of the materials conıpatibility data is unpublished. Some is difficult to obtain from the "unpublished" literature and it is especially hard to obtain corporate data. However, this is not to say that data are lacking for most technical materials. There are considerable data available, but, in some instances the inconsistencies produce a confusing picture. The principal sources containing information regarding the effect of pressure on oxygen compatibility are Attwood (1971), Baum (1962), Dean (1961), Guter (1967), Kimzey (1970), Kirschfeld (1961), (1965), (1967), (1968) and NASA MSC-02681 (1972). High pressure data from the se and other sources are tabulated in Appendix $I$. One extensive set of unpublished data included in Appendix I is from John Austin, Marshall Space Flight Center (1972.). An extensive tabulation of test data, contained in Appendix $E$ of NASA MSC-02681, (1972), is reproduced for convenience as Appendix II. Appendix II contains the high pressure compatibility test data of both metals and non-metals, not just non-metals as indicated by the title of the source document. The document. NASA MSC-02681 (1972) is periodically updated to include the most recent NASA test data. Additional updated copies may be obtained from

Chief, Reliability Division

Code NB

NASA-Manned Spacecraft Center Hciuston, Texas 7 7058.

In several instances, data have been reported and conclusions have been drawn by the investigators which can not bo noatly tabulatod in Appendix I 
or are difficult to summarize briefly. These data, often resulting from configuration and other non-standardized tests, are, however, very useful in asscssing the oxygen compatibility of materials. To make some of these results more readily available, the summaries, conclusions, and recommendations of these papers are presented in Appendix III for the convenience of the reader. For additional detailed data, the reader is referred to the references. We are not including further summarization of these papers individually, see for example McKinley (1971); however, some of the generalizations which follow are based on the results of these papers.

The sources of oxygen compatibility information include considerable data below 3000 psia; these data are not tabulated in Appendix I unless they are useful for projections at higher pressures. The discussion of the se data is separated into sections on (A) Metals and (B) Non-Metals. In Appendix I, metals are further separated into (1) Pure Metals and (2) Alloys. The nonmetals are divided into (1) Halogenated Compounds, (2) Non-Halogenated Plastics, (3) Seaiants, Threading Compounds and Lubricants, (4) Elastomers, and (5) Miscellaneous. The format of the tables in Appendix I is chosen to be similar to the format of NASA MSC-02681 (1972).

Table 1 contains miscellaneous thermal data for pure metals and alloys as well as a few selected polymers. These data are useful in the selection of materials for high pressure oxygen service.

\section{A. Metals}

McKinley (1971) has dowe a complete and objective review of the literature on ignition and combustion of metals. He includes both low and high pressures and compiles metal ranking lists according to various experiments. These lists show that nickel and copper and their alloys are most suitable for oxygen service. They also suggest that neither aluminum nor iron alloy (including stainlesa stoel) are highly donirable. Stainleas ateols, however, are gener.lly more oxygen compatible then aluminum. The overall 


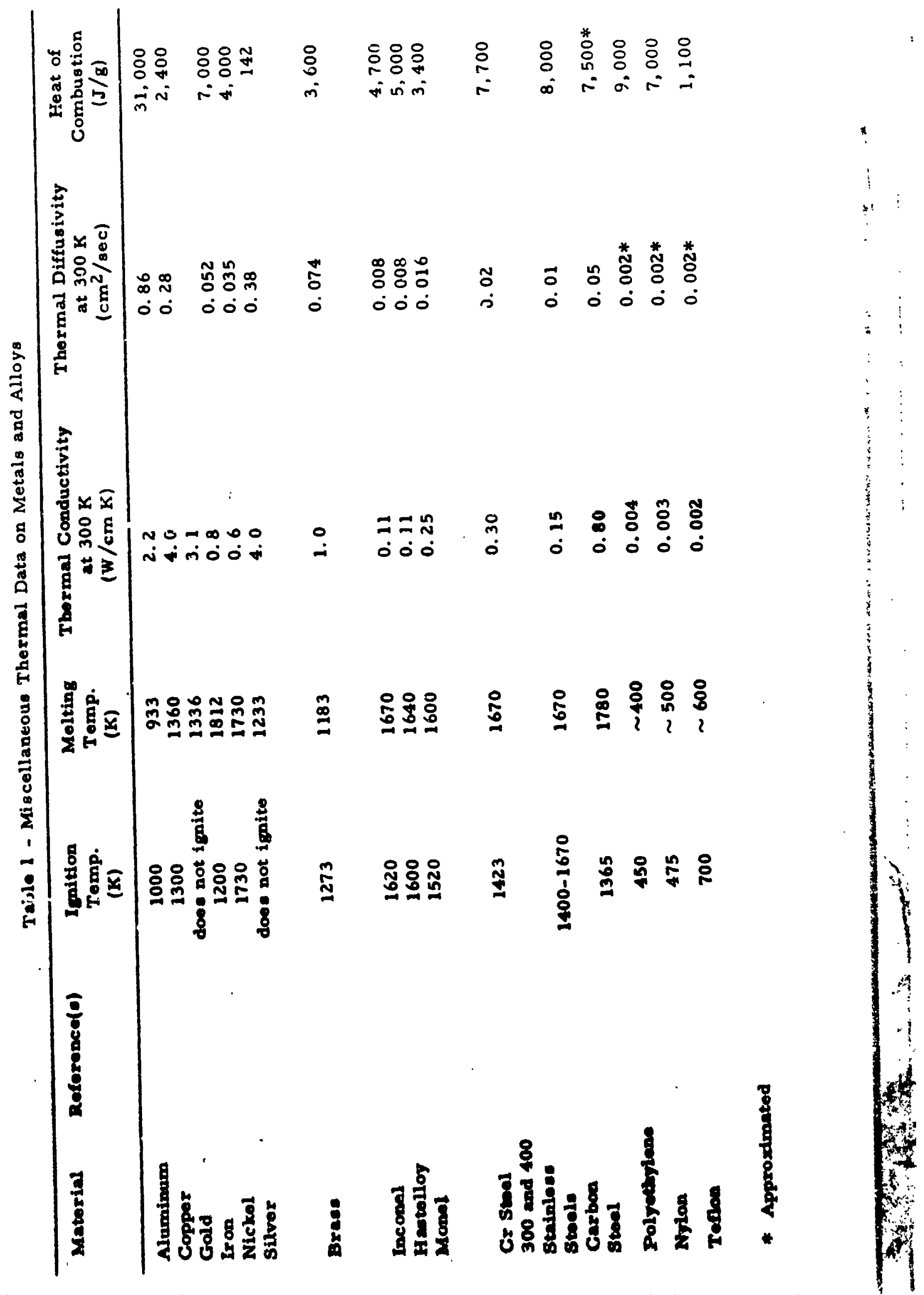


ranking suggested by Clark (1971) is in general agreement with these lists. Pelouch (1972) has also presented material ranking ilsts as a function of such parameters as strength, reaction intensity, volume, etc. and reaches essentially the same conclusions. Considering the lack of contradictory evidence at higher pressures, it is reasonable that the se rankiugs would also be valid at high pressures.

The existing compatibility data can be summasized as follows. The ignition temperatures of metals decrease with increasing pressure. However, the re are insufficient data available to quantitatively define this pressure dependence for but a few metals over relativeiy small uressure ranges. Figure 1 illustrates the available ignition temperature data which approach the high pressure range. It is interesting to note that the nickel alloy curve crosses the steel curve, suggesting the possibility that steels may be better suited for high pressure service. The ignition temperature data presented by Nesgorov et al (1968) were normalized to unity at low pressure. To obtain the data attributed to Nesgorov presented in figure 1, we used the low pressure ignition temperature values for nickel alloys and steels as listed in Appendix I. No ignition temperature data exist above 2000 psia. There appears to be a definite need for a careful measurement of ignition temperature as a function of pressure up to at least 10,000 psia for some of the more technically important metals. The effect of specimen size and shape should also be investigated.

The burning rate of metals varies as the square root of pressure and inversely with cros8-sectional area at low pressures; but at higher pressures burning rates decrease, Kirschfeld (1961), (1965), (1967), (1968). The nature of this reversal and the pressure at which it occurs are subjects for further study.

The oxygen compatibility of metale under mechanical impact has leen extensively studied; however, the repeatcbility of the data are in question as previously discussed. Because of this lack of repeatability, it is difficult to be certain from the avaisable data liated in Appendices I and II if metals are 


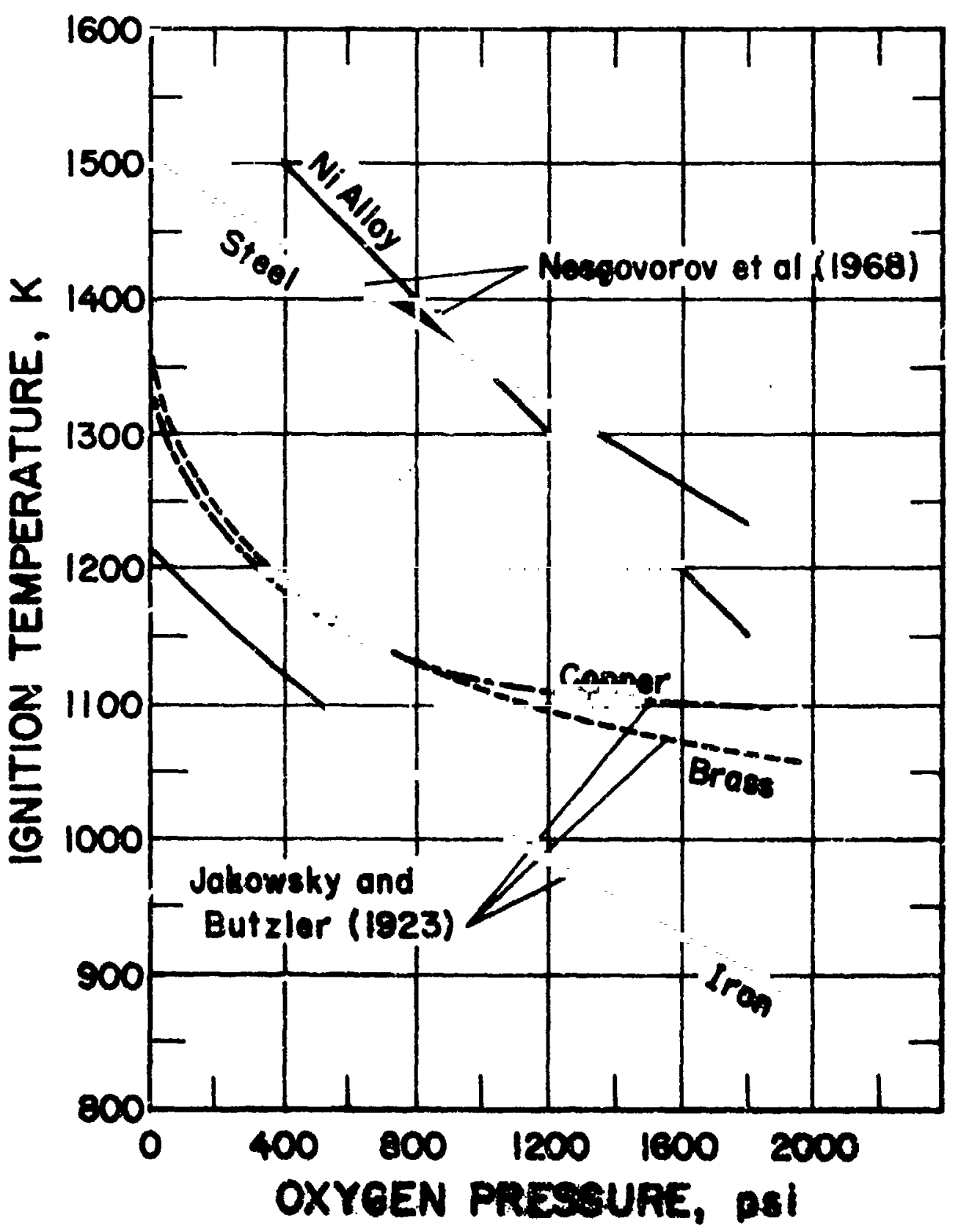

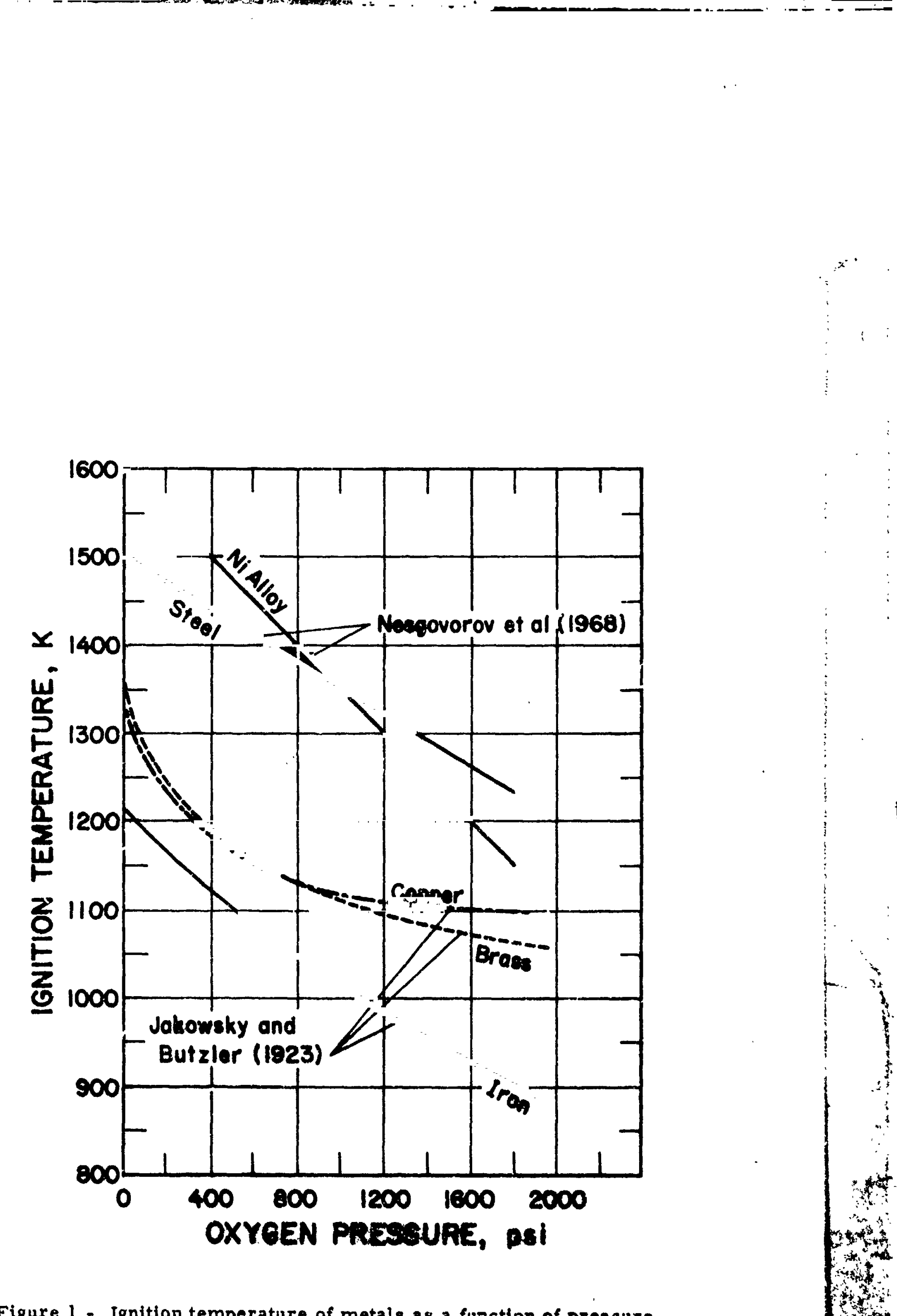

Figure 1 - Ignition temperature of metals as a function of presaure (Nesgovorov's relative data converted to absolute values by using low pressure data from Appendix I). 
more $r$ les's sensitive to mechanical impact at higher pressures. The dependence on pressure, according to these data, is, at best, small. On the basis of the impact test data alone, it appears that any of the common metals and alloys, including aluininum and stainless steel, are acceptable ior use. However, it is noted that the nickel and copper alloys are less sensitive to mechari:al impact than aluminum and stainless steel, in particular. This can be seen in table 2, which summarizes the metals impact data of Austin (1972). This table gives the reaction frequency of each alloy class as a function of pressure. It appears that aluminum is especially impact sensitive at 100 psi. We note that. the 50 psi rate is based on only 40 tests while at $e$. $h$ of the other pressures several hundred tests were conducted. Thus the reaction frequency at 50 psi may not be statistically significant. Ignoring the data at this pressure, we see that if all metals are considered as a group, there is little pressure dependence up to 1500 psi. Table 2 also shows the lack of precision in impact testing mentioned earlier. The mechanical impact screening test was probably never intended to be subjected to such a statistical analysis; however, it is felt that the availability of a large sampling of data introduces a worthwhile degree of significance into the results of the analysis. It is recommended that all impact data listed in NASA MSC -02681 (1972) be subjected to a similar analysis. However, since other variables besides pressure are present, a statistical analysis is essentially a problem in multiple regression analysis. The analysis performed here is of course much simpler and is the reason why orly Austin's data were used. In most of his data pressure was the only variable in successive test for each material.

Other high pressure data such as ignition by electric axc, particle impact, and flash and fire point data are being determinıd by Siradling (1972) for both metals and non-metals. Some of these measurements wili be at pressures to 10,000 pai and, therefore, will be very useful for material ranking.

In summary, it is recommended that all typos of compatibility data be extended to 10,000 pria. The data compiled in NASA MSC-02681 (1972) are 


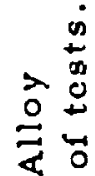

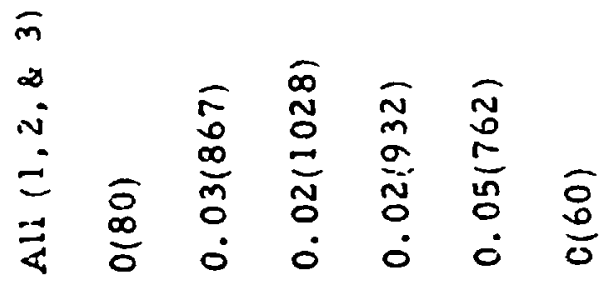

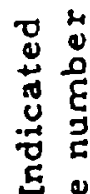

4
0
0
0
0
0

⿷

岳

$\rightleftarrows$

$-3$

N

a

$\Rightarrow$ J

c)

I

4

is

㟧

से

点

엉

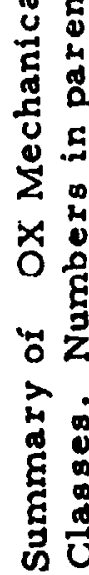

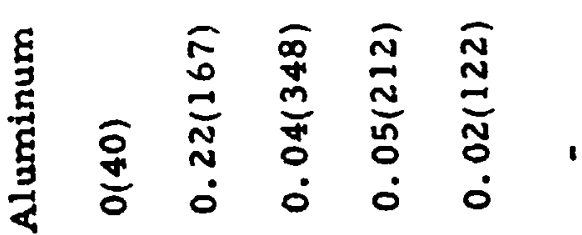

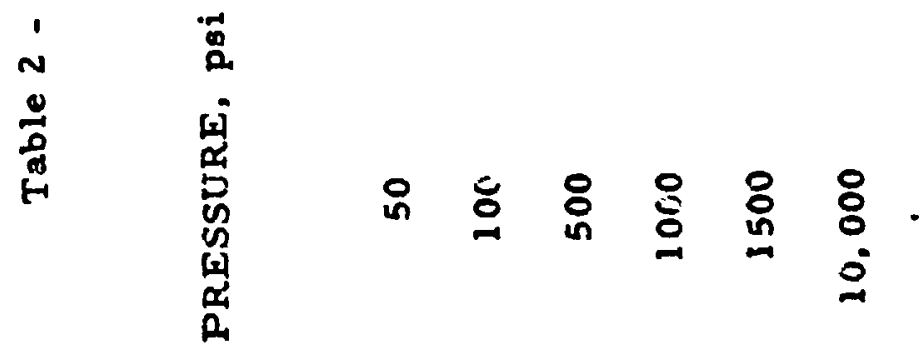


extensive; however, a statistical analysis of these along with other data is needed in obtain full benefit from this compilation.

B. No:-Metals

Compared to metals, most non-metals are highly combustible. Since some of the metals are considered incompatible for oxygen service, it folluws that most non-metals are oxygen incompatible. Because of their unique physical properties some crganics, such as the polymers polychlorotrifluoroethylene and polytetraflusroethylene, have been used extensively in oxygen service. These are probably the mozt compatible of the organic materials because they are highly fluorinated with stron ${ }_{5}$ fluorine-hydrogen bonds. Generally, the more halogenated (particulariy with fluorins! a hydrocarbon:s, the more compatible it is with oxygen. The reader should refer to Appendix III for specific criticism regarding the oxygen compatibility of other organic materials. Cumpatibility test data for non-metals are found in Appendices I, II and III. Some general observations are given below.

The ignition temperatures, as well as the related flash and fire point temperatures of non-metals, generally decrease with increasing pressure up to about 1500 psia. Above this pressure ignition teinperatures tend to be independent of pressure. A few typical curves of flash temperature versus pressure are presented in figure 2. The reade- should note the ciosc correspondence between flash point and ignition temperature. This correspondence may be even closer than appears in figure 2 because of the following: the flask poluts reported by Pippen and Stradling (1971) were oistained with a low pressure apparatus and a high pressure apparatus. The transition was at 50 psi. In almost all cases the flash temperatures from the low pressure apparatus were 50 to $100 \mathrm{~K}$ higher thin the tomper atures from the high pressure apparatus: The low pressurs data are not shown in figure 2; however, they suggest tinat the flash points shown may be too low by as much as $100 \mathrm{~K}$. Such an uncertainty would make high pressure 


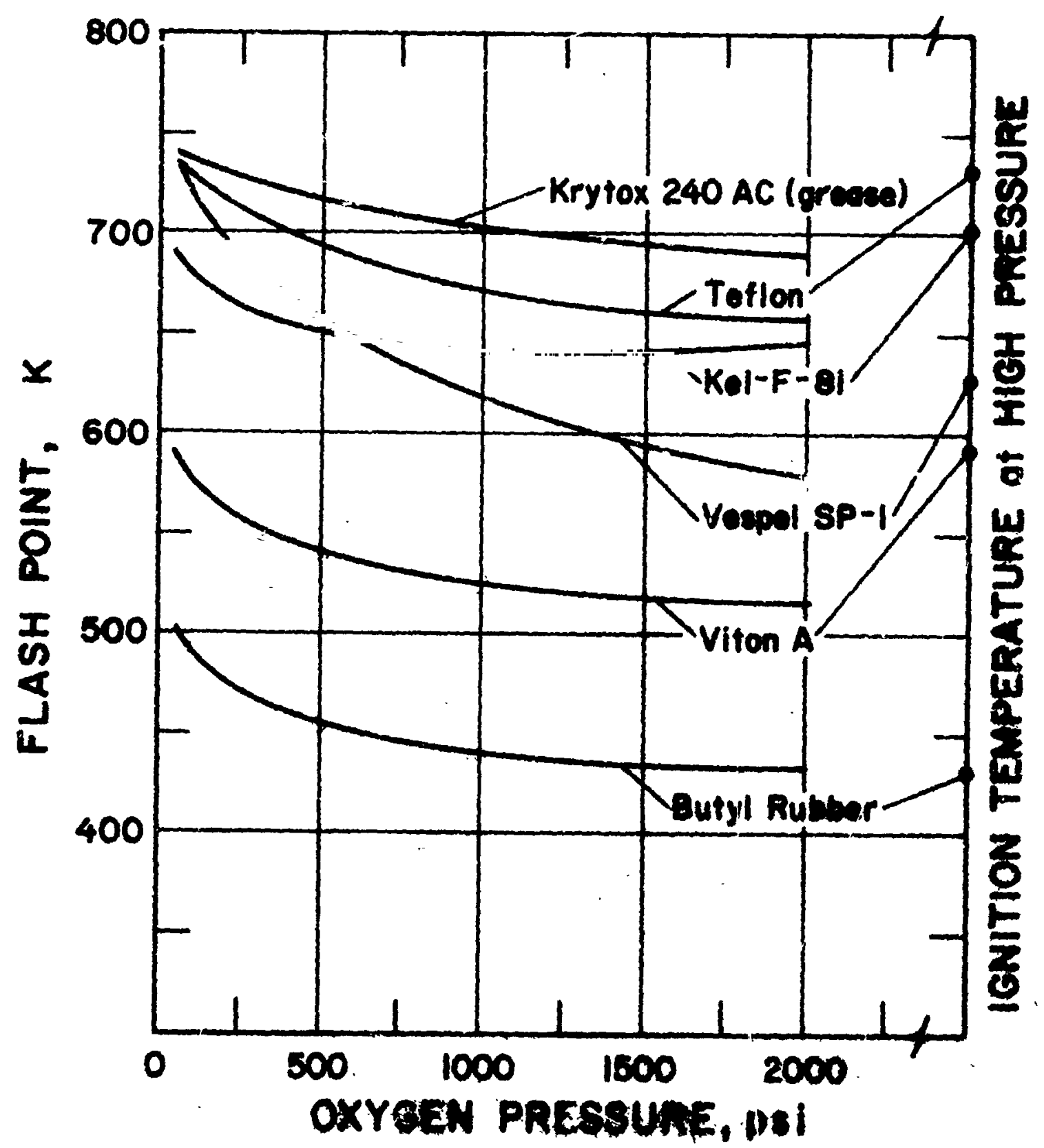

Figure 2 - Flanh point temperature as a function of prescure for some non-metale. 
ignition temperature and flash points the 8 ame within experimental error. It is also observed that the flash points are nearly independent of pressure at 2000 psi, strengthening the conclusion of Nihart and Smith (1964) that the ignition temperature is independent of pressure from 2000 to $7500 \mathrm{psi}$.

Due to the imprecision of tive mechanical impact data on non-metals it is difficult to readily detert a pressure dependence in sensitivity. To support this, the data of Austin (1972) were combined as shown in table 3. A similar analysis of all of the impact data is a very lengthy and complicated multiple regression problem which is not considered within the scope of this project. 'This however, is recommended as 3 project which needs to be done for both metals and non-metals.

The polymers, polyrhlorotrifluoroethylene and polytetrafluoroethylene, often used as valve seat materials, are oxygen compatible according to the mechanical impact data listed in Appendix I. Although more compatibility data exist for non-metals than metals, additional data at. high pressures are needed to confirm the pressure dependence of ignition and impact characteristics. A more critical need, however, is the investigation of other non-rnetals to find those with the highest oxygen compatibiiity. Some areas which have probably not been fully explored are the ceramics and composites.

V. High Pressure Oxygen Equipment

Some effort has been directed toward the acquisition of info 'mation regarding the availability of high pressure oxygen service equipment. The equipment suppliers listed below have been contacted and all hav sent information regarding their off-the-shelf items. This supplier list is not intended to be complete nor is it an endorsement of these companies but rather, it ic a random selection of high proseure uquipment suppliers intended only to illustrate the degree of avallability of such equipment. In parenthesis after each of the listing we show few of the more common products of each of these suppliers. From an assessment of this literature it appears that conoiderable oquipment is rendily available which is, or by 


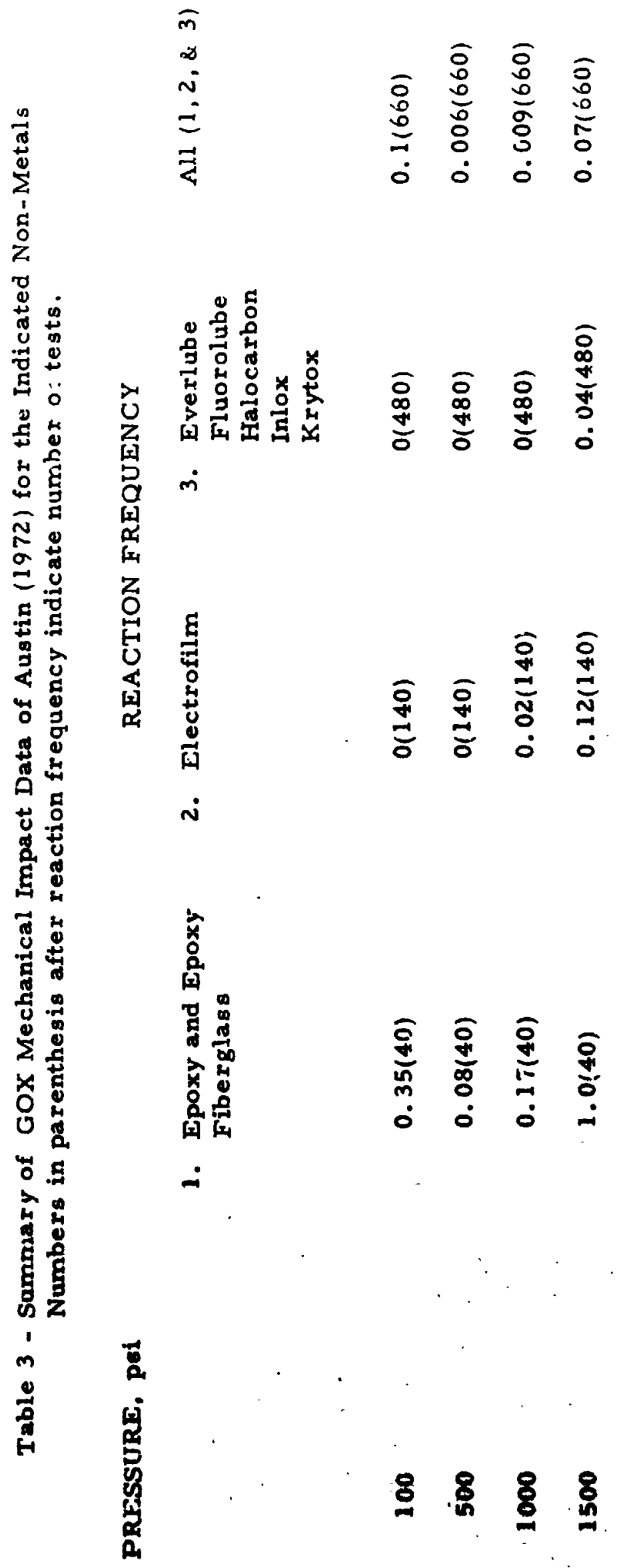


specification can be made, compatible with high pressurc oxygen. The manufacturers arc aware of the problems with oxygen and are both willing and able to construct equipment tsing oxygen compatible materials. Their catalogs often do not specifically mention applications for oxygen, however, the materials lists and equipm:nt design show that oxygen compatibility was considered. Manufacturers, of course, re!y heavily on the user to assist in selecting oxygen compatible materials. Metals most commonly used in high pressure oxygen compatıble equipment are 300 series stainless steels, and nickel alloys. Aluminum and 400 series steel alloys are used in fewer instances. The poly- . mers $\mathrm{K} \in \mathrm{l}-\mathrm{F}$ and Teflon are frequently used in valves and regulators. It has been recommended by Burmeister, Loser and Sneegas (1967) that these as well as other organics be replaced with metal parts whenever possible. It has beer recommended that material ranking lists $s$, various experimental tests be established. Such specifications will be necessary to remove the incompatible materials such as the organics in existing high pressure equipment.

In specifying equipment for use at high pressures one should be particularly careful of adiabatic compression heating. For this reason, safeguards such as slow opening valves and heat sinks to absorb the energy from cumpression heating should be included whenever possible. In a high flow rate system, the sharpness of pipe bends should be limited, solid particles should be removed from the stream, sharp edges should be eliminated, and electric charge build-up should be avoided. Whenever possible, organic materials should be replaced by metal components, such as in valve seats and regulator parts. Since materiale compatibility lists used by manufacturers may differ from lists established by NASA, the purchasing agency must bear the final responsibility of materials compatibility for spocific applications. 
Random Selection of High Pressure Equipment Suppliers

Contacted for Oxygen Compatibility Information

1. Airco Cryogenics Division, 1900 Main St., Irvine, Calif. 92664, Ph. 714-540-3010 (cryogenic purmps)

2. AiResearch Manufacturing Division of the Garrett Corporation, .9851 Sepulveda Blvd. Los Angeles, Calif. 90009, Ph. 213-588-1153 (storage vessels).

3. American Instrument Co., 8020 Georgia Ave. Silver Spring, Maryland, 20910, Ph. $301-589-1727$ (pumps, valves)

4. Autoclave Engineers, Inc., 2930 W. 22nd St., Erie, Pa., 16512, Ph. 814-838-2071 (storage and reactor vessels, valves, tubing, pumps, intensifiers, metal diaphragm compressors, flanges)

5. Bingham - Willamette Company, Div. of Guy F. Atkinson Company, 2800 N.W. Front Ave., Portland, Oregan 97210, Ph. 910-464-8031 (pumps)

6. Cosmodyne Corp., 2920 Columbia St., Torrance, Calif., 90509, Ph. 213-320-5650 (pumps, vaporizers, tube trailers, storage vessels)

7. CVI Corp., P.O. Box 2138, Columbus, Ohio, 43216, Ph. 614-876-7381 (cryogenic piping, valves, vaporizers)

8. Flodyne Controls, Inc., 48 Commerce Dr., Murray Hills, New Jersey, 07974, Ph. $201-464-6200$ (valves)

9. Harwocd Engineering Co., Walpole, Mass, , 02081, Ph. 617-668-3600 (tubing, fittings, valves, pumps, compressors, intensifiers, gauges)

10. High pressure Equipment Co., 1224 Linden Ave., Erie, Pa., 16505, Ph. 814-838-2128 (tubing, couplings, fittings, valves, pressux, and reactor vessels, pumps, intensifiers, gauges)

11. Linde Company, Dov, of Union Carbide Corporation, Tonawainda, New York, Ph. 716-555-1212 (pumps)

12. Ruska Instrunient, 6123 Hillcraft Ave., Houston, Texas 77036, Ph. 713-774-2533 (hichh pressure instrumentation)

13. Ryan Industries Inc., 4800 Allmond Ave., Louiville, Ky. 40214, Ph. 502-368-1633 (pumps, vaporizers, tube tratlers, storage veasels) 
At the present time the bilix of the high pressure oxygen compatibility research is being done ac NASA-MSFC (Marshall Space Flight Center) and NASA-WSTF (White Sands Test Facility). Existing high pressure programs at NASA-MSFC concentrate on impact and flammability testing. High pressure programs have been initiated at NASA-WSTF on ignition by abrasion and electric arc as well as high pressure GOX and LOX impact testing and flash and fire point testing. The impact apparatus at MSFC and WSTF, although not identical, are quite similar. Present information indicates that practically no oxygen compatibility research is being conducted at private laboratories in the 3,000 to 10,000 psi range. The use of very high pressure oxygen is presently nearly restricted to NASA.

One exception is the use of high pressure breathirg oxygen systems in the medical profession and aircraft industries. Mcst of the past highpressure research and experience stems from the development of such breathing systems as well as those used in NASA programs. Johnston (1970) has compiled characteristics of these high pressure systems, along with the failures experience of the metal and non-metals used. Rocketdyne is establishing a facility to conduct mechanical impact studies at pressures to 10,000 psia. The impact tester now being built is the same as the one used by NASA-MSFC.

The following list of facilities includes principally those that are prezently doing research or engineering involving high pressure oxygen compatibility as well as a few that have considerable high pressure applications experience. Their testing capabilities and other pertinent facte are given in parentheses after each entry.

\section{Battelle Memorial Institute} Columbus, Ohio (past competibility research from 2500 to 12,000 psi including effecte of vibration, shock, adiabatic compression, flow, and temperature) 
2. British Oxygen Co., Ltd

Fngland

(ignition temperature to $3790 \mathrm{psi}$ )

3. Kennedy Space Center, NASA

Cocoa Beach, Florida

(10,000 psi GOX usage)

4. Linde Company, Division of Union Carbide Corp.

Tonawanda, New York

(past: compatibility testing to $7500 \mathrm{psi}$, including adiabatic compression, galling, powder impact, promoted ignition, and mechanical impact; most not to high pressure. present: ignition and calorimetric bomb testing to $2000 \mathrm{psi}$ )

5. McDonnell-Douglas Aircraft

Huntington Beach, California

(high pressure $\mathrm{O}_{2}$ applications)

6. Manned Space Center, NASA

Houstor Texas

(high pressure $\mathrm{O}_{2}$ applications, no teating)

7. Marshall Space Flight Center, NASA

Huntsville, Alabama

(extensive LOX and GOX testing to 10,000 psi - mechanical

impact, low pressure ilammabiltty testing)

8. Naval Ship Research and Development Center

Annapolis Laboratory

Annapolis, Maryland

(ignition temperature testing to $3000 \mathrm{psi}$ )

(also some lower pressure adiabatic compression and hot $\mathrm{O}_{2}$ flow) 
9. Rocketdyne Division, North Arnerican-Rockwell

Canoga Park, Califorisia

(mechanical impact testing to $10,000 \mathrm{psi}$ )

10. White Sands Test Facility, NASA

White Sands, New Mexico

(GOX and LOX compatibility testing to $10,000 \mathrm{psi}$ - mechanical impact, abrasive impact, pneumatic, flash and fire point).

\section{Recommendations}

The extension of GOX and LOX applications to pressures above 3000 psia is reasonable based on the present data. However, in cases where extremely high reliability is demanded, such as in manned space flight, the extension is considered marginal without further compatibility testing. Considerable compatibility data exist at pressures up to 2000 psia; the sparse compatibility data up to 7500 psia suggest no additional problems will be encountered. However, to obtain high reliability, extensive materials compatibility testing to 10,000 psia will have to be done. Some of these data are now being obtained at NASA-MSFC and W STF. Standardization of test procedures and materials is essential to reliability and interagency comparisons, and will also encourage involvement of indust, $y$ in compatibility testing. New data need to be combined with existing data to be analyzed for proper interpretation. Old teste need to be studied for degree of validity, and new tests which better describe oxy den compatibility are desirable. Design and applications guidelines will oncourage safe use of oxygen and uniform practice throughout NASA. Data necessitated by future design applications must be anticipated. In support of these general recommendations, an excerpt from the Apollo 13 - High Pressure Oxygen Report (Johnston 1970) is given below: 
Despite the many standards and specifications reviewed by this panel, it has become obvious that a void exists in several areas. One area of major concern is the apparent lack of sufficient detail on nonmetallic materials and their application for high pressure oxygen systems to enable a designer to select the proper material for his system.

The reason for this is that a comprehensive test program has yet to be defined and accomplished. Although some work has been started in this area, it appears that the required effort is a major one and should begin with developing a standard approach to the problem on the part of both Government and industry so that all data developed can ultimately be universally used without the requirements for interpolating test results from a many faceted approach.

The second area of concern is that no standards and/or specifications appear to exist on a total system which points out the hazards resulting from misapplication oi a component which may serve its function well in some applications, but may be trigger mechanism of disaster in another application.

Based upon these generalities, the following specific recommendations are suggested:

1. Extend Measurements indicated below to high pressure $(10,000$ psi) for materiais of immediate interest (Include effects of contamination).

(a) Ignition temperature

(b) Impact sensitivity

(c) Flash and Fire temperatures

(d) Pertinent configuration testo

2. Develop and Standerdize Tests and Materials

(a) The standardization of test procedures is essential if meaningful results are to be obtained. This standerdigation is probebly best coordinated by a group not directly involved in conducting the messuremente. Involvement of ASTM would be very denirable and posalbly NBS could assiat in developiag standard test methods, with the cooperation of tept fscllities. 
(b) Standard reference materials for use in compatibility

tests should be established. These materials, which can be stocked for distribution ty the Office of Standard Reference Materials, National Bureau of Standards, are invaluable for the intercomparison of existing apparatus as well as the standardization of new apparatus. The establishment of standards should be done through a cooperative effort of NBS and testing facilities.

(c) The development of new tests more closely related to fundamental physical or mechanical properties of materials is desirable. Examples of existing tests which fall in this category are: ignition temperature and flash and fire ternperature.

(d) An independent statistical analysis of the repeatability of mechanical impact test data is needed. Past studies have not been conclusive and the continuing controversy and wealth of data is justification for an in depth study.

3. Analyze Data to obtain best values.

(a) A statistical analygis of all existing compatibility data to determine dependence on pressure, in particular, but also on other factors affecting the reliability of the material. Multiple regression analysis would be necessary to extract this information from the existing data. The data to be analyzed are principally ${ }^{*}$ ose listed in this report. This analysis is not a trivial task; however, the resulting increased wor ch of the data justifies the effort. The general validity and uncertainty estimates of material ranking data will be considerably improved as a result of this exitical analysis.

(b) More universal agreement should be obtained on material ranking liats. This can be initiated by establishing such a list for each standz i test within NASA. Work ahould proceed to extend the acceptance of these liats by other government agencies and induatry. Ultimately international accoptance is desirable. It cannot be overatresed that the test conditions are an integral part of any ranking liat. 
(c) A compilation of the rmodynamics data relevant to material compatibility is essential to any effort to understand compatibility. Test methods, test results, ranking lists, etc. are all more meaningful when they can be related to fundamental properties. Such properties as ignition temperature, heat of combustion, thermal diffisivity, melting and vaporization temperatures of metals and their oxides should be considered.

4. Adopt Guidelines for design and procedures for oxygen systems. Participation of oxygen producers and equipment manufacturers is indispensable in this process.

(a) Oxygen system or components design can have many inherent safety features that can be spelled out for the design engineer. This should include the :naterials used, flow rates, valving rates, heat sinks, cleaning accessibility, filters, internal flow cross sections, temperature limits, an.? many others.

(b) Cleanliness standards and procedural guidelines that are NASA wide and even nation wide are essential to the safe operation of high pressure oxygen systems.

5. Fundamental Research should be pursued in all areas of ignition and combustion, because understanding alwaye leade to better and safer applicaicicns. Two areas in particular stand out as areas of concern for high pressure oxygen:

(a) The mechanical proparties of materials in the presence of high pressure oxygen has been virtually ignored. Oxygen embrittiement is small at low pressures but may be siguificant at 10,000 psi. Fatigue behavior anit crack propagation rates in the presence of cxygen are nos known for any pressures.

(t) The burning behavior at high oxygen pressure is in real doubt. Since the degrse of damage is directly relaied to the burning rate, this ohould be known. The only study of burning rates vefaus presaure indicate posaibls dramatic changes around 2000 pei. 
Some of the above recommendations are already being pursued by NASA. ASRDI is sponsoring some ignition research at White Sands and is establishing design and cleanliness guidelines at Lewis Research Center. MSFC is funding some lower pressure combustion studies at INBS. These should be considered an integral but initial part of NASA's pursuit of the safe applications of high pressure oxygen.

VIII. Summary

Based on the available data it appears that no fundamental problems would prevent the common use of high pressure GOX or LOX. There are dangers involved, of course, but with a reasonable set cf rules and guidelines, these dangers can be reduced to a workable level. It aptears tha. a large proportion of pasi accidents are caused by material incompatibility but an even larger proportion are causef by personal careleseness or equipment failure. With care, the added hazards due to high pressure will not increase accident rates sid nificantl j.

In high pressure systems the enhancement of existing ignition sources is more important than the decreaset ignition temperature of materials. For examp $e$, in high pressure applications the effect of adiabatic compression becomes increasingly important, higher flow sates enhance the probability of ignition from friction, impact, static discharge, etc., and reaction intensities increase because of the increased density and availability of $\mathrm{O}_{2}$. The posability of ignition due to mecbanical fallures is also greater.

Thera are little compatibilits data on most raterials above 3000 paia and much is neecied. It is also desirablu to have more quzntitative fundarnental data. This reguires study of the juyaical phenomena involved and the design of experiments to develop parameter representing these phenomena. There is a atrong need for more enginenring compatibility characterization measurements, wach es confleuration and component tenta by manufacturera. 
From the available data the pressure dependence of ignition and burning are not well characterized. Metal burning rates are proportional to $\sqrt{\mathrm{P}}$ at lower pressures but at higher pressures burning rates decreas?. Only a few ignition tensperature versus pressure data are available. These data show the ignition temperature decreasing with increasing pressure. It would be unwise to extend these few data to other materials without further confirming measurements. Some impact test data as a function of pressure are available but considerably more are needed. These show, but not clearly, an increasing sensitivity with pressure. Flash and fire point data also show an increased sensitivity for non-metais at higher pressures.

Equipment for the handling and storage of high pressure oxygen, both liquid and gas, is readily available. In some instances it is necessary to specify the elimination of marginal materials. This presents a problem only if a better substitute material is not yet available. Equipment manufacturexs are eager to cooperate in fabrication of more reliable components.

Present high pressure compatibility testing facilities are restricted nearly totally to NASA- WSTF and MSFC. Commercial laboratories have performed various compatibility tests in the past but generally not above about 3600 psi.

It is recommended that NASA extend specific experimental tests to higher pressures, establish standard tests and reference materials, perform statistical analyses of existing data, develop material ranking lists, and encouxage new test methods and fundamental research. 
Aerojet Nuclear Systems Co., Sacramento, Calif. Materials Properties Data Handbook, (Contract SNP-1, SNPO of NASA and AEC, Cleveland, Ohio, 1970). Available from National Technical Information Service, Springfield, Va.

ASTM Designation: D2512-70, Standard Method of Test for Compatibility of Materials with Liquid Oxygen (Impact Sensitivity Threshold Technique) Volume 18, p. 692 (1970).

ASTM Designation D 286́3-70, Standard Method of Test for Flammability of Plastics Using the Oxygen Index Method, p. 719 (1970).

Attwood, H. C. and Allen, G. R., On the Spontaneous Ignition Tenperature of Organic Materials in Oxygen, Ministry of Defense, London, England, C.P. No. 1172 (1971).

Austin, J., NASA-Marshall Space Flight Center, private communication (1972)

Bankaitis, H., and Schueller, C., ASRDI Oxygen Technology Survey: Cleaning Requirements, Procedures and Verification Techniques, To be published as a NASA Special Publication.

Bauer, H., Wegener, W., and Windgassen, K. F., Fire Tests on Centrifugal Pumps for Liquid Oxygen, Cryogenics 10, 241 (1970).

Baum, J. V., Goobich, G., and Trainer, T. M., An Evaluation of High-Pressure Oxygen Systems. Battelle Memorial Institute, Columbus, Ohio; Final Report AMRL-TDR-62-102, Centr. 33 (616)8267, Air Force Systems Command, W right-Patterson Air Force Base, Ohio. (1962).

Blackstone, W. R., Development of an Improved Gaseous Oxygen Impact Test System, Final Report by Southwest Research Institute, San Antonio, Texas, prepared for NASA MSC (July 1970).

Blackstone, W.'R., Baber, B. B., and Ku, P.M., Development of New Test Techniques for Determining the Compatibllity of Materials with LOX Under Impact, AFAPI TR. 67-41 USAF (Dec. 1967). 
Blackstone, W. R., and Ku, P.M., An Assessment of Impact Test Techniques for Determining the Fire or Explosion Hazards of Materials Exposed to LOX, ASTM-Materials Rezearch anci Standards, 30, 52 (1971).

Brooks, S. H., Oxygen-Oil Explosions. Preliminary Report ILI. Spontaneous Ignition of Oils in Oxygen Under Pressure, U. S. Bureau sf Mines, Pittsburgh, Pa., (1923).

Burmeister, L. C., Loser, J. B., and Sneegas, F. C., Advanced Valve Technology, NASA SP-5019 (1967).

Carlson, R., Linde Division, Union Carbide Corporation, Tonawanda, New York, Private communication (1971).

Clark, A. F., The Compatibility of Structural Materials with Oxygen, Interim Report 275.05-71-2, Cryogenics Division, National Bureau of Standards: DOT order number DOT-AS-10059, (Oct. 1971).

Conrad, H., "The Cryogenic Properties of Metals," High-Strength Materials, John Wiley and Sons, New York,(1965).

Dean, L. E., and Thompson, W. R., Ignition Characteristics of Metals and Alloys, J. Am. Rocket Soc. 31, No. 7, 917 (1961)

Grosse, A. V. and Conway, J. B., Combustion of Metals in Oxygen, Ind. Eng. Chem. 50, 663 (1958).

Guter, M. Ignition in High Pressure Oxygen, British Oxygen Co., Ltd., Rept. No. R/D-1312, MA S/T Memo $13 / 50$ (1967).

Isaacs, J. L., The Oxygen Index Flammability Test, J. Fire and Flammability, 1, 36 (1970).

Jackson, J. D. , Boyd, W. K. , and Miller, P. D., Reactivity of Metals with Liquid and Gaseous Oxygen, DMIC memorandum 163, Jan. 15, 1963. (Battelle Memorial Institute, Columbus 1, Ohio).

Jamison, H. H., Development of a Gaseous Oxygen Impact Testing Method, Mat'ls. Res. and Stds. 1122 (1971).

Jamison, H. H., Development of a Method for Qualifying Spacecraft Materials Used in Pure Oxygen, NASA Internal Note MSC-01553 (1970).

Johnston, R. S., Chairman of Panel 8, MSC Apollo 13 Inveatigation Team, NASA Final Report - High Pressure Oxygen Syiteme Survey, (May 1970). 
Keeping, W. O., Compatibility of Materials with Oxygen, Compressed Gas Association, Oxygen Compressors and Pumps Symposium, Atlanta, Georgia, Nov. 9-11 (1971).

Key, C. F., and Riehl, W. A., Compatibility of Materials with Liquid Oxygen, NASA TM X-78-5, MSFC (1964).

Key, C. F., and Riehl, W. A., Compatibility of Materials with Liquid Oxygen, MTP-P and VE-M-63-14 (1963).

Key, C. F., Compatibility of Materials with Liquid Oxygen II, NASA TM X-53052, MSFC (1964).

Key, C. F., Compatibility of Materials with Liquid Oxygen III, NASA TM X-535 33, MSFC (1966).

Key, C. F., Compatibility of Materials with Liquid Oxygen IV, NASA TM X-53773. MSFC (1968).

Kimzey, J. H. , Review of Factors Affecting Ignition of Metals in High Pressure Oxygen Systems, NASA Div. Int. Note MSC 03461 (Oct., 1970).

Kirschfeld, L., Apparatus for Combustion Tests on Metals Under Oxygen Pressures Up to 200 Atm and the Combustibility of Iron Wire in High Pressure Oxygen, Arch. f. d. Eisenhuettenw. 36 No. 11, 823 (1965).

Kirschfeld, L., Combustibility of Steel and Cast Iron in Oxygen at Pressures of up to $150 \mathrm{~atm}$, Trans. Archiv. f. d. Eisenhuettenw. 39, 535 (1968).

Kirschfeld, L., Combustion Rate of Light Metal Wires in High Pressure Oxygen, Metall. 15, 873 (1961).

Kirschfeld, L., On the Burning Rate of Metals in Oxygen to 200 atm Pressure, Metall. 21, 98 (1967).

Linde Division, Union Carbide Corp., Study of Handling Standards and Safety Criteria for Liquid and Gaseous Oxygen Systems. NASA-Lewis Research Cenier, Cleveland, Ohio, Contri. NAS3-15082 (1971) (NASA ONLY)

Lucas, W. R., and Riehl, W. A., An Instrument for Determination of Impact Sensitivity of Materials in Contact wh Liquid Oxygen; ASTM Bulletin 29-38 (1960). 
Marzani, T. A., Private Communications, Spontaneous Ignition in a High Pressure Oxygen Environment (NSRDC) (July 2, 1969).

Marzani, J. A., Spontaneous Ignition of Solid Materials at Elevated Pressures, Eastern Section of Combustion Institute, University of Massachusetts, Amherst, Mass., Oct. $21-22$ (1968a).

Marzani, J. A., Spontaneous Ignition of Valve Packing Materials in a High Pressure Oxygen Environment, NSRDC Report 2579 (1968b) (Naval Ship Research and Development Center, Annapolis, Md.)

McKinley, Experimental Ignition and Combustion of Metals, Compressed Gas Association, Oxygen Compressors and Pumps Symposium, Atlanta, Georgia, Nov. 9-11 (1971).

McQuaid, R. W. and Cole, E. L., A Survey of Compressed Gas System Casualties Due to Spontaneous Ignition During 1968 - 1971, Naval Ship Research and Development Center Report 28-148 Annapolis, Md. (1972).

McQuaid, R. W., Private communications (1972)

Evaluation of Combustibility of a New High Temperature Resistant Polymer in a High Pressire Environment (Oct. 26, 1970).

Spontaneous Ignition of Four Rubber Compounds in a High Pressure Environment, Report 8-649 (Nov. 6, 1970).

Ignition temperatures of nonmetallic components of an oxygenregulator valve, Report 28-12 (Feb.4, 1972).

Meyers, D. D., Flainmability, Odor, and Offgassing Requirements anc Test Procedures for Materials in Envirouments that Support Combustion, NASA-NHB 8060.1 (1971).

NASA, MSC-02681, Non-metallic Materials Design Guidelines and Teat Data Handbook, Revision C, (Feb. 1972).

NASA Pauel 1, Apollo 13 Spacecraft Incident Investigation, N71-1995; NASA-TM-X-66934, Inventigation of Crack Growth Threnold of Inconel. 718 Exposed to High Pxespuxe Oxygen, Vol. 3, Sec. B. 63, page 401 (1970).

Nesgovorov, L. Y., Prozorov, U. A., and Cholin, V. G., Experimental Determining of Minimum Ignition Temperatures of Metallic Materials in the Presence of Gaseous Oxygen, LATV. Pex Zin. Anad. Vest., Fiz. UNTEHM. ZIN. 1, 70 (1968). 
Nihart, G. J., and Smith, C. P., Compatioility of Materials with $\mathbf{7 5 0 0}$ psi Oxygen, Linde Division, Union Carbide Corp., Tonawanda, N. Y., Report No. AMRL-TDR-64-76, Contr. No. AF33(657)-11686, 80 pp., NASA N65 11897, (1964).

North Atlantic Treaty Organization (NATO), Advisory Group for Aeronautical Research and Development, Materials Properties Handbook (Technical Dept., Royal Aeronautical :oc., London, 1959), NASA-W ashington, D. C. 20546

Olson, R. E., Safety Design Considerations for High Pressure Oxygen Systems, Martin Marietta Corr., Denver, Colo. Rept. M-67-29 (1967).

Ordin, P. Mishaps with Oxygen in NASA, Compressed Gas Assciation, Oxygen Compressors and Pimps Symposium, Atlanta, Ga., Nov. 9-11, 1971.

Pel such, J. J., Jr., ASRDI Oxygen Technology Survey: Metals and Alloys, (To be published as NASA Specall Publication, 1972).

Pippen, D. L., and Stradling, J. S., Techniques for Determination of Flash and Fire Points and Impact Sensitivity of Materials in GOX, ASTMMat. Res, and Stds., 35, 53 (1971).

Reynales, C. H., Selection of Lubricants and Thrcad Compounds for Oxygen Missle Systems, Adv. Cryo. Eng. 6, 117 (1961).

Reynales, C. H., Compatibility of Materials with Oxygen, Report No. D81 -444, Douglas Aircraft Co., Inc., Long Beaci,, Calif. (1958).

Reynales, C. H., Safety Aspecte in Design and Operation of Oxygen Systems, Paper No. 741, Chemical Clearing ot Missile Iaunching Facilities and Components Symposium, Tulsa, Okla., (Jan., 1959).

Schmidt, H, W., Siewert, R. D., and Eorne, D. E., ASRDI Oxygen Technology Survey: Centrifugal Pumps ( to be published as a NASA Special Publication, 1972).

Schmidt, H. W., ASRDI Oxygen Technology Survey: Cleaning Requirements, Procedures and Verification Techniques (to be published as a NASA Special Publication, 1972).

Schwartzberg, F. R., (Martin-Marietta Co,, Denver, Colo., Cryogenic Materials Data Handbook, Technical and Scientific Information Clearinghouse, Defense Document Center, ML-TR-64-280, 1968), provioiuly R. P. Reed, (Cryogenics Div., Boulder, Office of Technical Servizes, PB171809, 1963). 
Schwinghamer, R. J., Impact Sensitivity of Materials in Contact with Liquid and Gaseous Dxygen at High Pressure, Compressed Gas Association, Safety Symposium, Atlanta, Ga., Nov. 9-11, 1971.

Stradling, J., Ignition by Abrasives, NASA TP-WSTF-193 (19?1).

Van Dyke, B. H., Hazards of Cryogenic Systems, Proc. 1959 Safety Conf., (1959) p. 13.

Weiss, V., and Sessler, J. G., Aerospace Structural Metals Handbook, (Syracuse Univ. Press, DDC No. AD487355, ASD, WPAFB, Ohio, 1963, 1966). Avail. NTIS.

White, E. L. and Ward, J. J., Ignition of Metals in Oxygen, Defense Materials Information Center, Battelle Memorial Institute, Columbus, Ohio, DMIC Report 224, Feb., 1966.

Wigley, D. A., Mechanical Properties of Materials at Low Temperatures, (Plenum Press, New York, (1971) p. 275. 


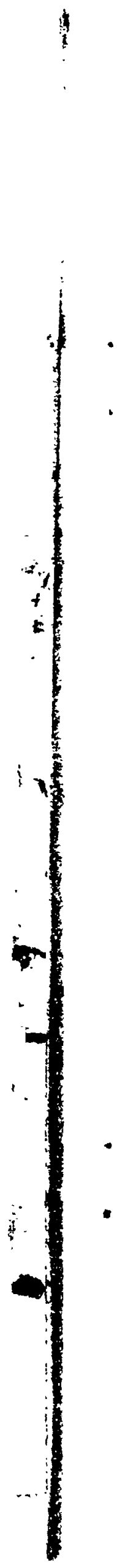

APPENDIX I - HIGH PRESSURE OXYGEN COMPAr IIBILITY DATA 


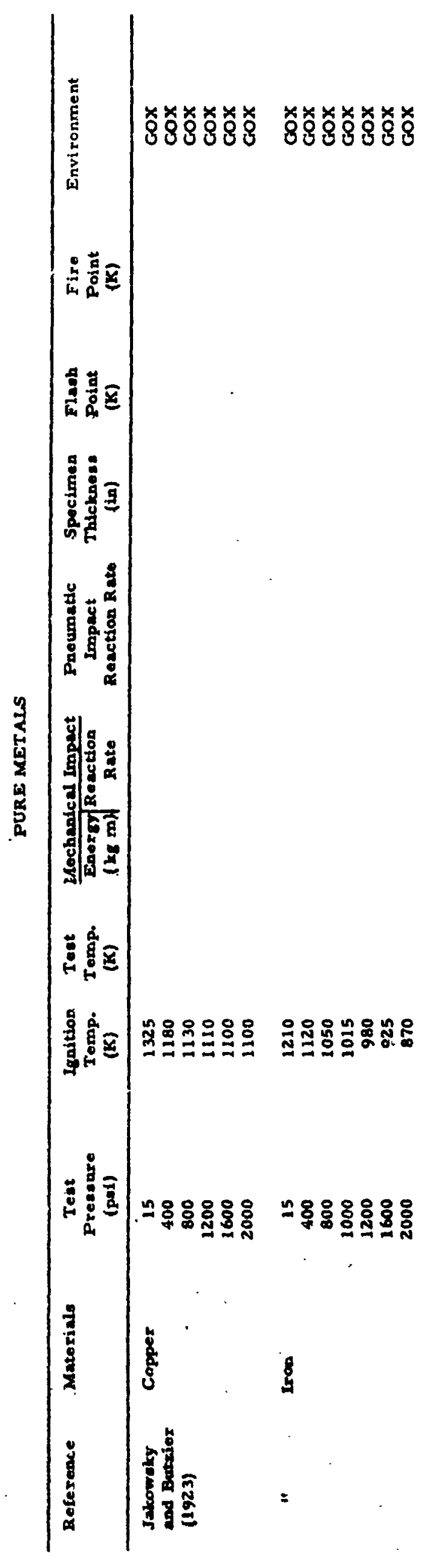




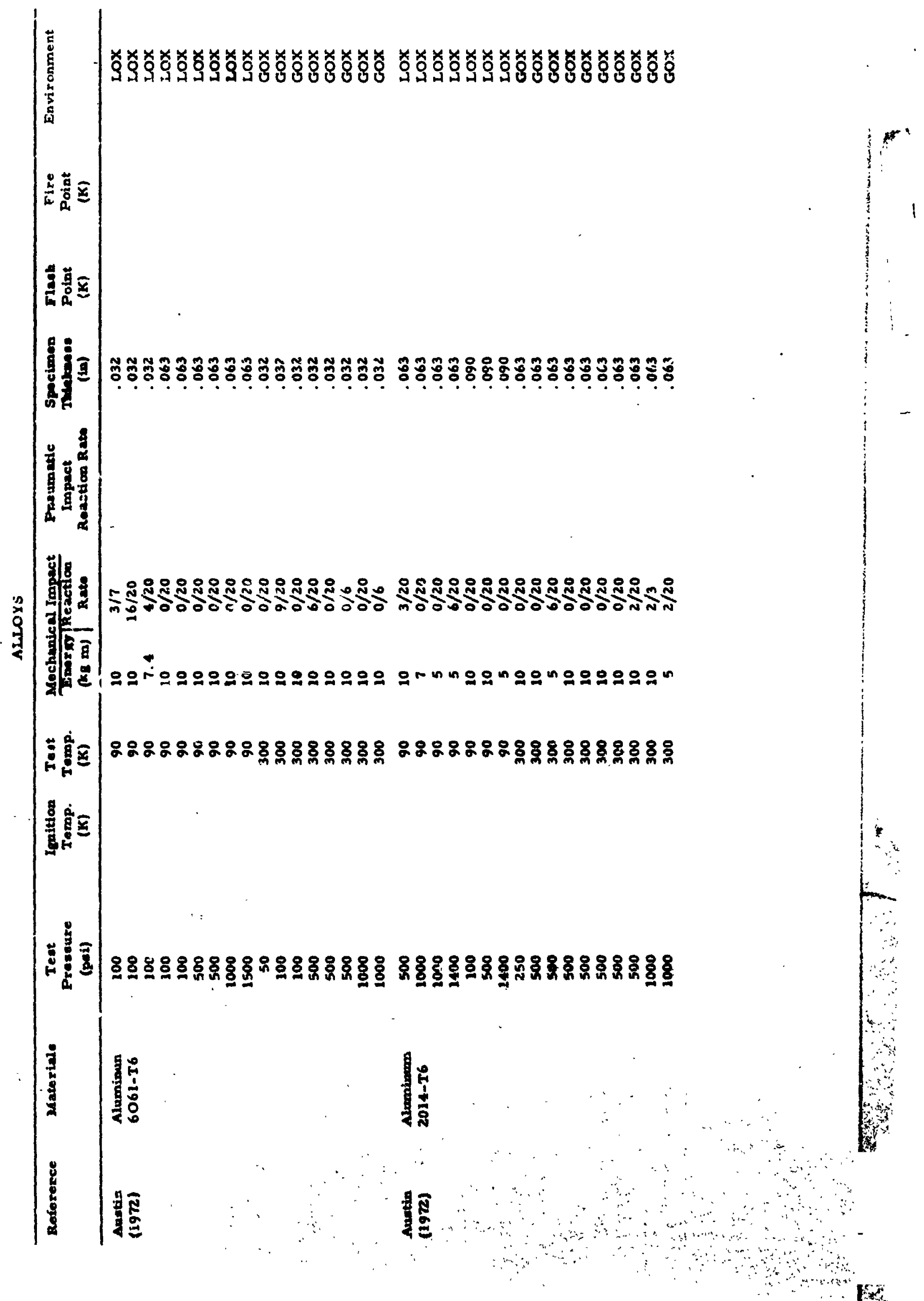





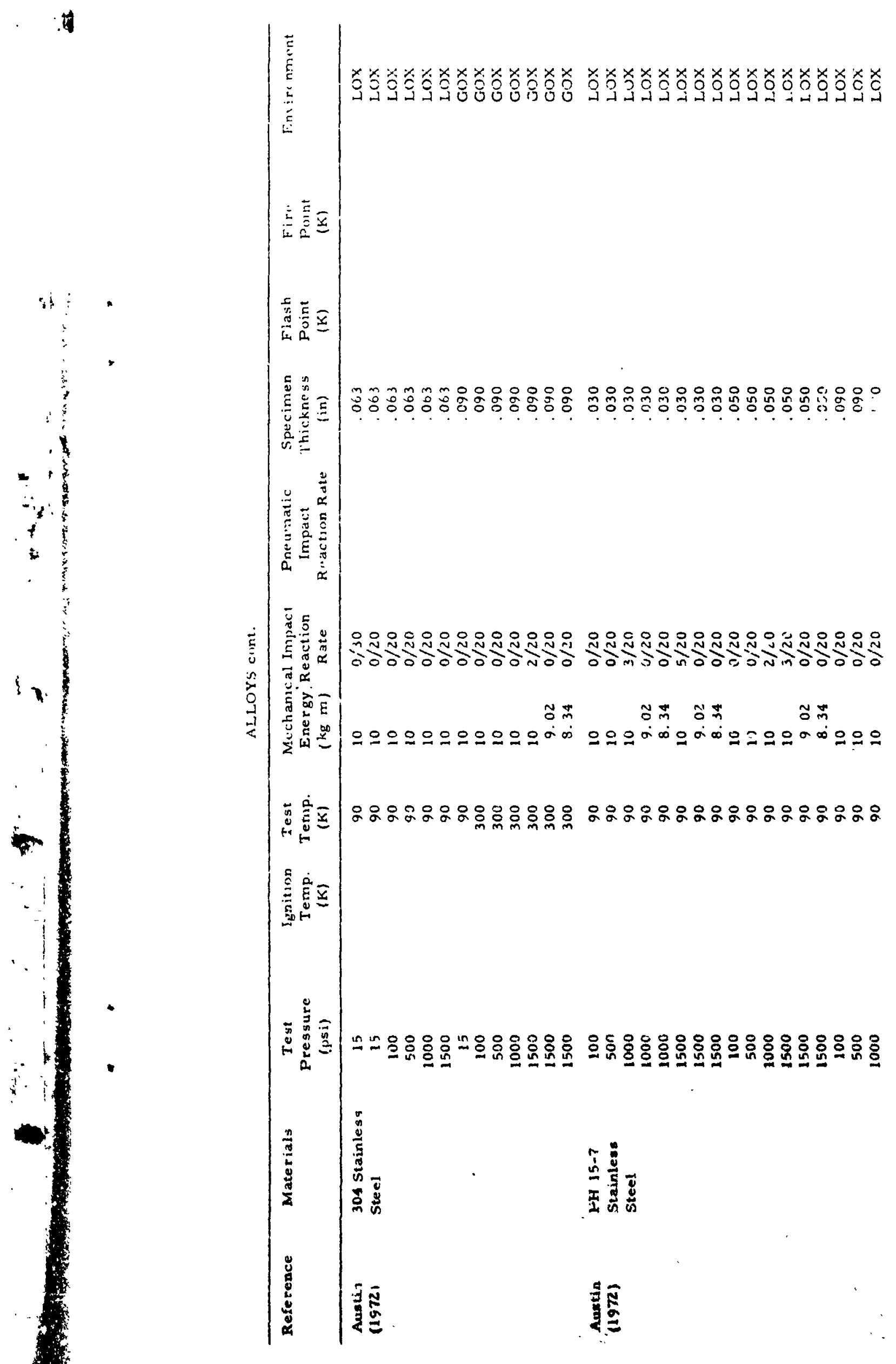





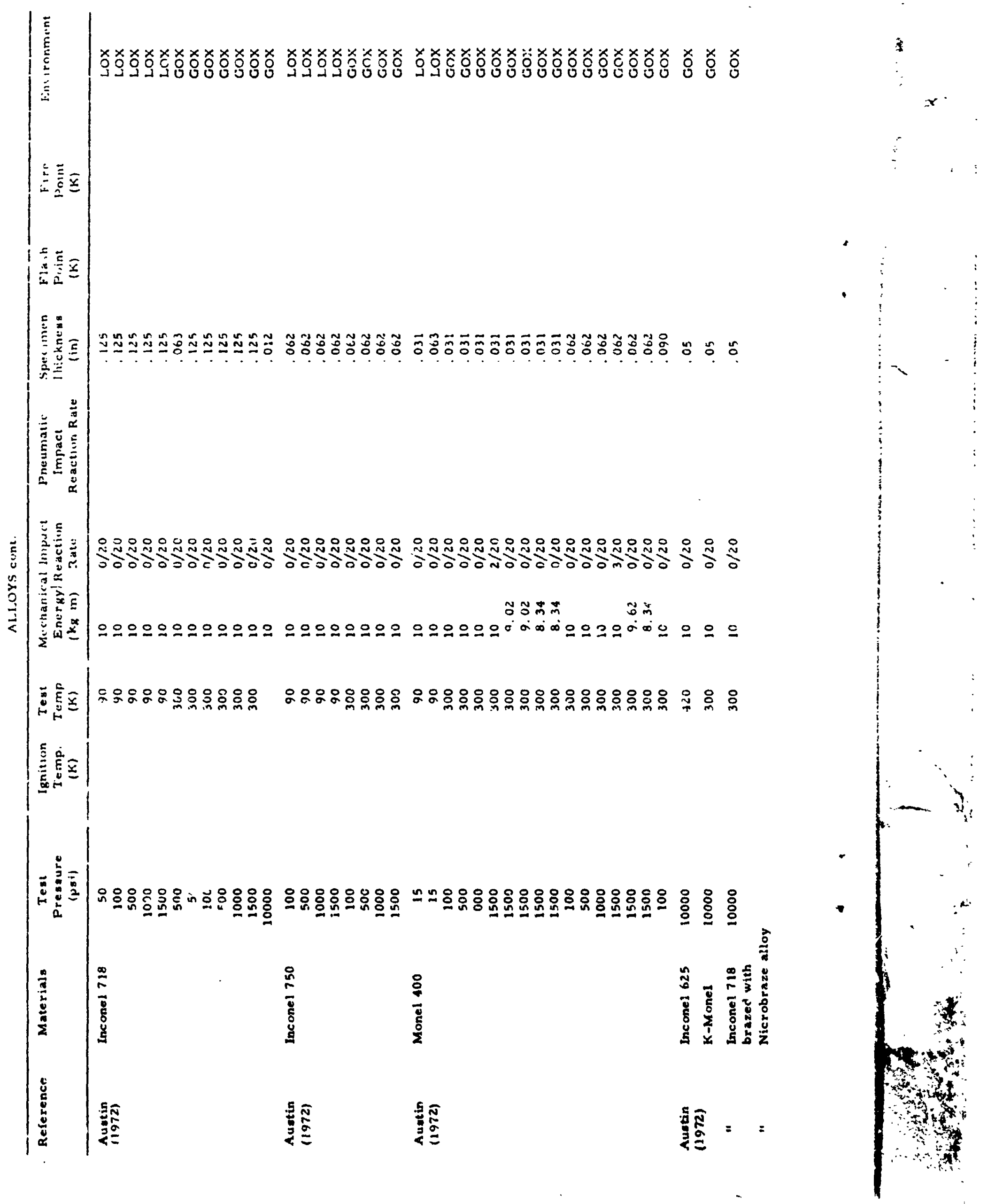




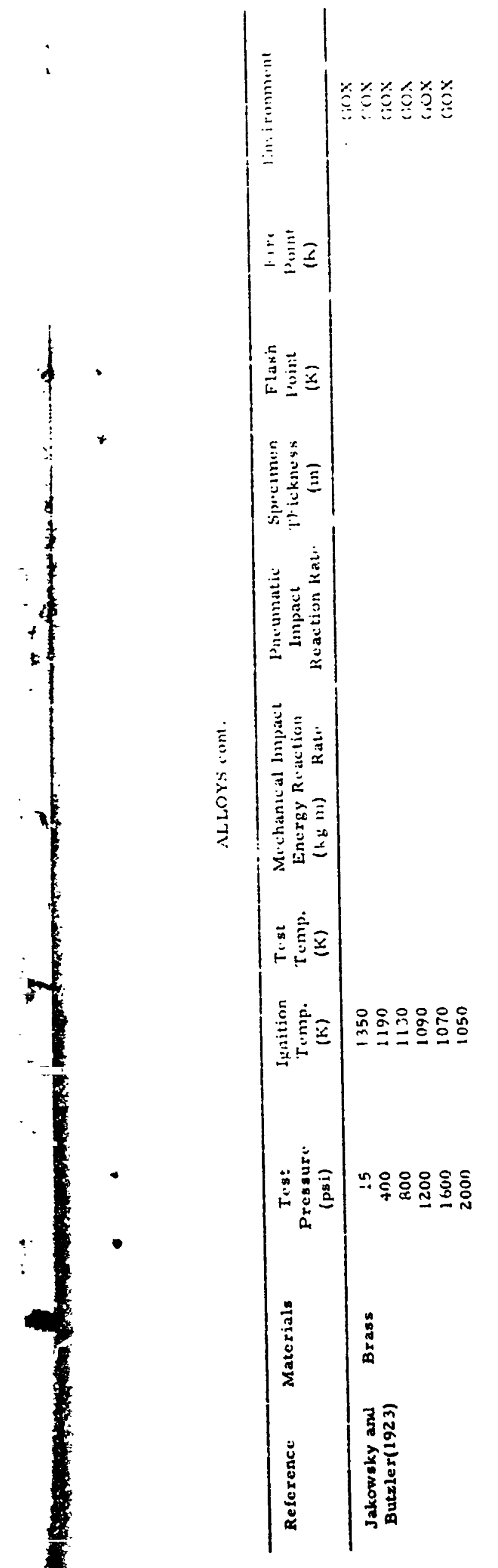




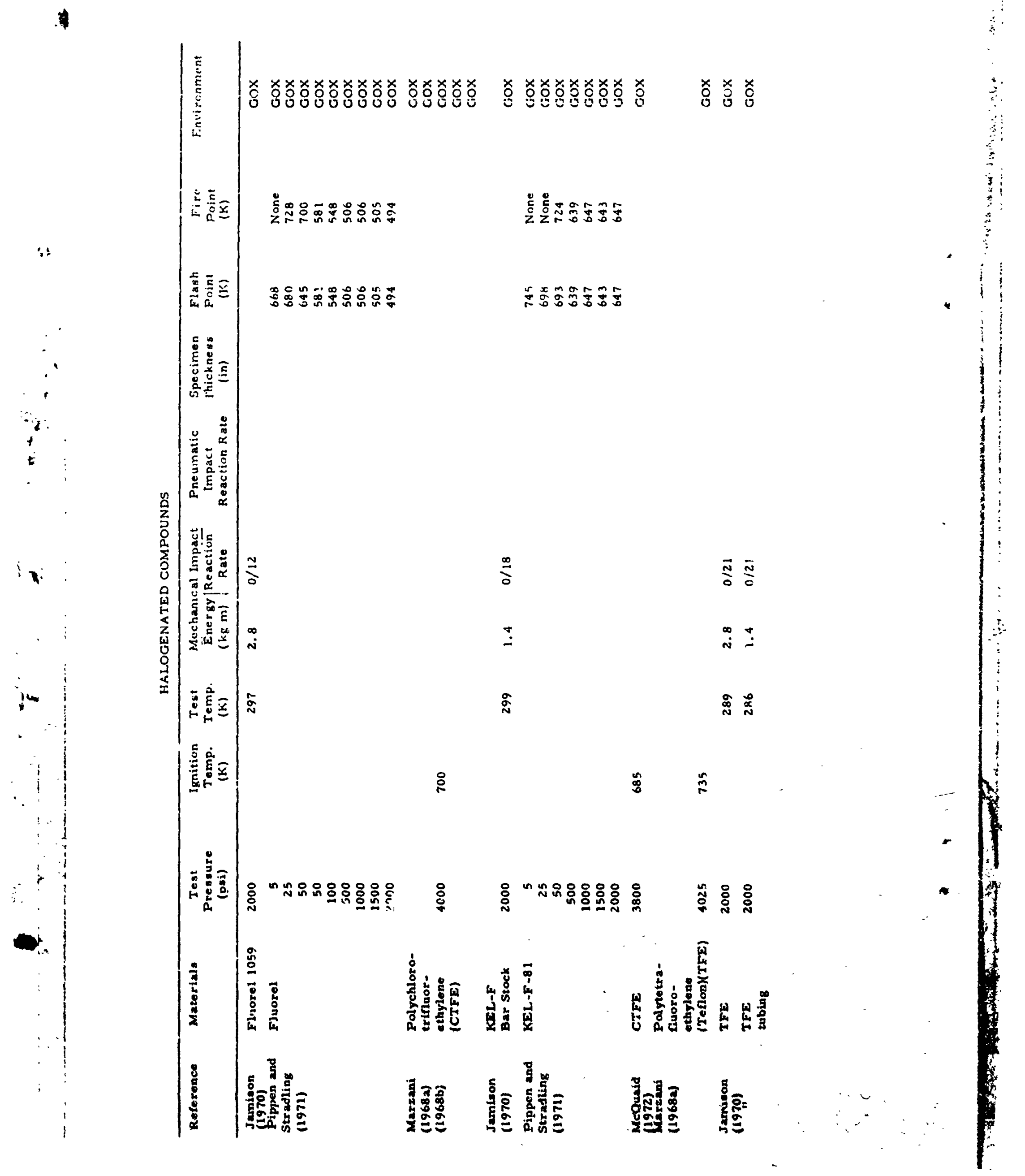




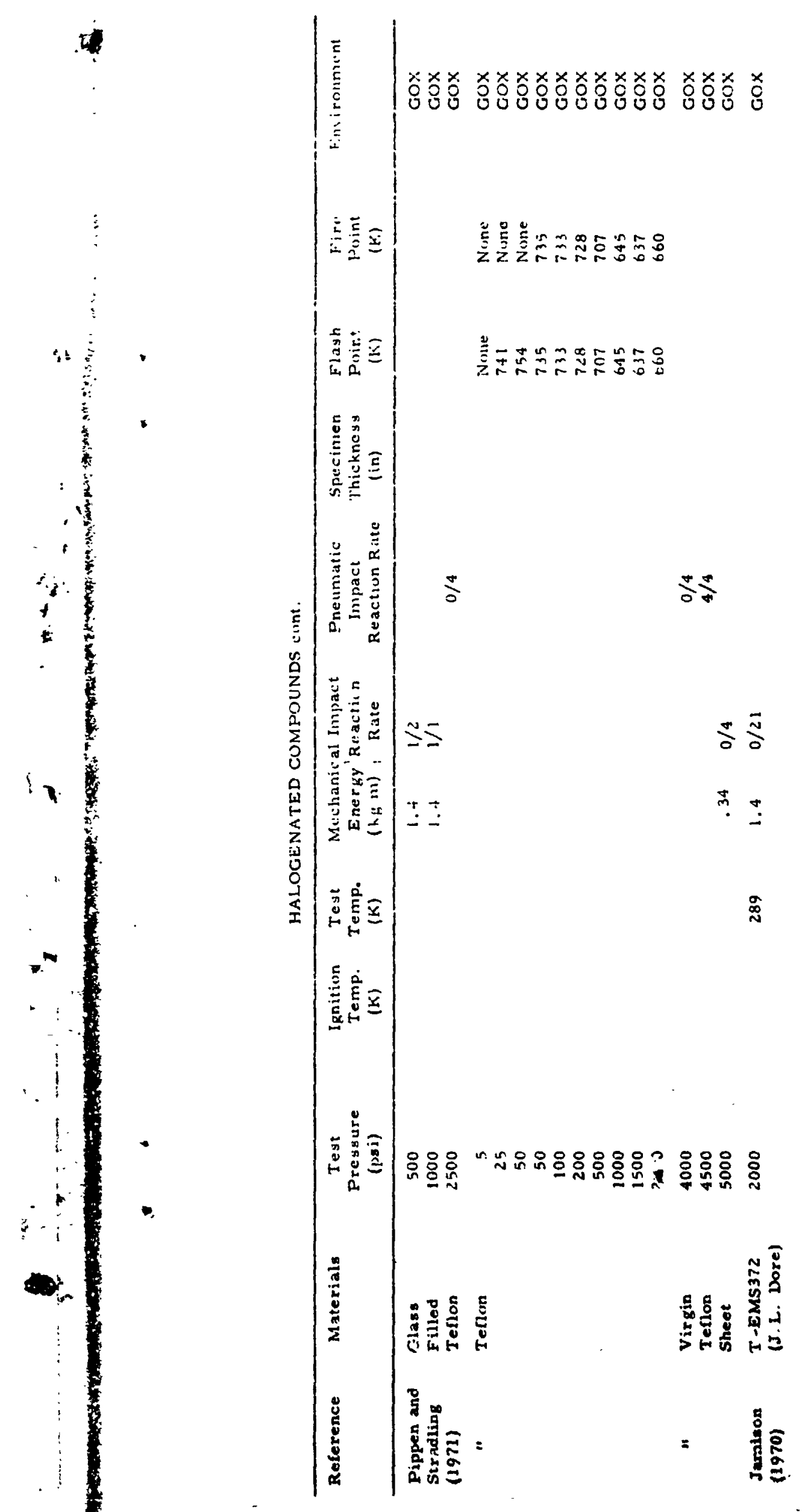




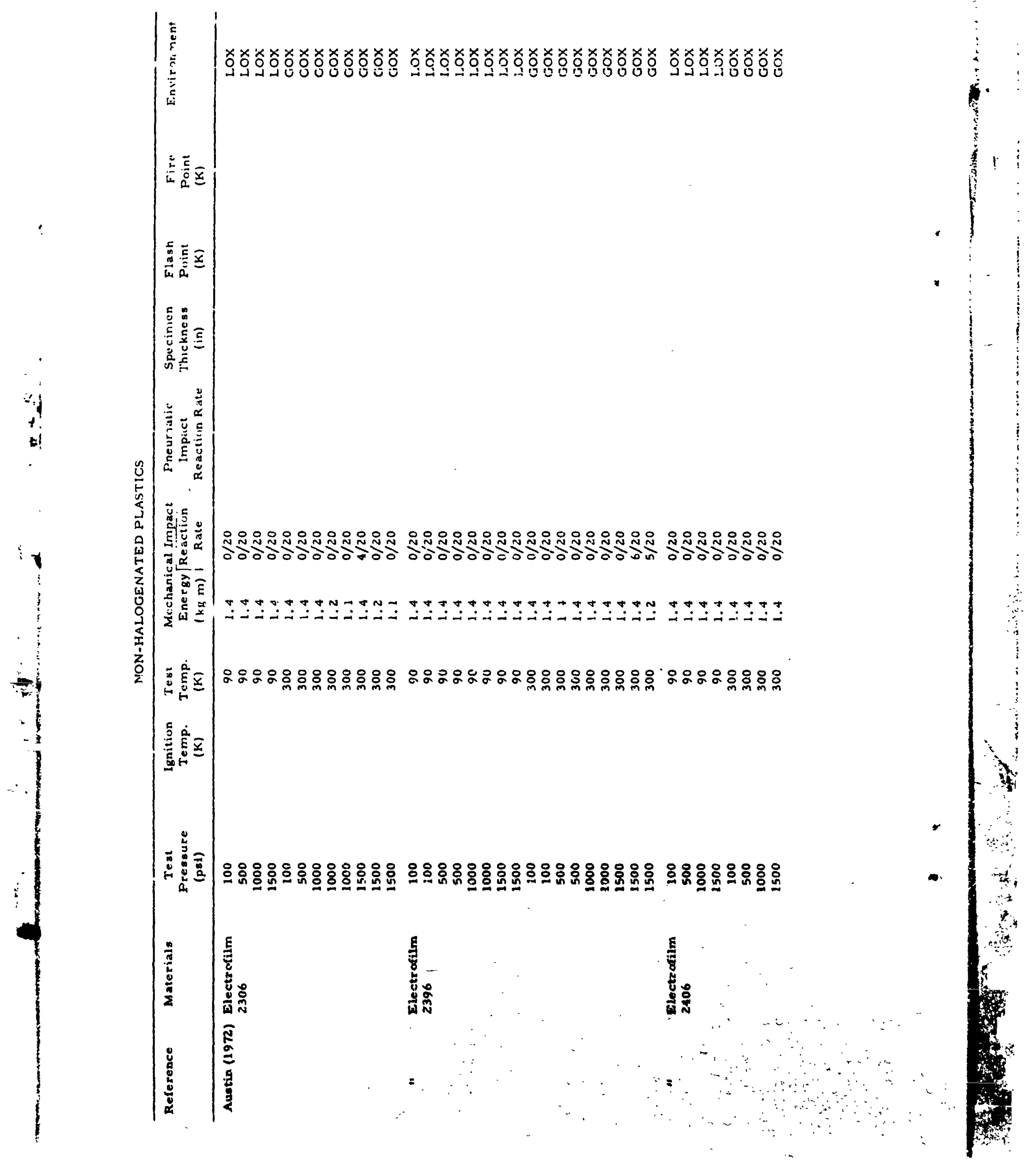




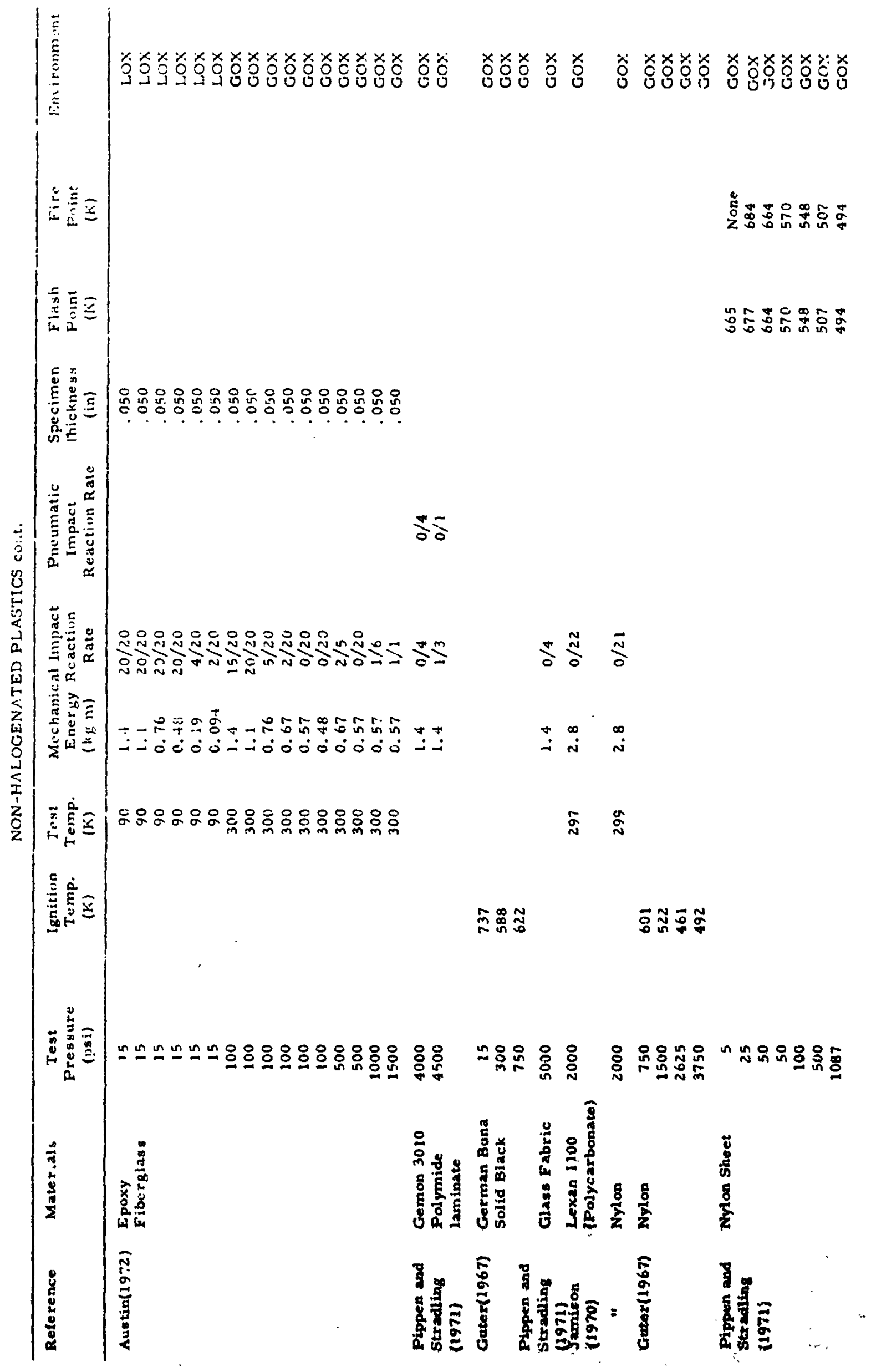



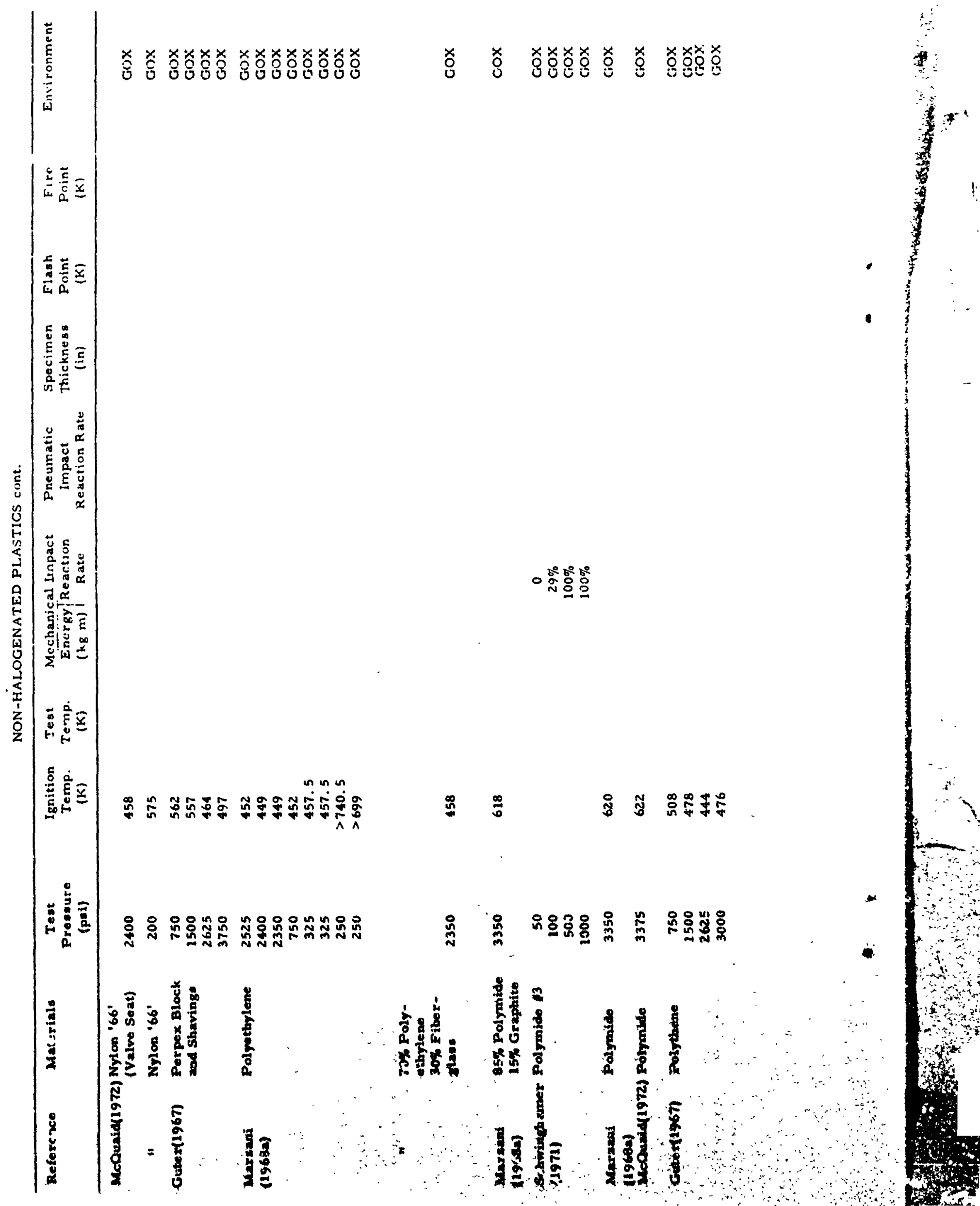


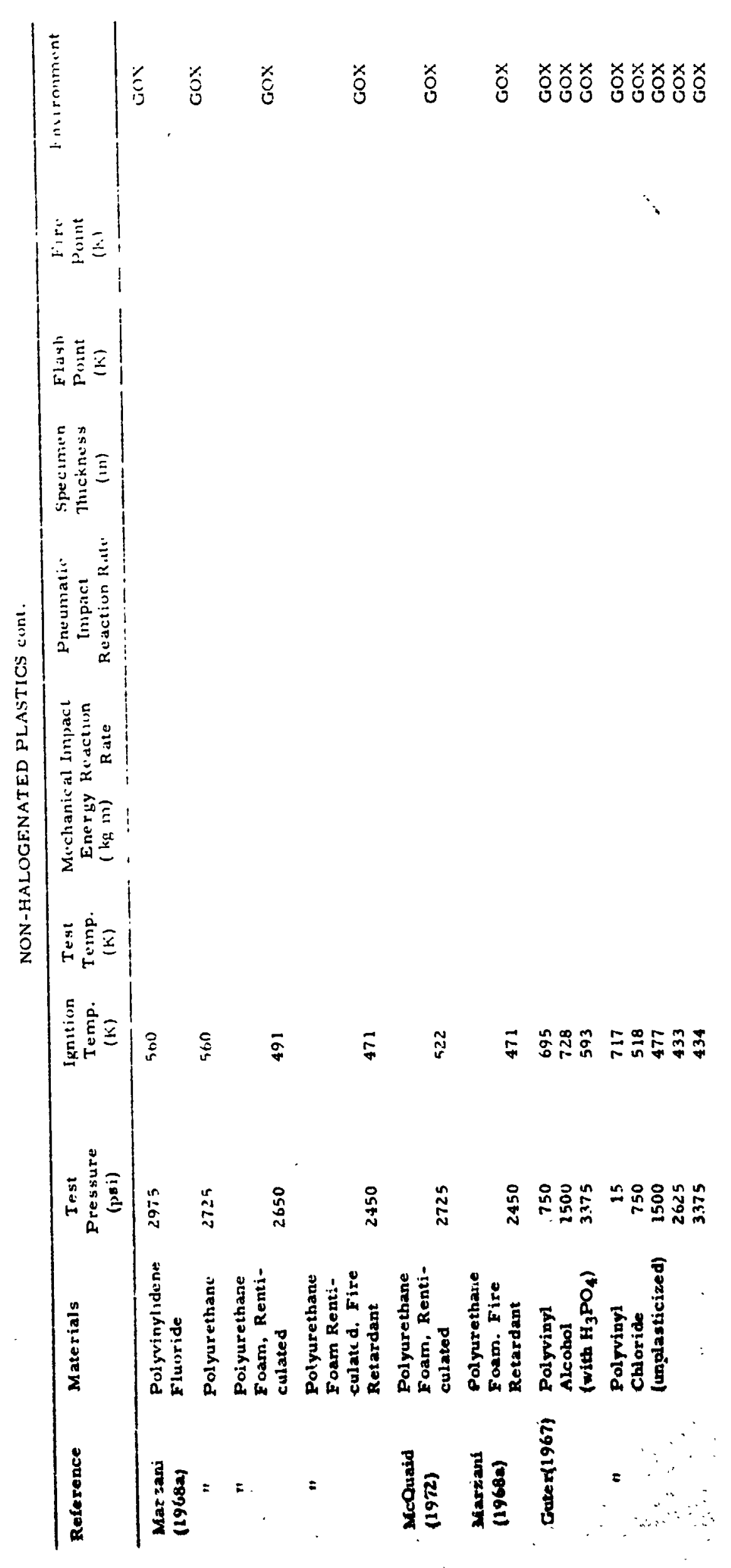




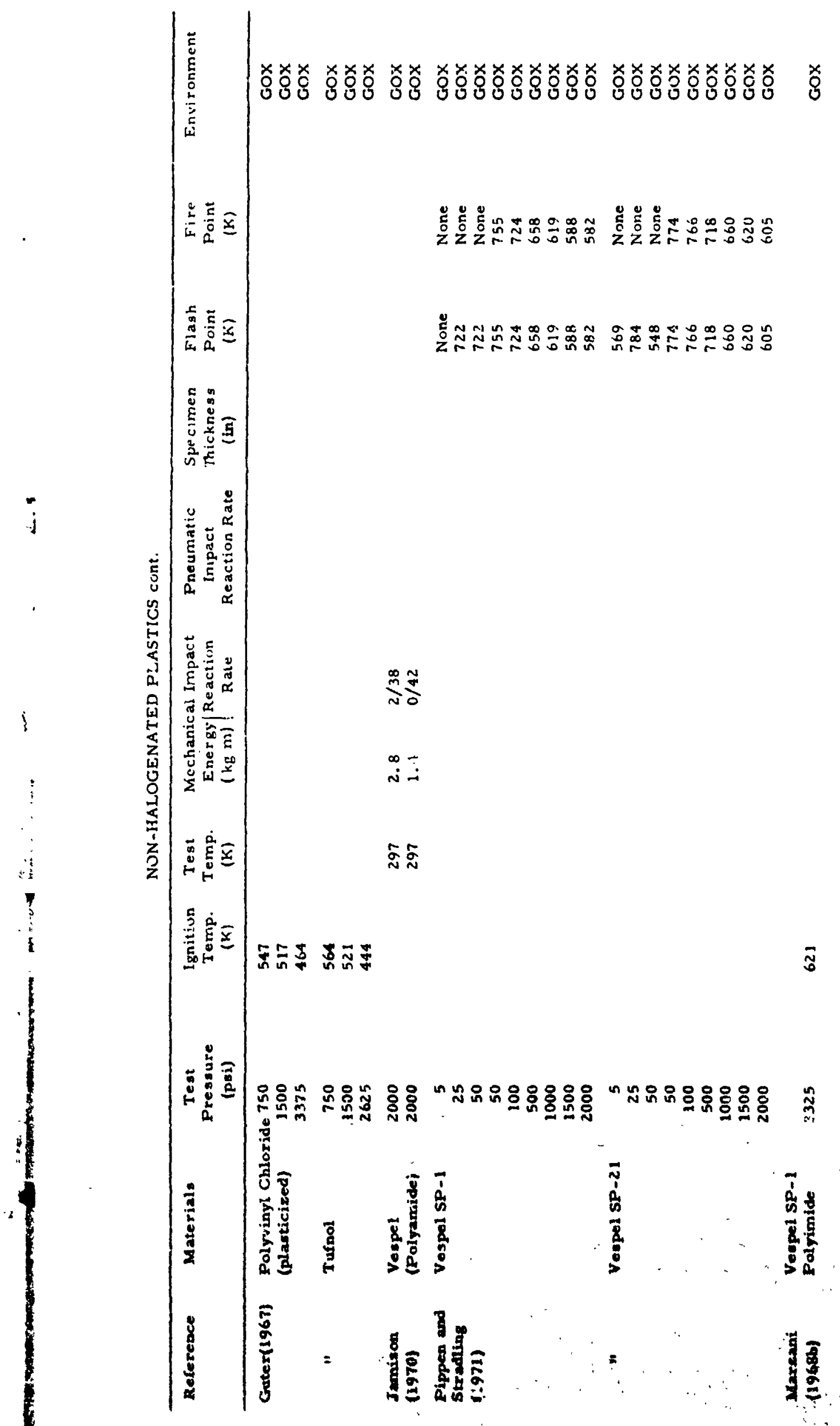




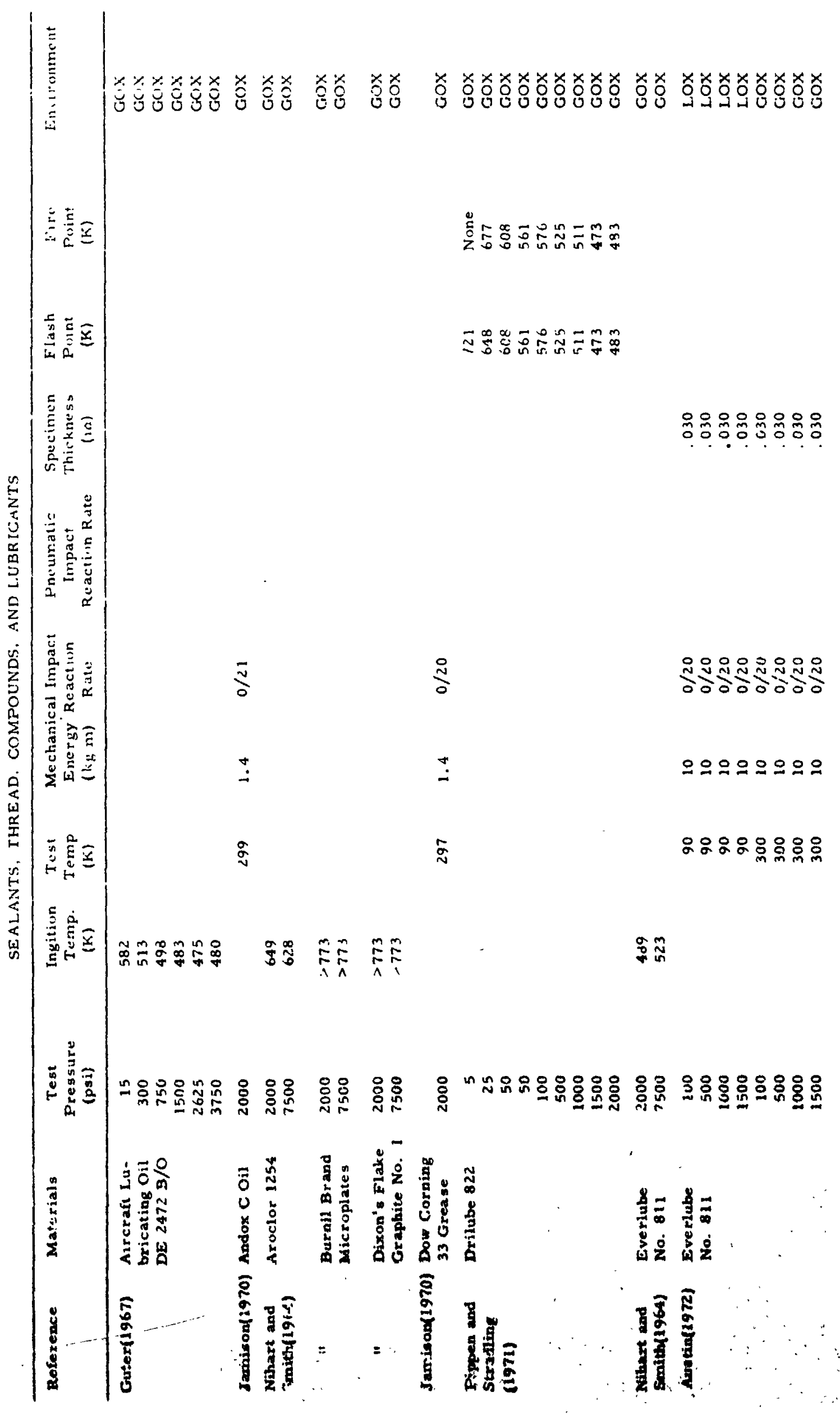




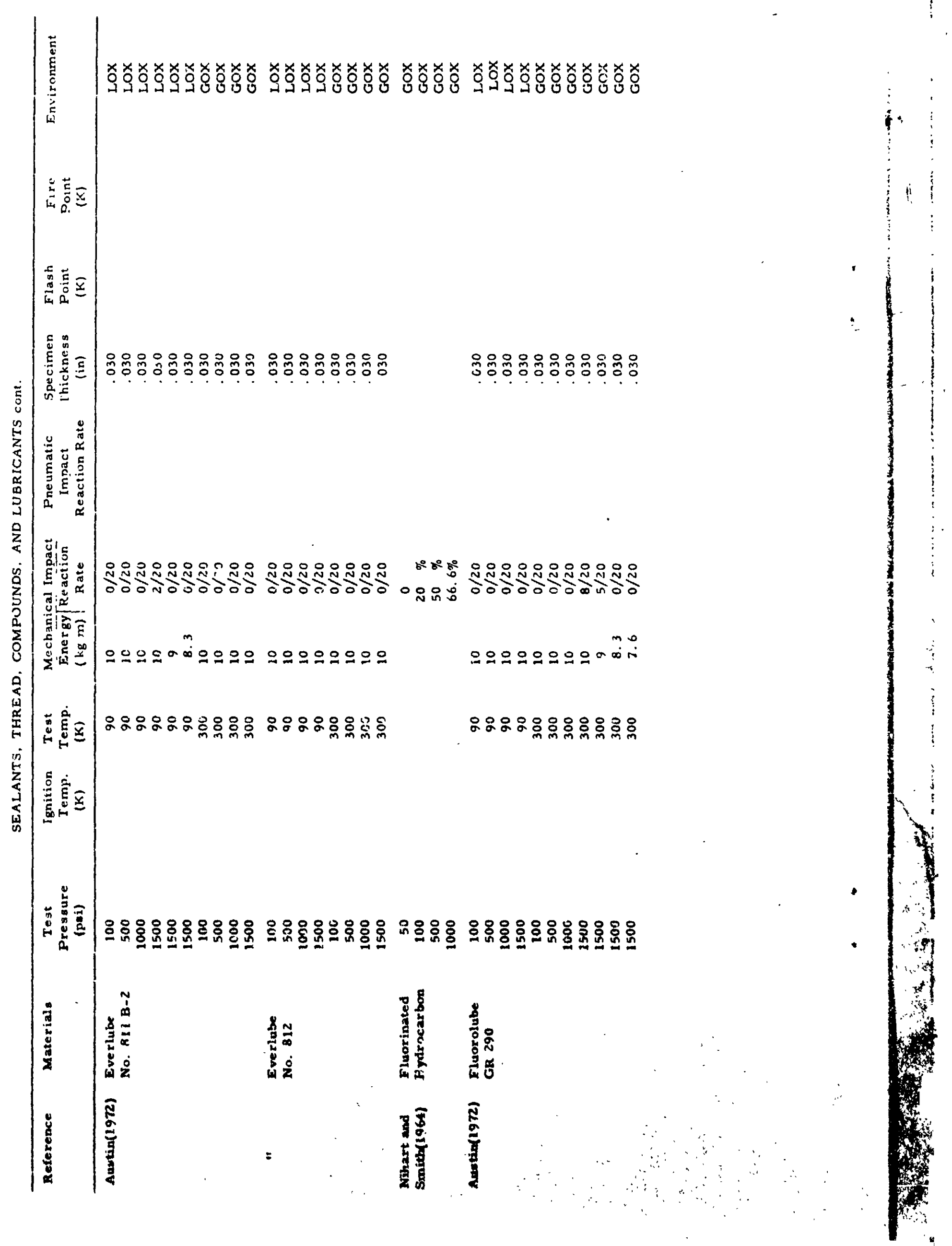




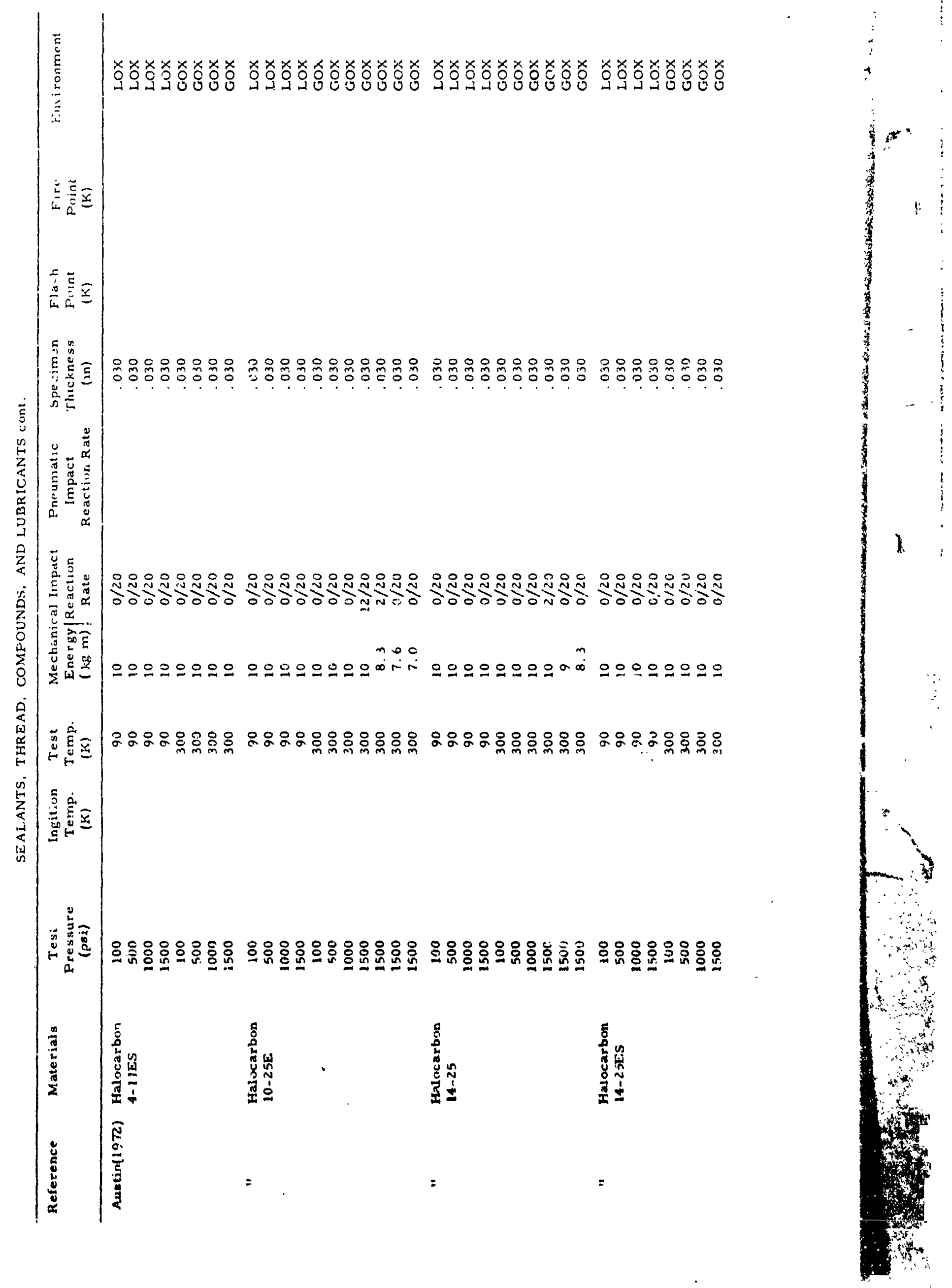




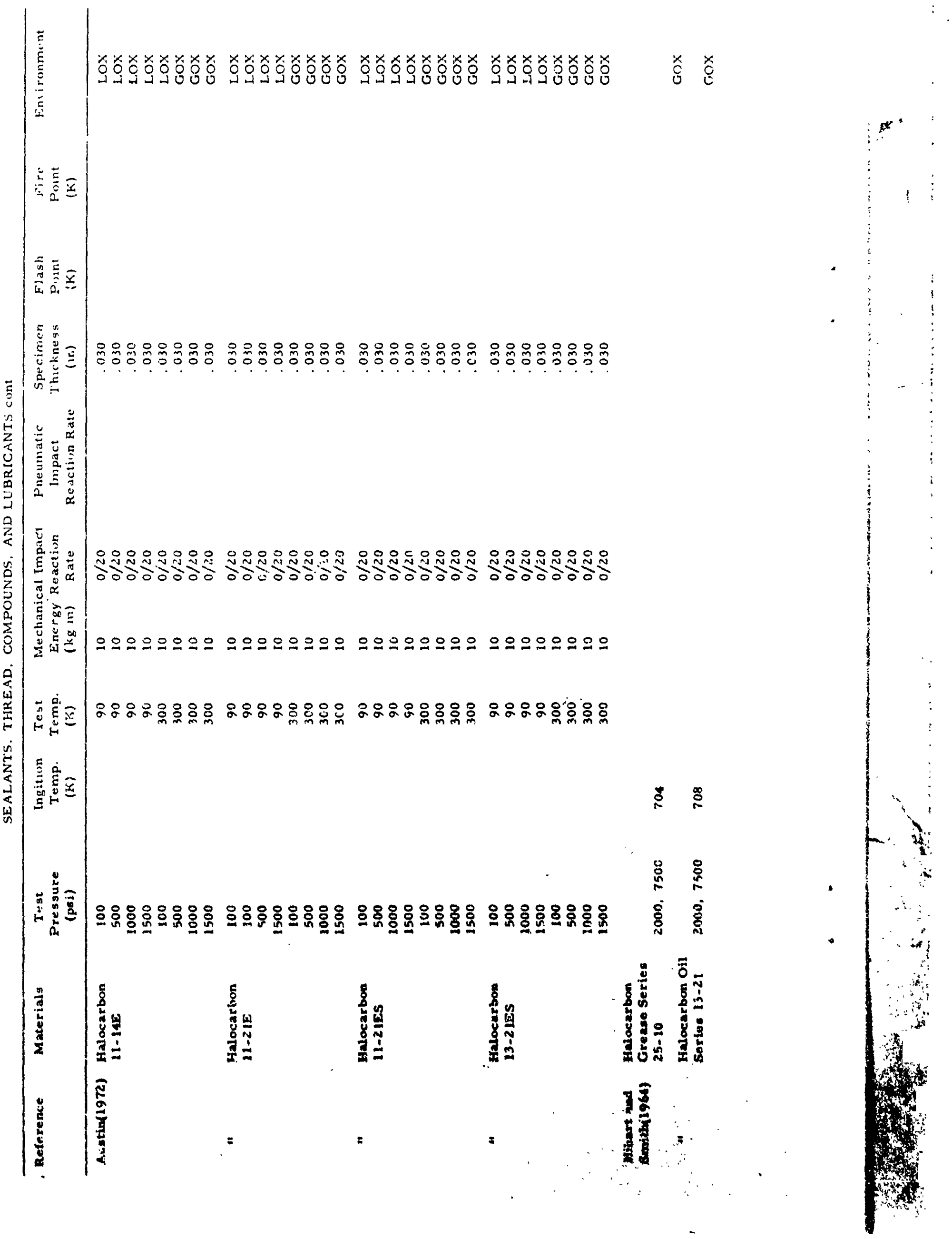




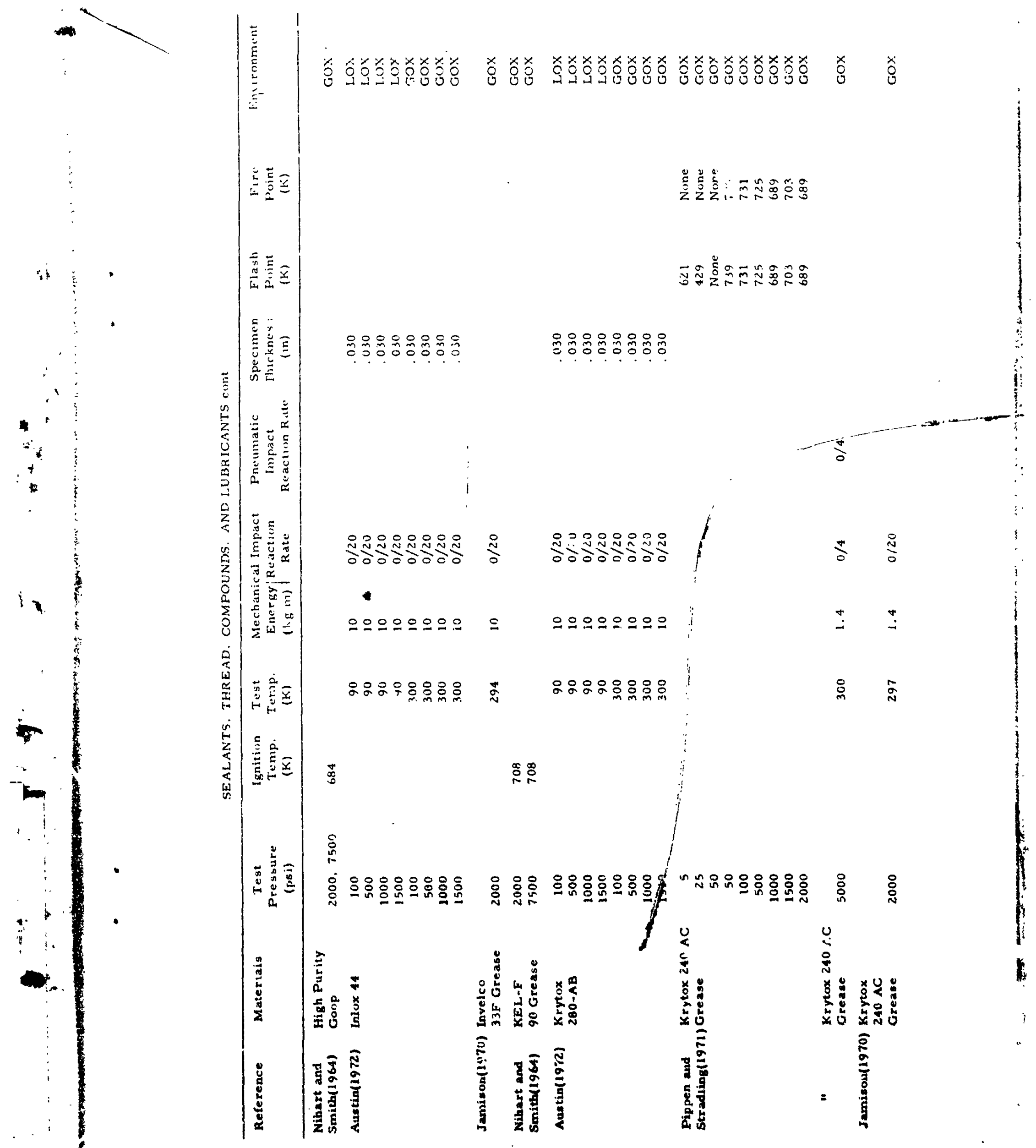




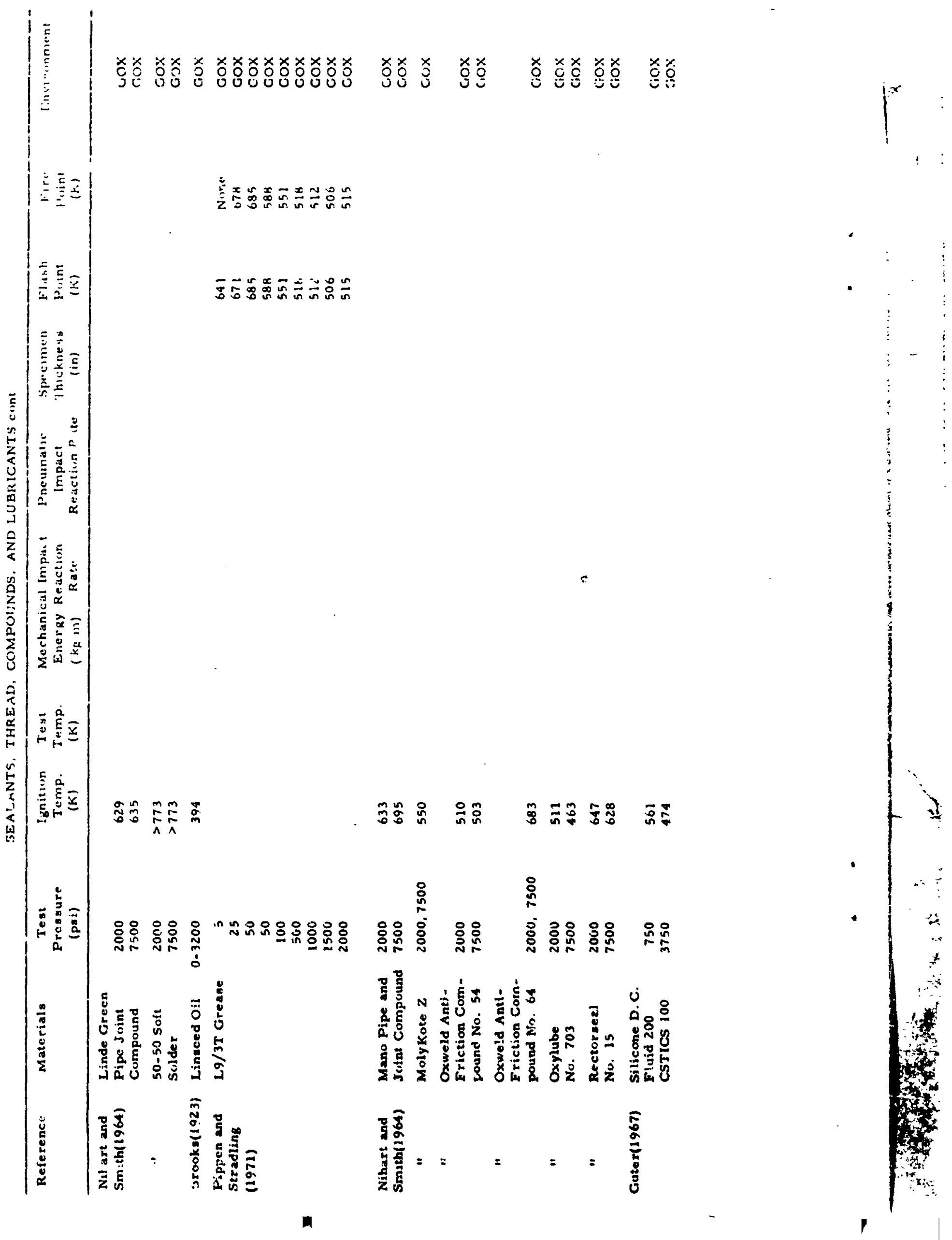




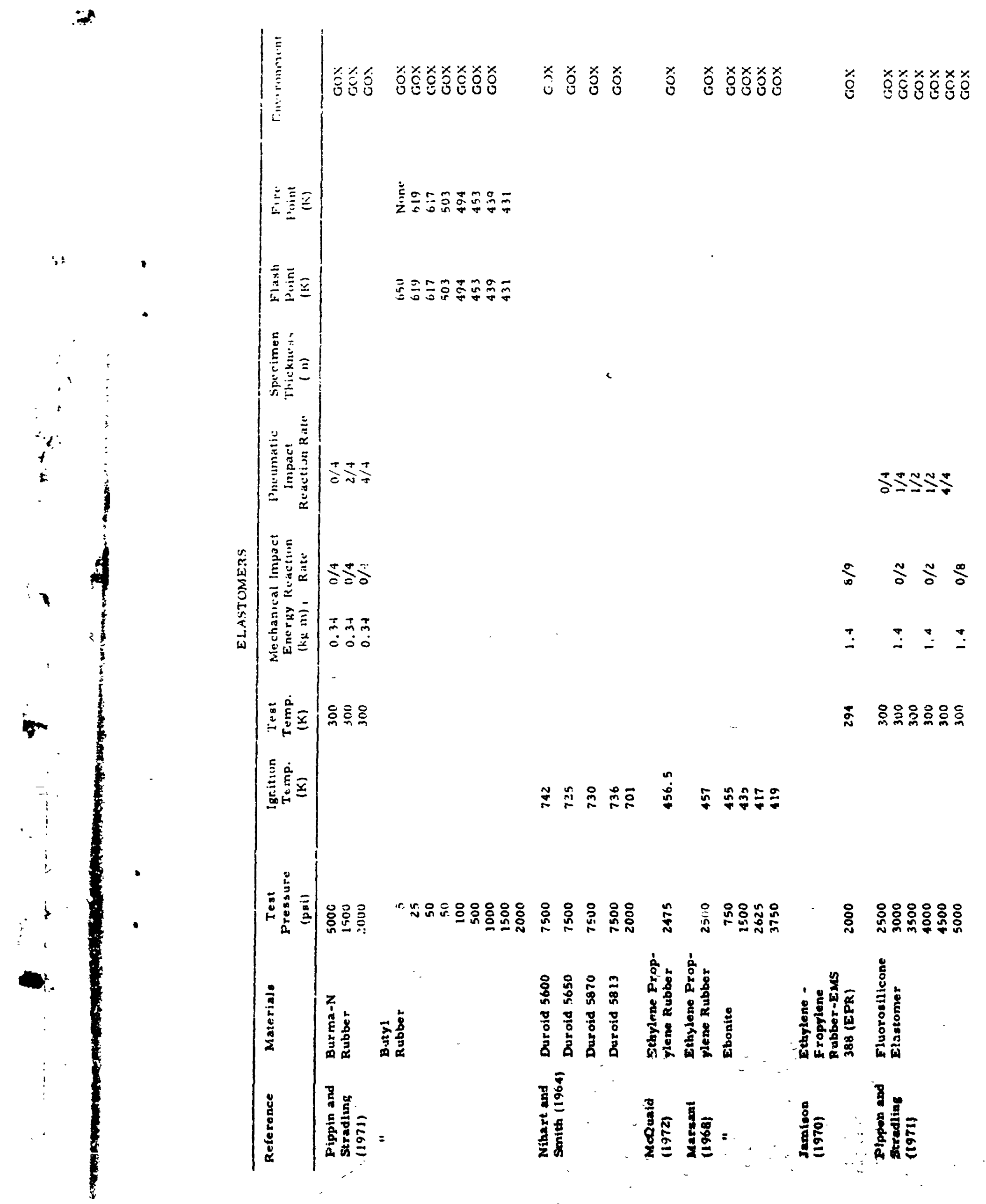




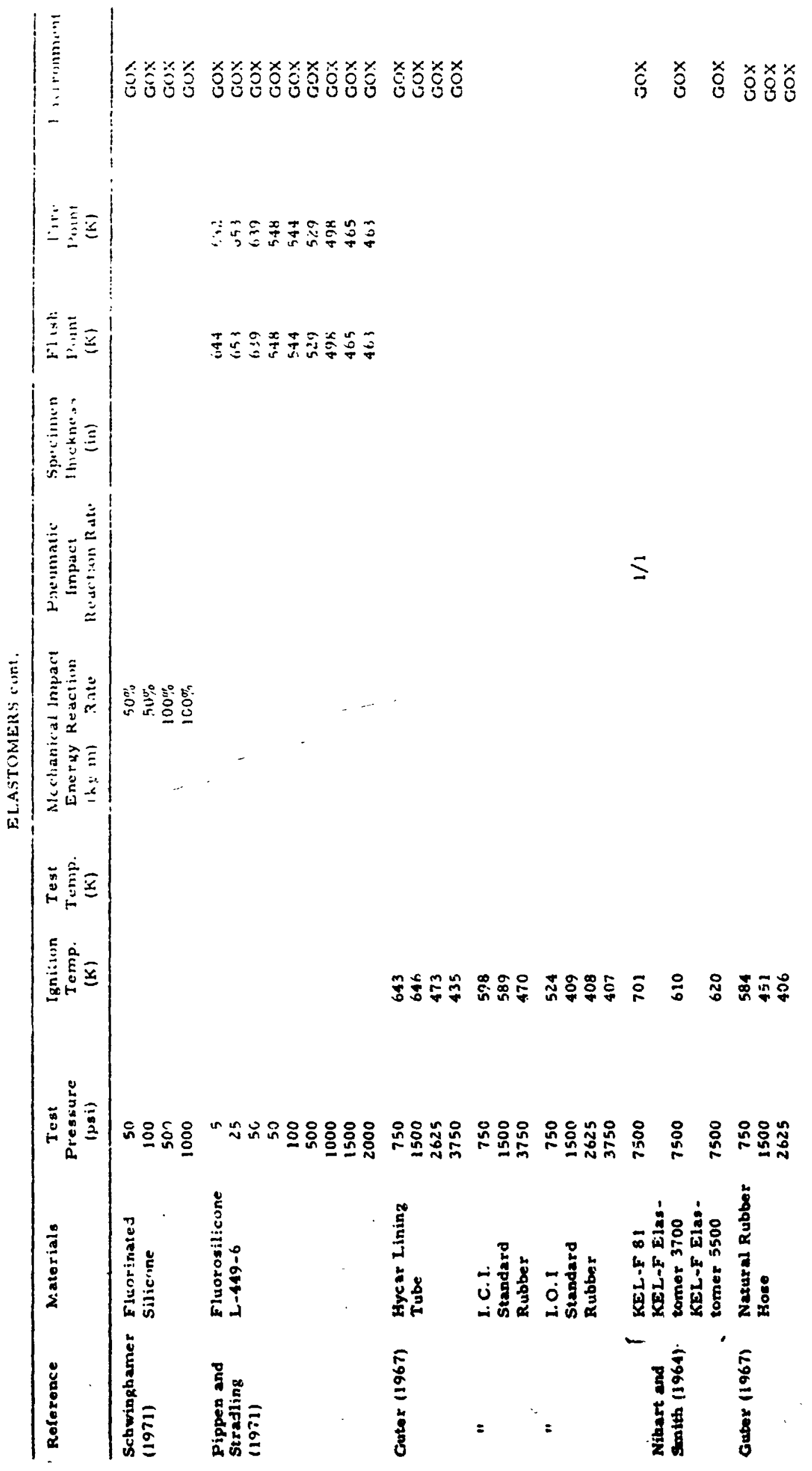




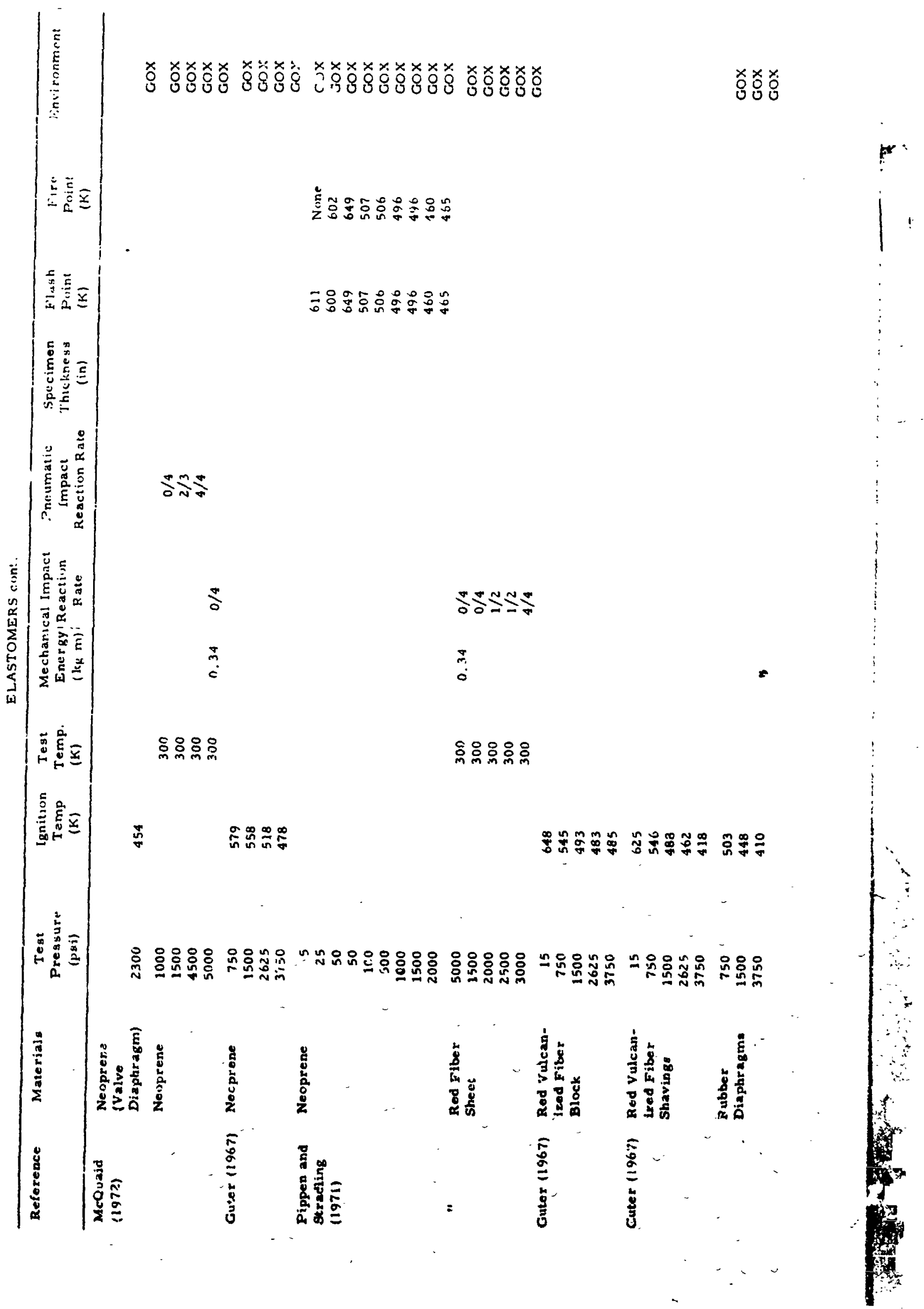




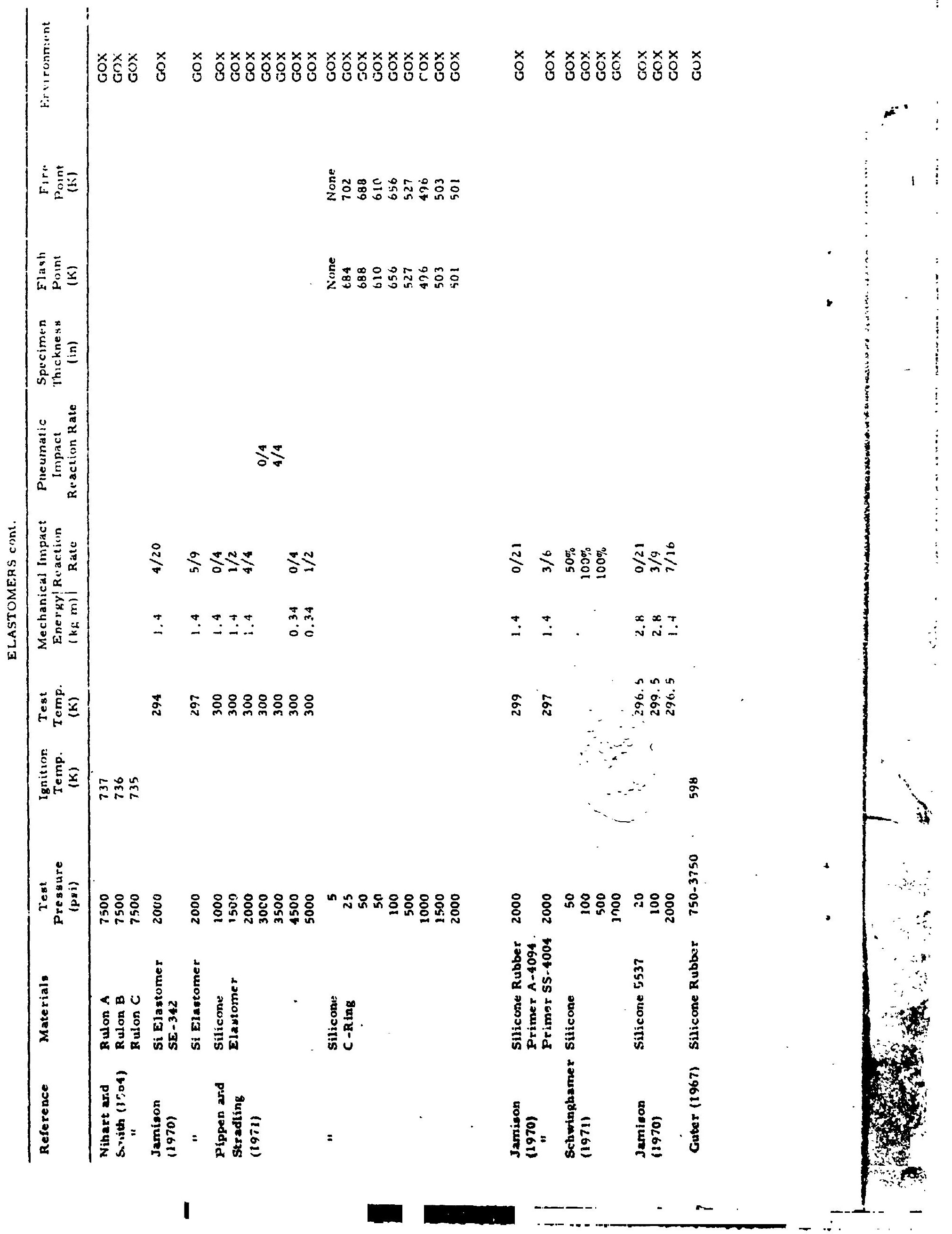




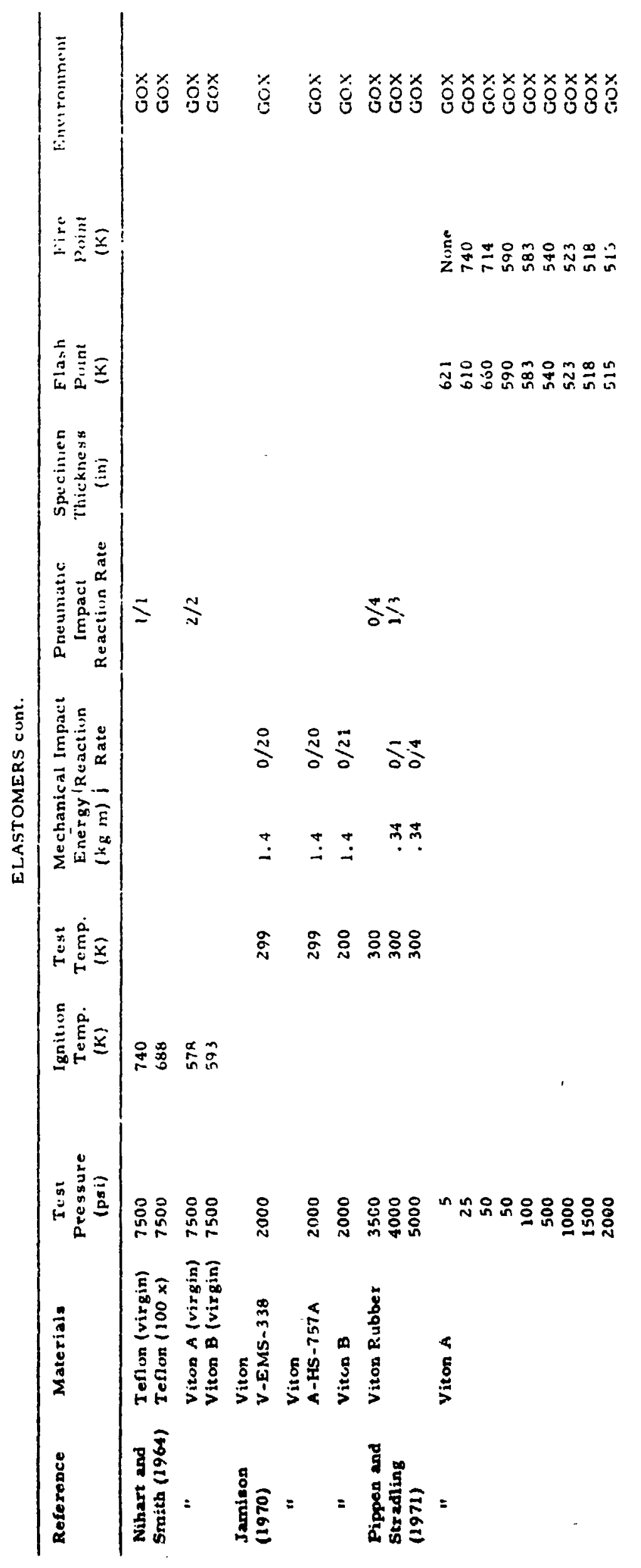




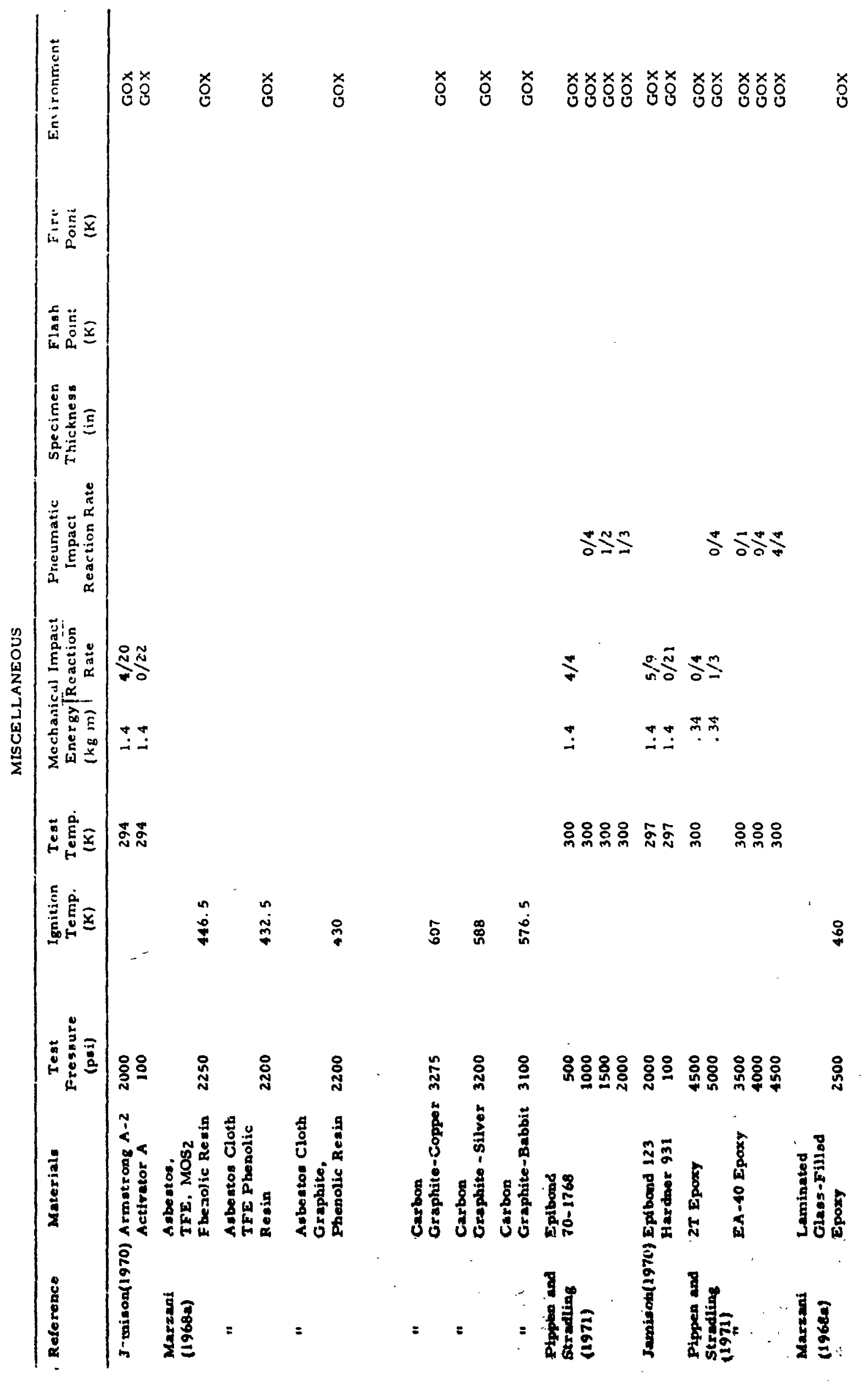




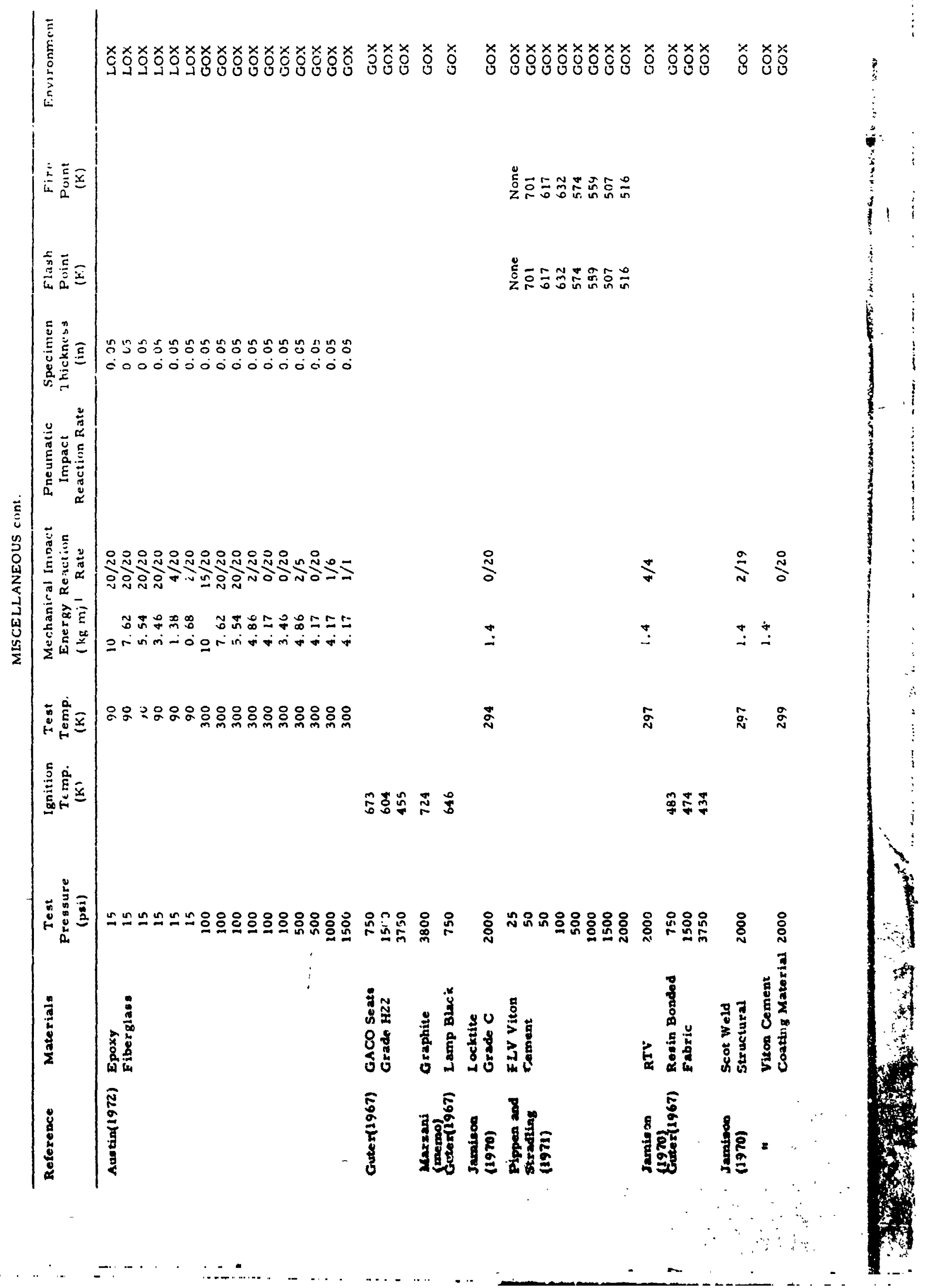


APPENDIX II - NONMETALLIC MATERIALS DESIGN GUIDELINES AND TEST DATA HANDBOOK, APPENDIX E MATERIALS TEST DATA FOR APPLICATIONS IN HIGH PRESSURE OXYGEN AND OTHER HAZARDOUS FLUIDS, NASA, MSC-02681 (1972) 


\section{APPENDIX E MATERIALS TEST DATA FOR APPLICATIONS IN HIGH PRESSURE OXYGEN AND OTHER HAZARDOUS FLUIDS}

\section{E1.0 INTRODUCTION}

The test data presented in this appendix is from a computer generated report, NB/RT-71-45, dated February 1972. It is sorted by manufacturer's designation and presents thermal reaction data hi: materials tested in oxygen or other hazardous fluids. These tests were initiated as a result of the Apollo 13 investigation ano were incorporated as Apollo Progr im Office requirements by addendum 2 of MSC-PA-D-67-13, Apollo Spacecraft Nonmetallic Materials Requirements.

The tests included in this report are:

- Pneumatic impact in gaseous oxygen

- Mechanical impact in gaseous oxygen

- The:mogravimetric analysis

- Flash and fire point

- Reaction propagation in fluids other than oxygen

- Auto ignition

- Fluid impact in liquid oxygen and other fluids 


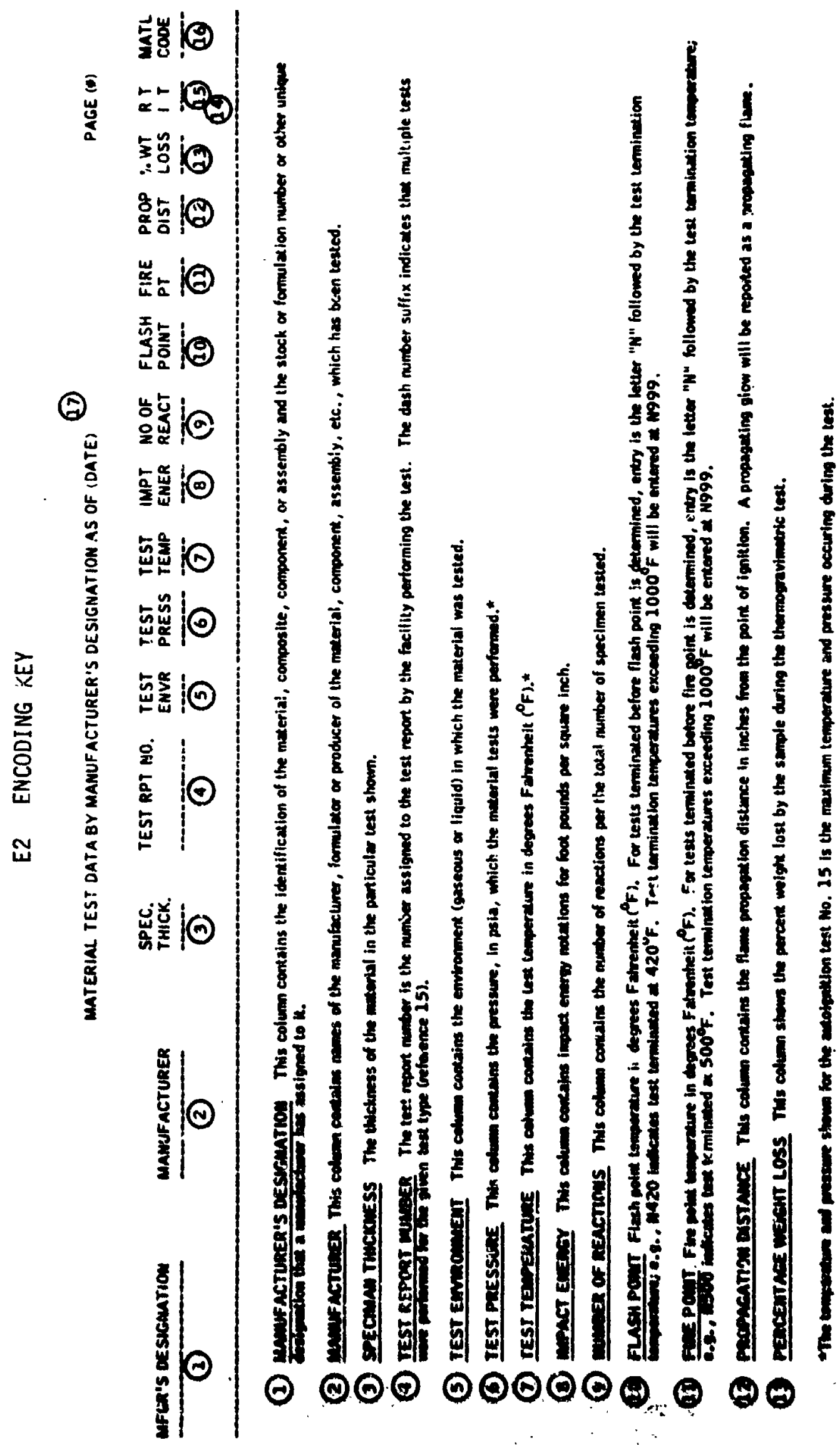




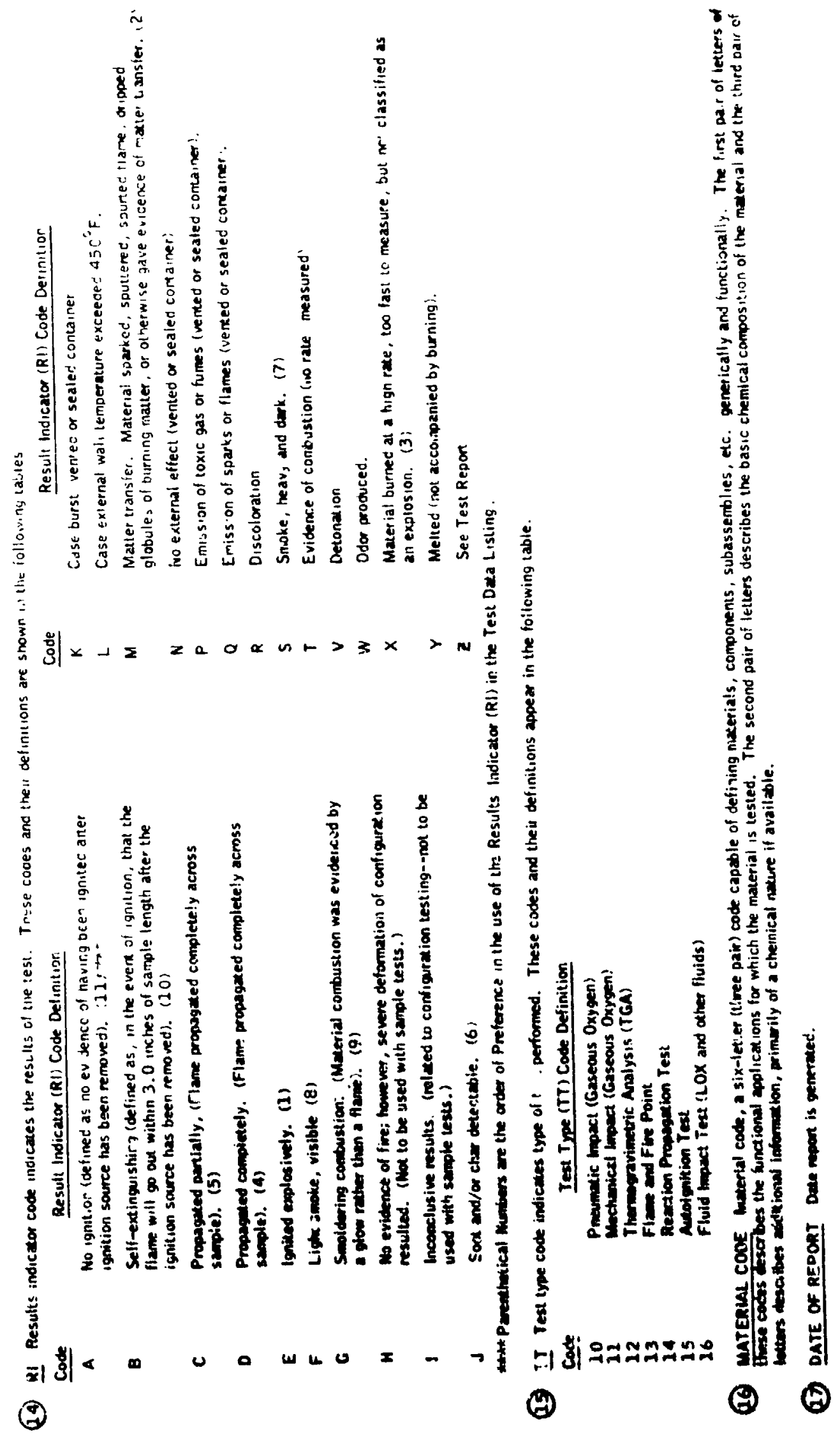


The following information is a l:-ting of material usage and generic identification found in the NB/RT-71-45 Test Data Listing. This code contains six letters (three groups of two each). The first group refers to the functional application of the material, while the second gives the chemtcal composition. The third group will give additional information, usually chemical information if available. Reference is made to all of this information as number sixteen of the key on pages E2-1 and E2-2. 


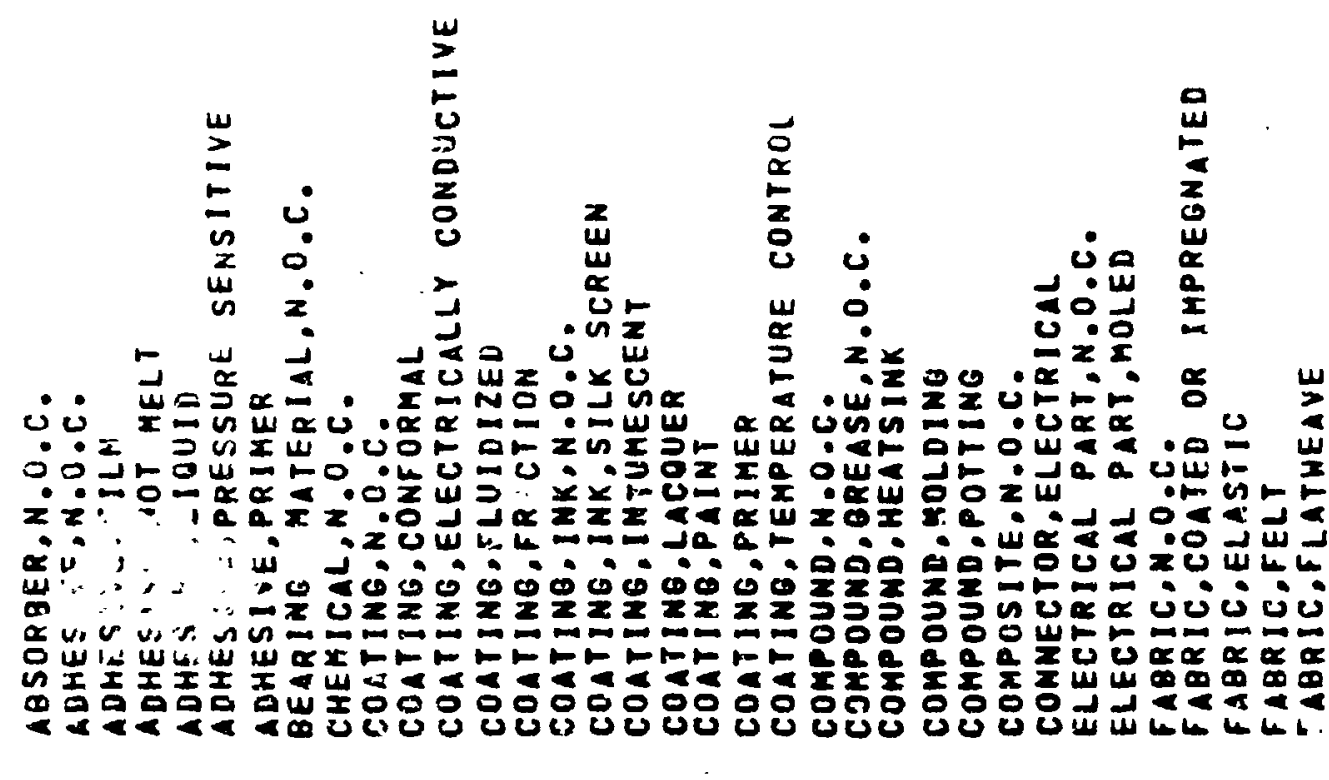




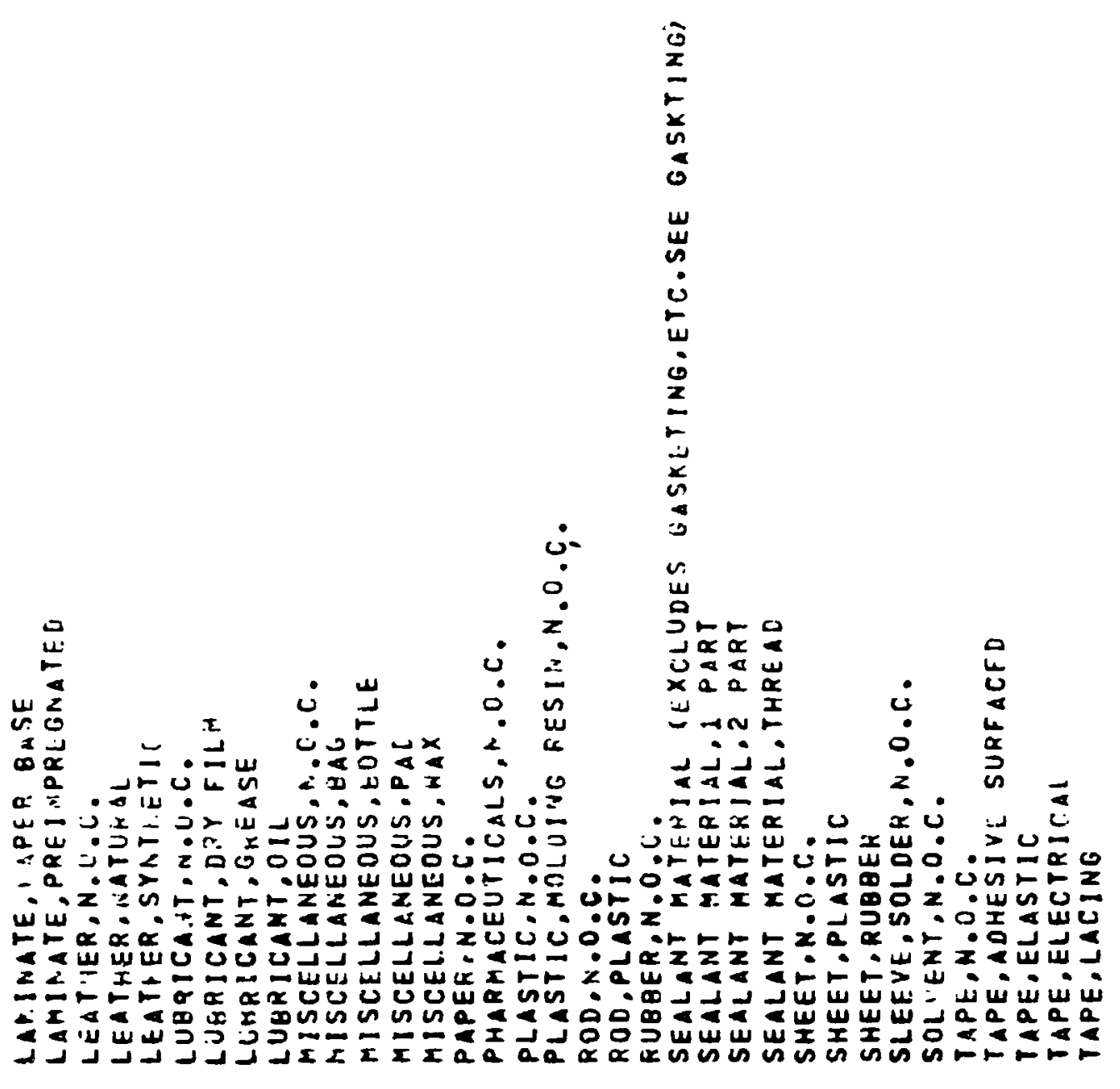


1

w $\vec{\infty}$

$\because$

is
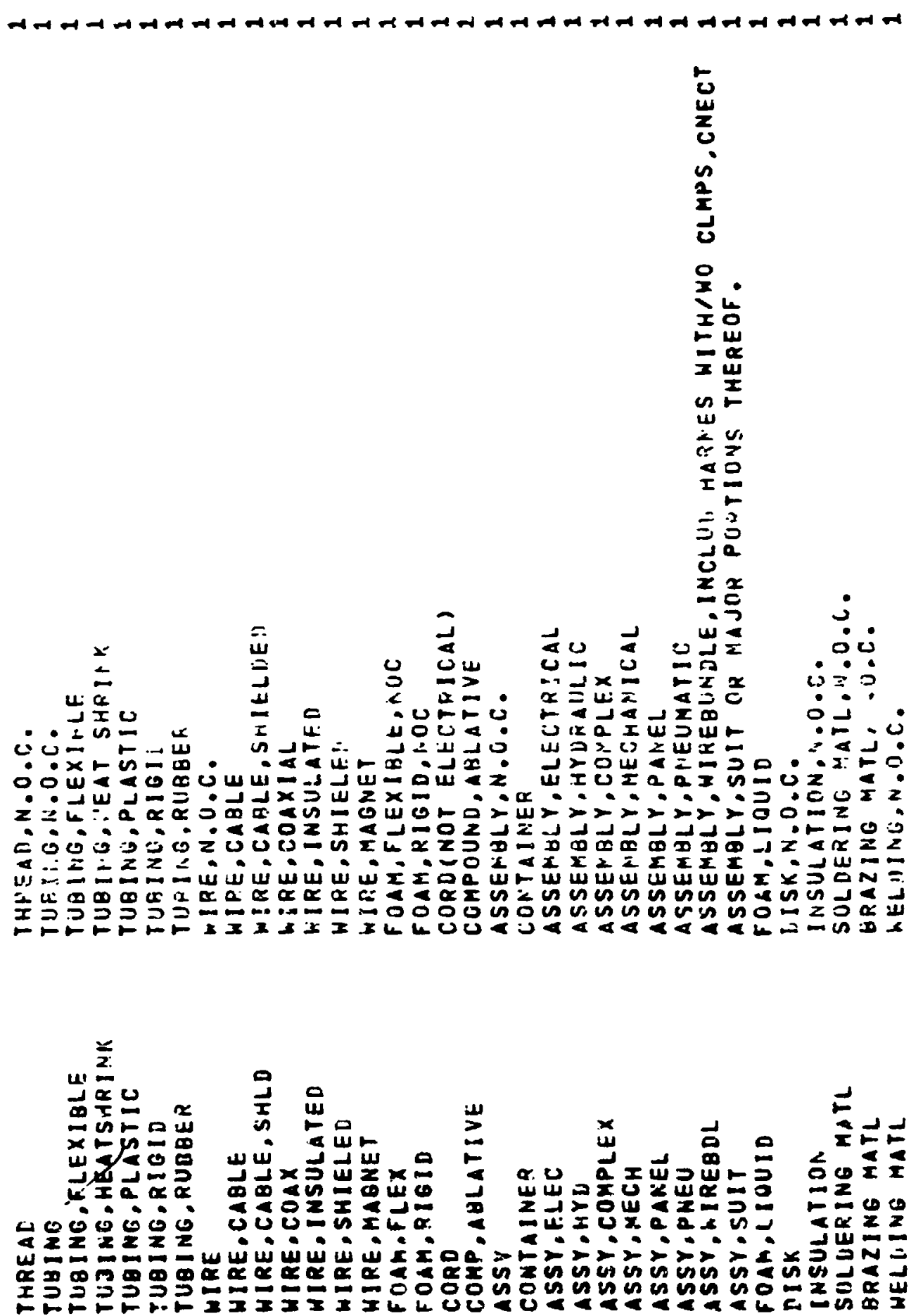

㟔

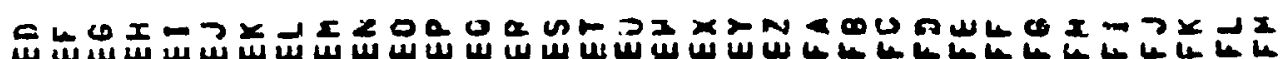


in

H-

ב

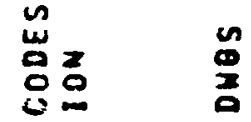

至至

is

2

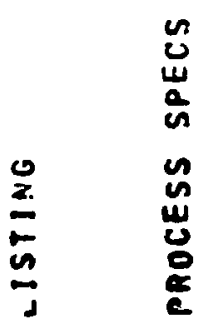

岁

E2-8 
سم พกับก พ

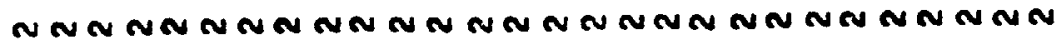

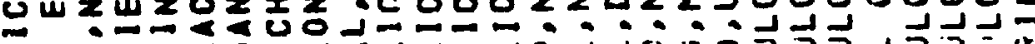

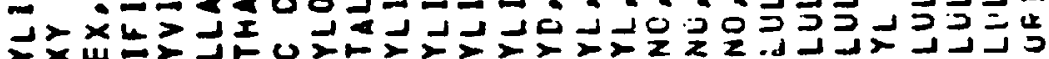

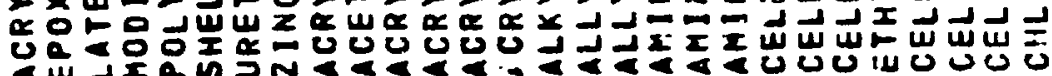


$1 \omega$ w 0 a ن حس

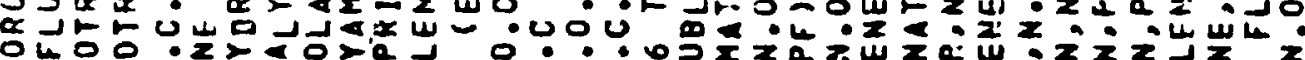

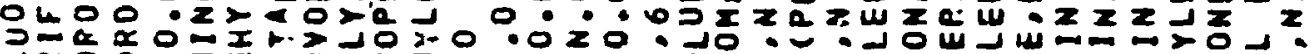

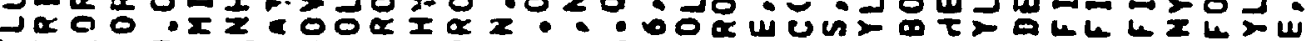

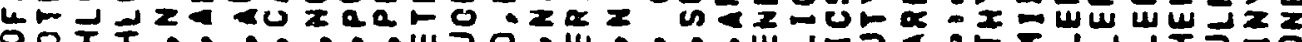

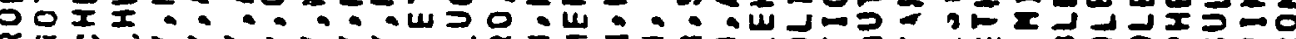

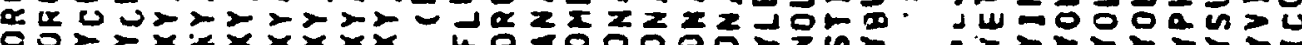

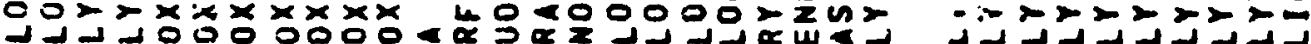

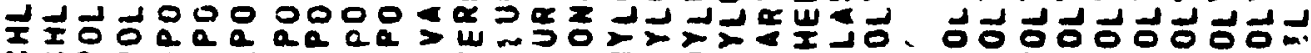
vóa w山 $\dot{x}$

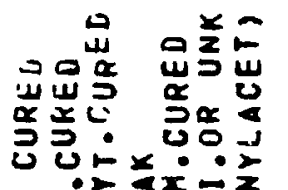

일

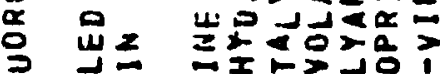

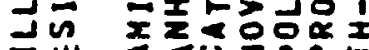

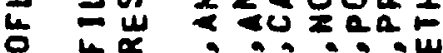

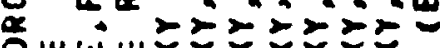

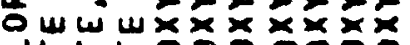

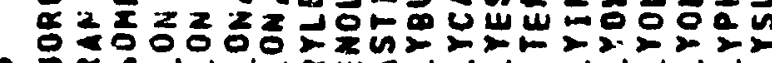

可

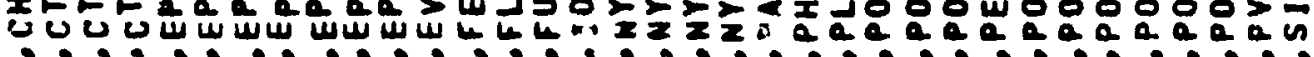

岑

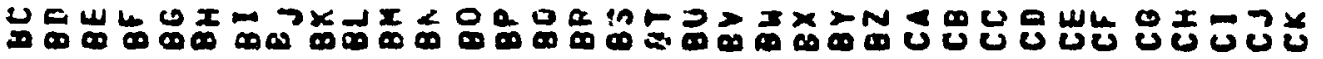




\section{iw

点

용

$\because \approx$

$\vec{a} \bar{z}$

$\bar{\pi}$

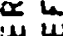

崖

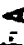

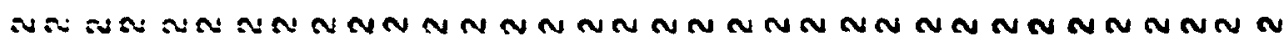

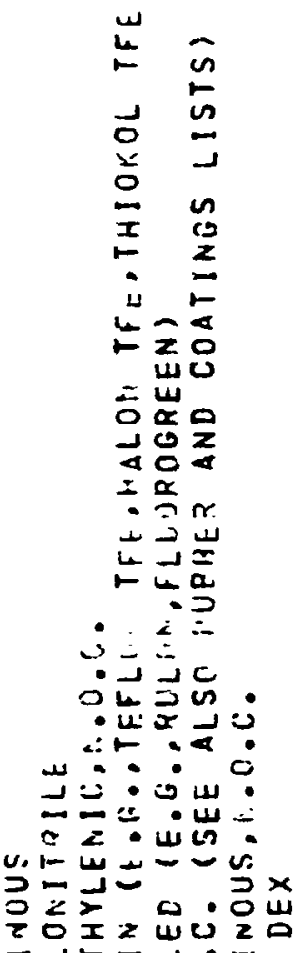

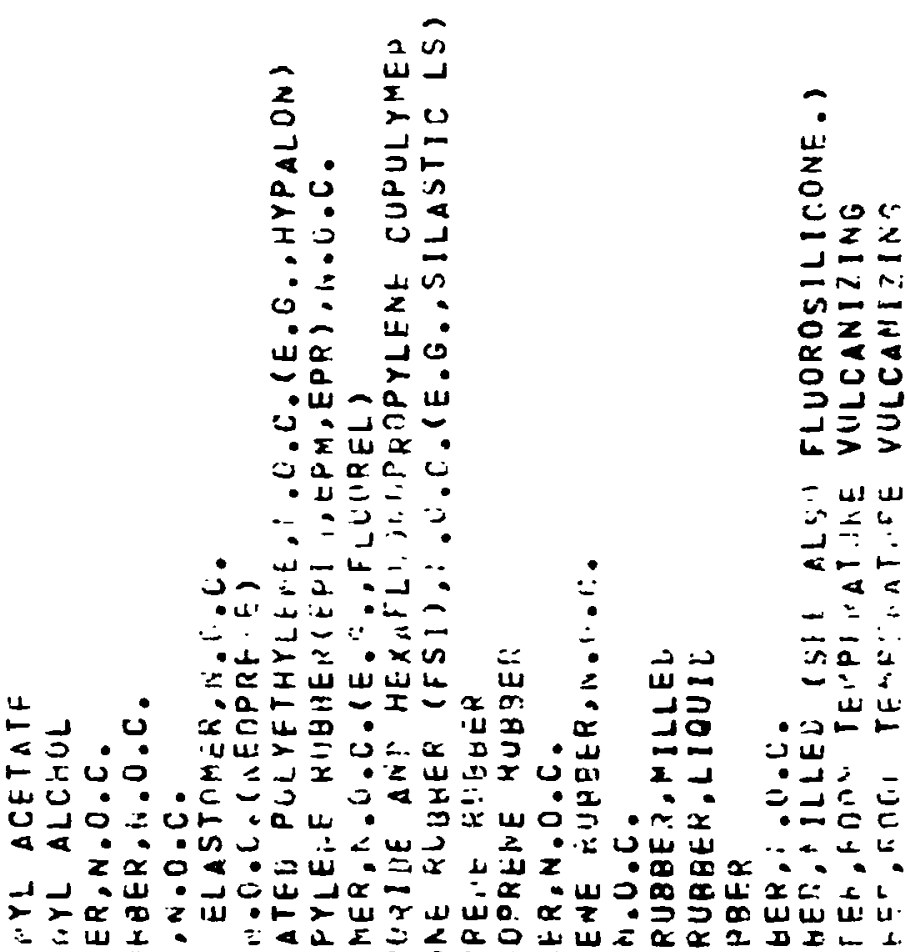

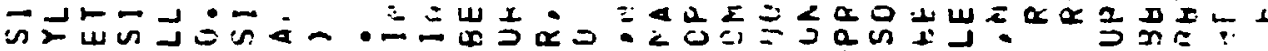

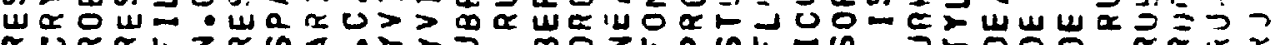

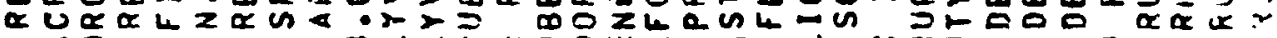

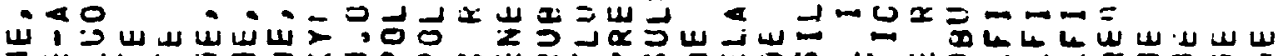

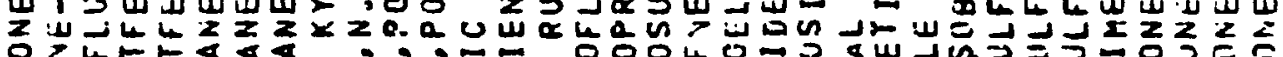

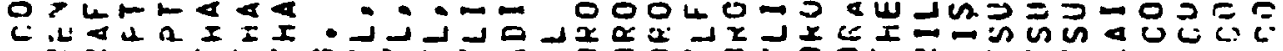

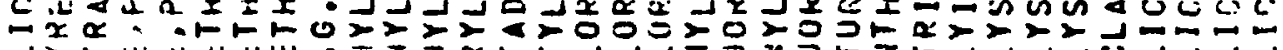

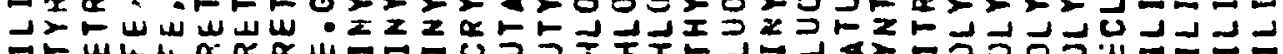

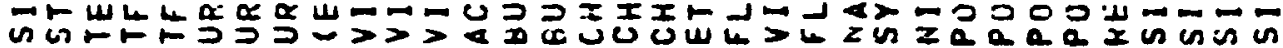

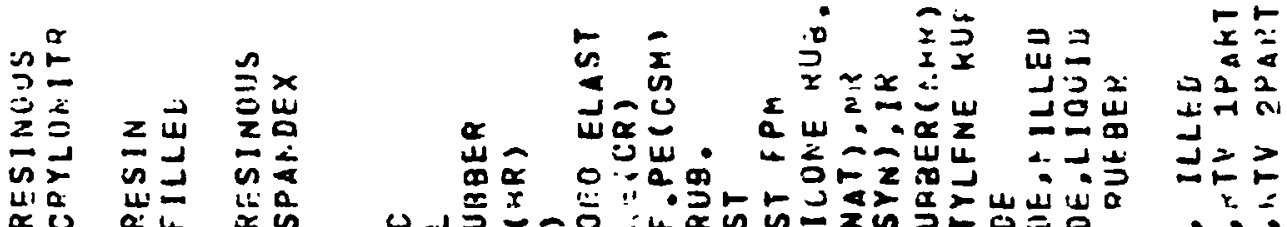

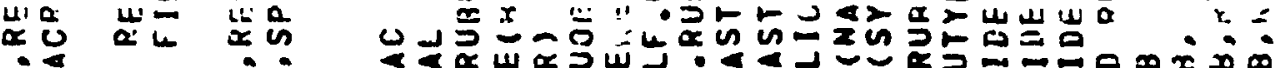

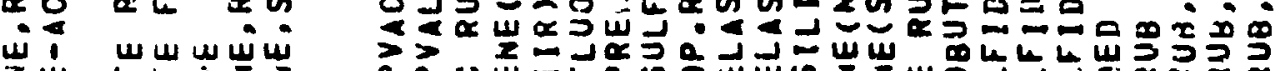

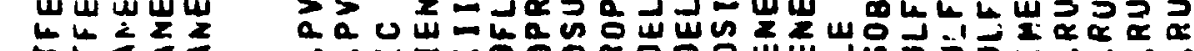

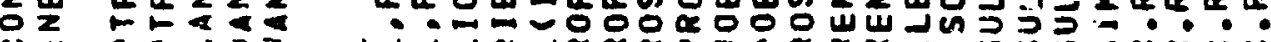
U a a I Ox

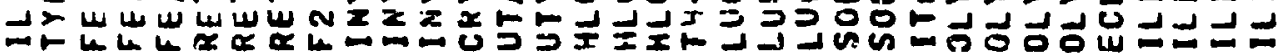

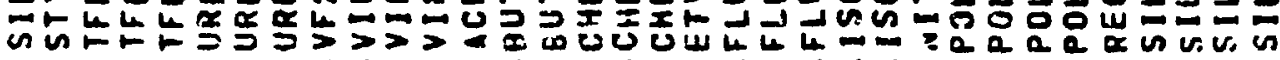

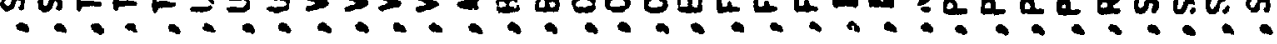




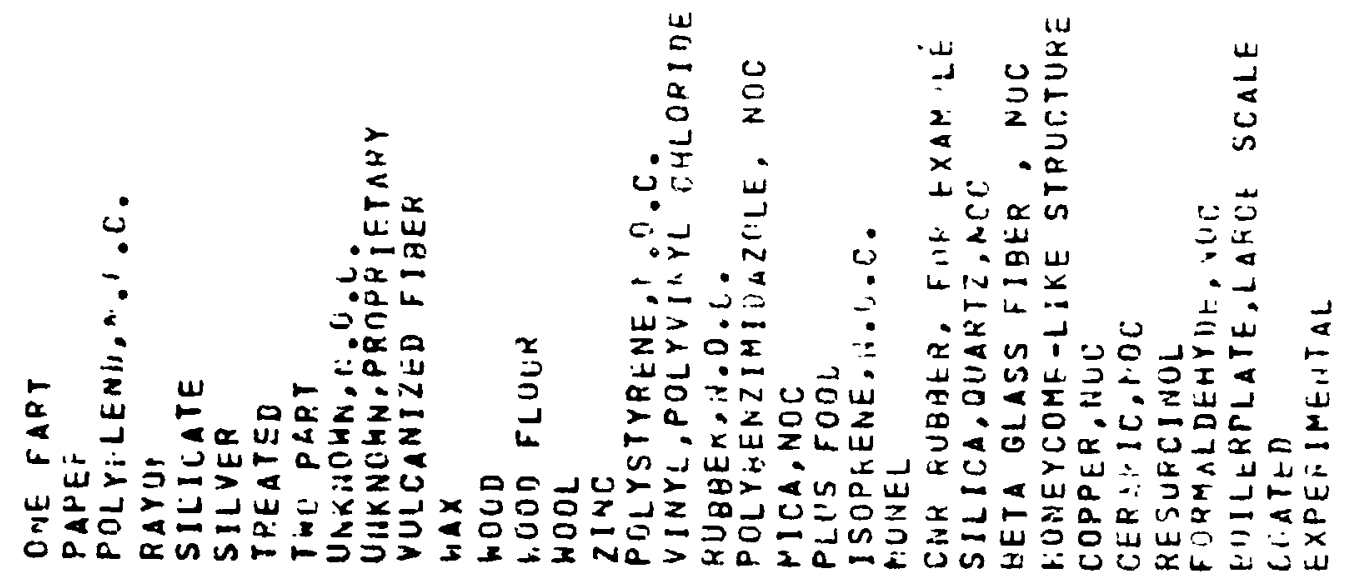

$\frac{0}{5}$
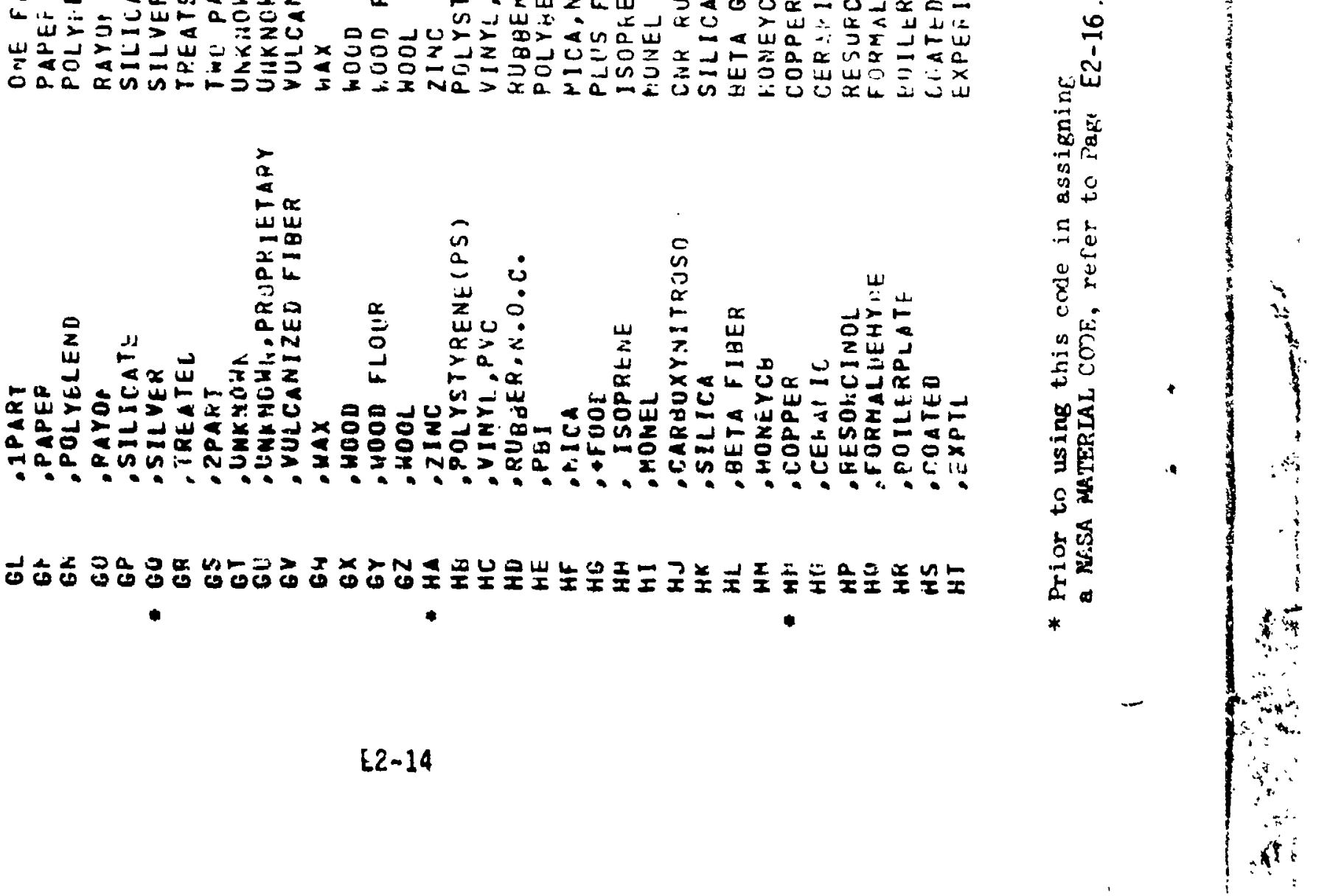


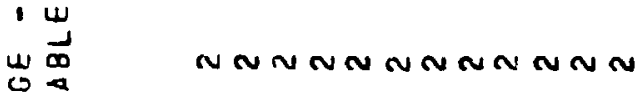

0

-

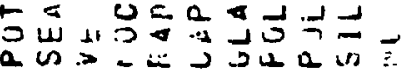

$$
\text { 的 }
$$

$\stackrel{1}{5}$

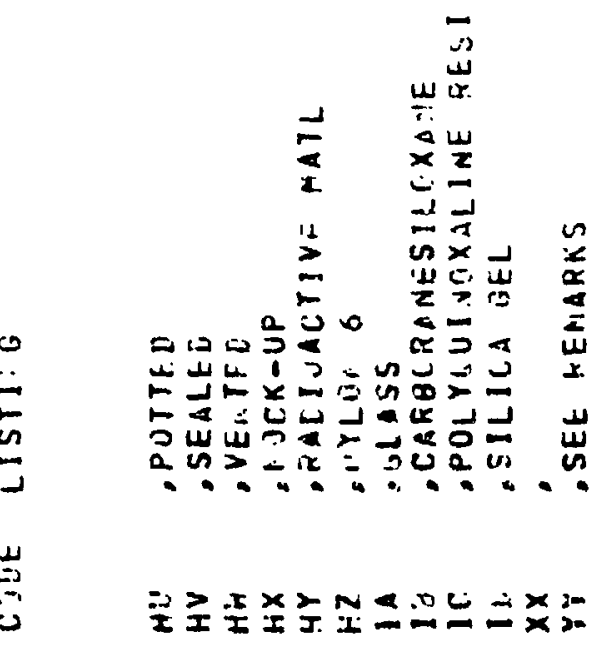




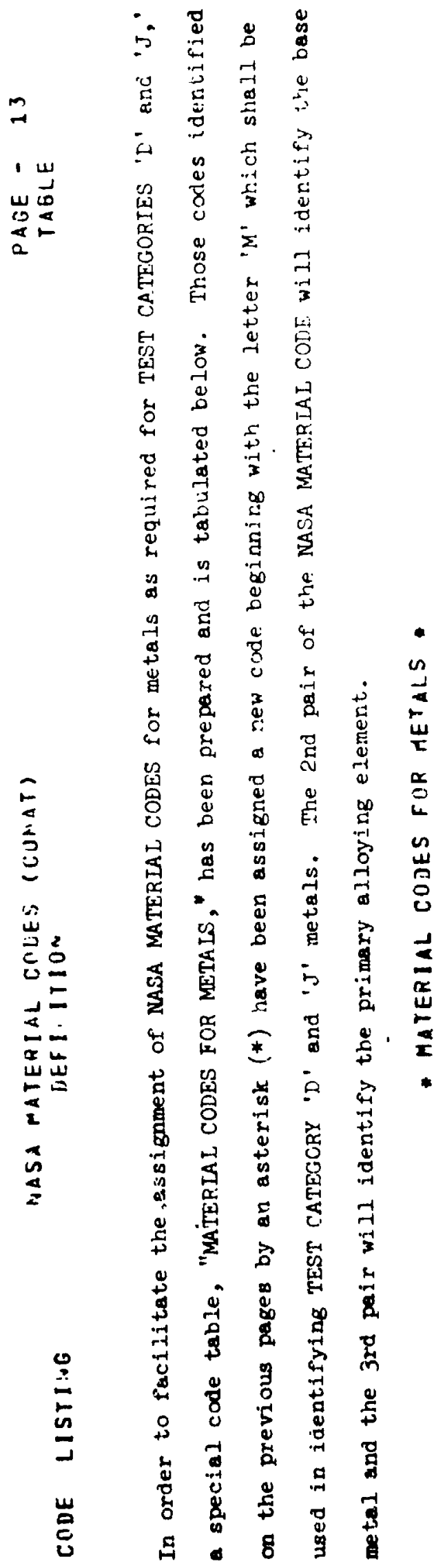

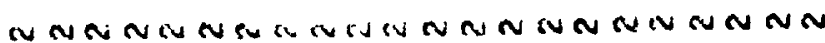
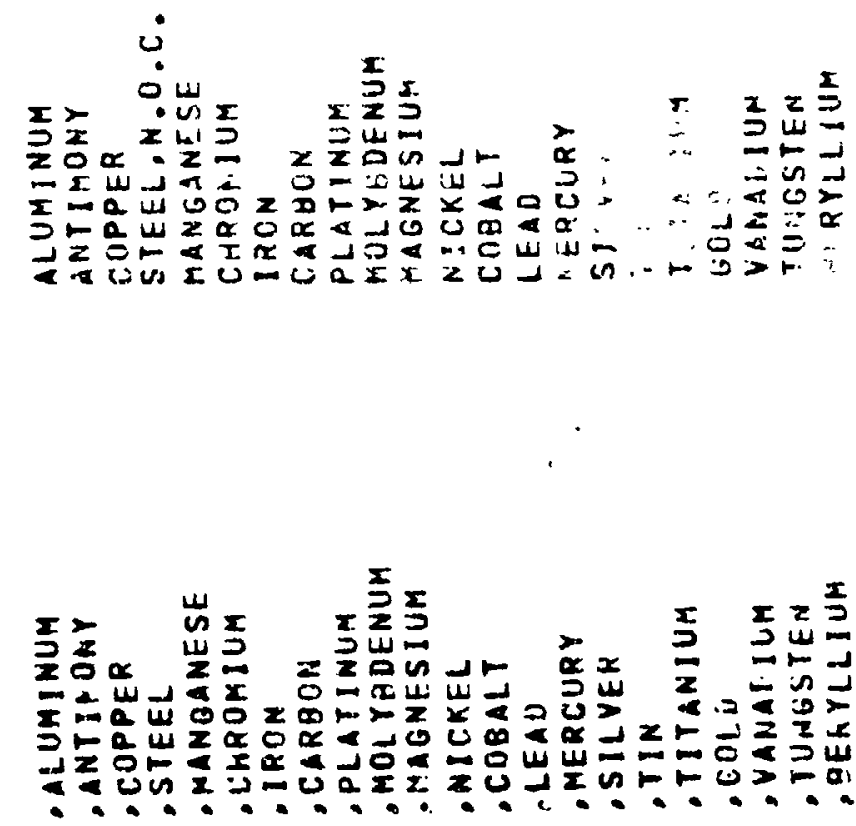

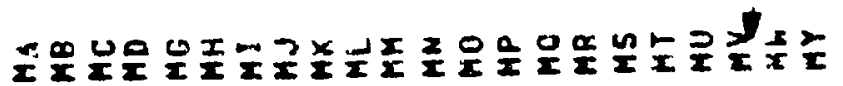


لע

v

4

$\underset{2}{0}$

3

章

包忌

吉云

$\therefore$

$\frac{4}{2}$

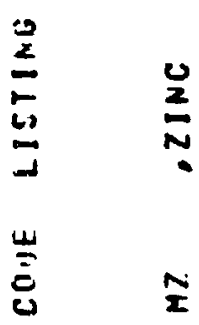




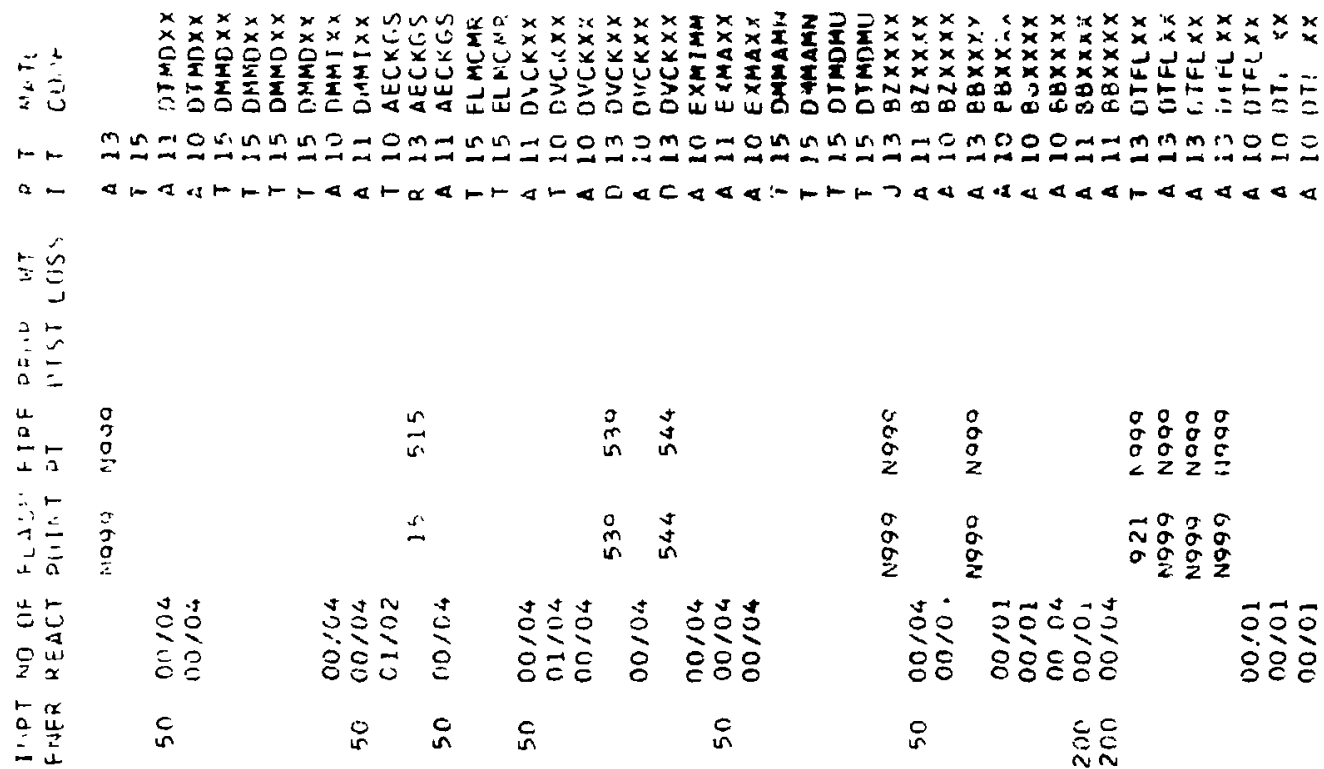

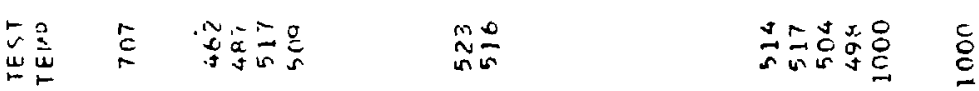

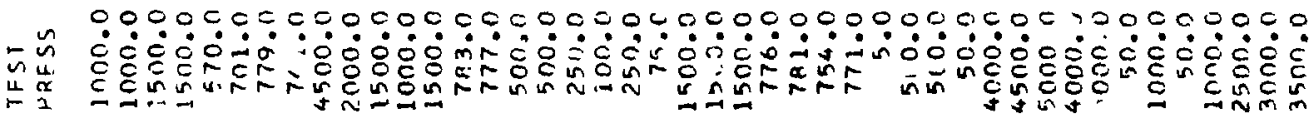

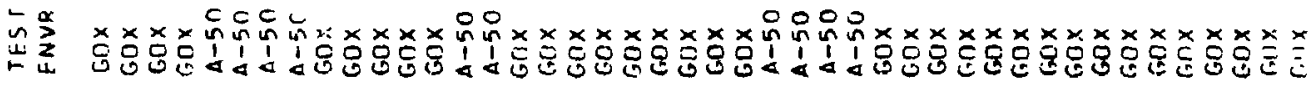

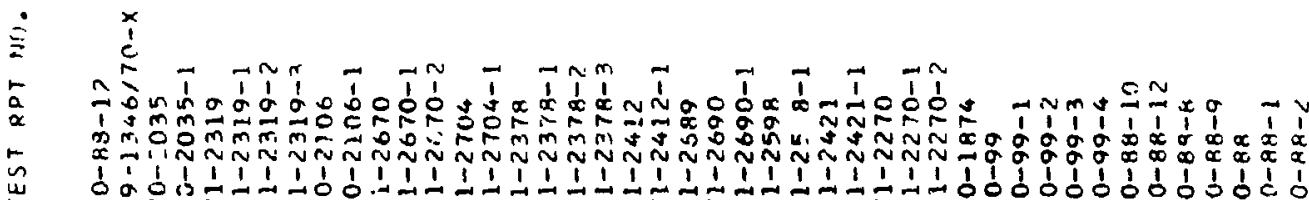

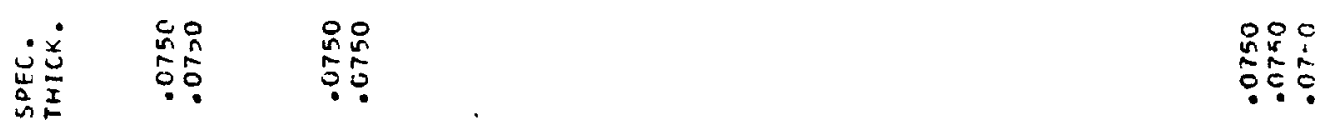

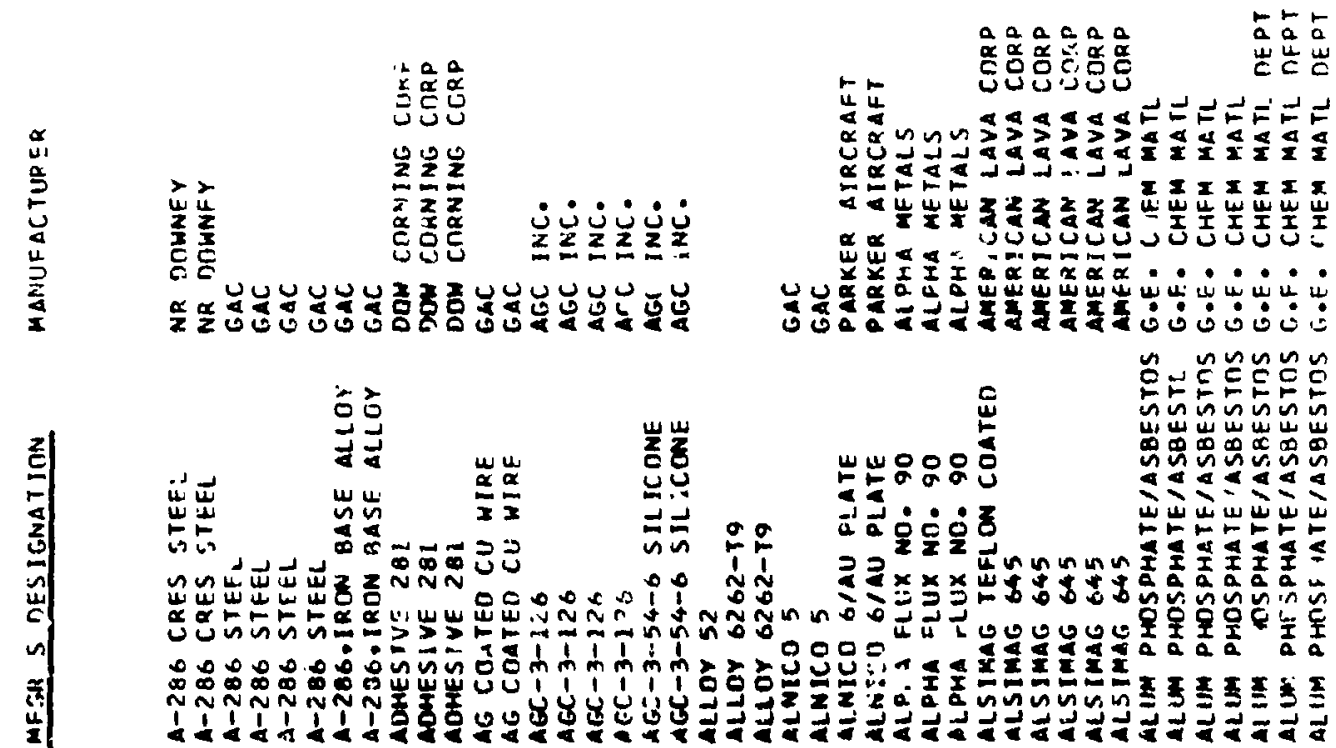




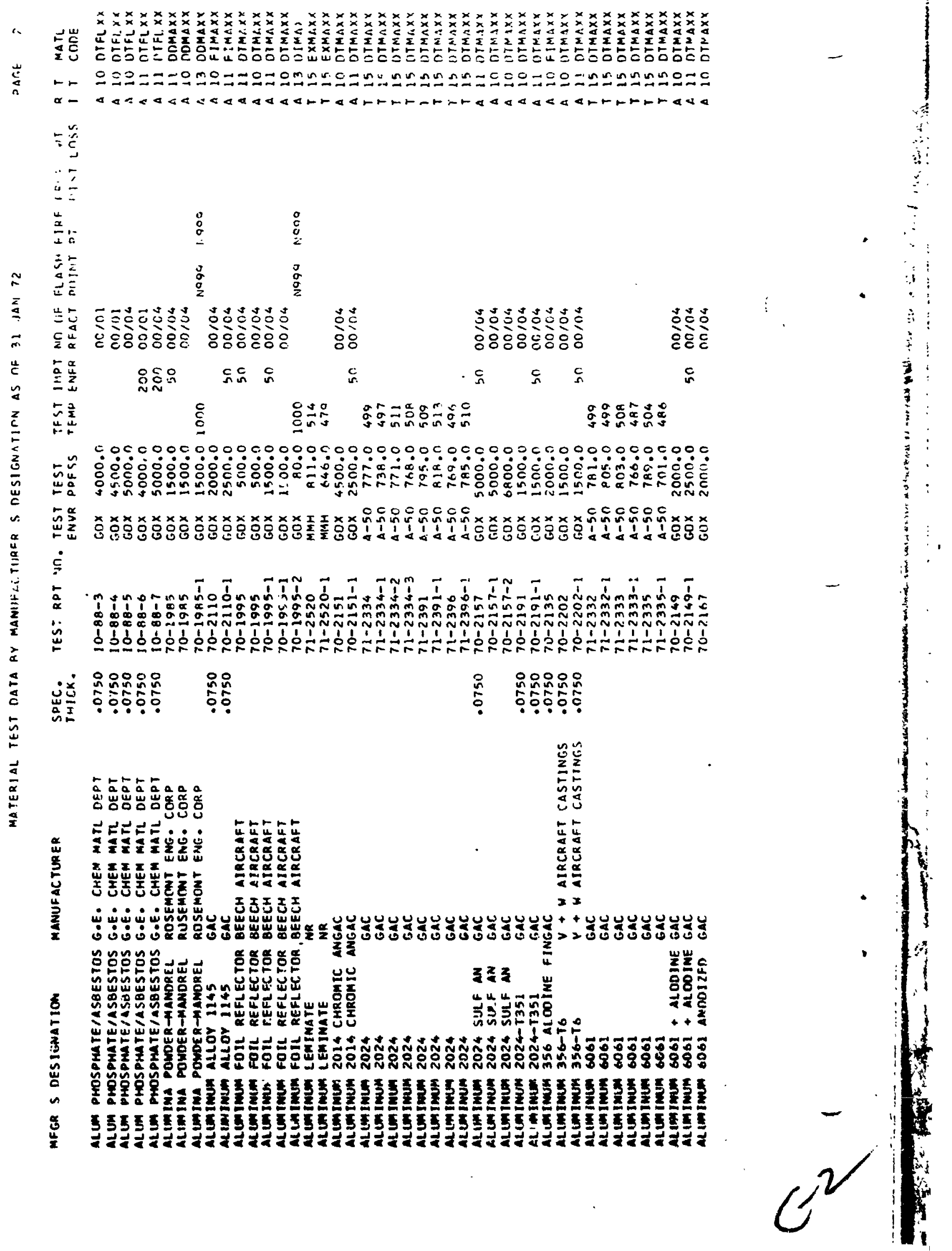




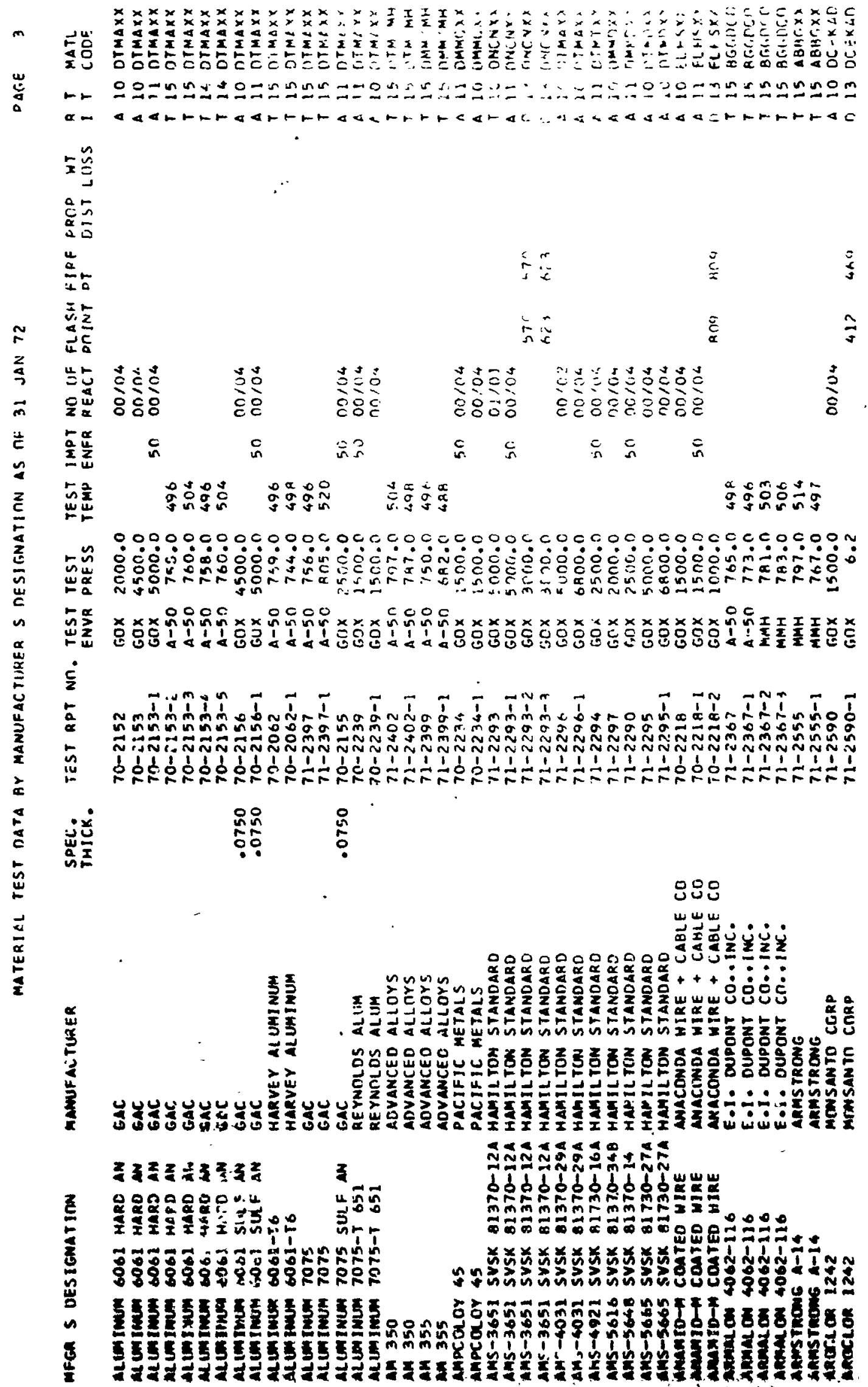




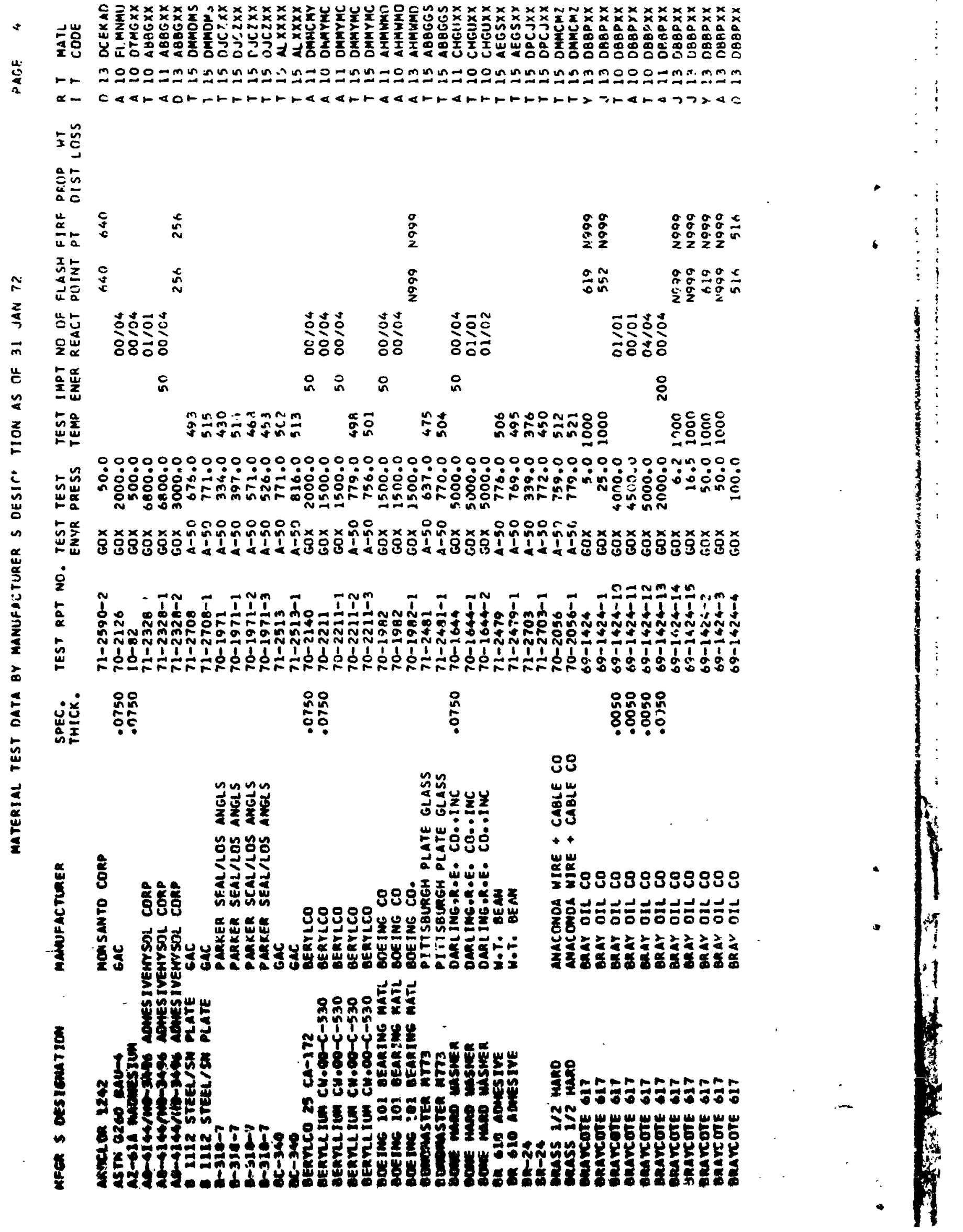




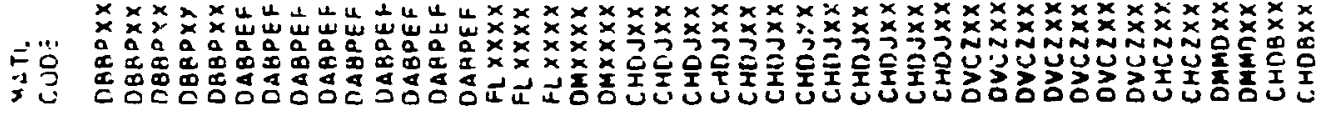

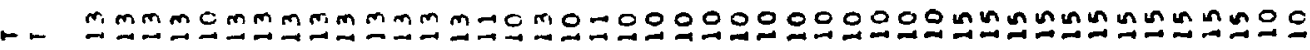

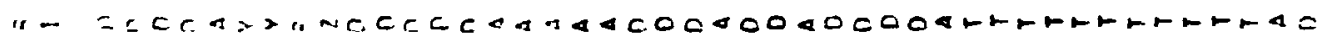

$-\div$

$\stackrel{2}{2}=$

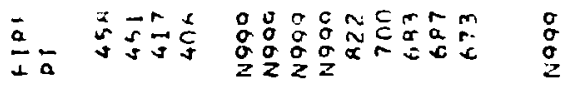

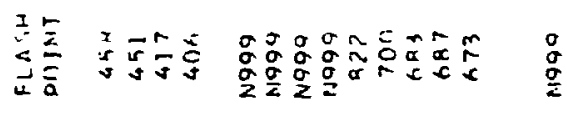

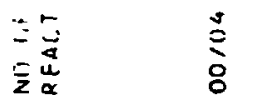

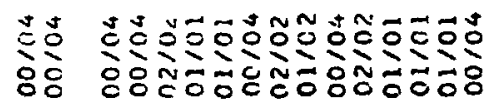

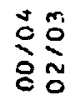

$\stackrel{0}{a} \sum_{i}^{-\alpha}$

或变 in

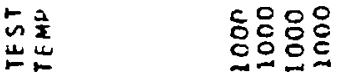

¿

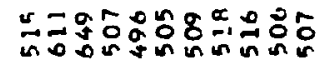

点芯

00000000000000000000000000000000000000000000

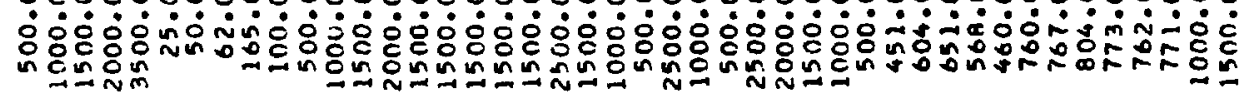

点售

势 $\dot{\dot{z}}$

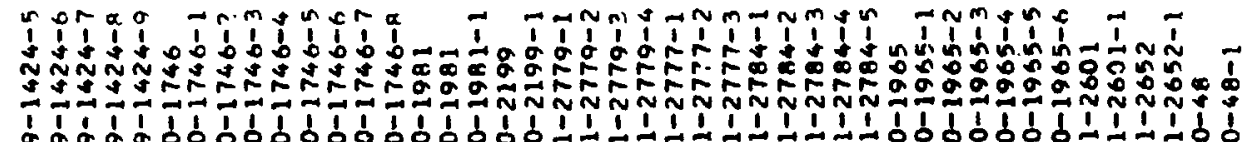

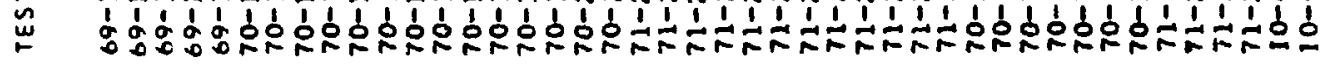

这总

$\stackrel{8}{:}$

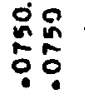

.

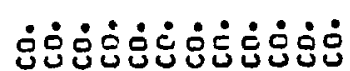

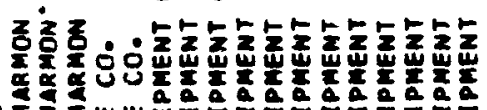

88088080488088

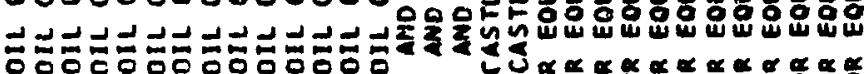

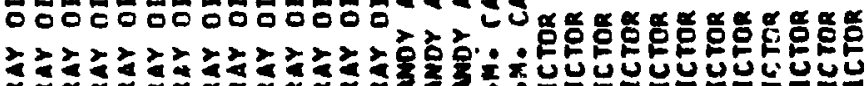

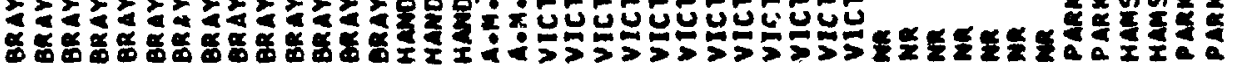




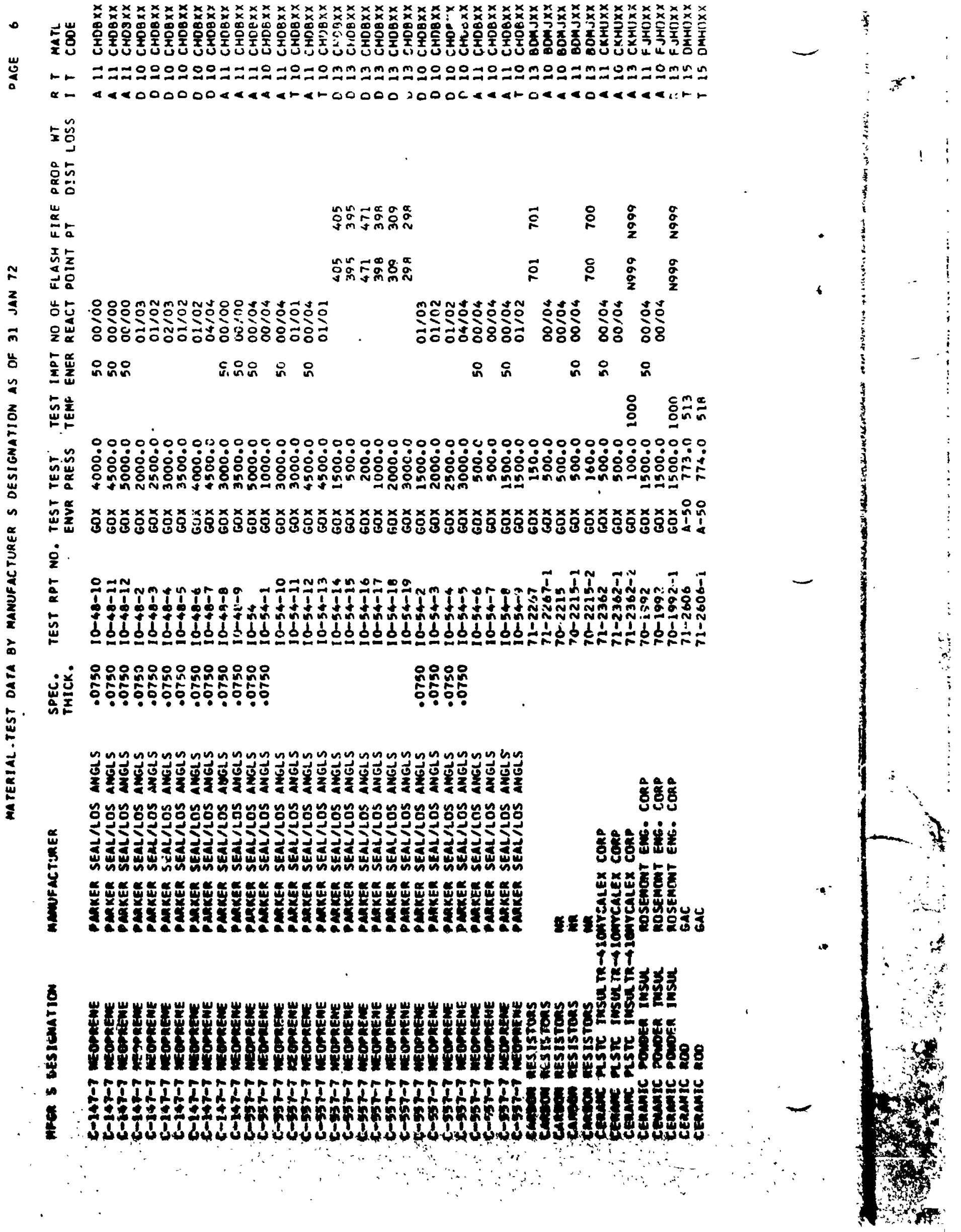




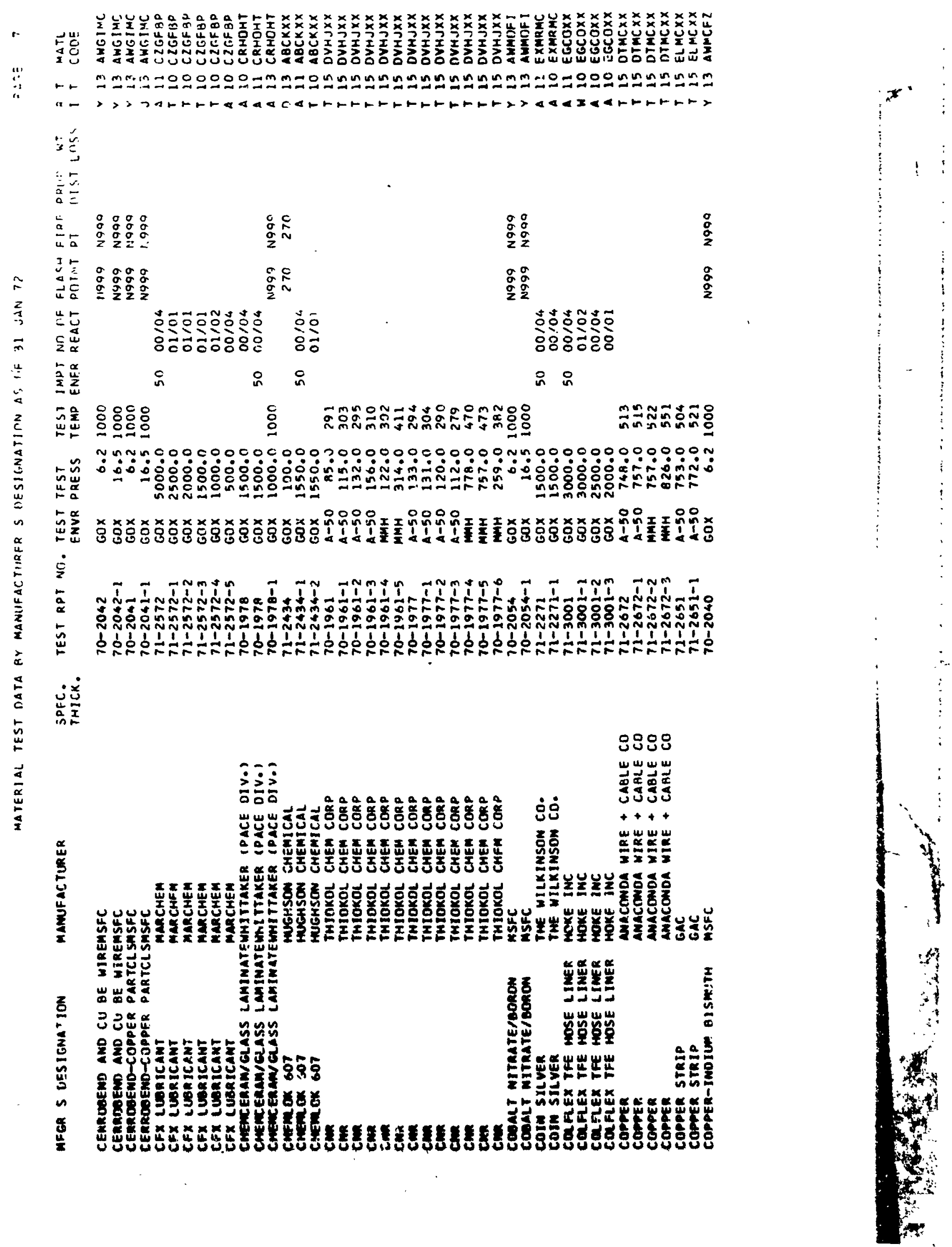




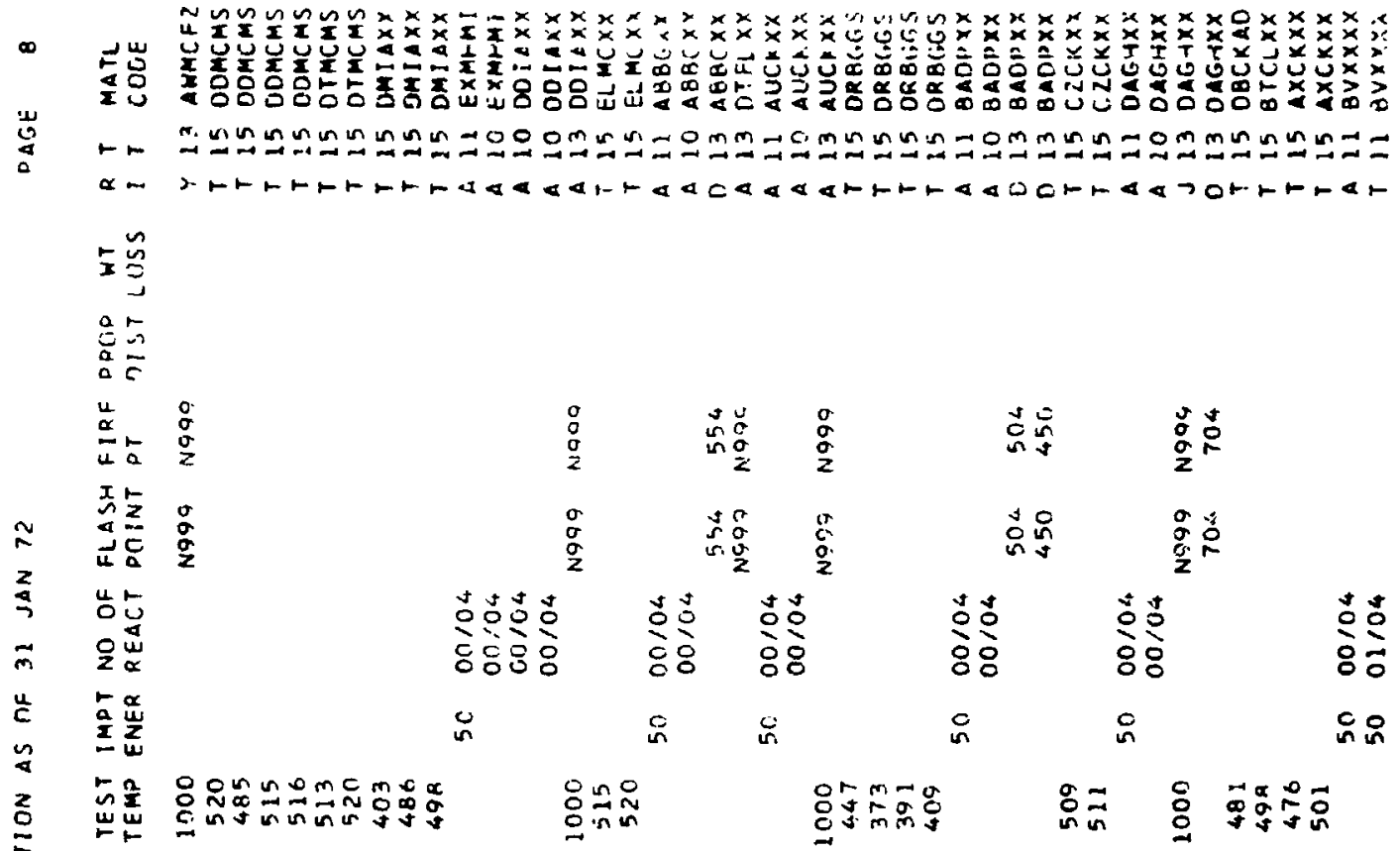

出

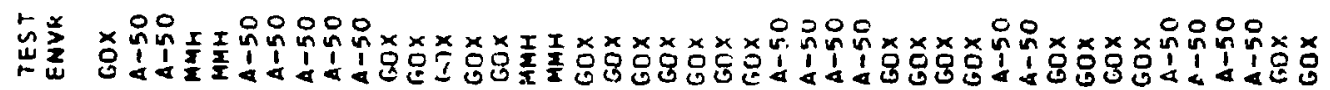
$\dot{2}$

a

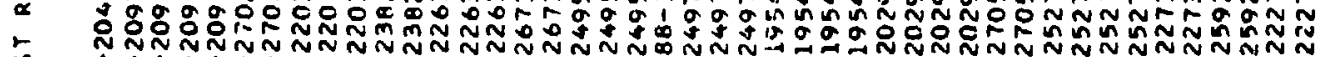

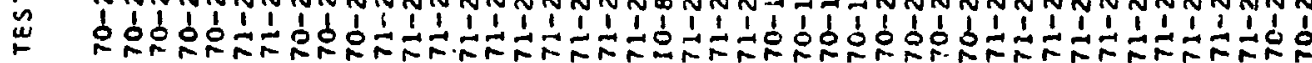

ن⿺辶ّ

奠足

8980

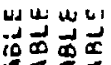

S过

$+++$

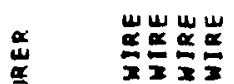

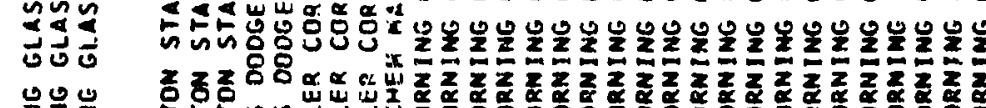

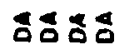

过

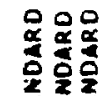

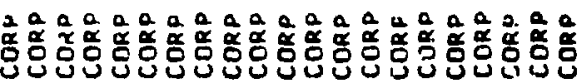

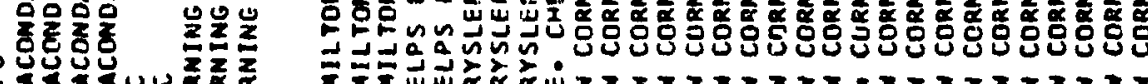

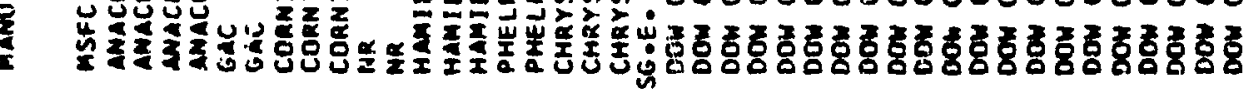

조을

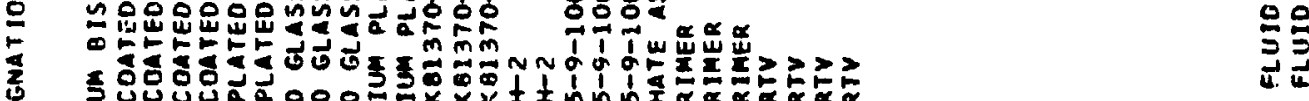

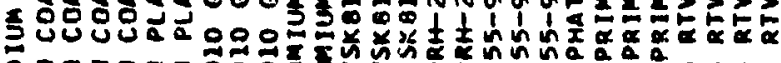

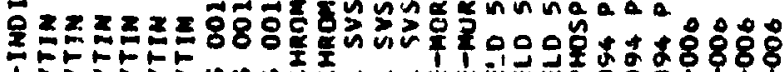

喜题

n

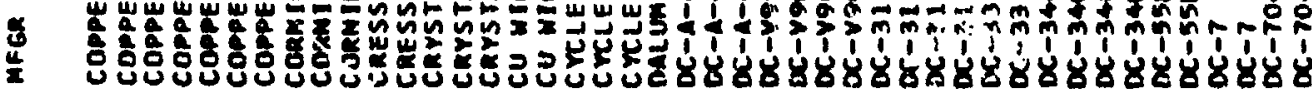




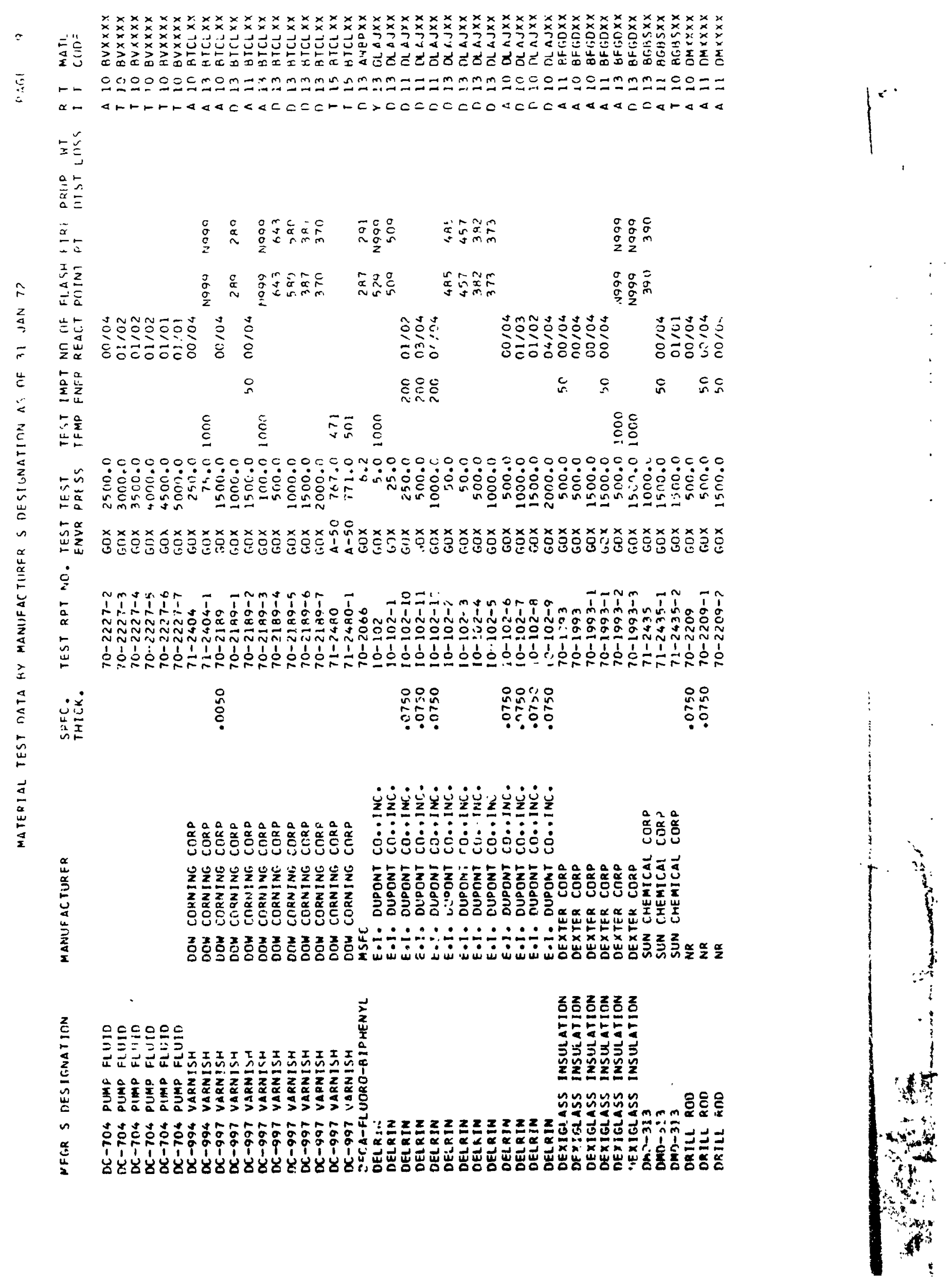




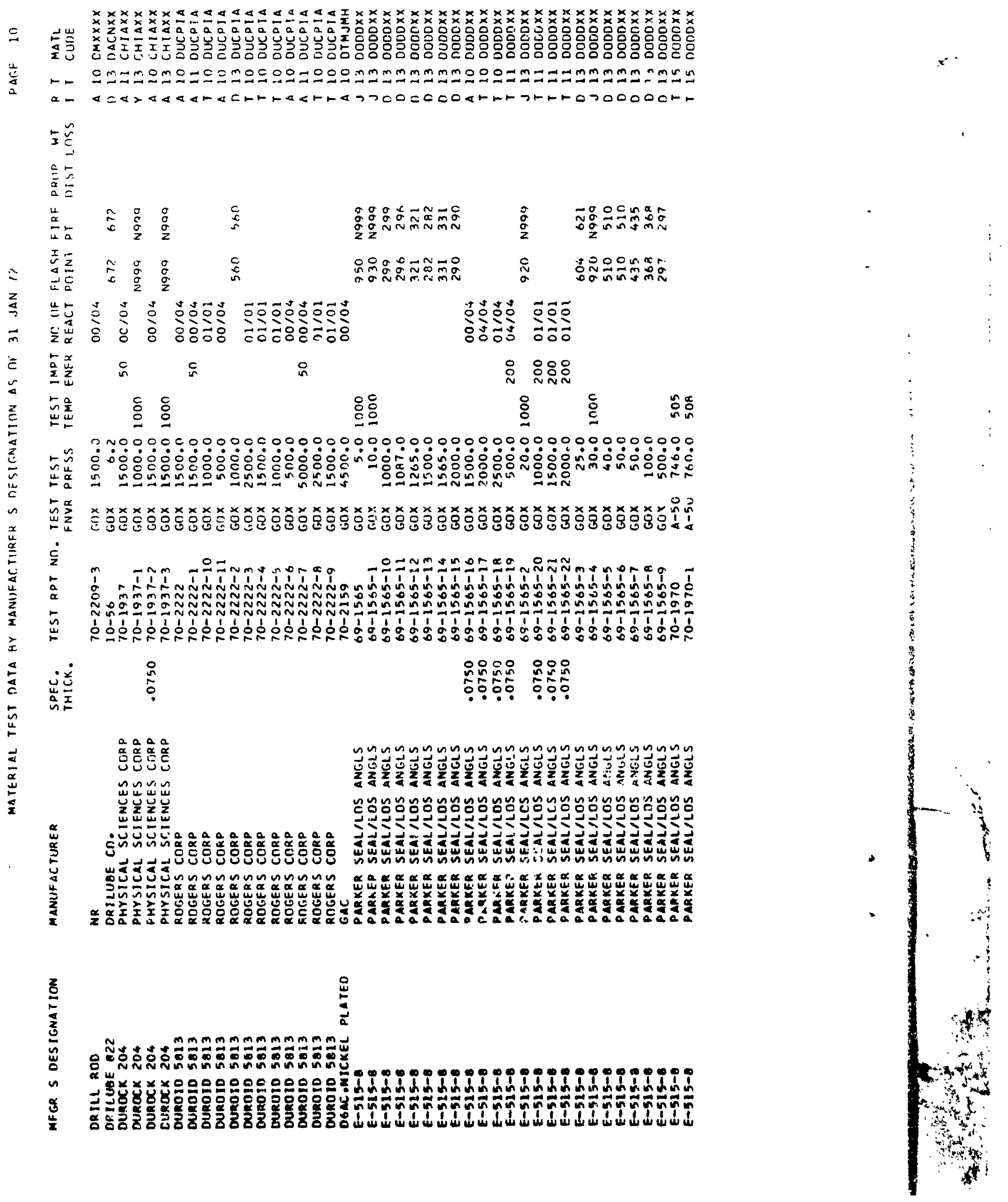




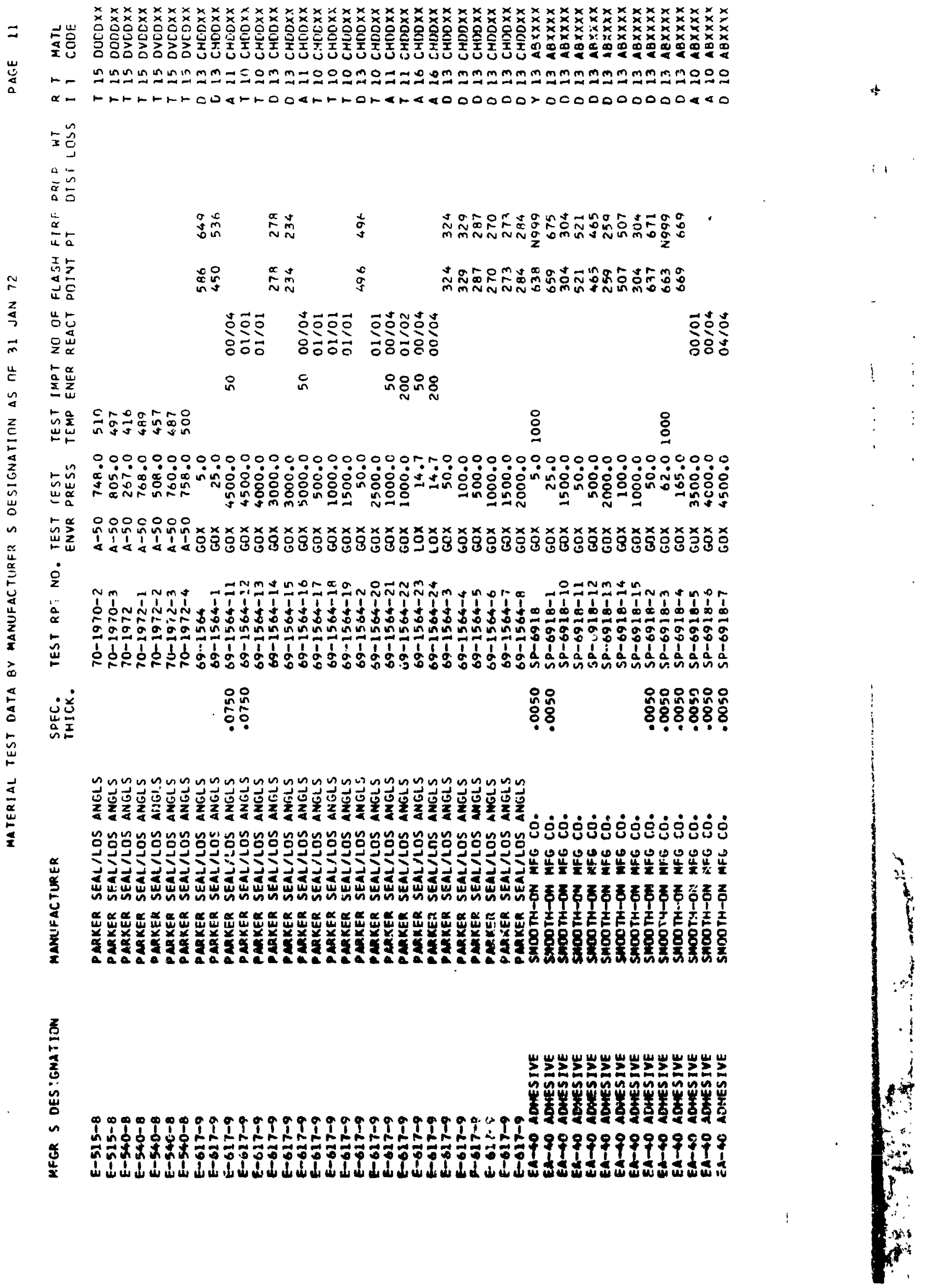




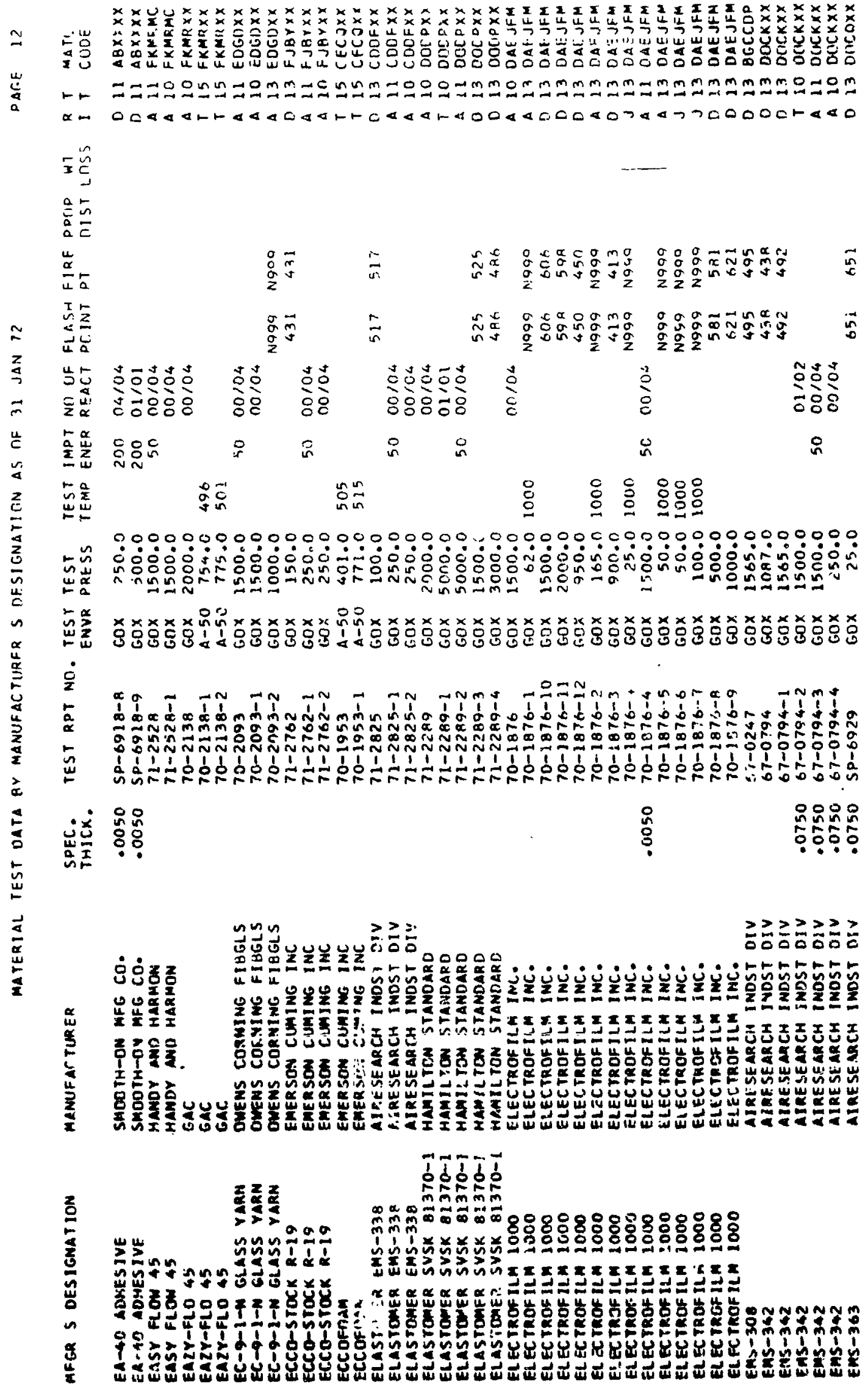




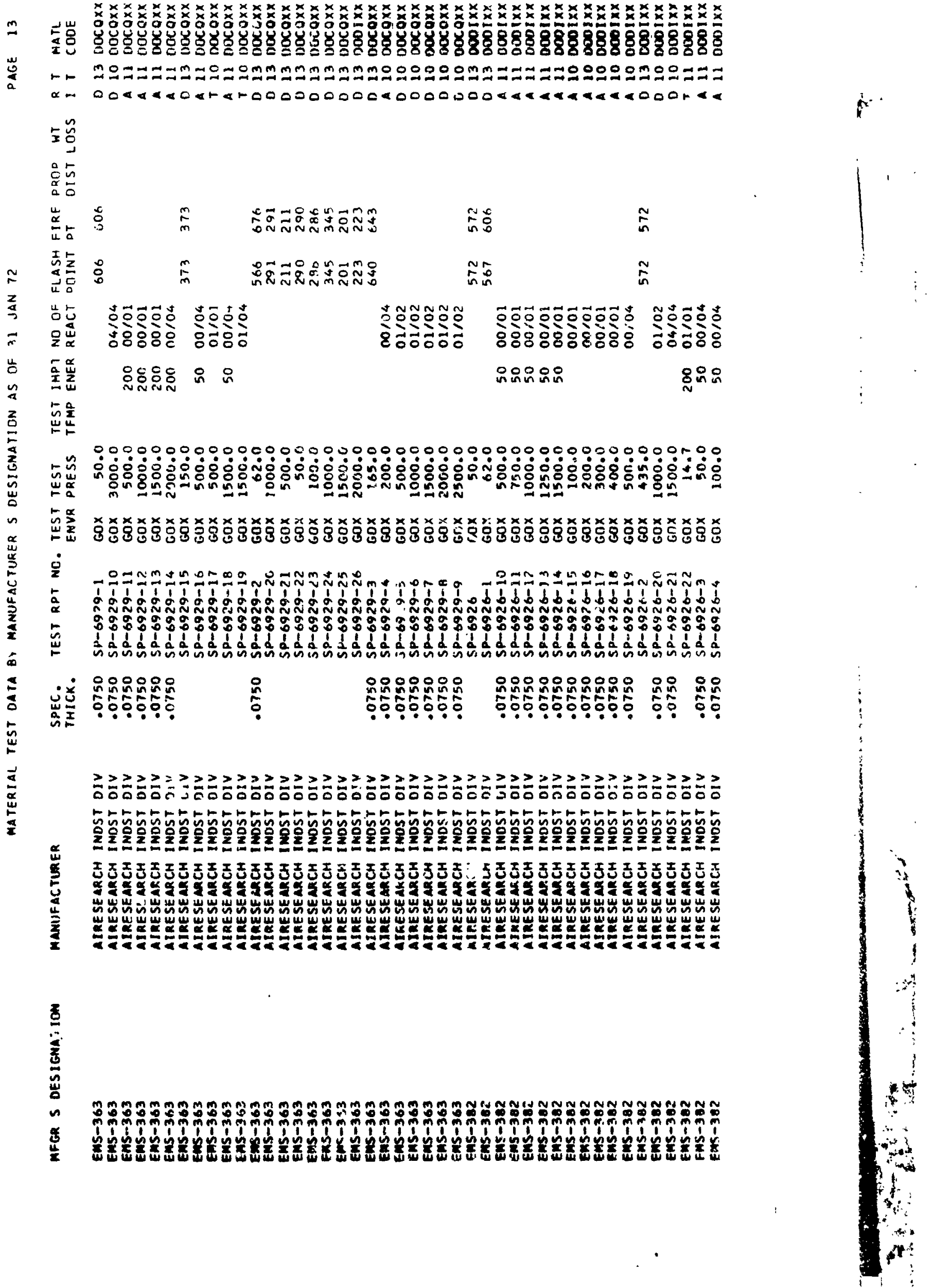




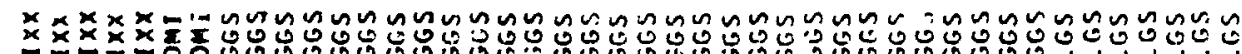
定 秃家

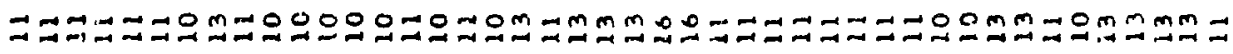

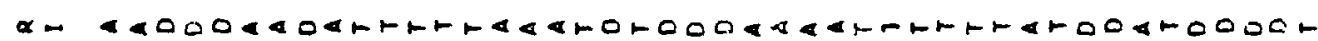

$5 \tilde{g}$ 亳告 容$\stackrel{0}{5}$

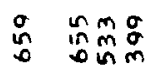

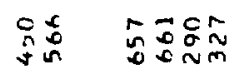
敋 $\frac{5}{5}$

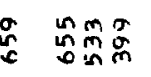

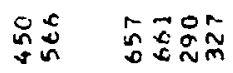
는

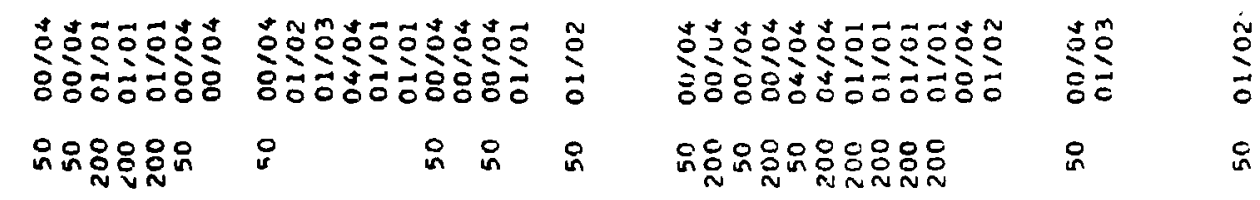
然 跣

点岕 $000000000000000000000004 r 0000000000000000000$

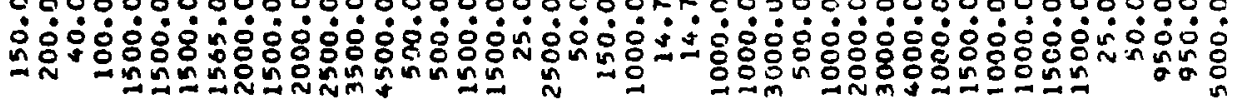

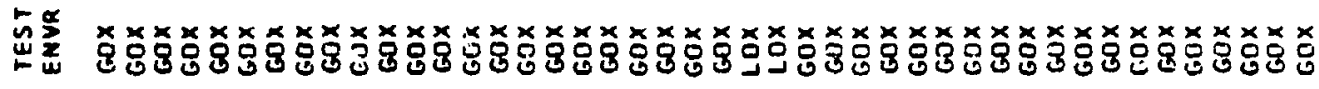
$\dot{2}$

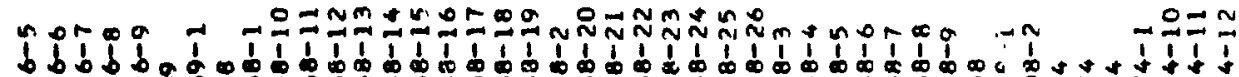
Noñ

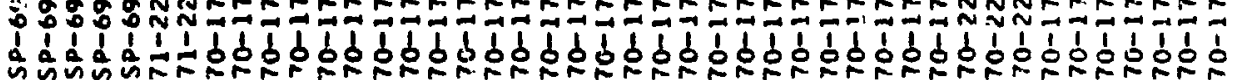

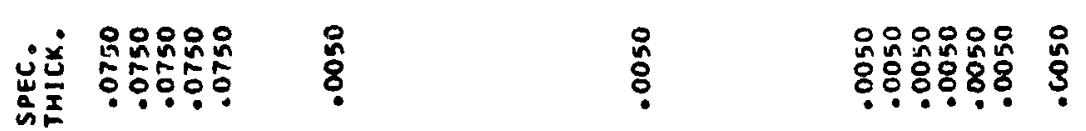

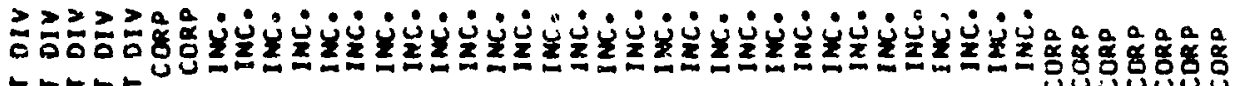

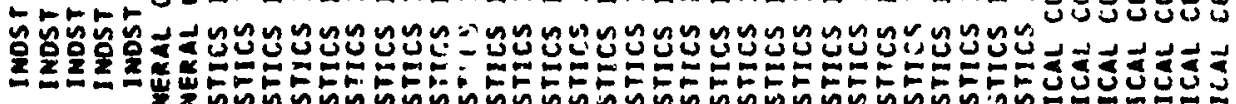

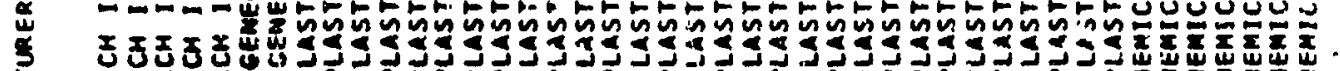

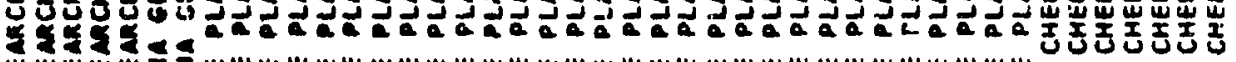

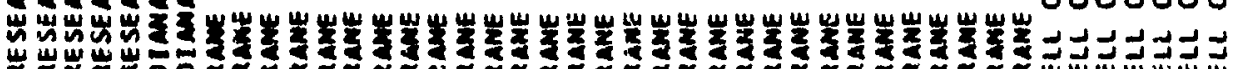

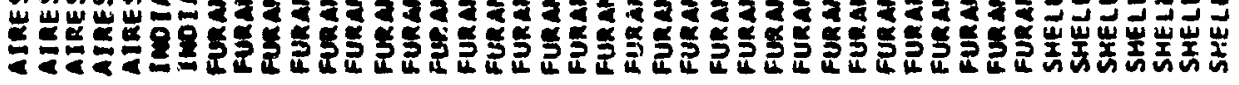

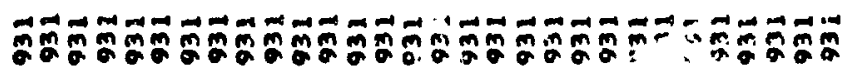

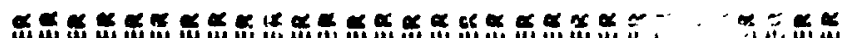

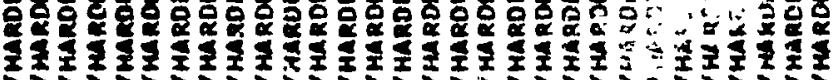

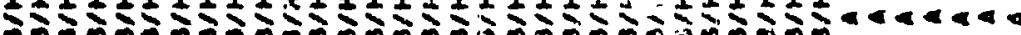

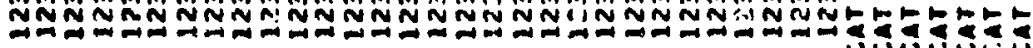

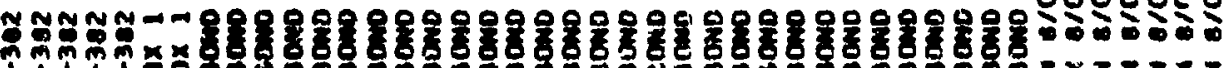

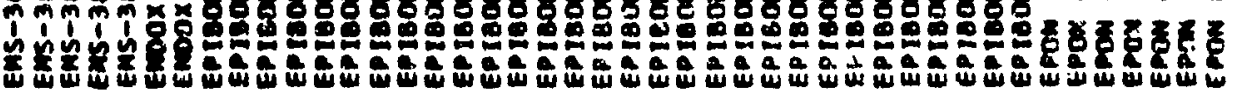




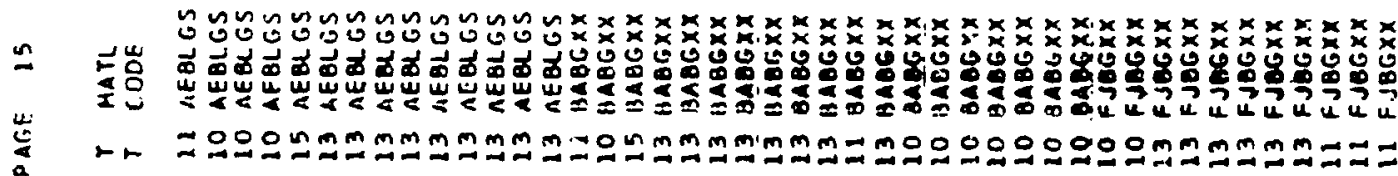

$\alpha-4 r<0000000000<000000-0<0 r-10 r-1000000<4$

$5 \check{c}$

aำ

à

$\underset{\Sigma}{\underline{a}}$

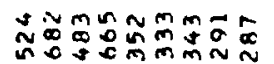

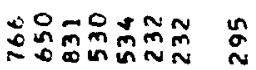

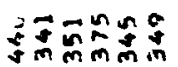

$\approx \quad \int^{I}$

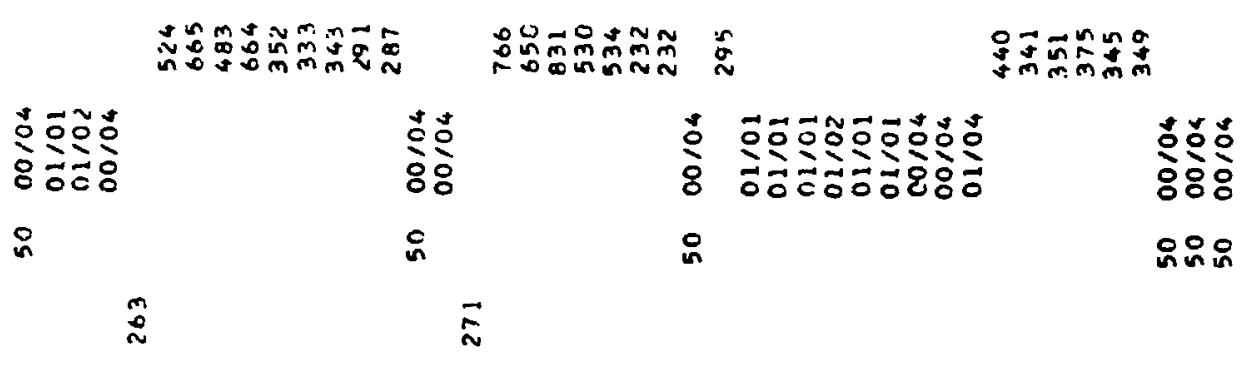

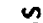

00000000400000010000000000000000000000000000

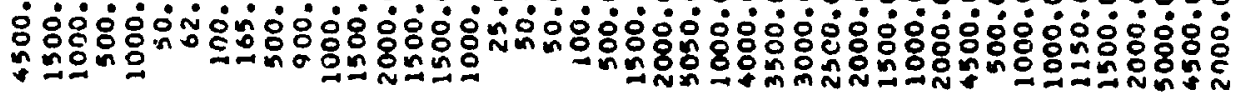

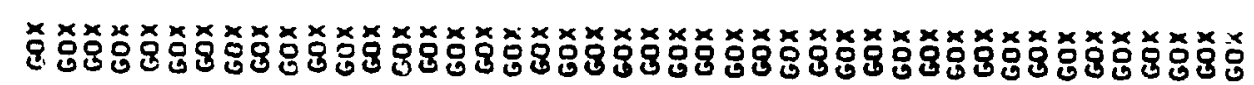
$\dot{0}$

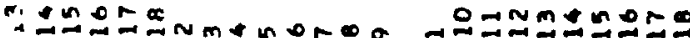<smiles>[CH]N=[V]</smiles>

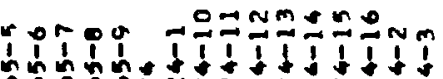

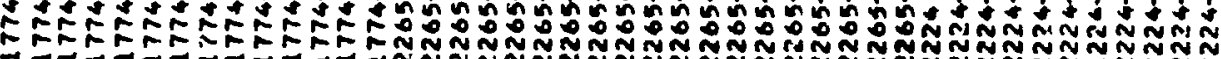

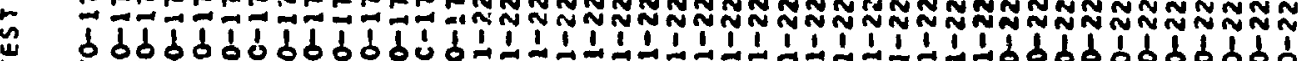

莒总

象员

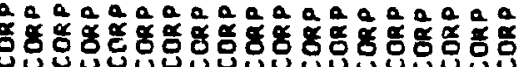

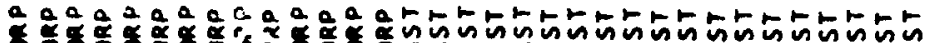

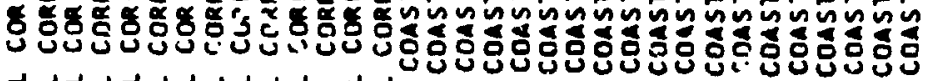

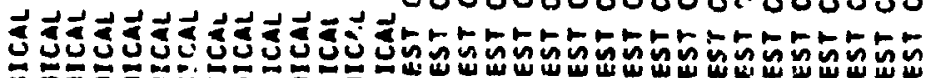

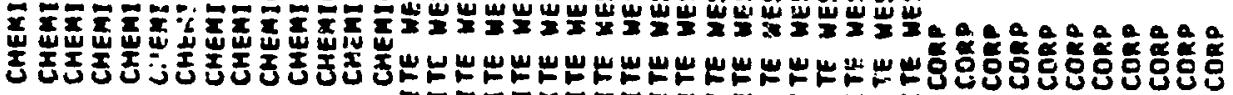

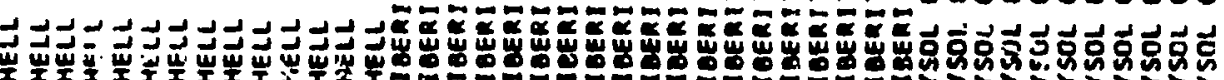

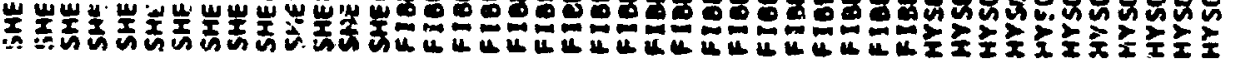

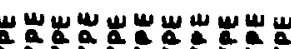

a

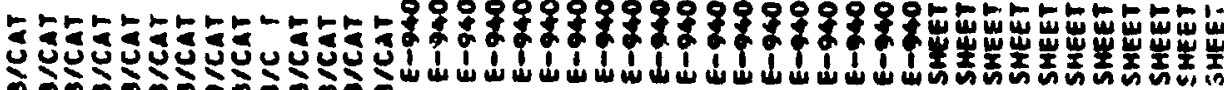

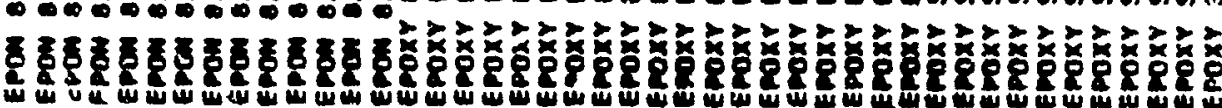




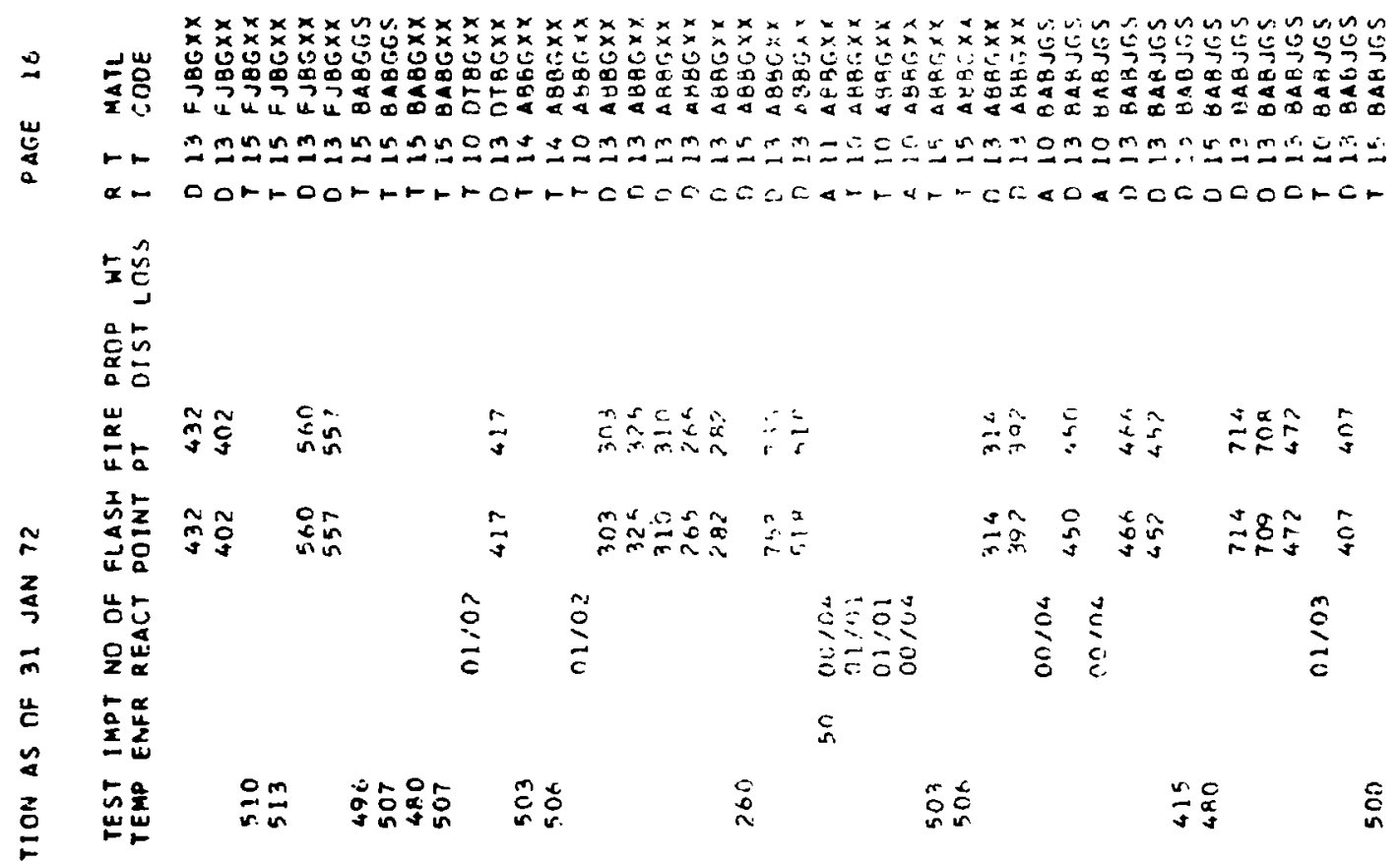

ヶ

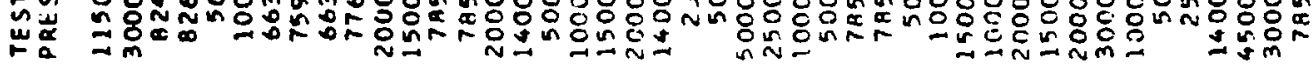
至妾 $\dot{\mathrm{z}}$

a

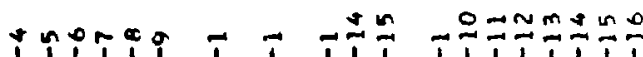

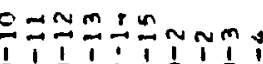

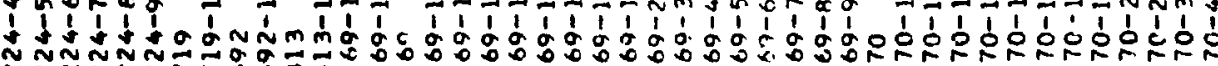
N NNNNNN 出

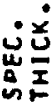

$\stackrel{\circ}{\circ}$

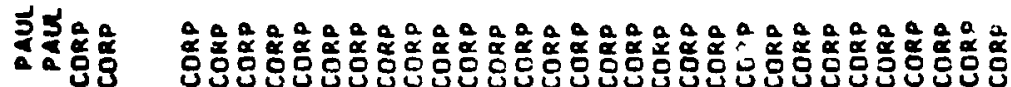

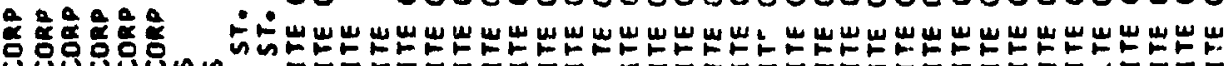

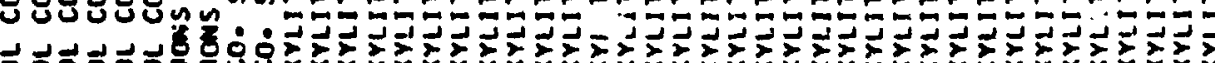

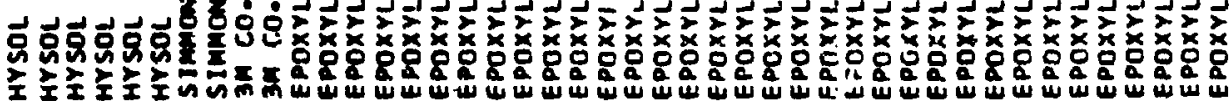

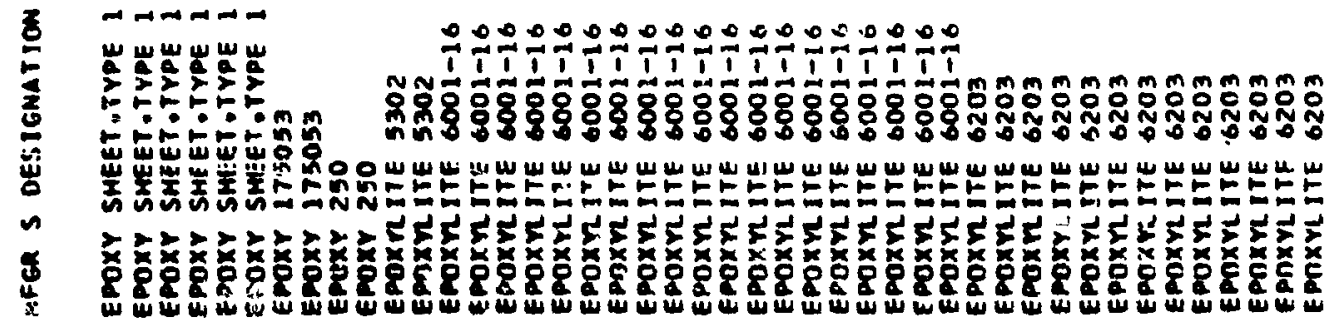




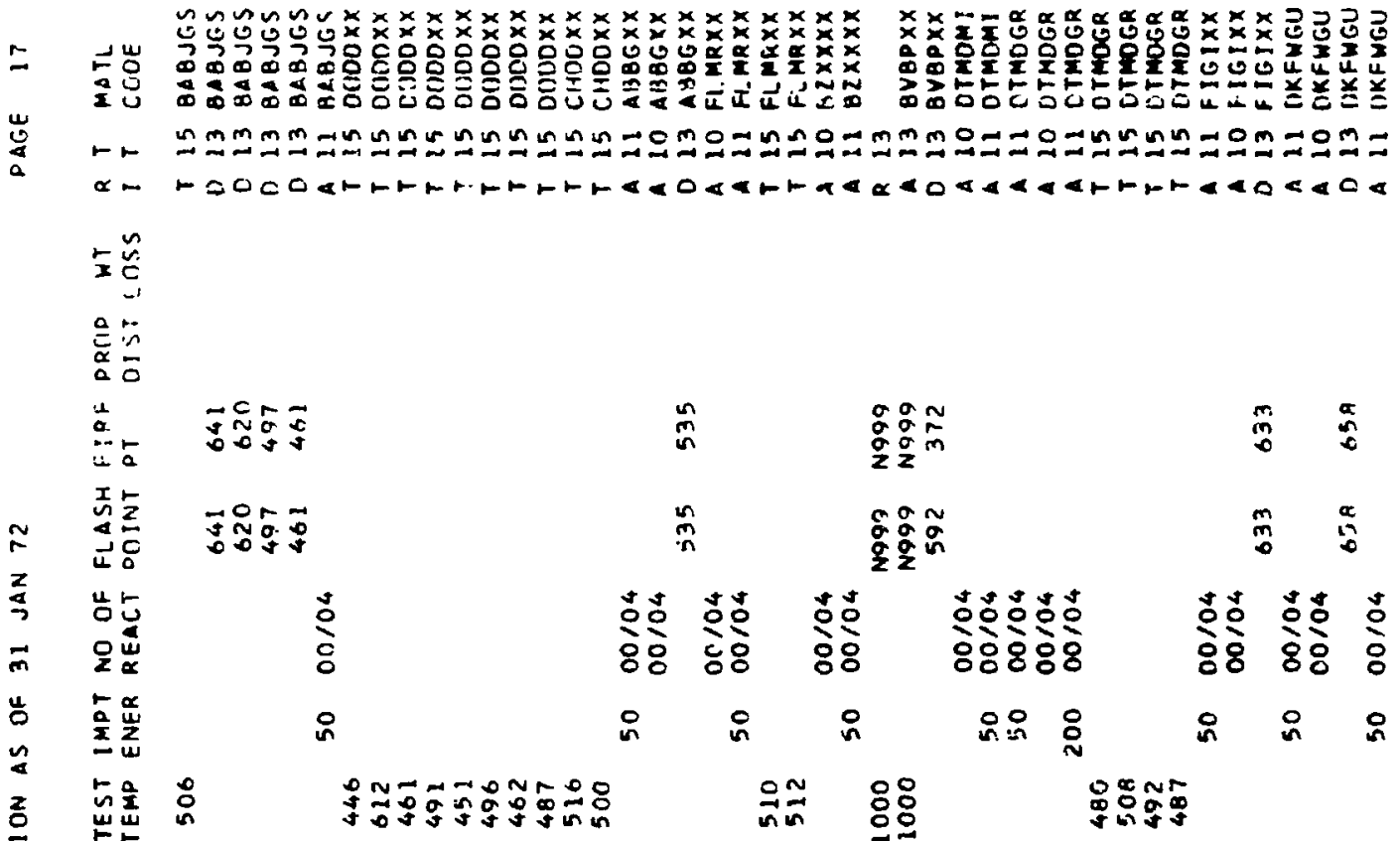

气岕

00000000000000000000000000 Nn0000000000000000 N

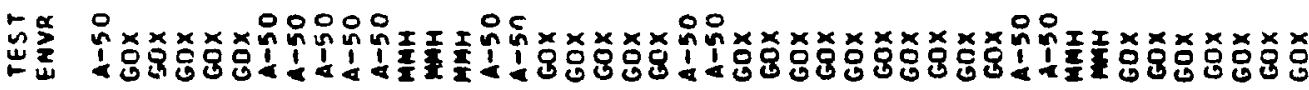
\&

a

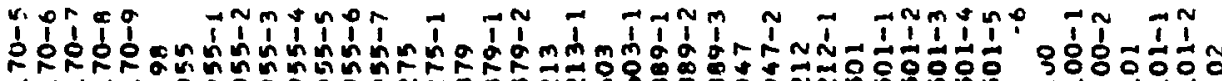

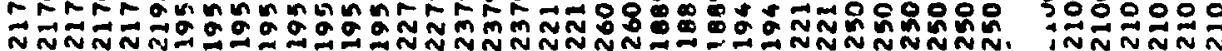

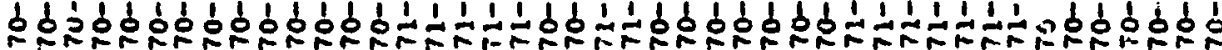

递总

:

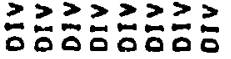

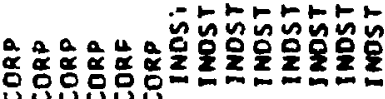

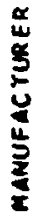
山世山س山س

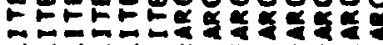

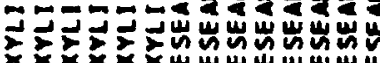

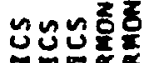

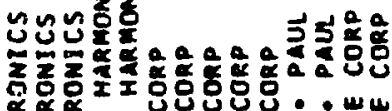

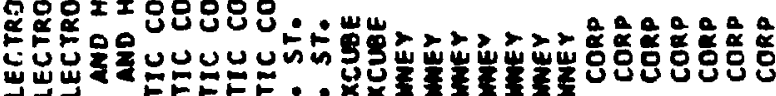

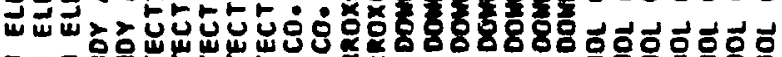

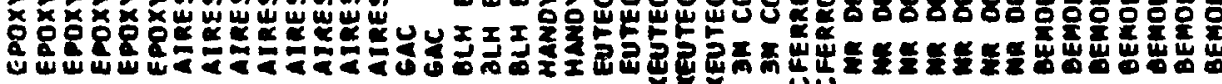

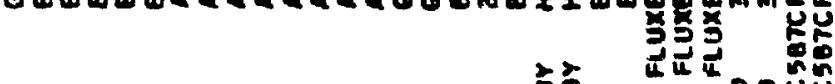

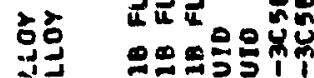

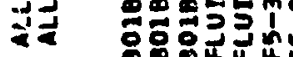

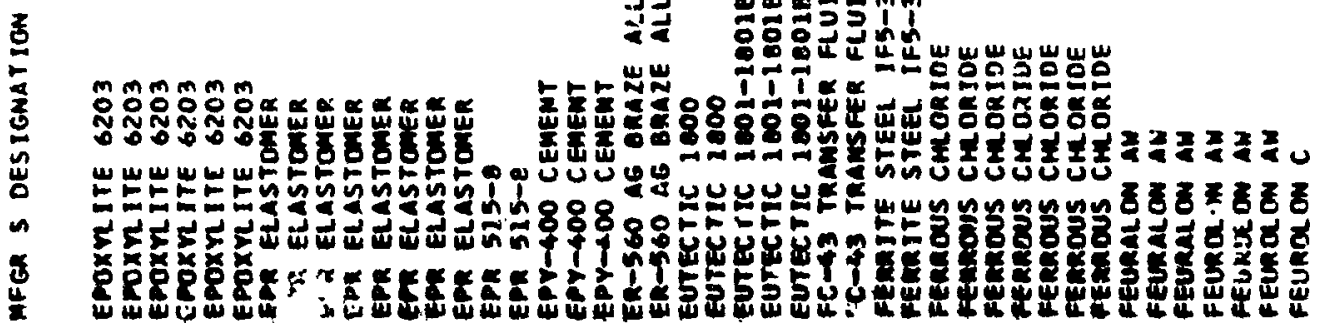



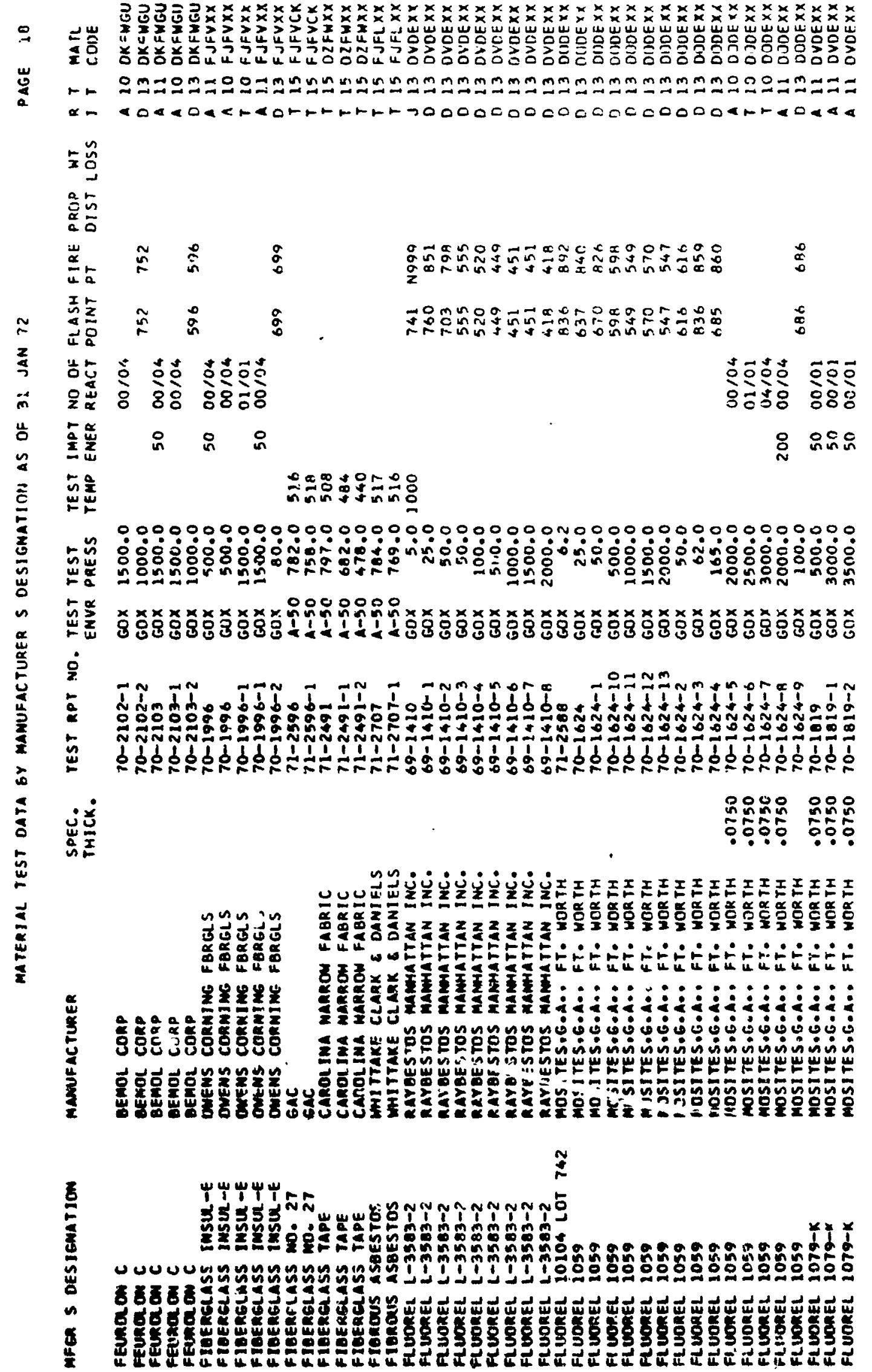



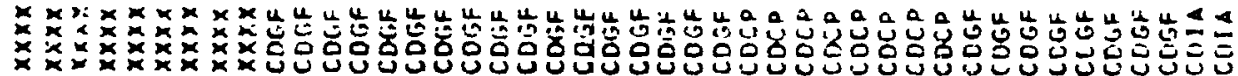

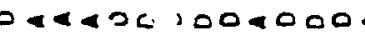

×气̆

$8 \frac{2}{2}$

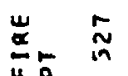

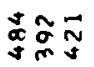

$\underset{\sim}{\infty}$

琶色放

in

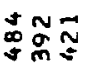

$\stackrel{x}{\sim} \frac{5}{6}$

范

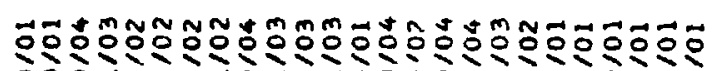

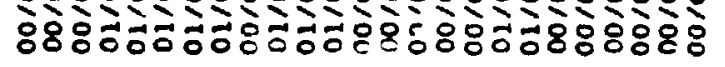

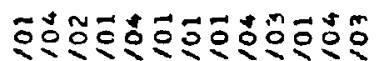

눈

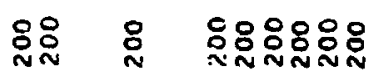

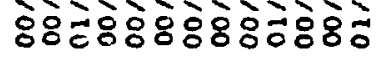

西

nัu

:

ํํํํำ

凯昰

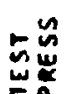

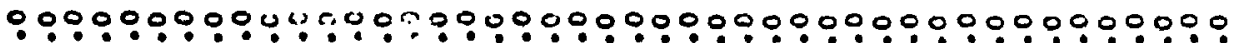

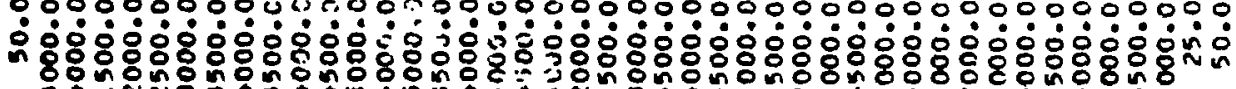

等

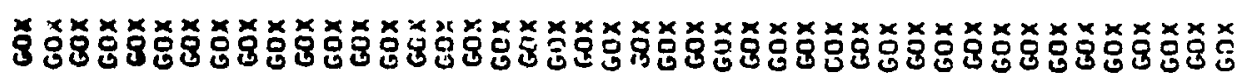

$\dot{8}$

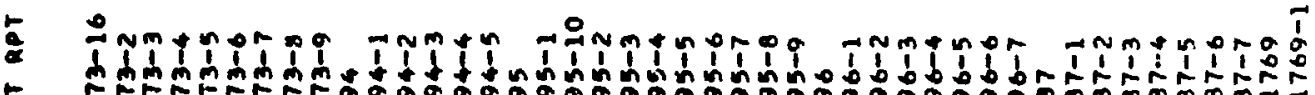

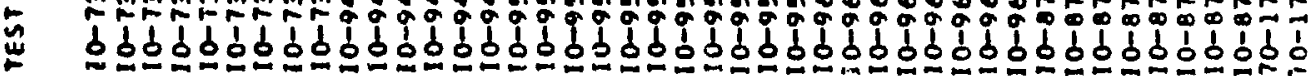

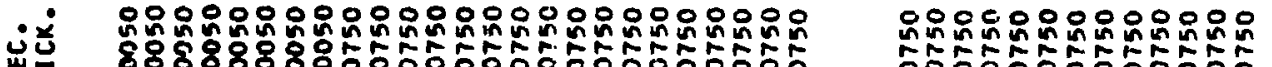

嵌
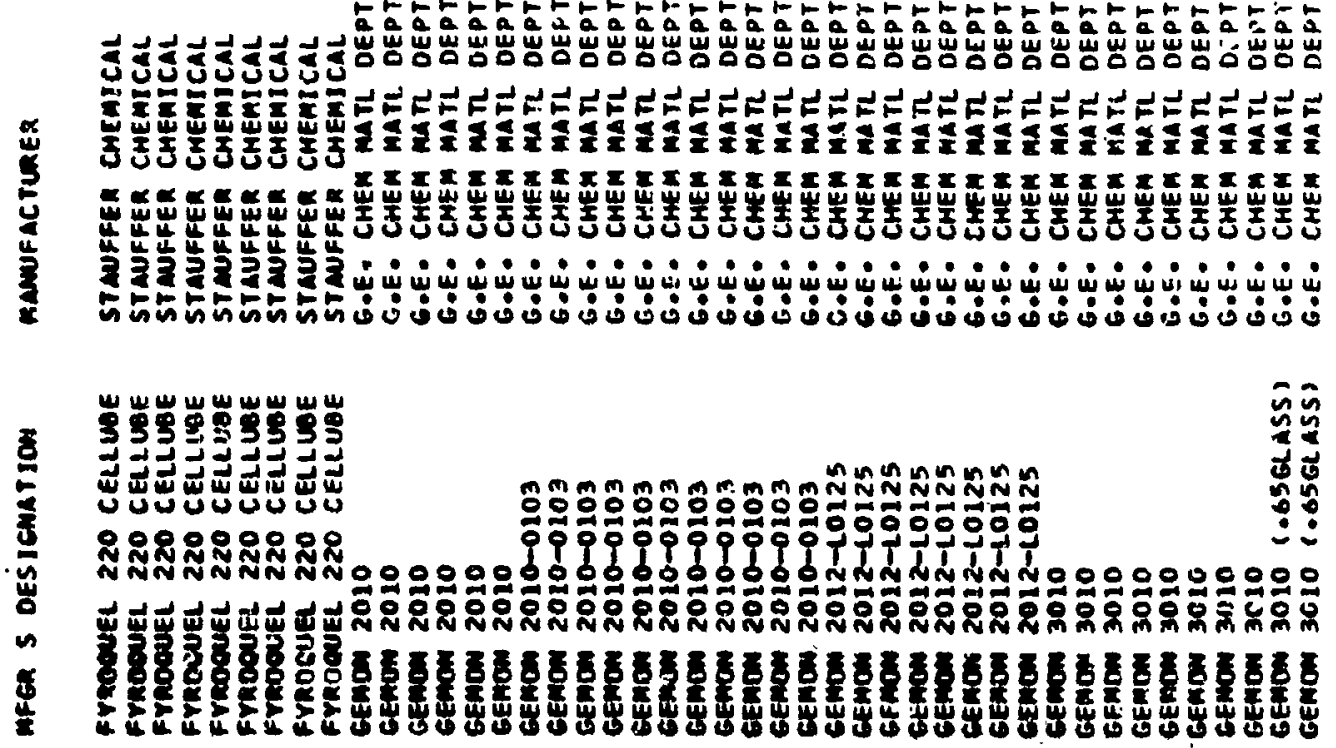


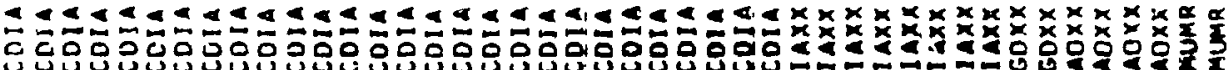

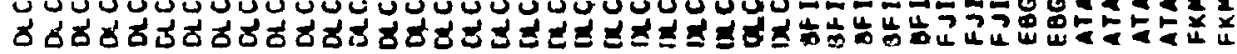

岁

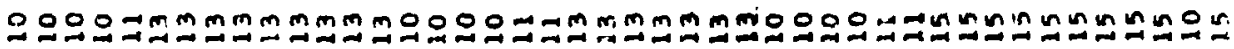

x

空些

$\stackrel{\boldsymbol{x}}{\boldsymbol{\alpha}}$

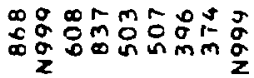

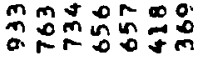

兵尗

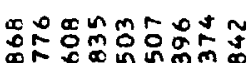

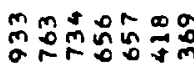

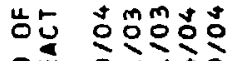

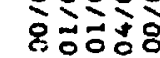

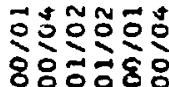

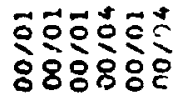

$\frac{4}{8}$

눈

¿̊ำ

:웅

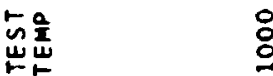

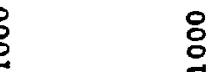

8

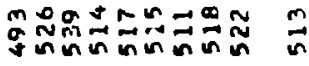

出

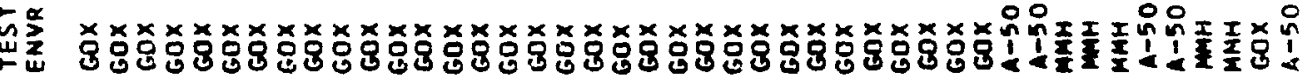

$\dot{0}$

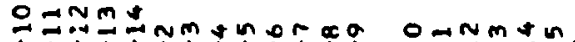

a

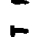

点

có

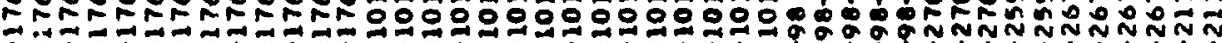

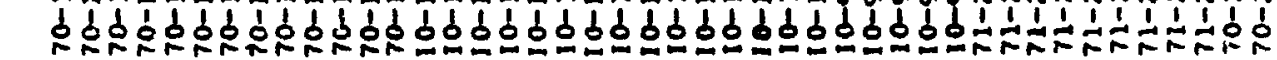

ix 울요요요

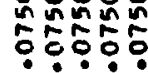

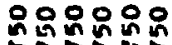

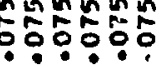

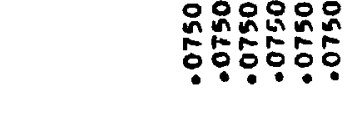

5 ज小

(2)

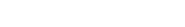

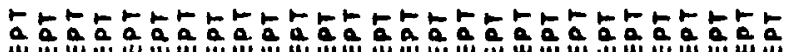

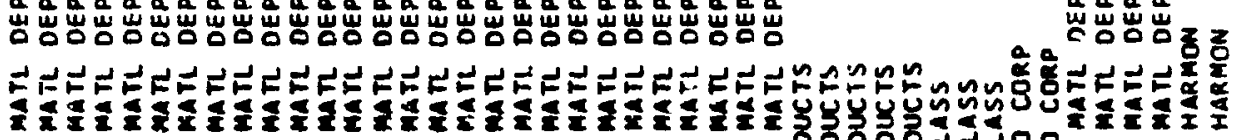

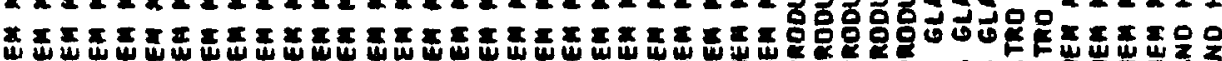

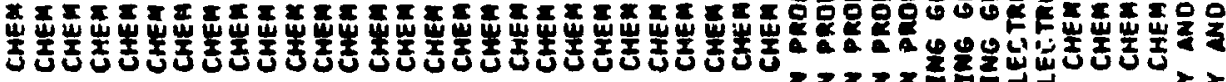

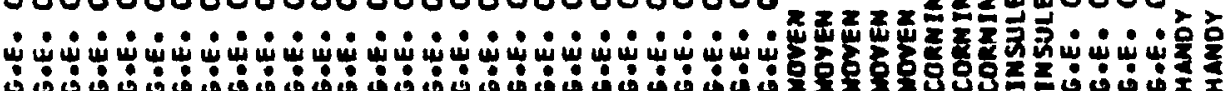

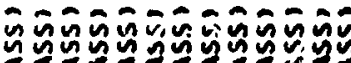

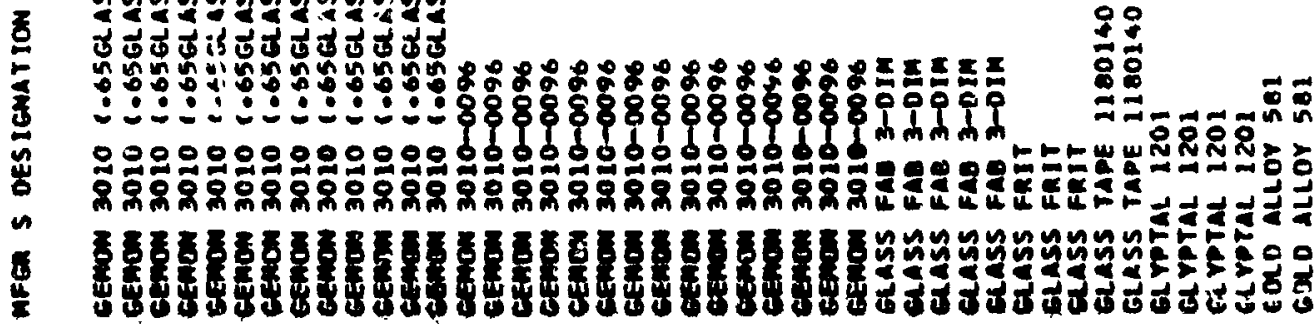




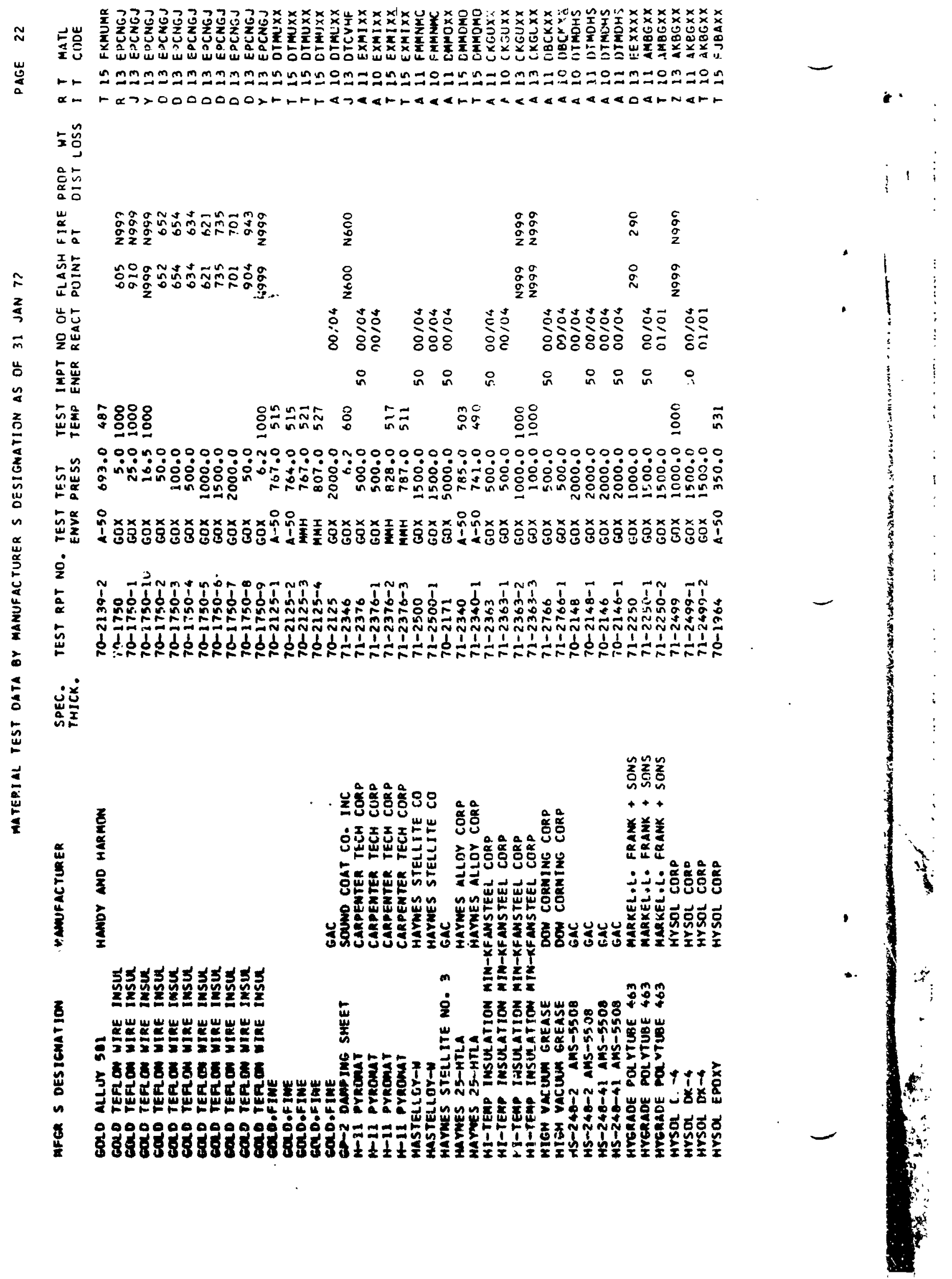




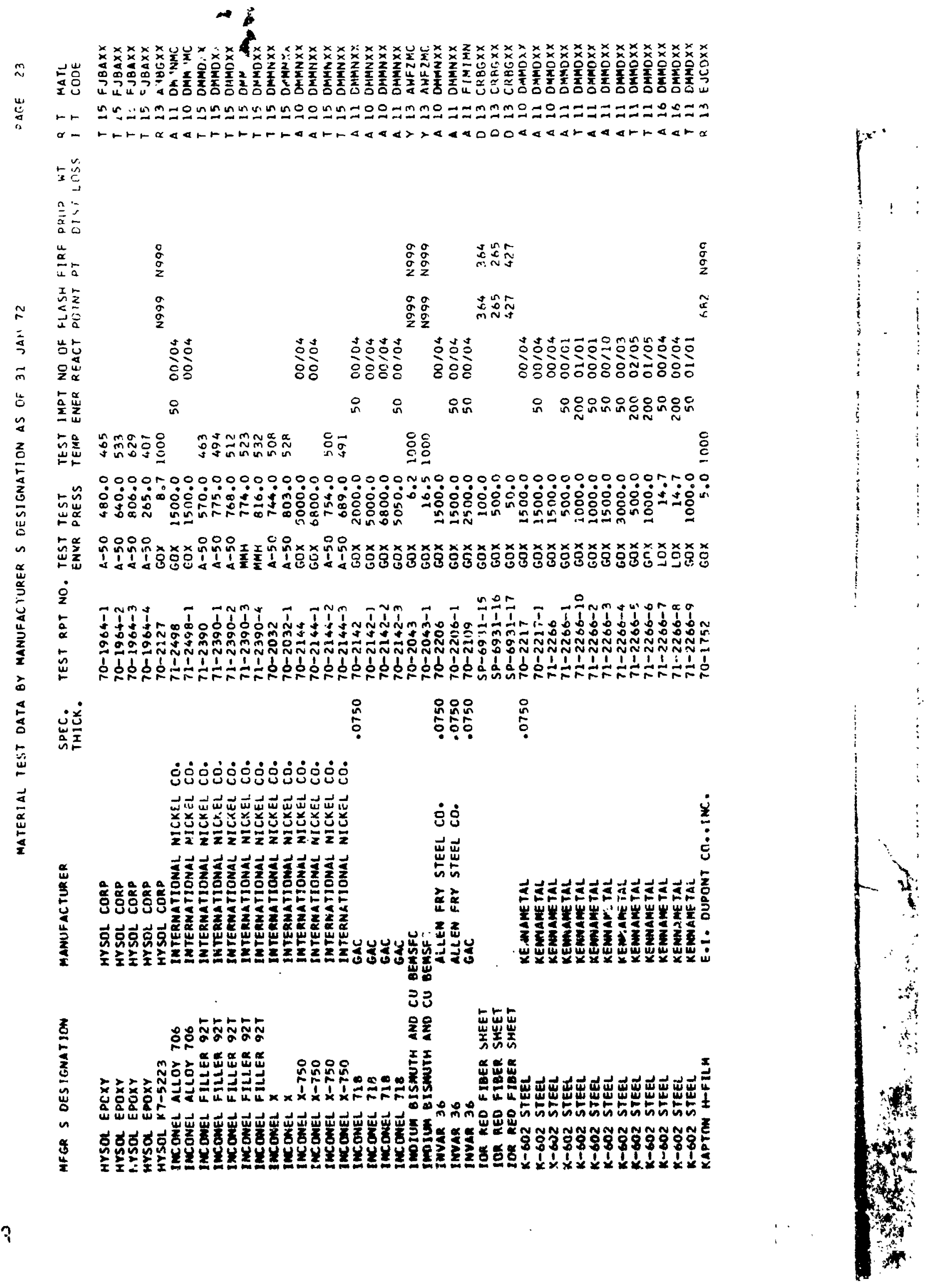




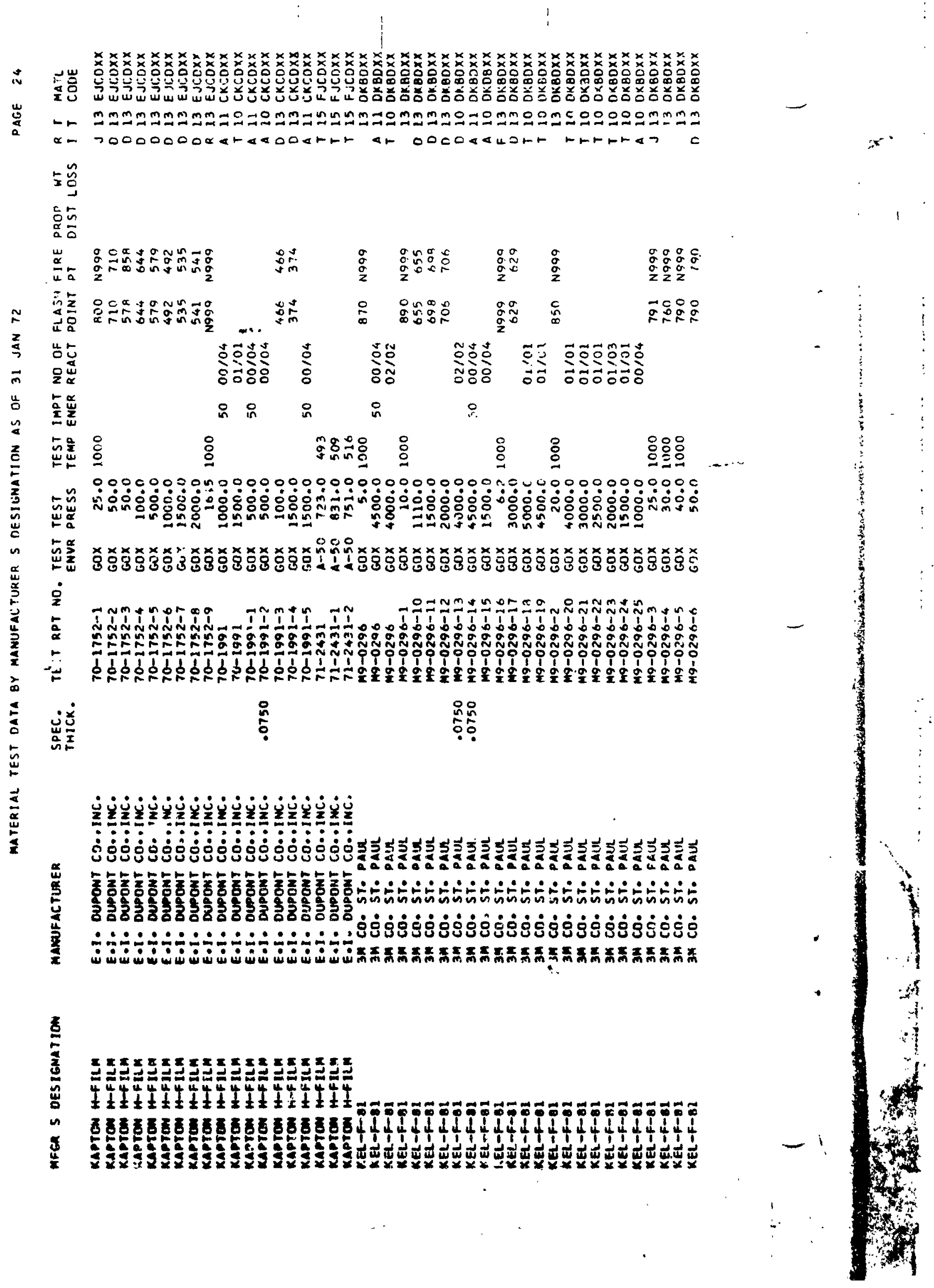




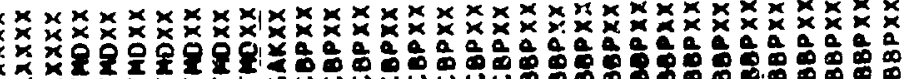

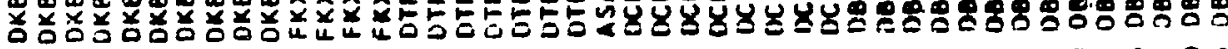

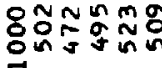

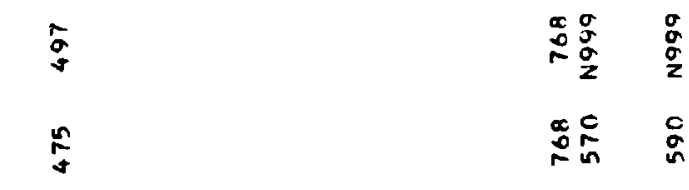

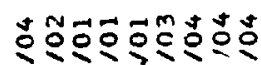

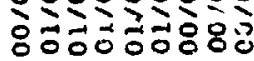

造

in

$\therefore$ in in in in

in

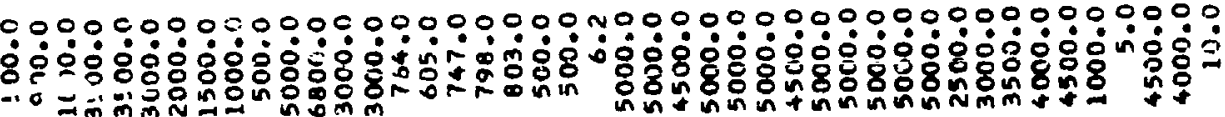

点管

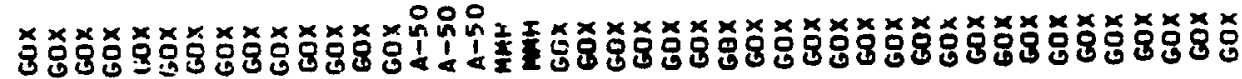

$\dot{2}$

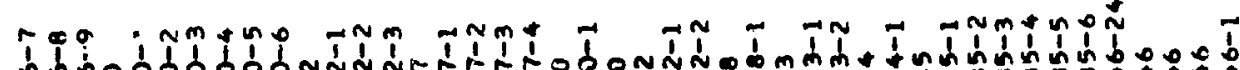

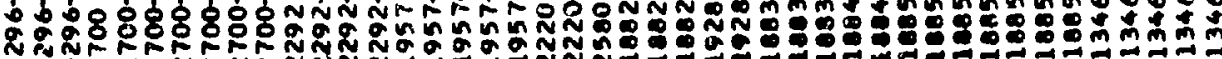
范

苔总

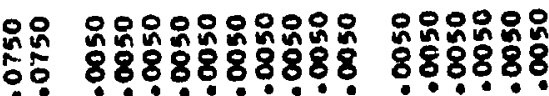

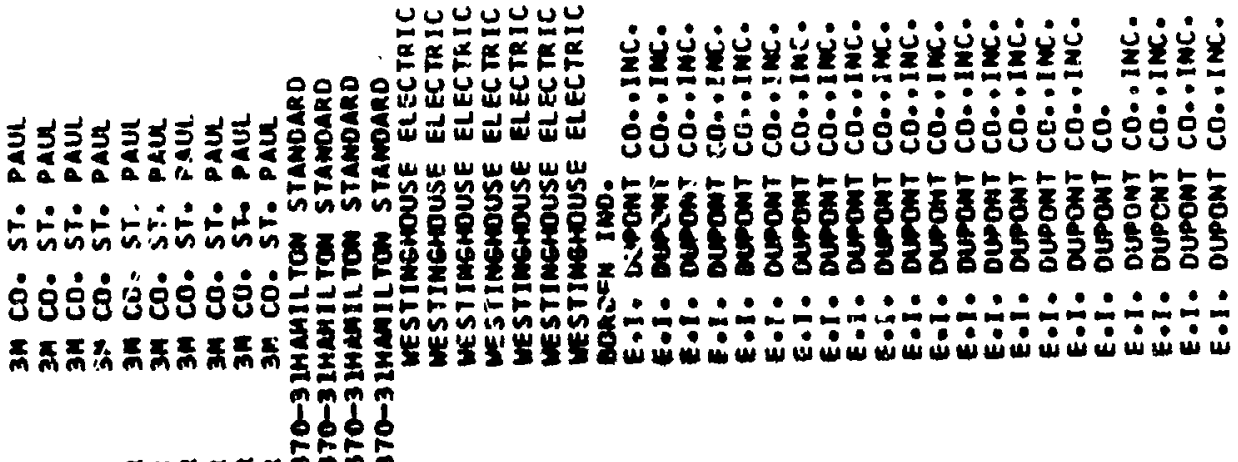

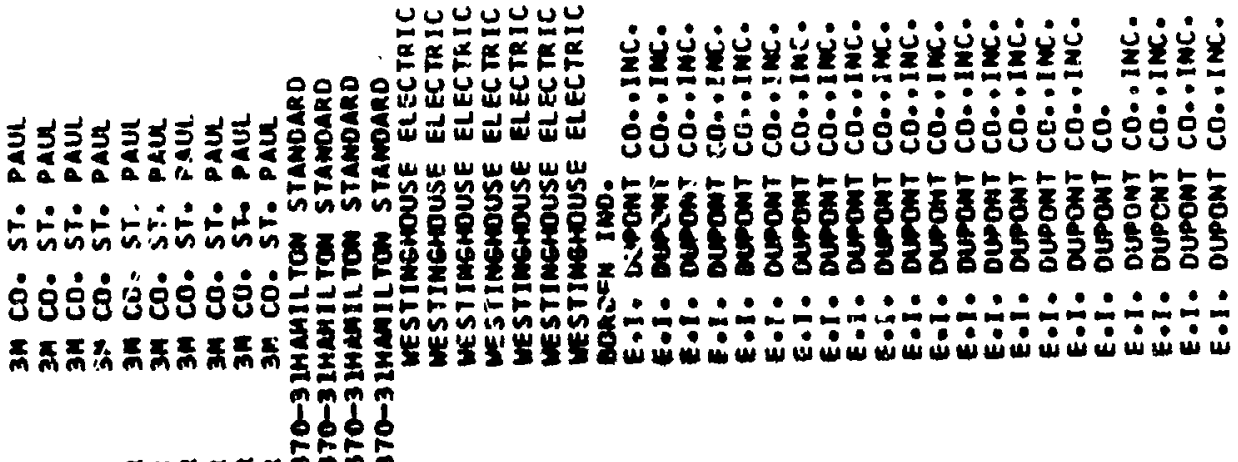

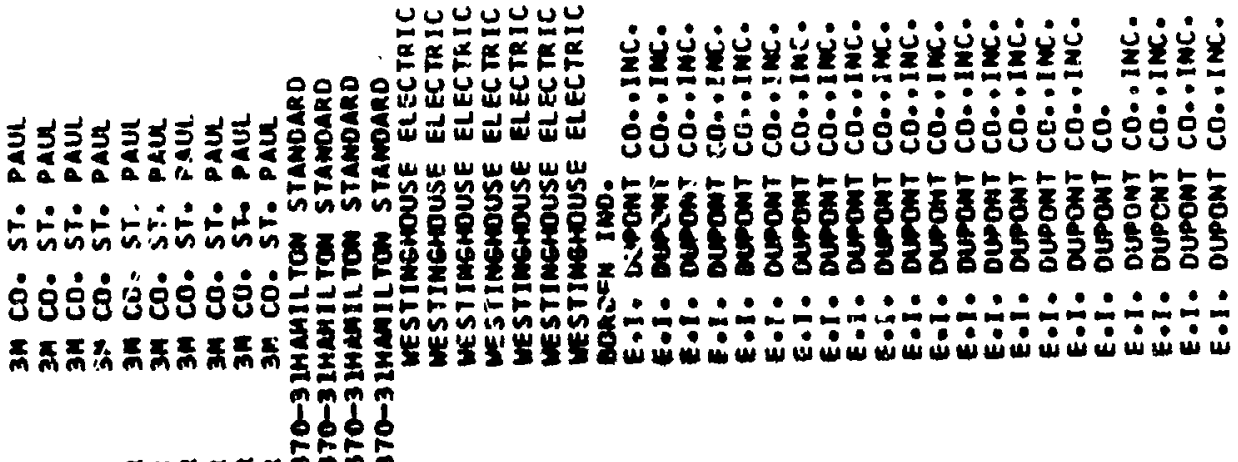

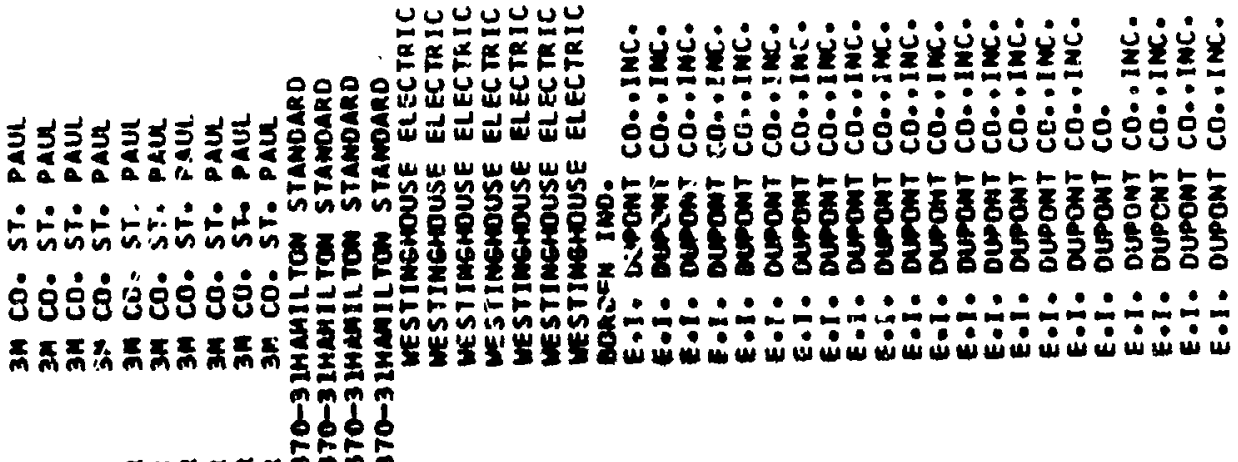

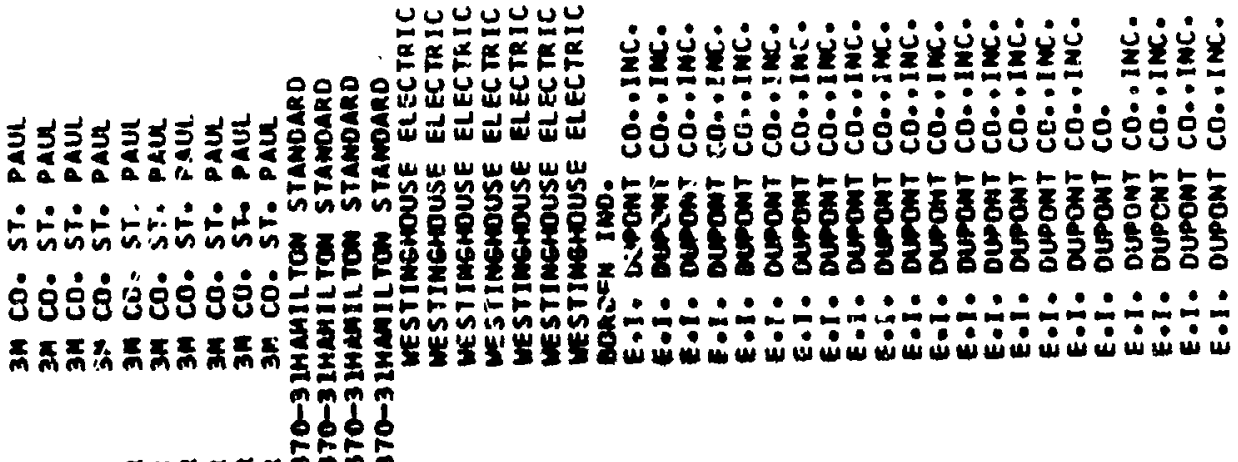

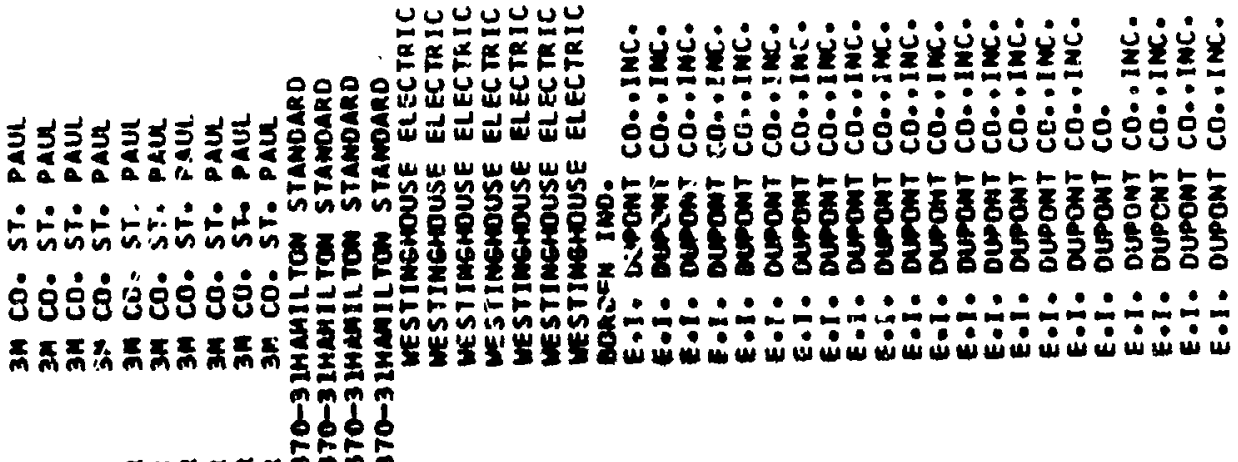

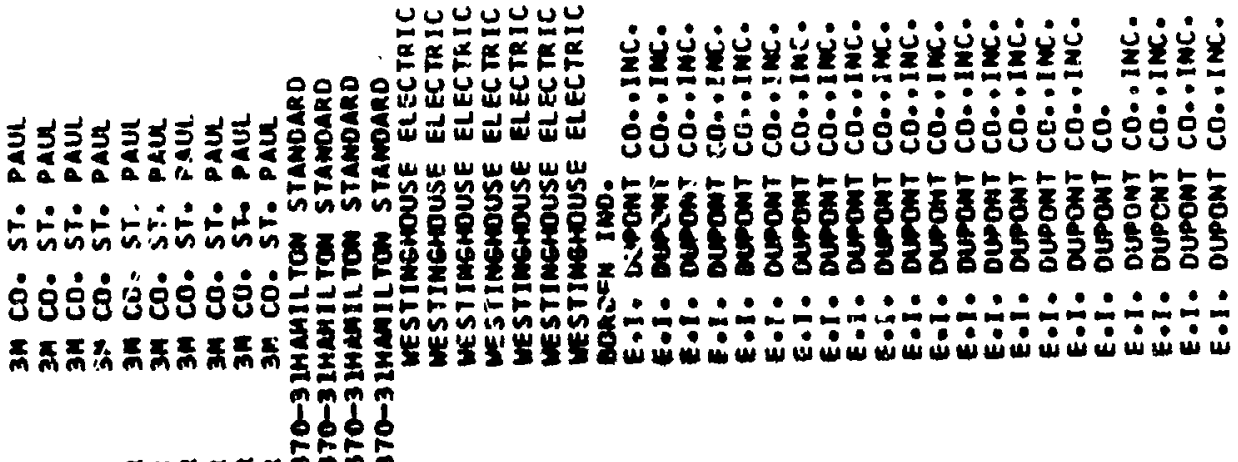

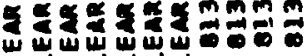

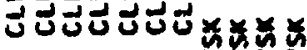

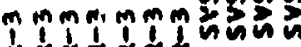

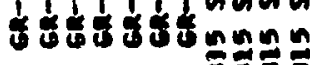

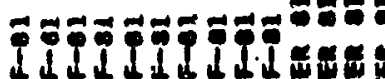

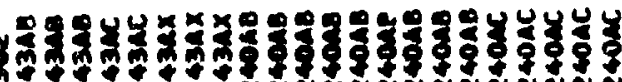

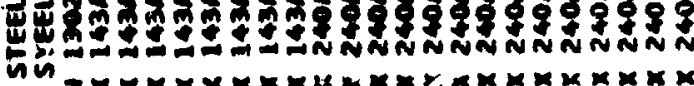
4 


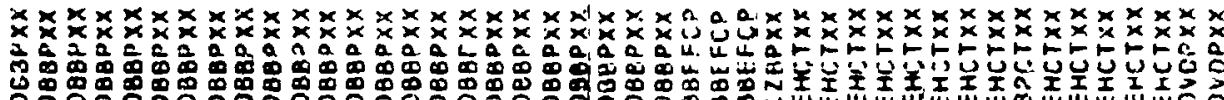

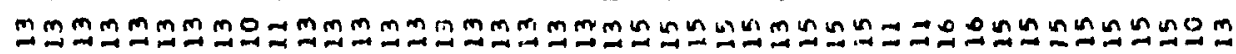

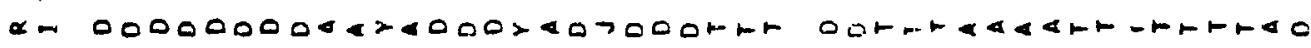

茎

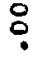

这占

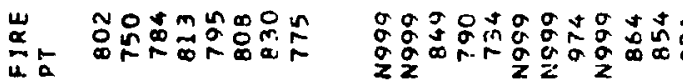

$\therefore$

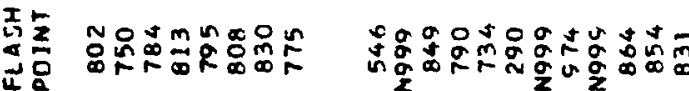

岁管

ㅇํㅇ

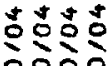

ะะ๐ั

을

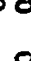

ํํำํํㅇ

占是

$\stackrel{10}{2}$

$\circ$

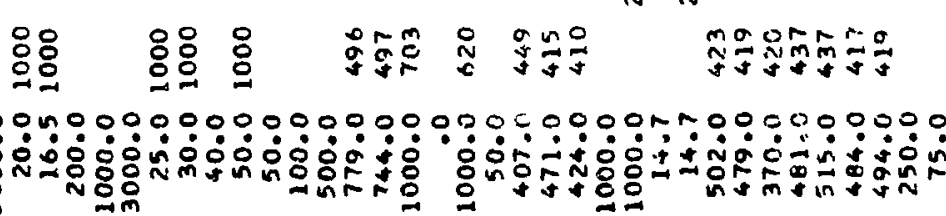

战

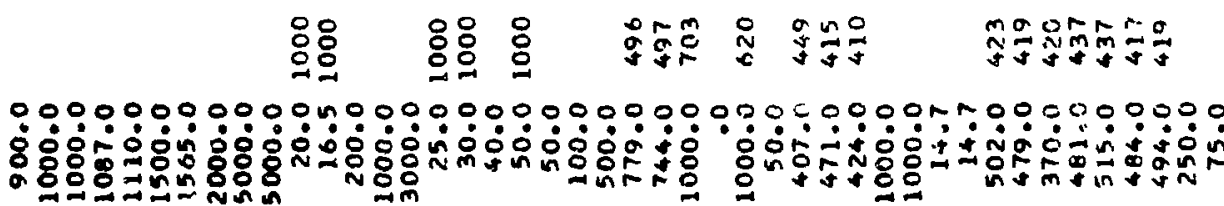

点

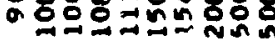

\section{0}

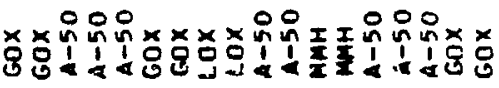

$\dot{8}$

a

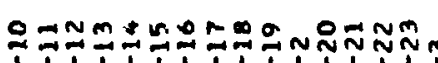

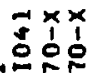

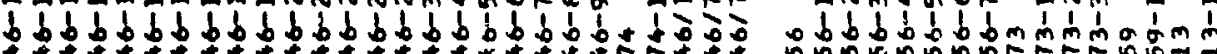

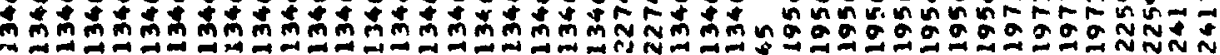

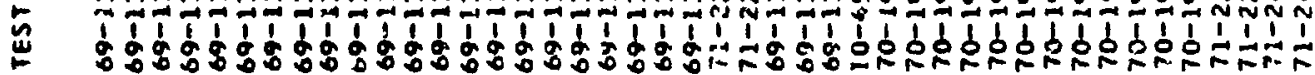

递总

号昂

\&.

aํ.

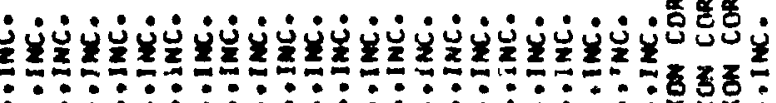

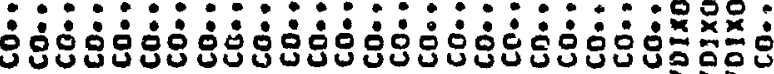

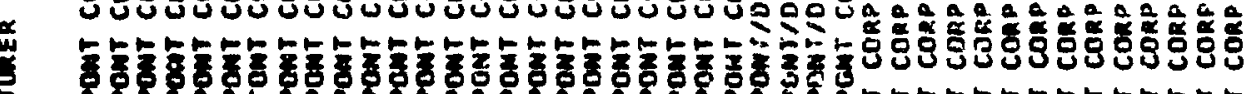

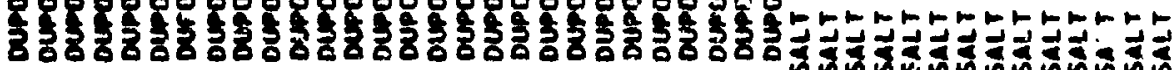

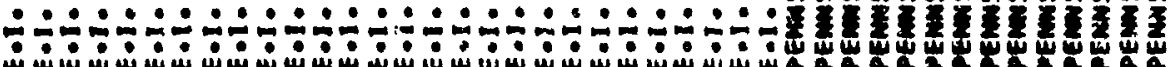




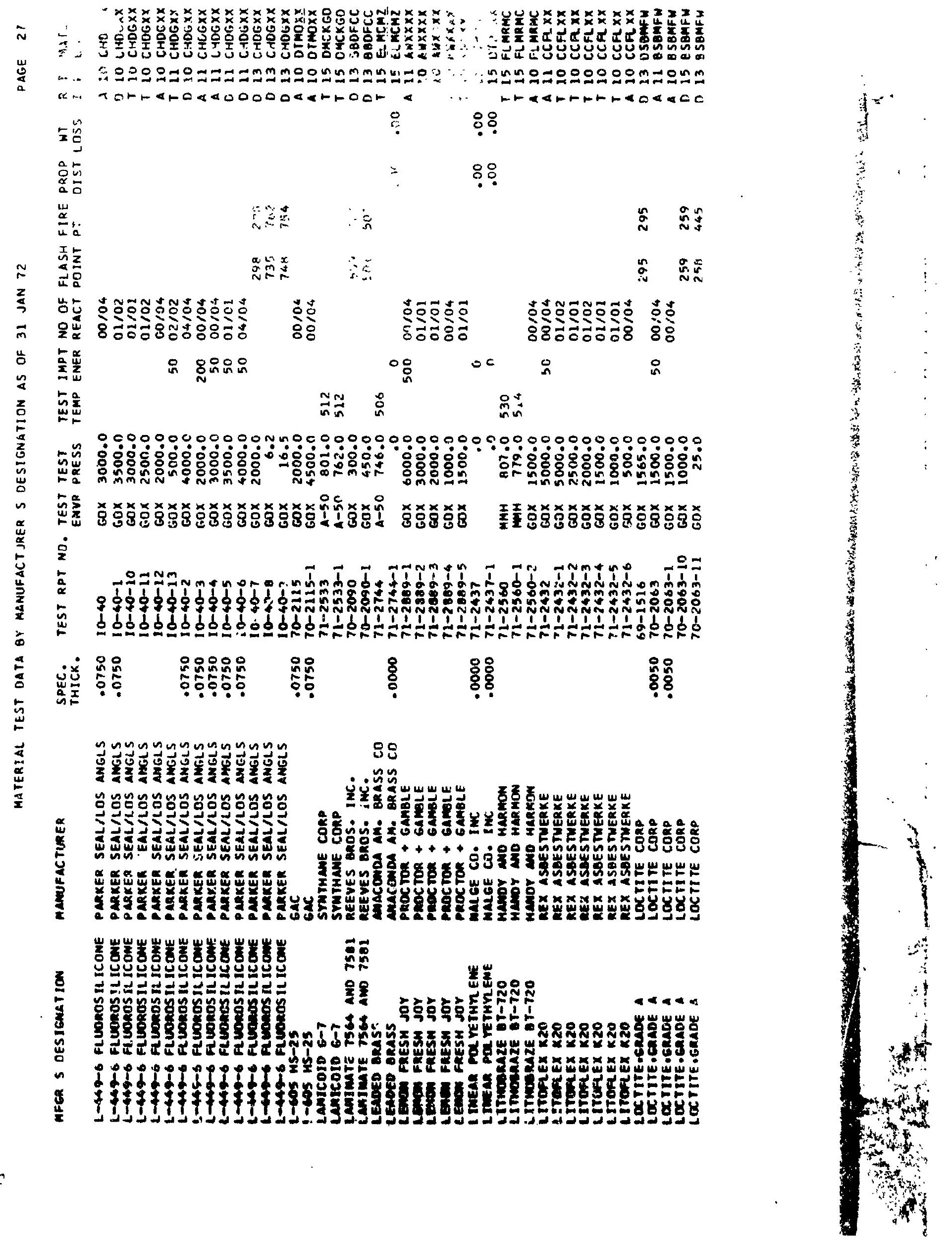




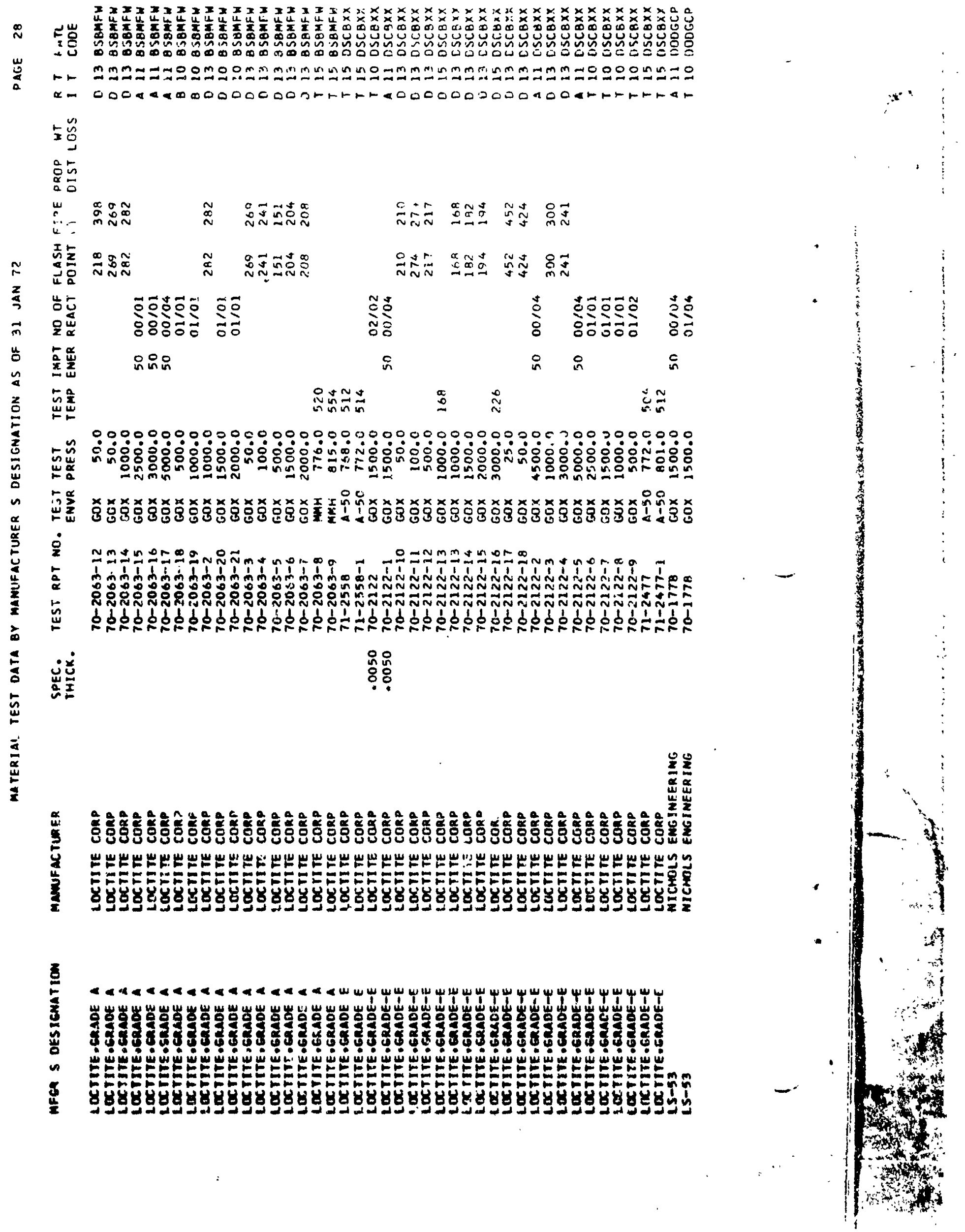




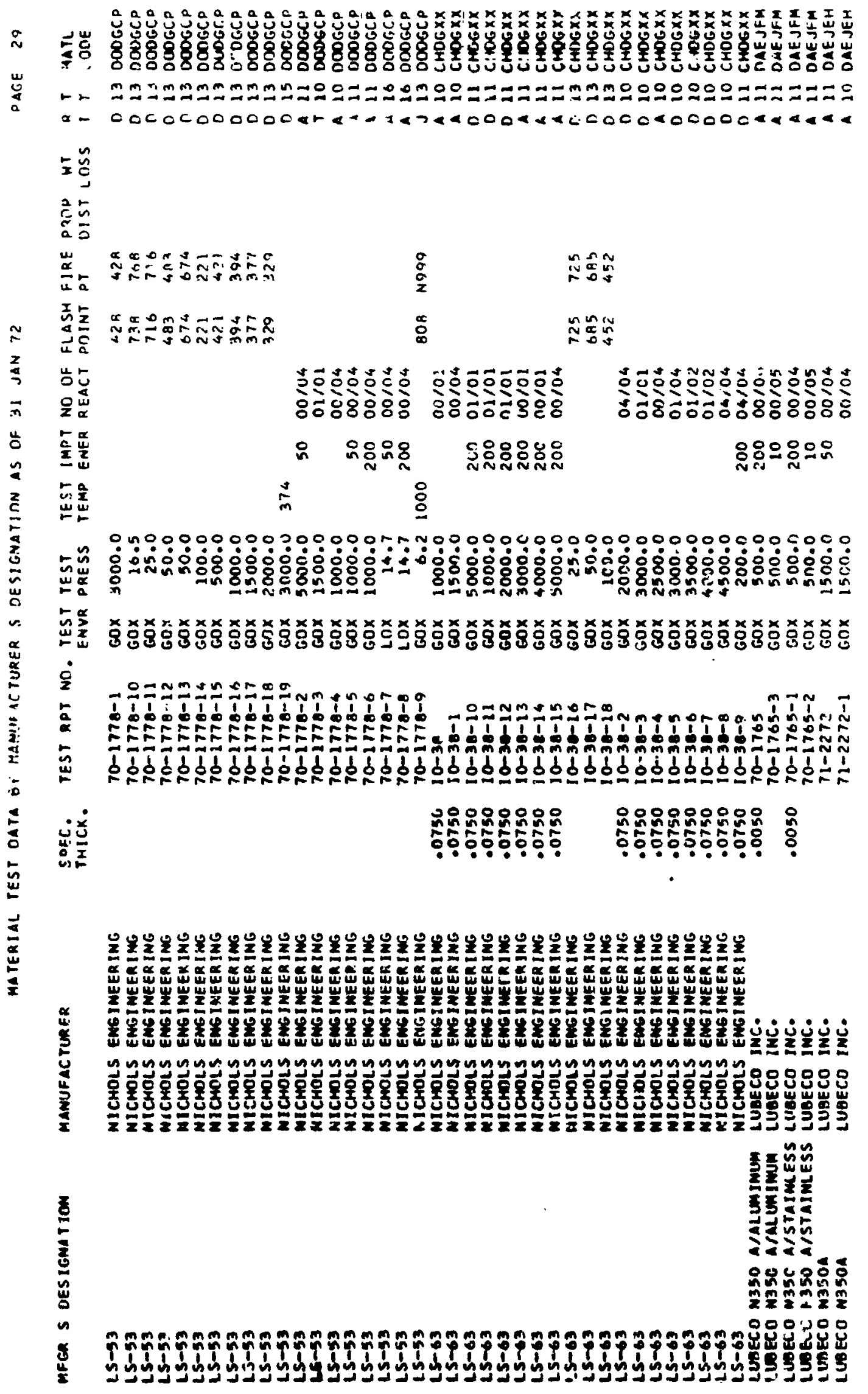




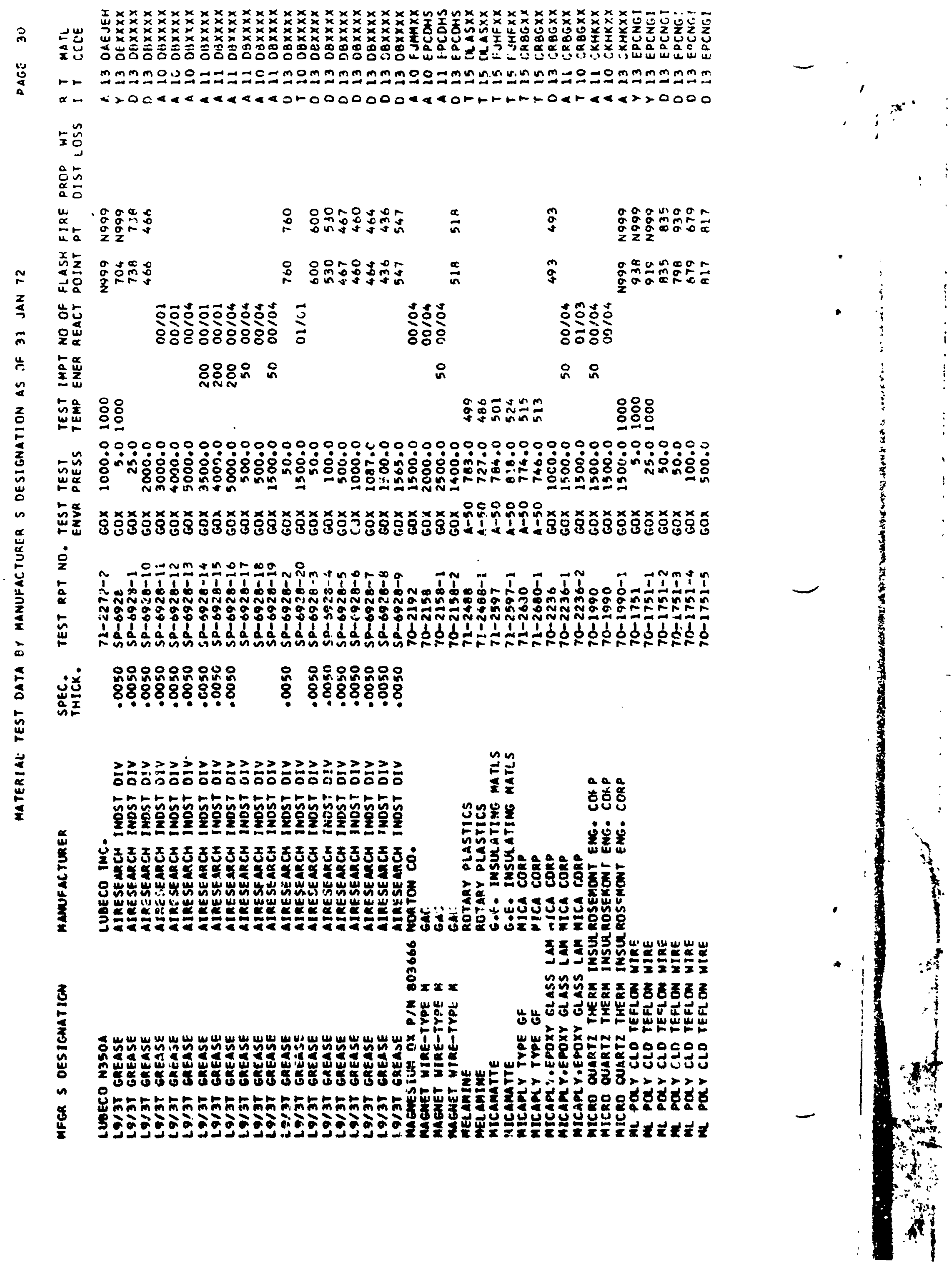




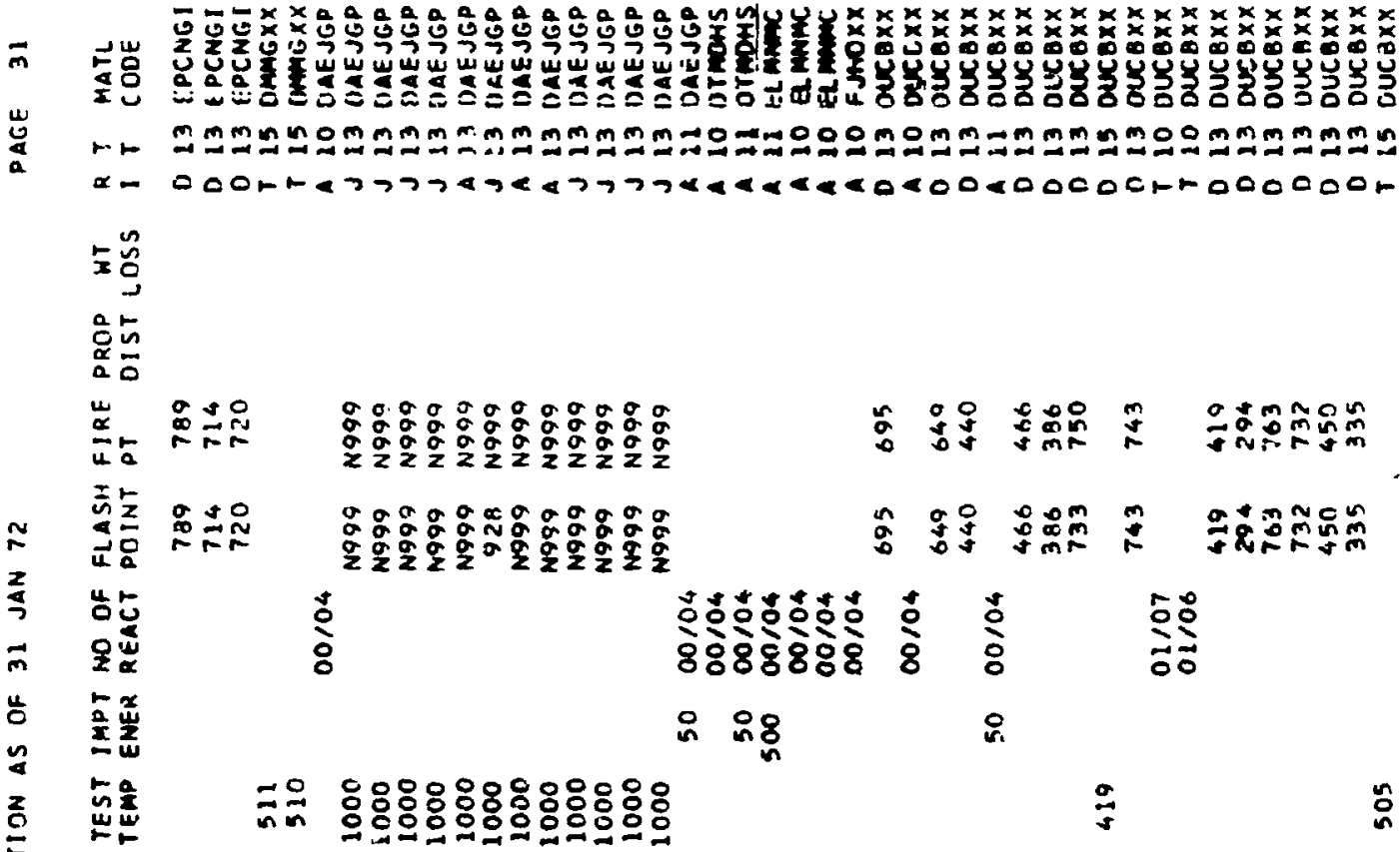

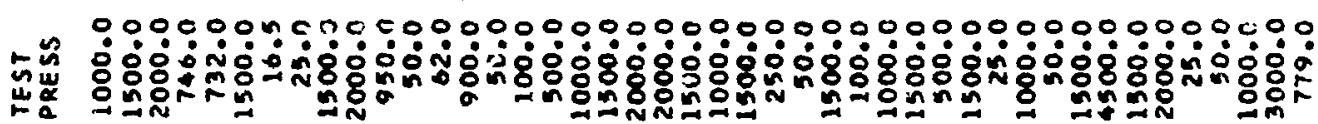

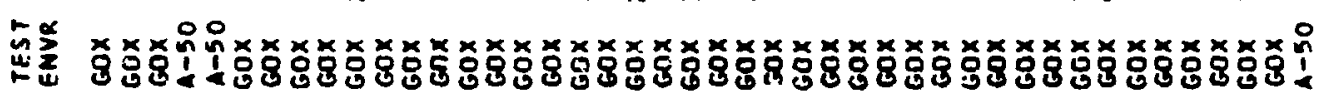
$\dot{\mathrm{i}}$

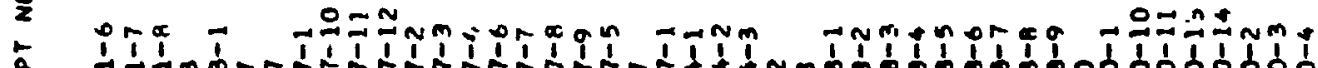

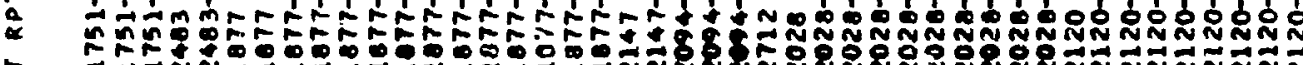

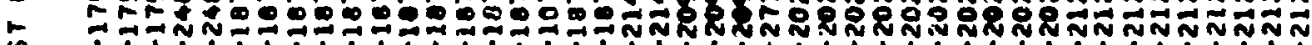

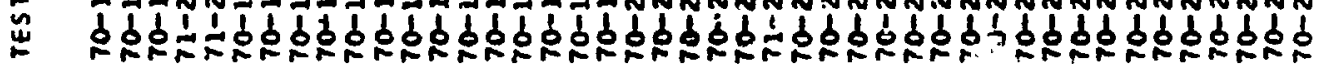

递总

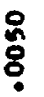

品号:

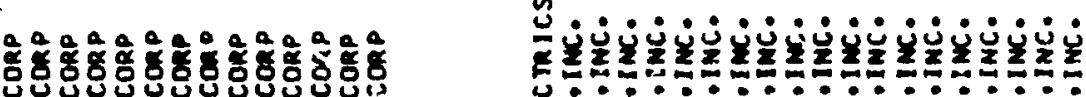

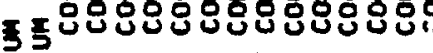

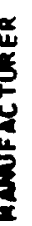

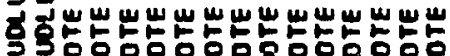

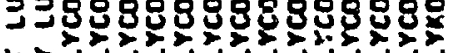

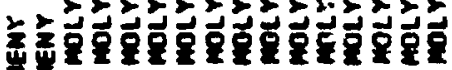
s்ं宀்

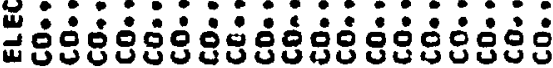

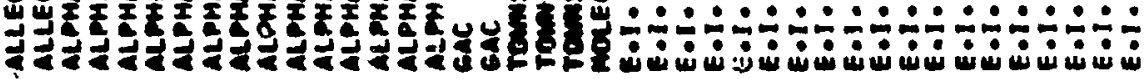
送崖

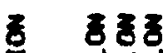

年

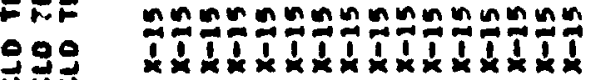

త d

88

กิ山

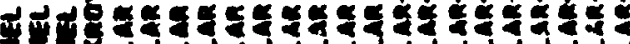

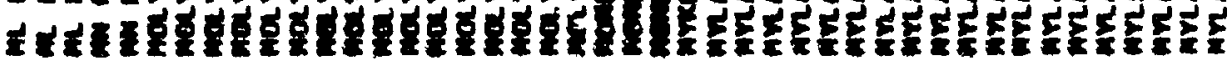




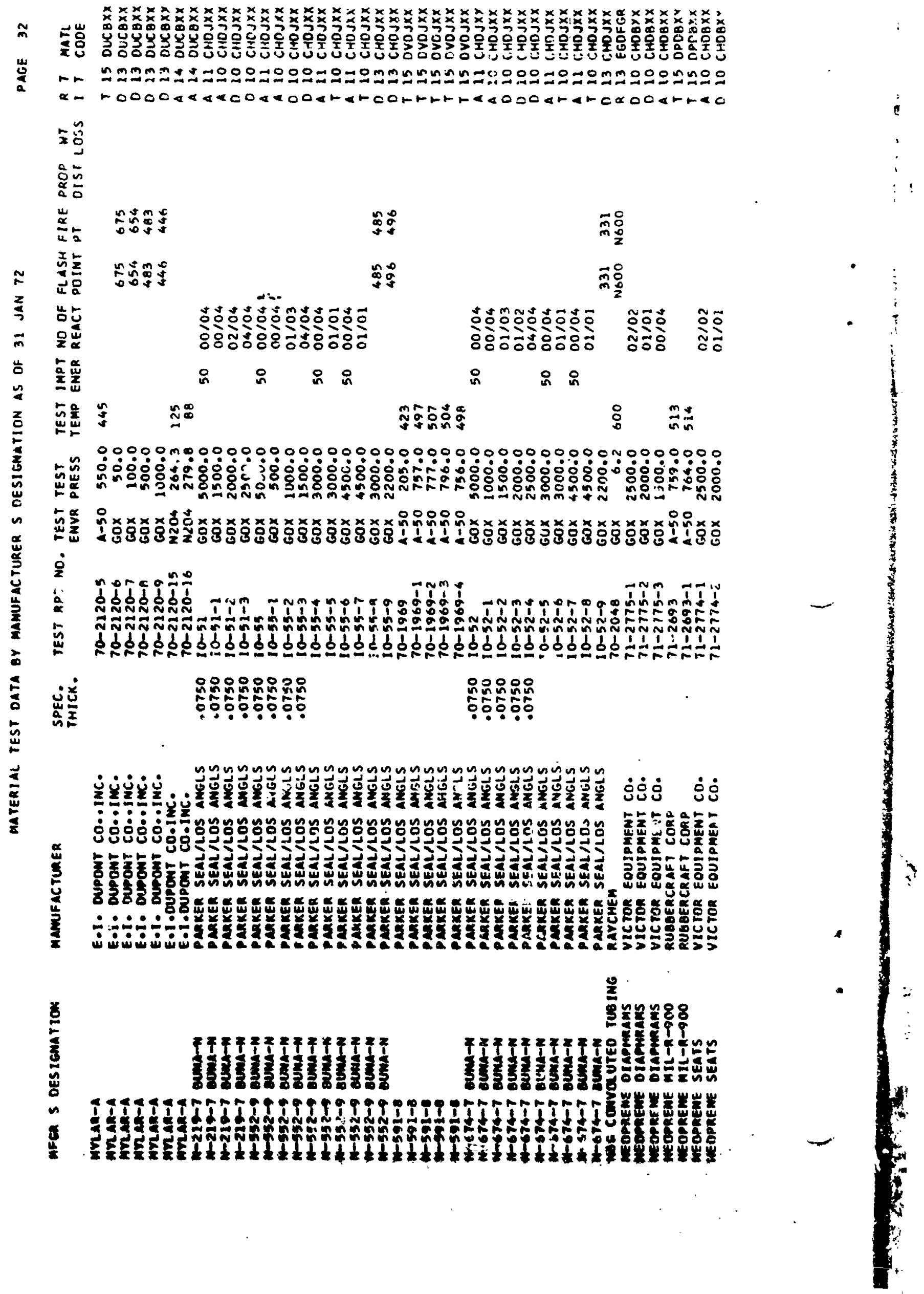




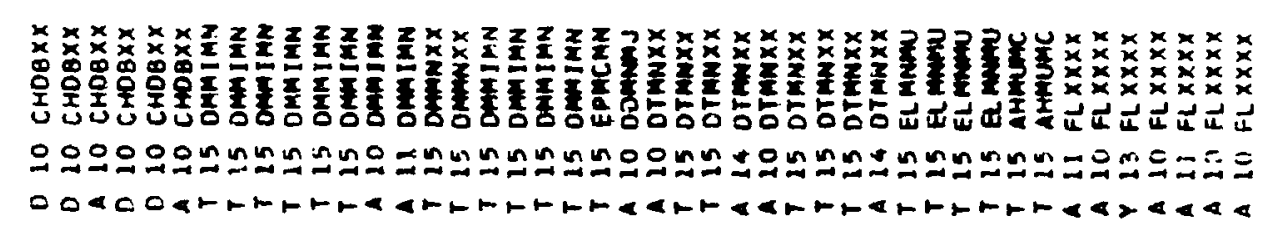

$\tilde{x}$

:

岮点

*).

垫

䓃育

อิำํำำ

응ํํ영

웡ㅇㅇㅇ

ํํㅇํํ

$\frac{\sigma}{2}$

.

in

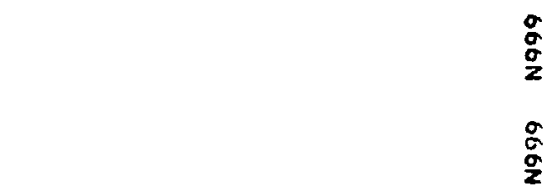

$\frac{2}{2}$

号疍

於客

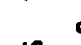

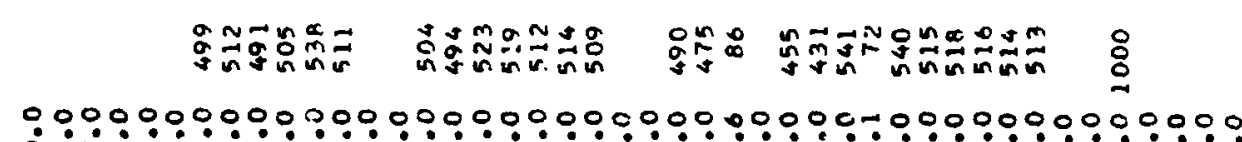

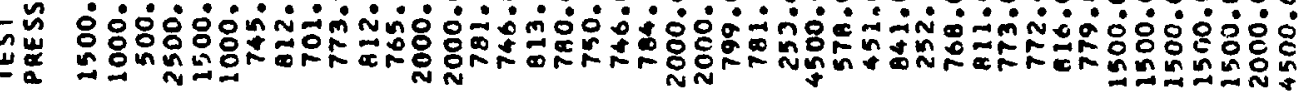

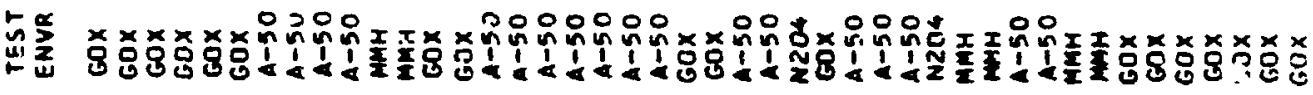
$\dot{\mathrm{g}}$

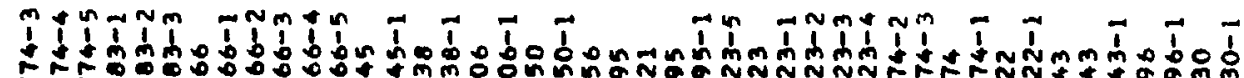
NNN

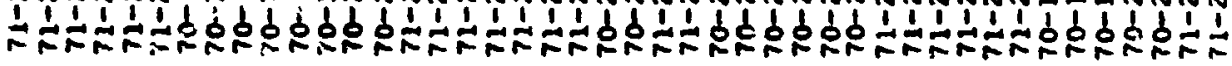

递总

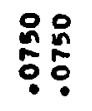

:

(5)
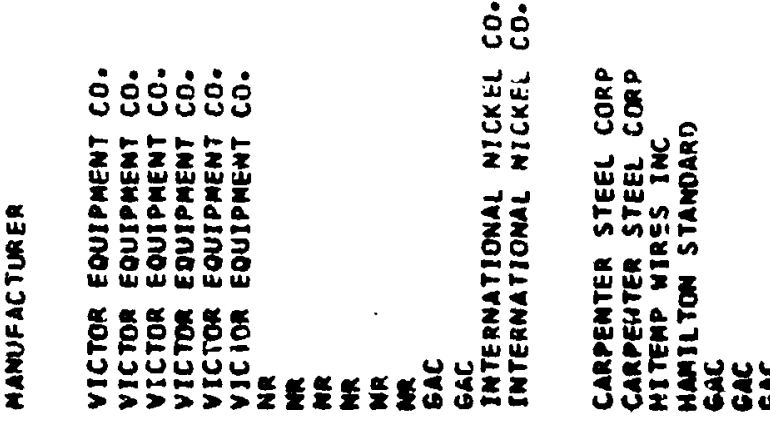

恼

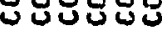

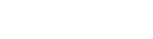

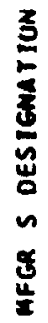

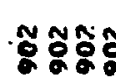

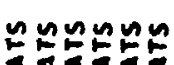

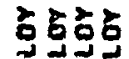

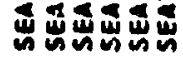

दूखे

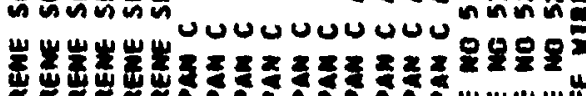

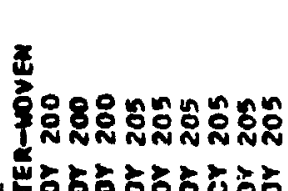

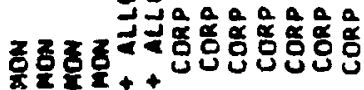

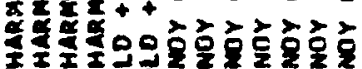

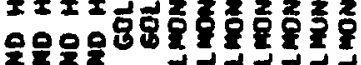

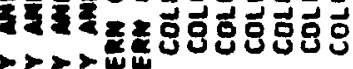

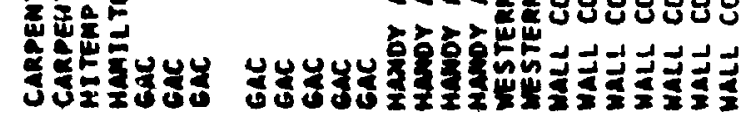




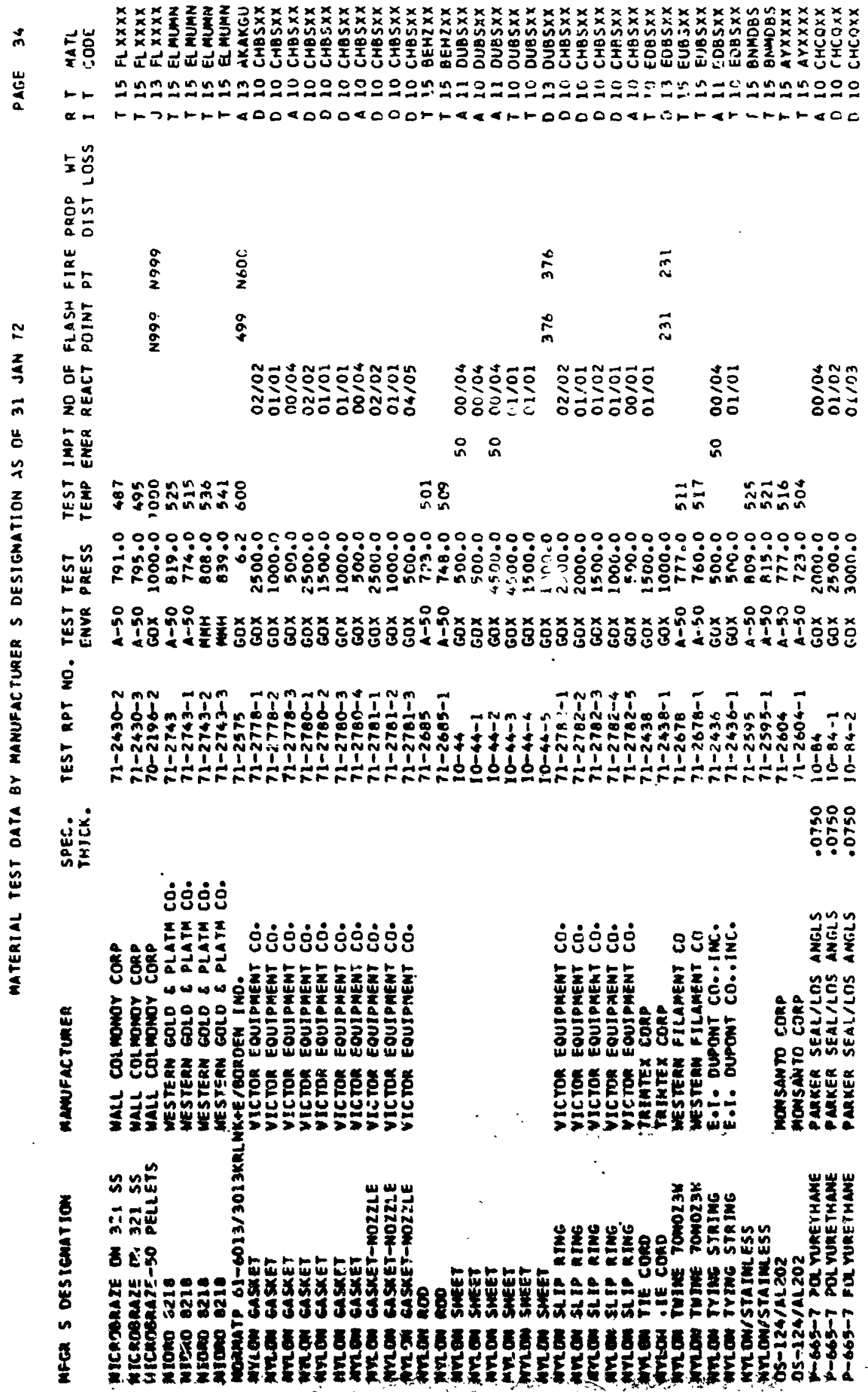




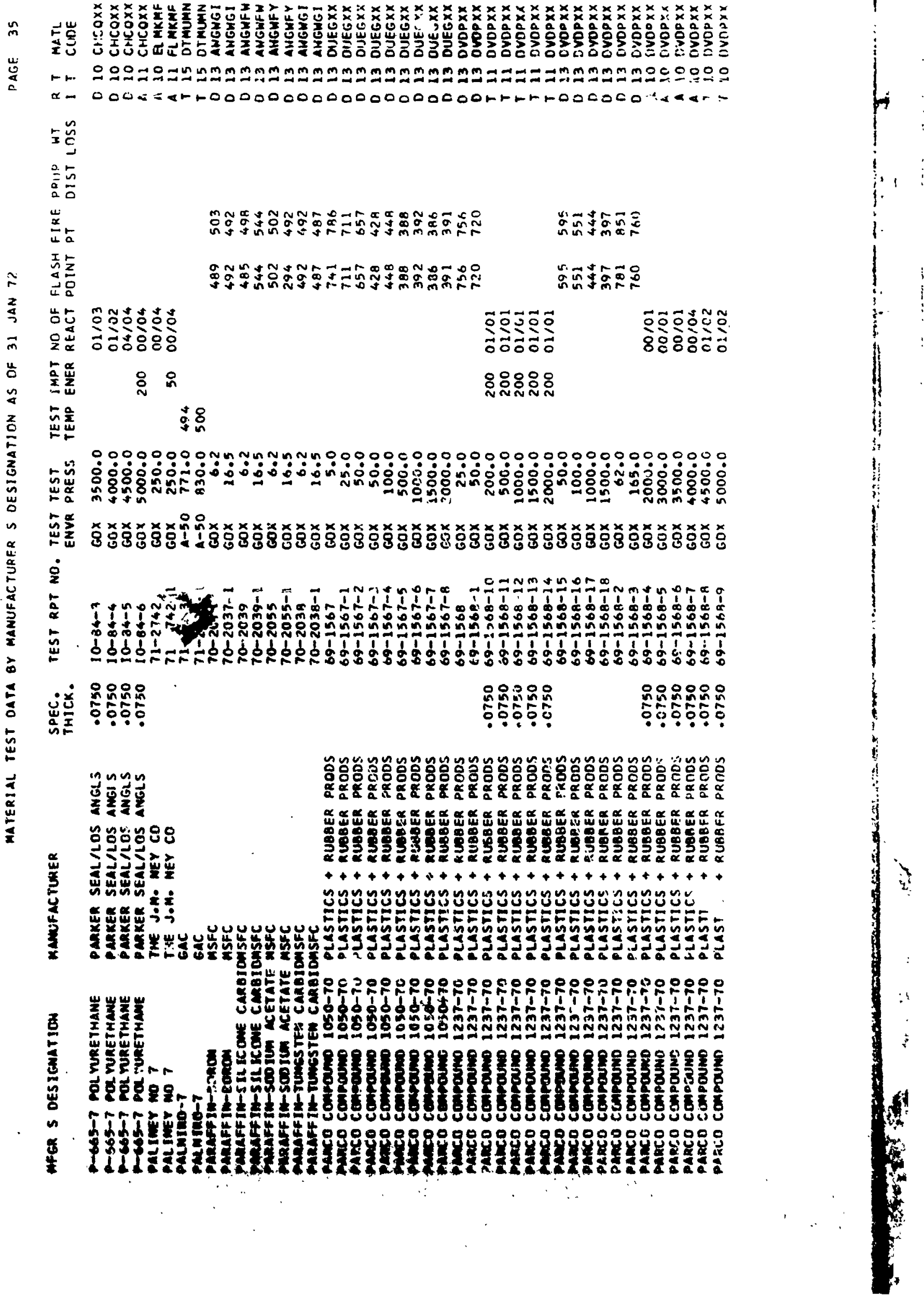




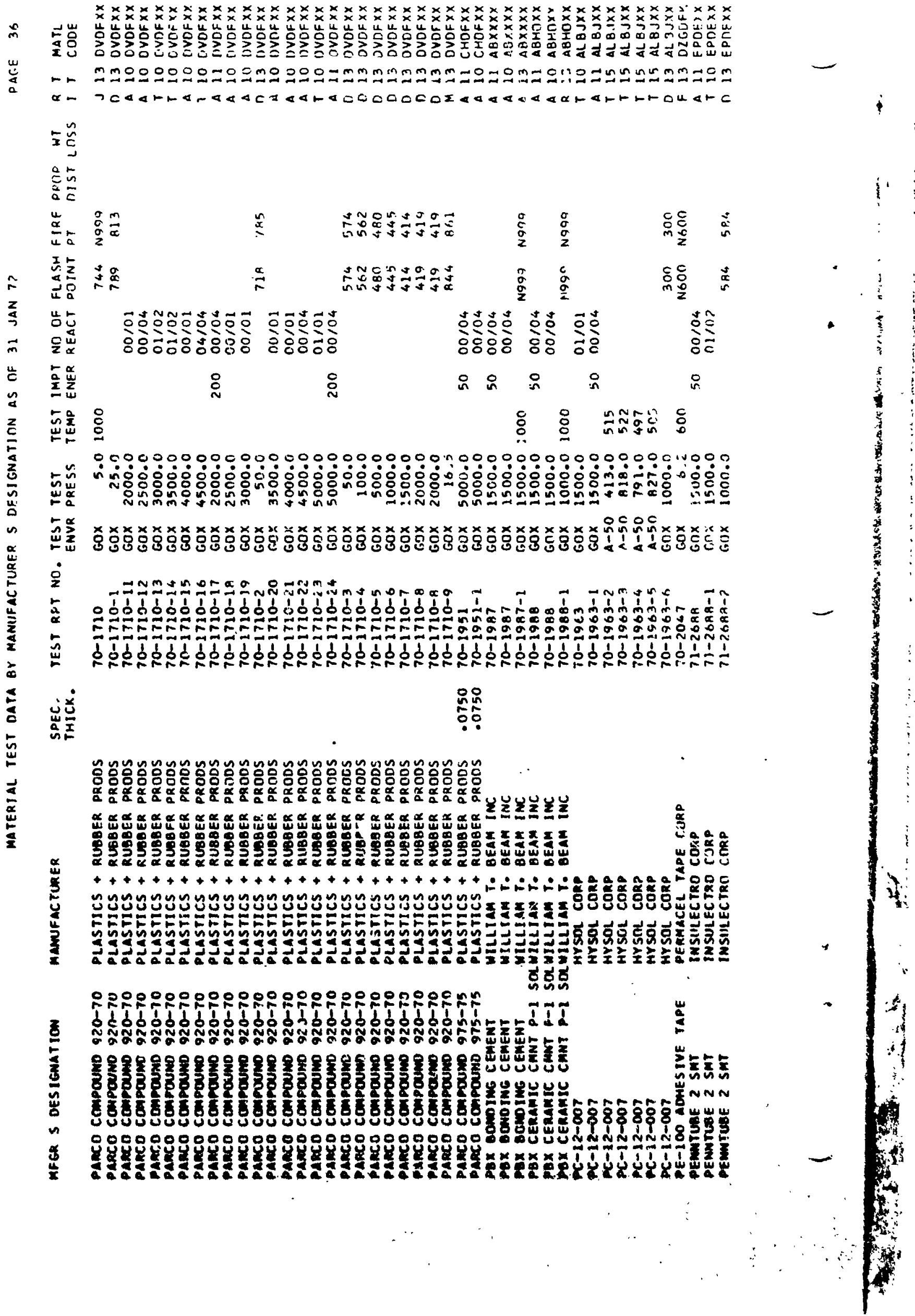




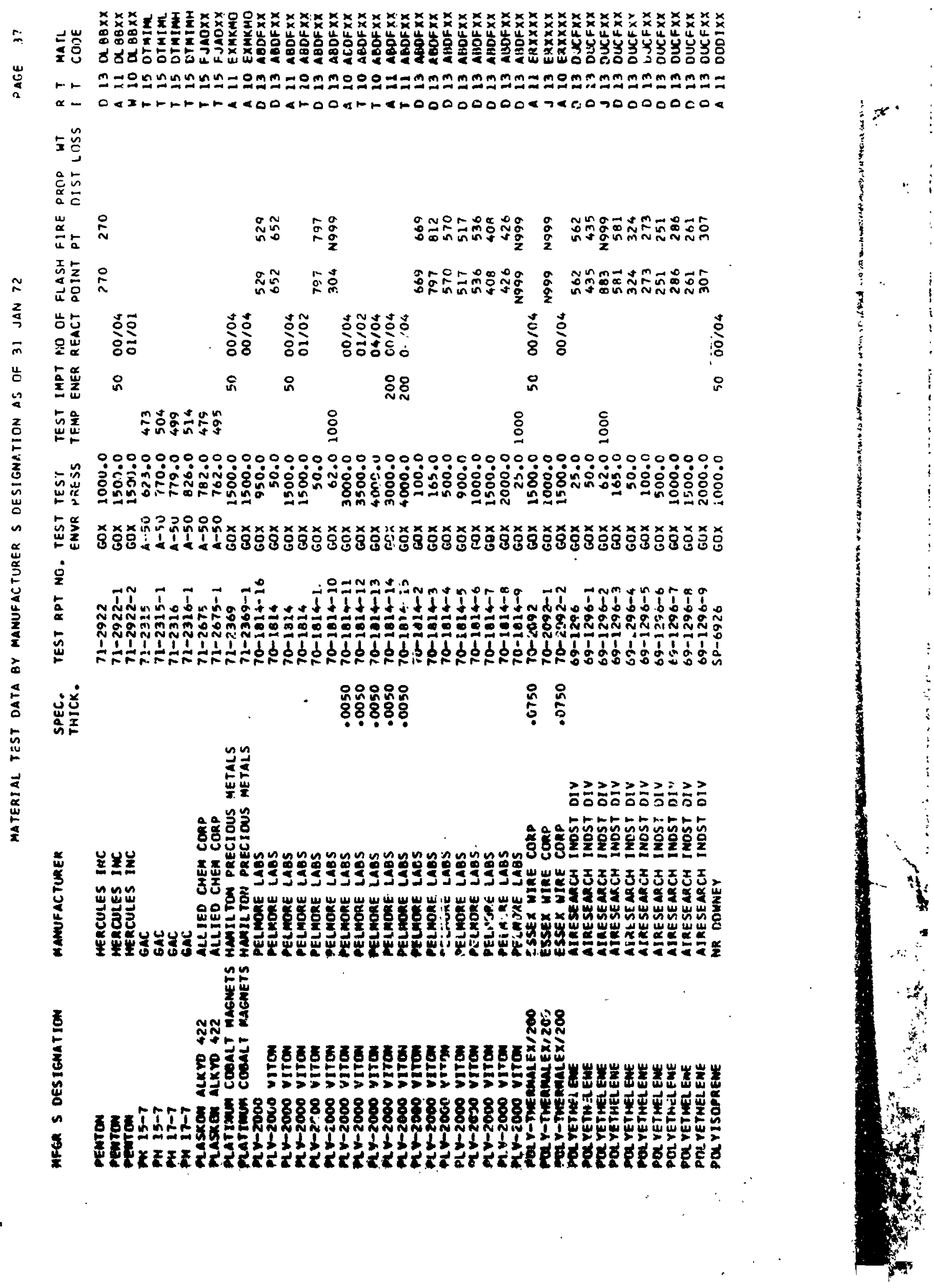




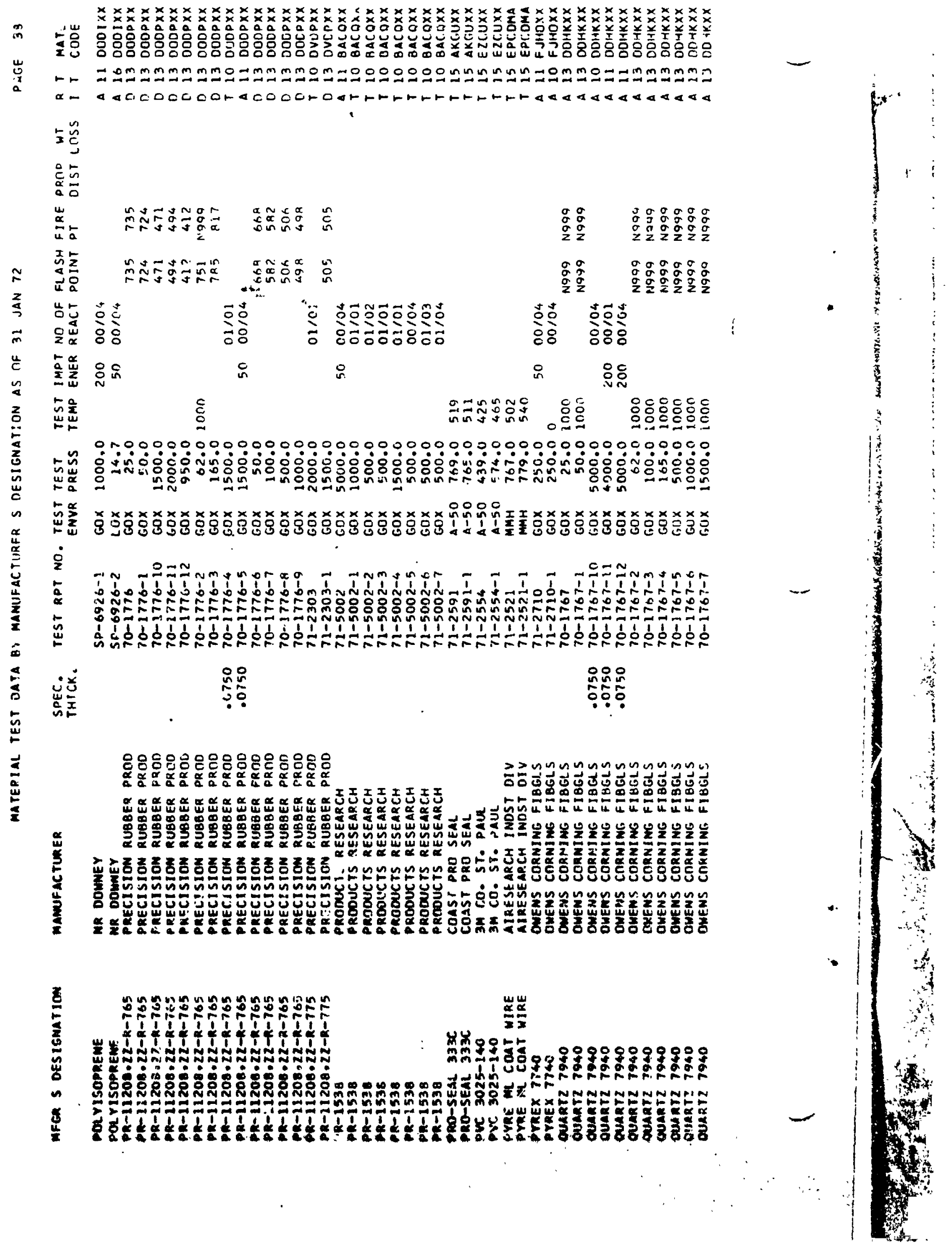




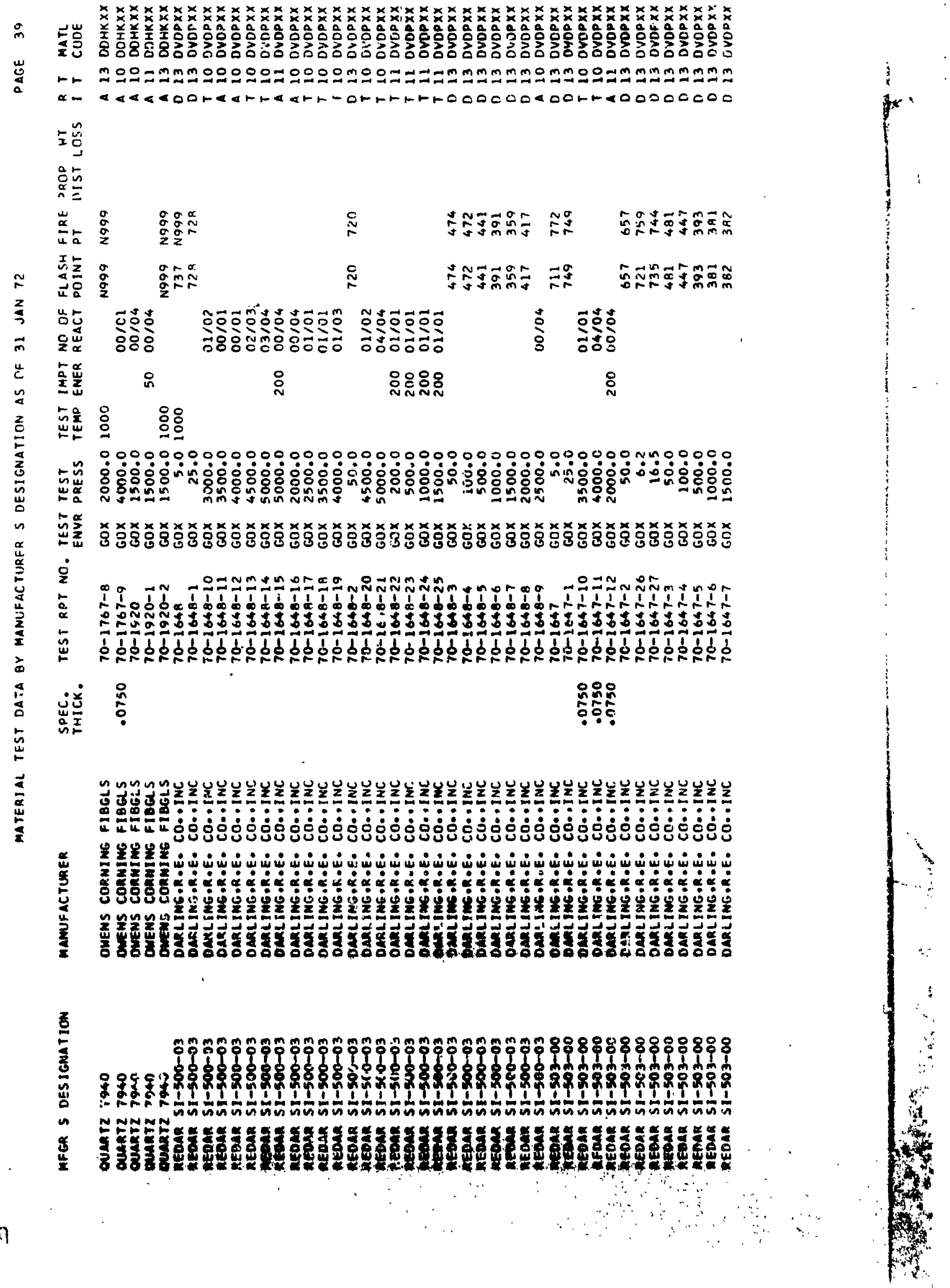




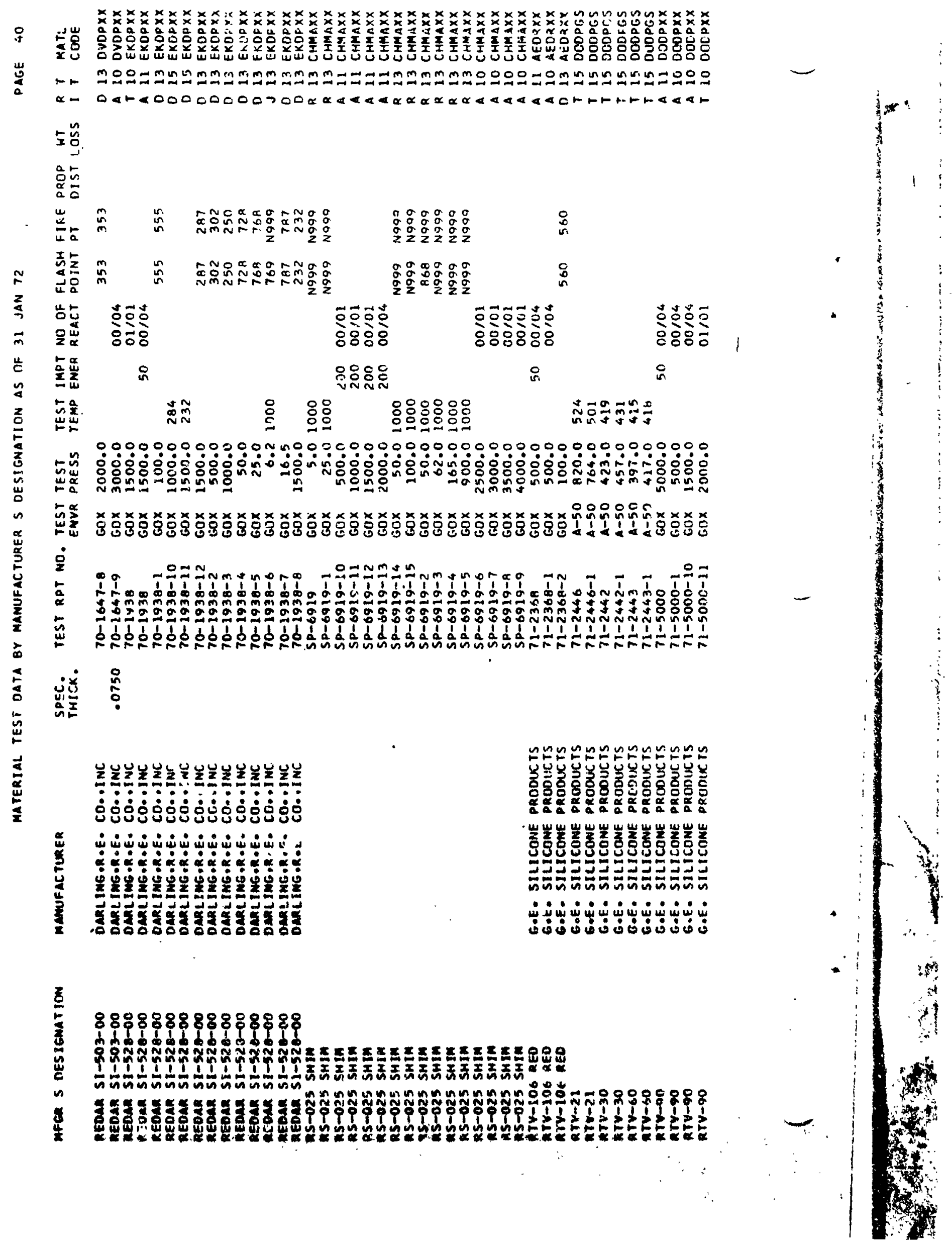




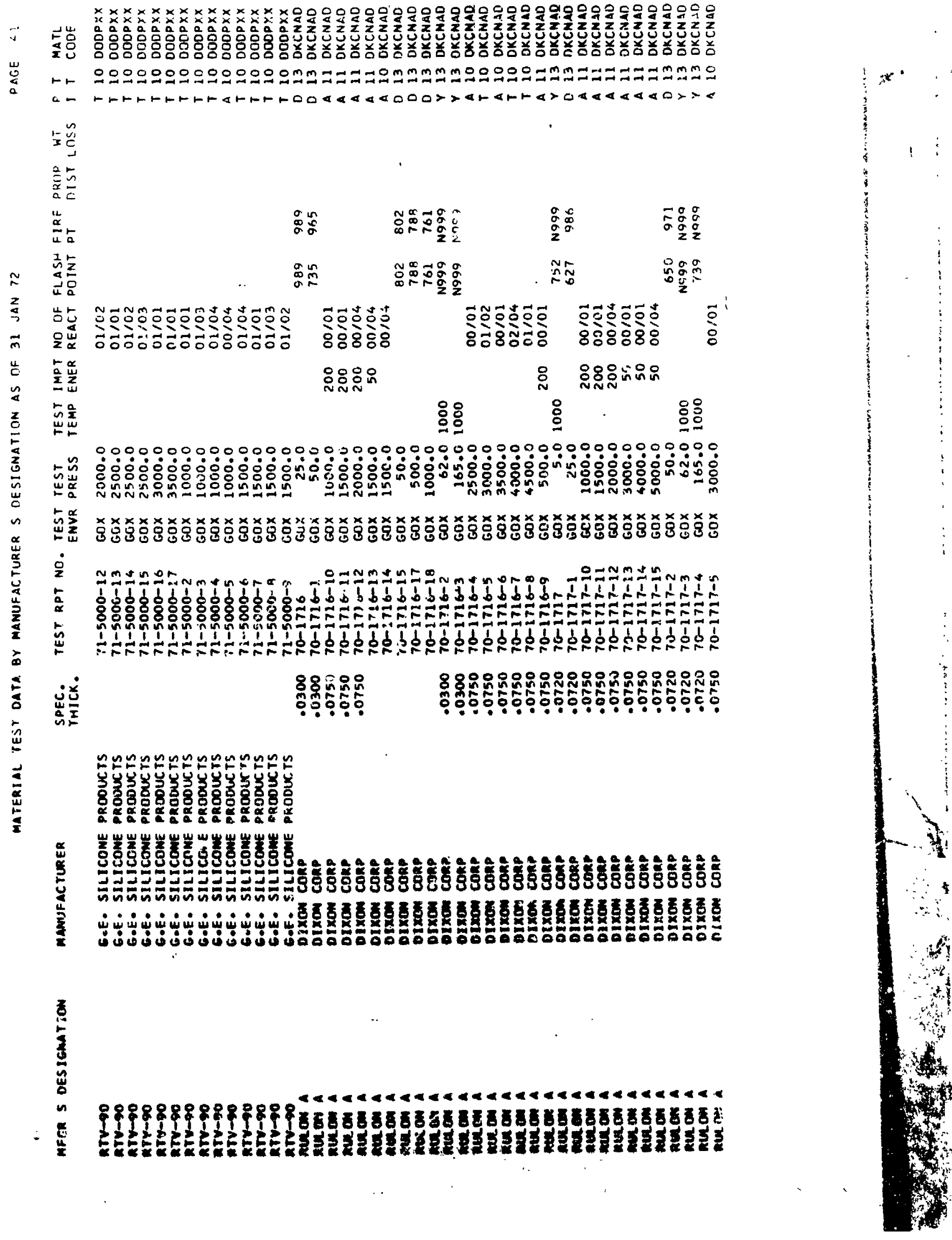



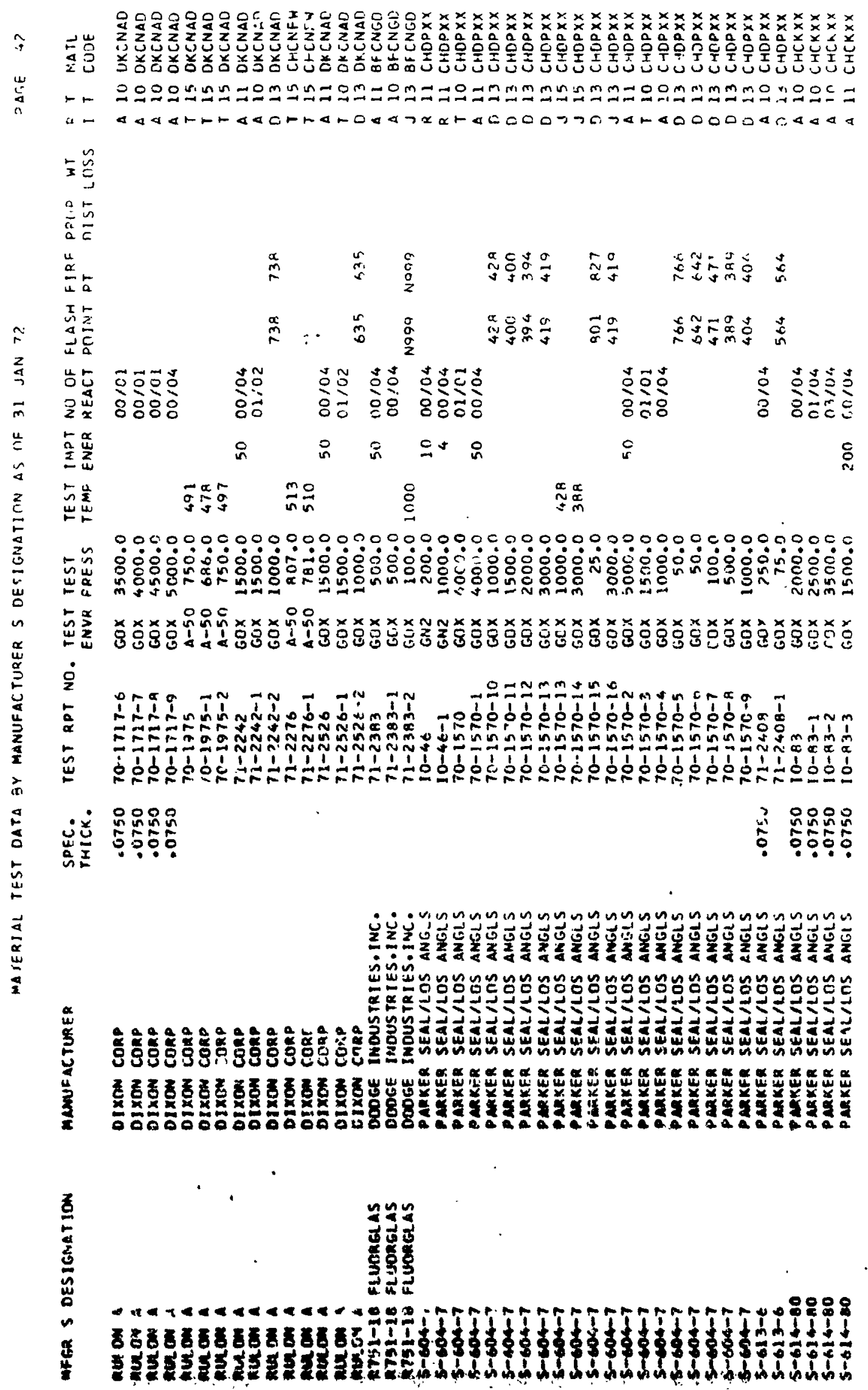


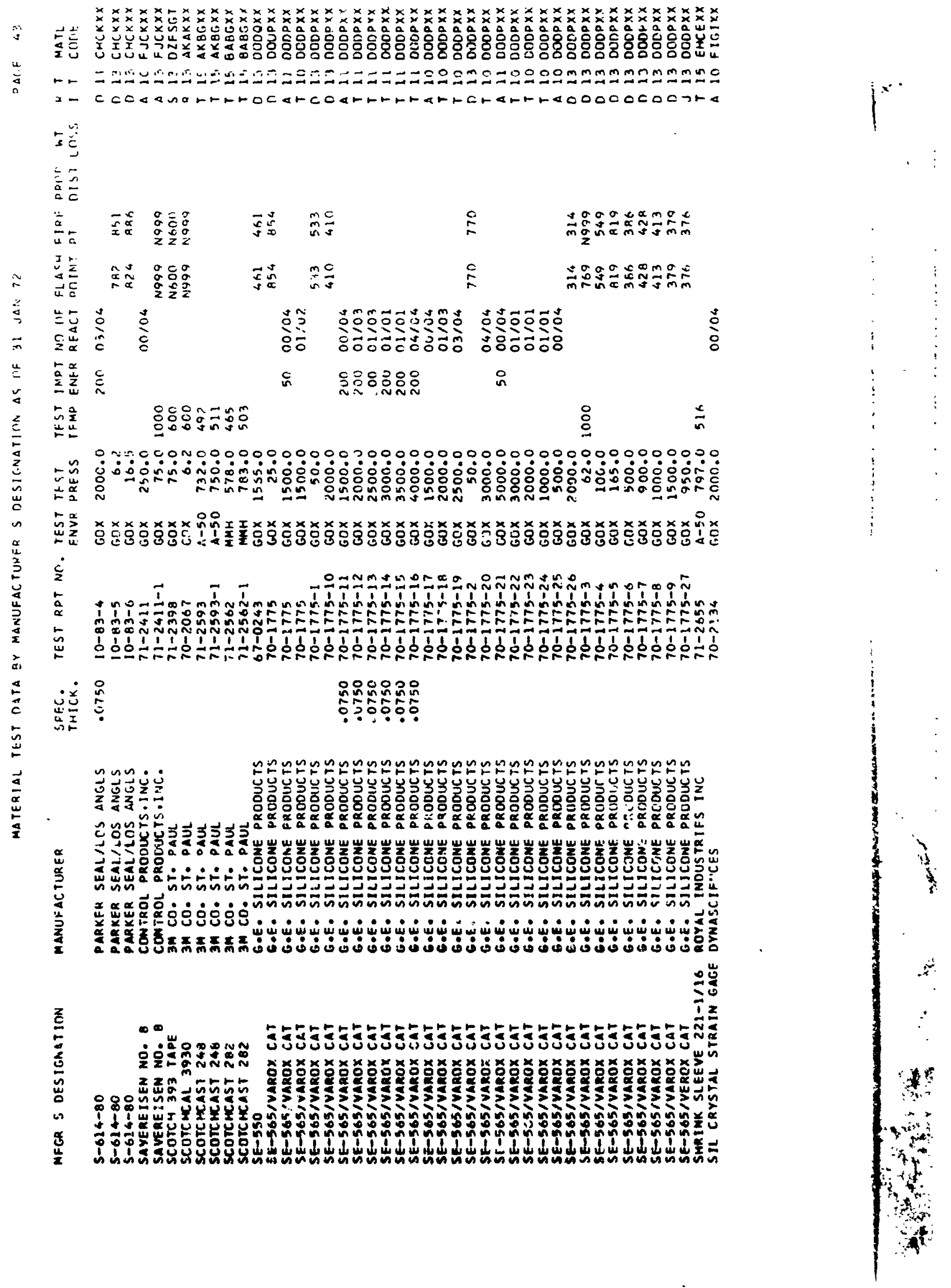





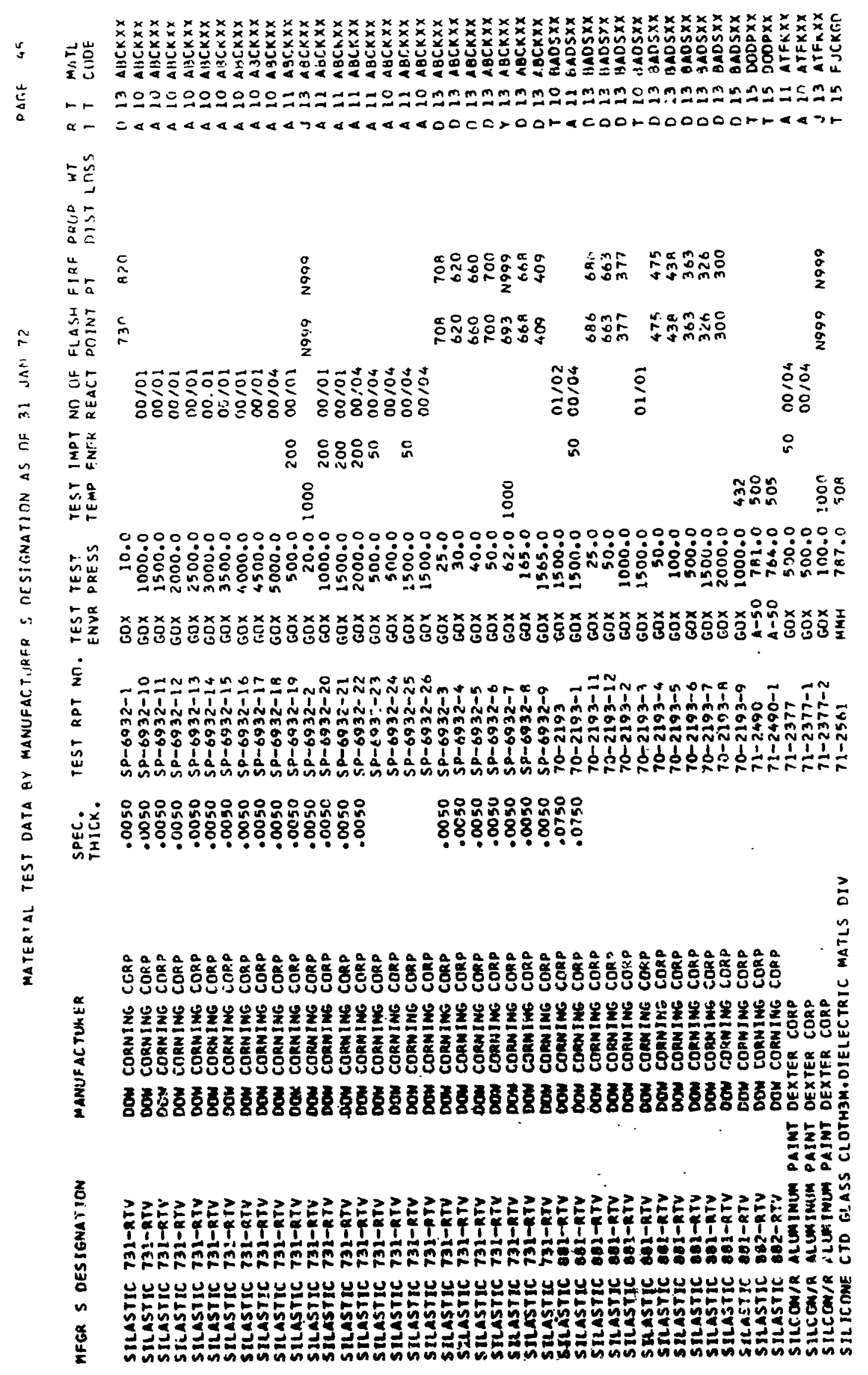




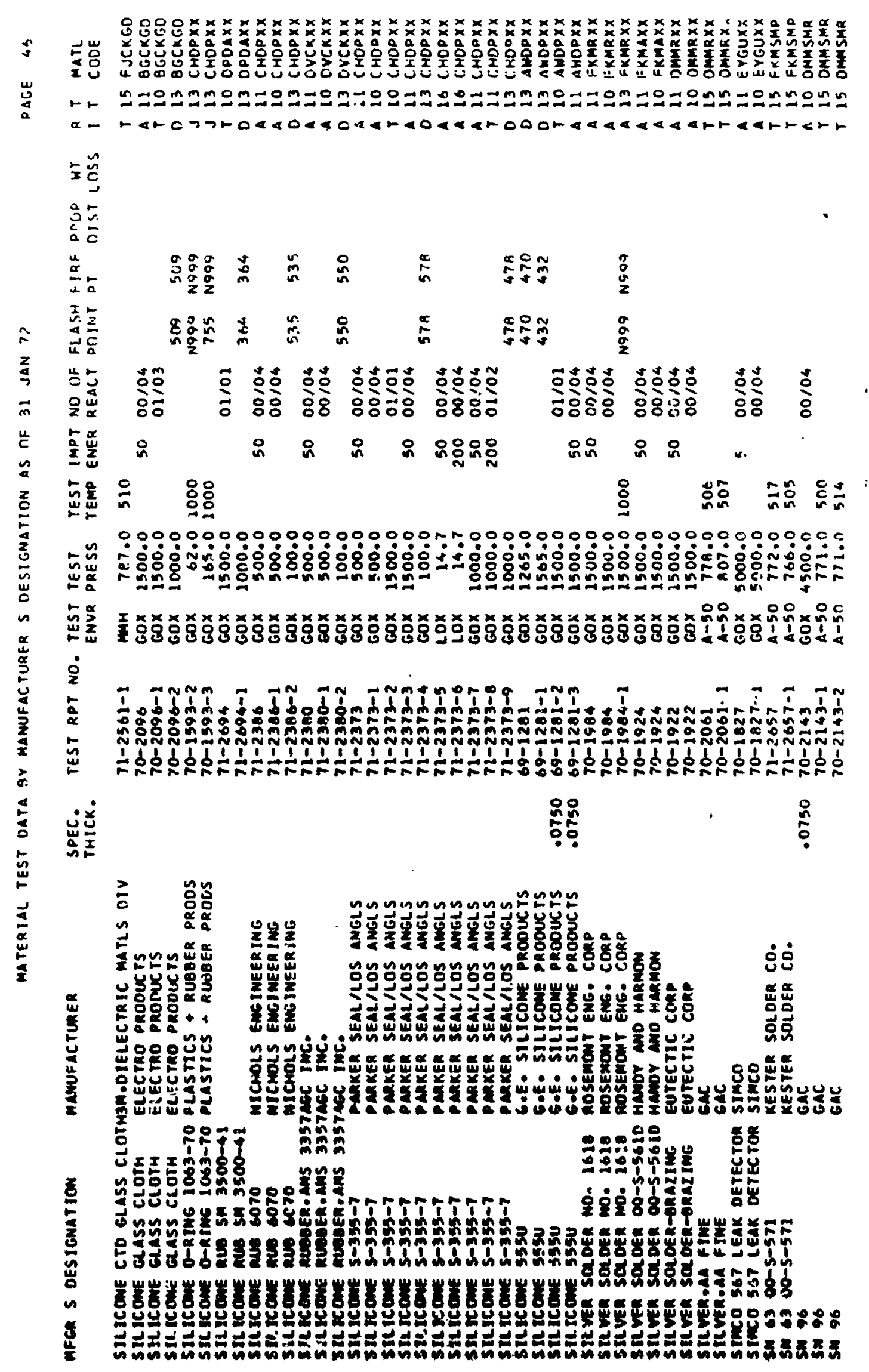




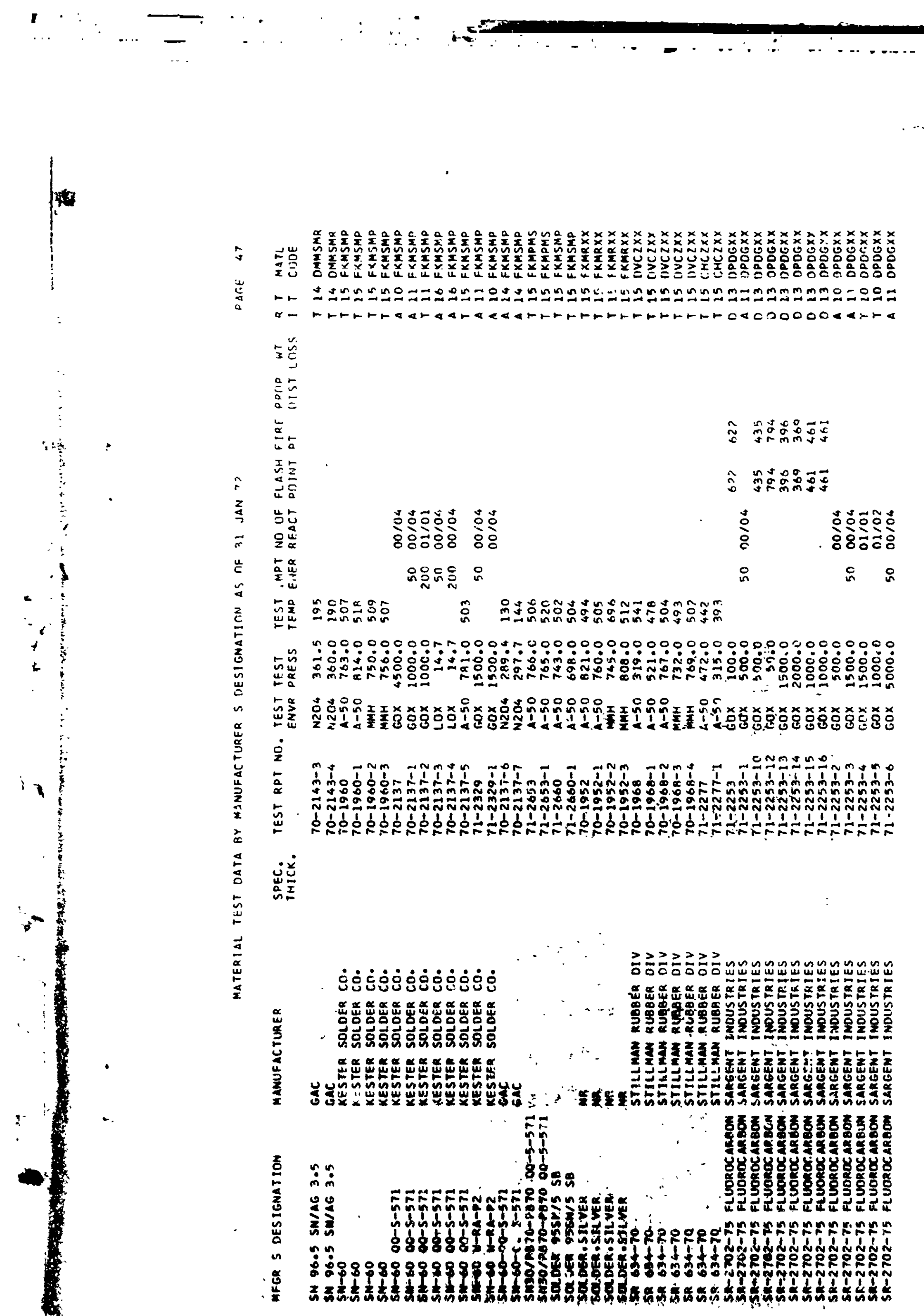




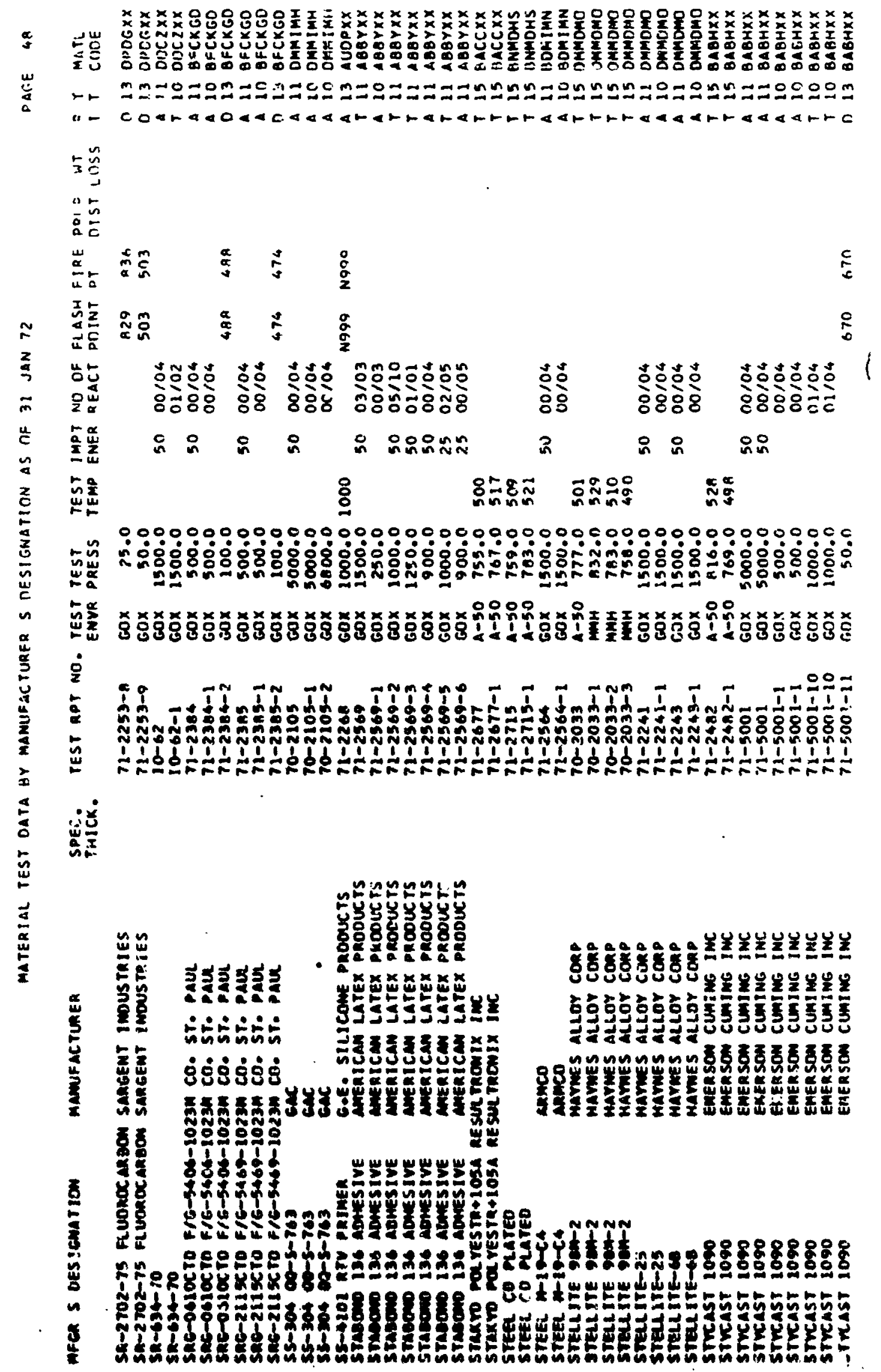




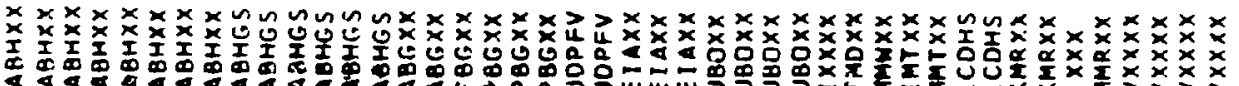

10

$\underline{x} \cong$

$\stackrel{0}{0} \frac{1}{0}$

$\stackrel{4}{a}$

แ⿺辶

$\approx \quad \frac{I}{4} \frac{\pi}{4}$

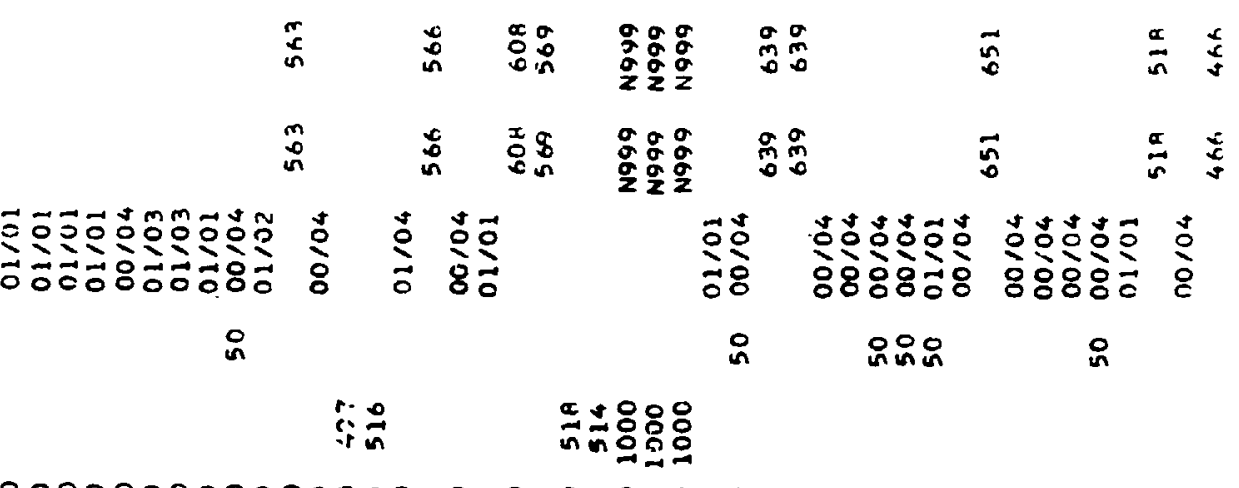

0000000000?0000000?000000000000000000000000=

ヶ

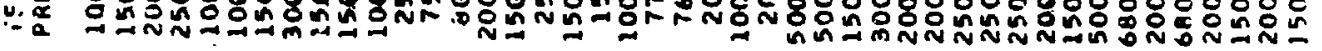

$\stackrel{n}{\omega} \sum_{i=1}^{\infty}$

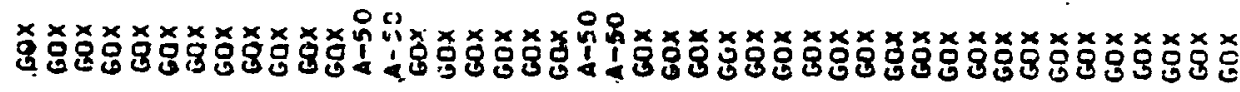

$\dot{c}$

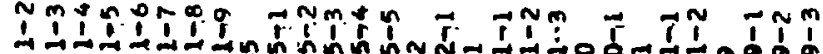

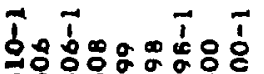

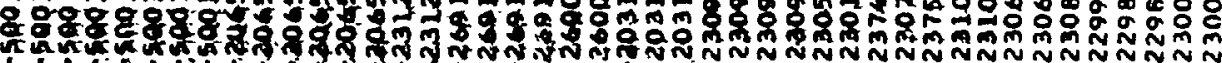

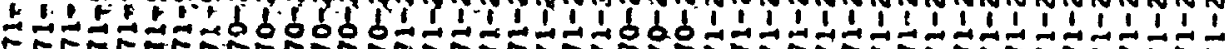

递总

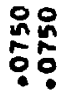

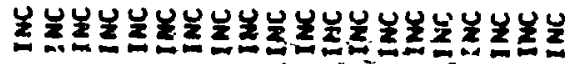

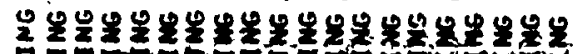

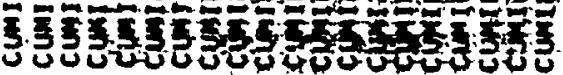

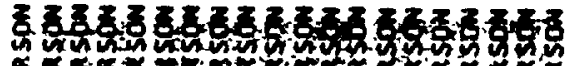

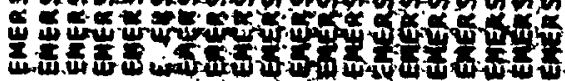

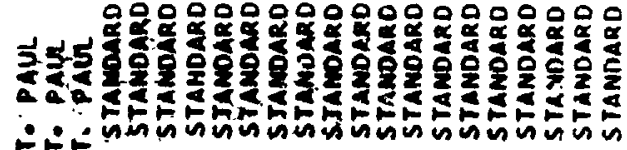

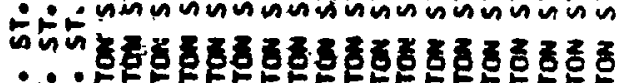

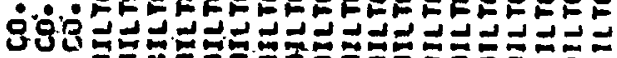

플

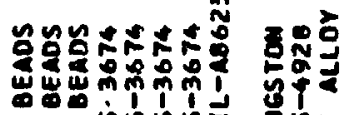

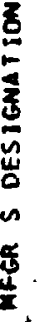

acosogaco

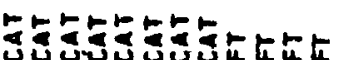

ñuñ

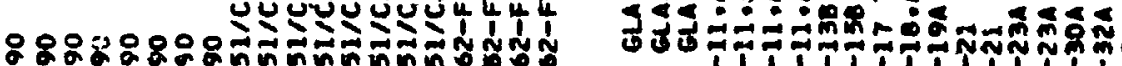

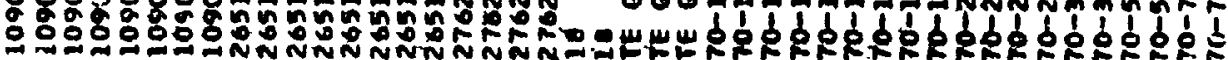

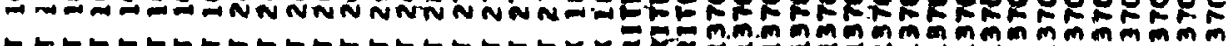

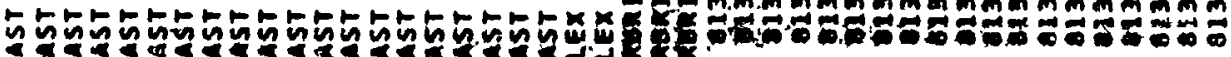

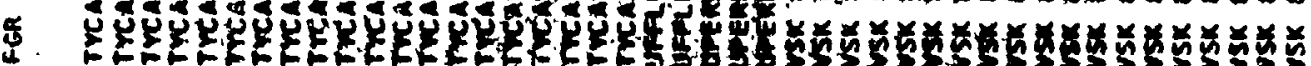

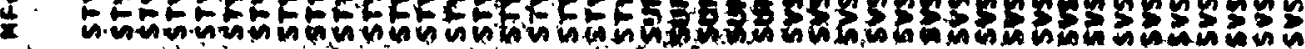


$\propto$

6

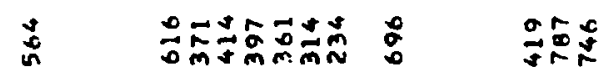

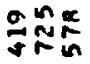$$
\text { 只 }
$$

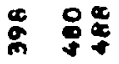

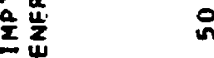

유요

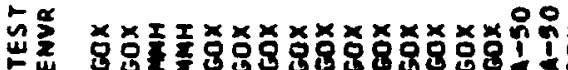

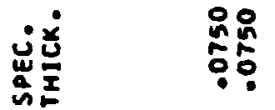

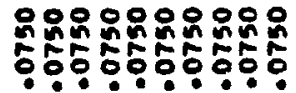

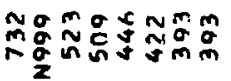

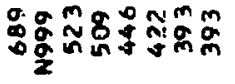

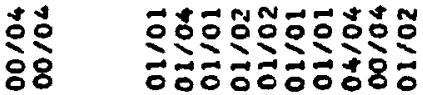
$\begin{array}{lll}8 & 80 \\ 8 & 8\end{array}$
ㅇํㅇ
客

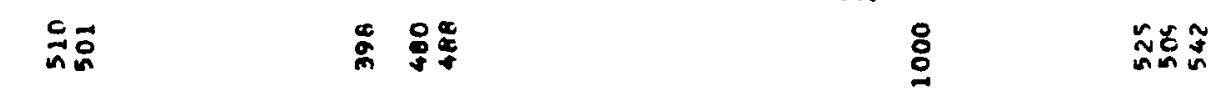

$000000000000000000000000000000000 n 0000000000$

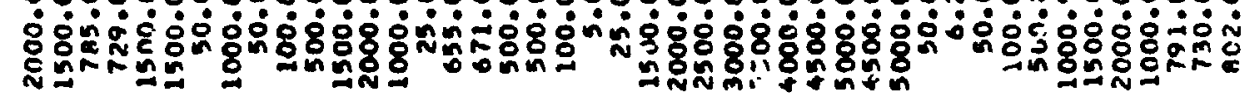

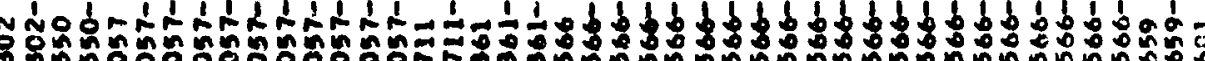

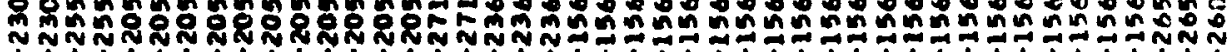

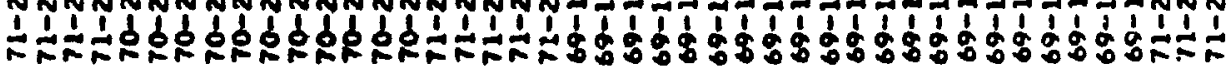

:

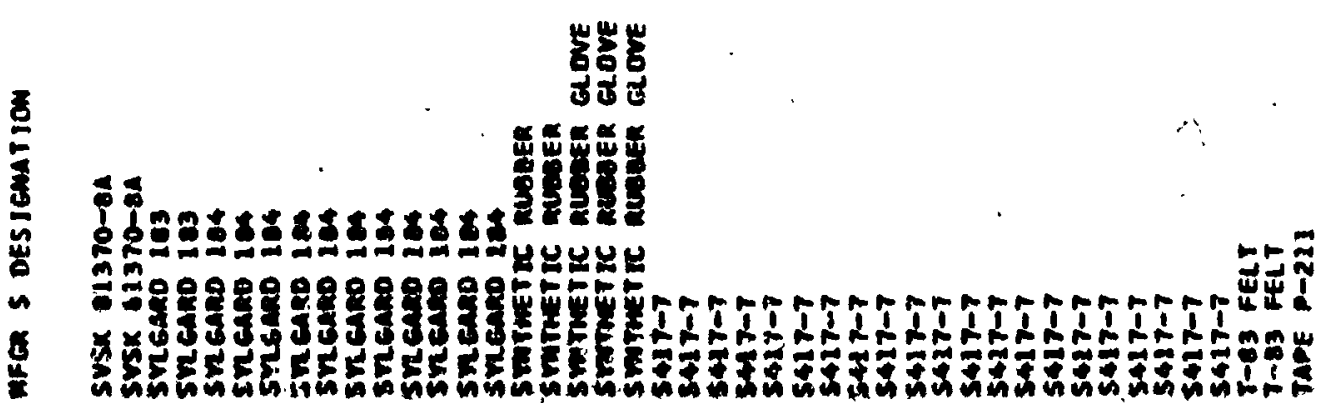




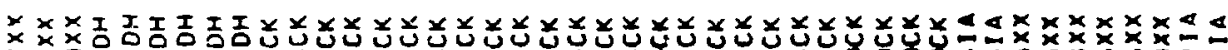

$\bar{n}$

岂

3

$\therefore \quad \frac{I}{4}$

3 范

$\vec{\sim} \quad$ 这

$\stackrel{t}{\mathrm{a}}$

$\therefore \quad$ 至

z 究恋



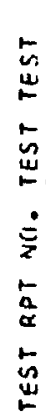

崫

$$
\text { in }
$$

mond

พี

$\frac{0}{\circ} \frac{g}{\sigma}$

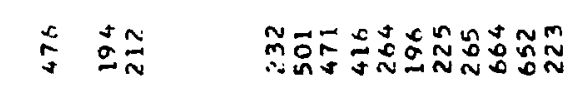

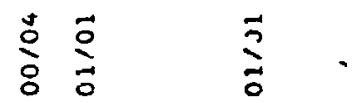

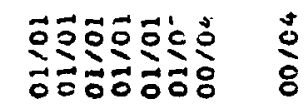

调品品品

年

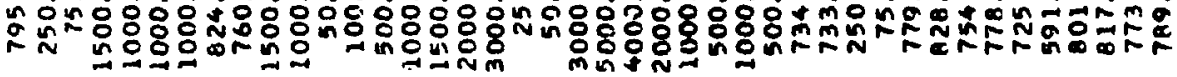

䠌

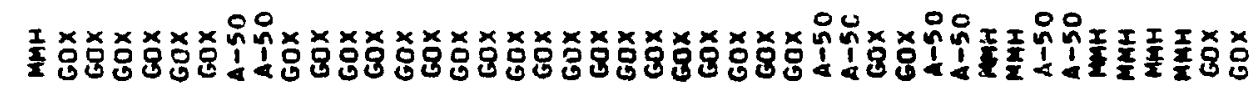

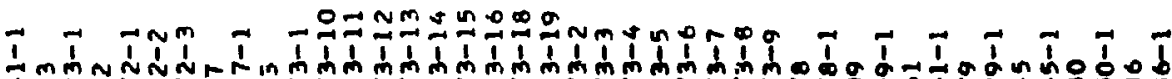

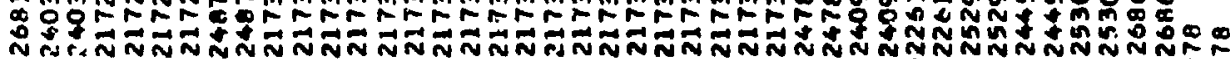

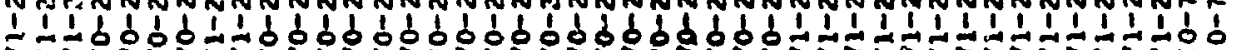

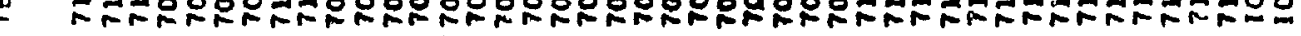

苔总

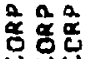

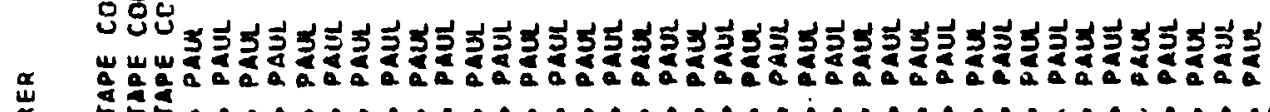

然

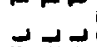

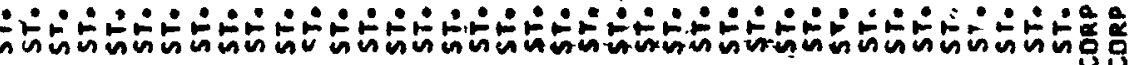

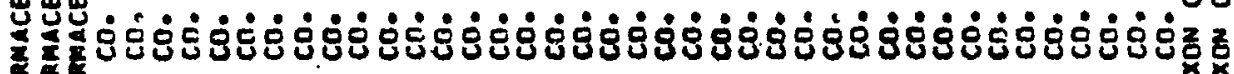

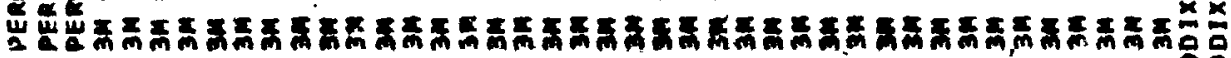

บิ

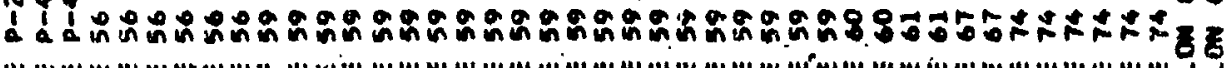

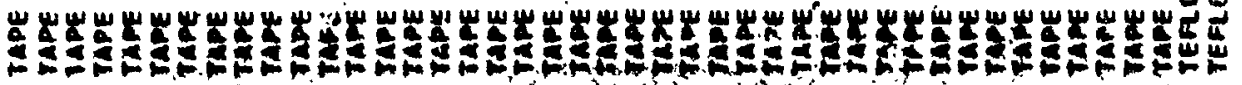



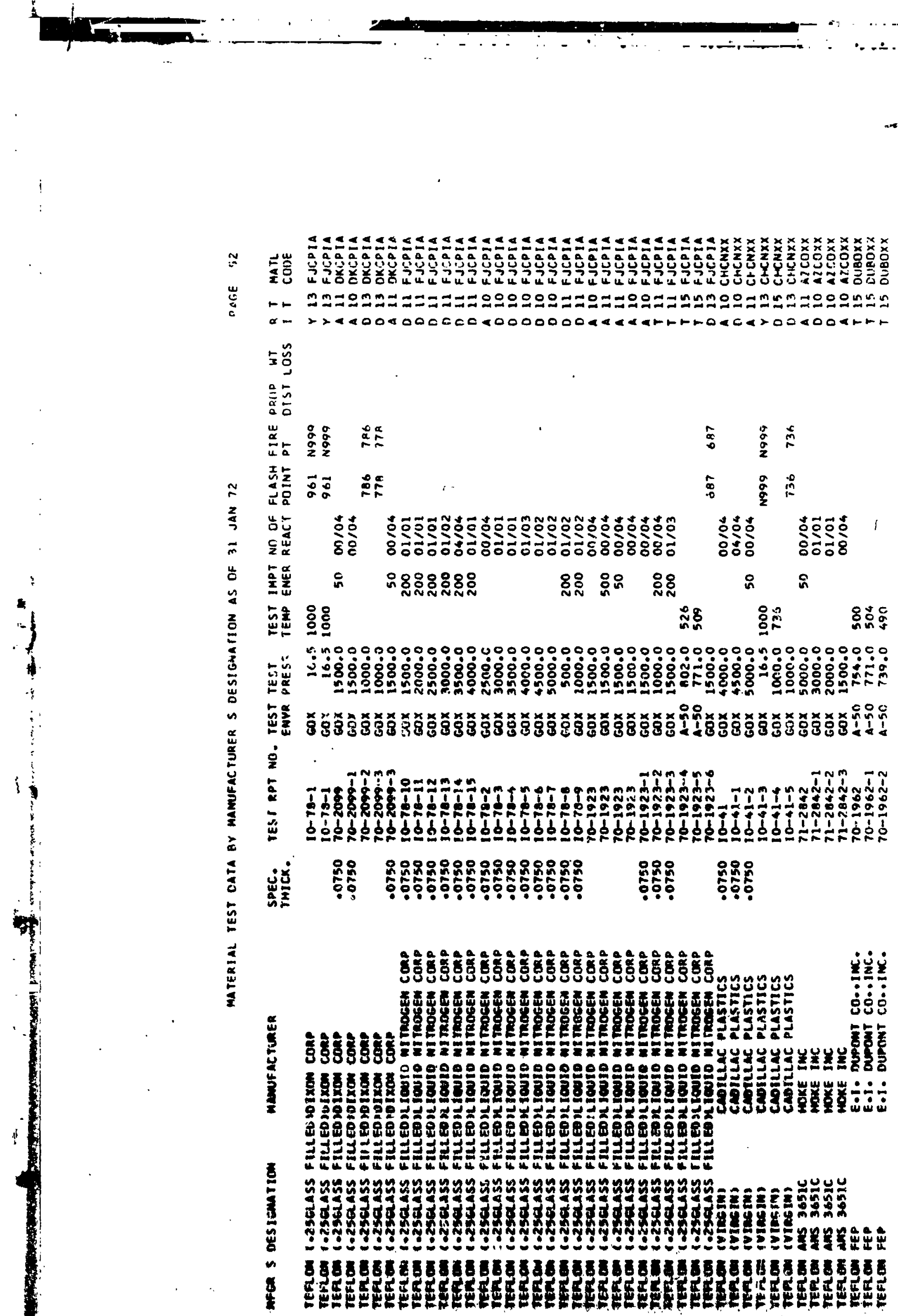



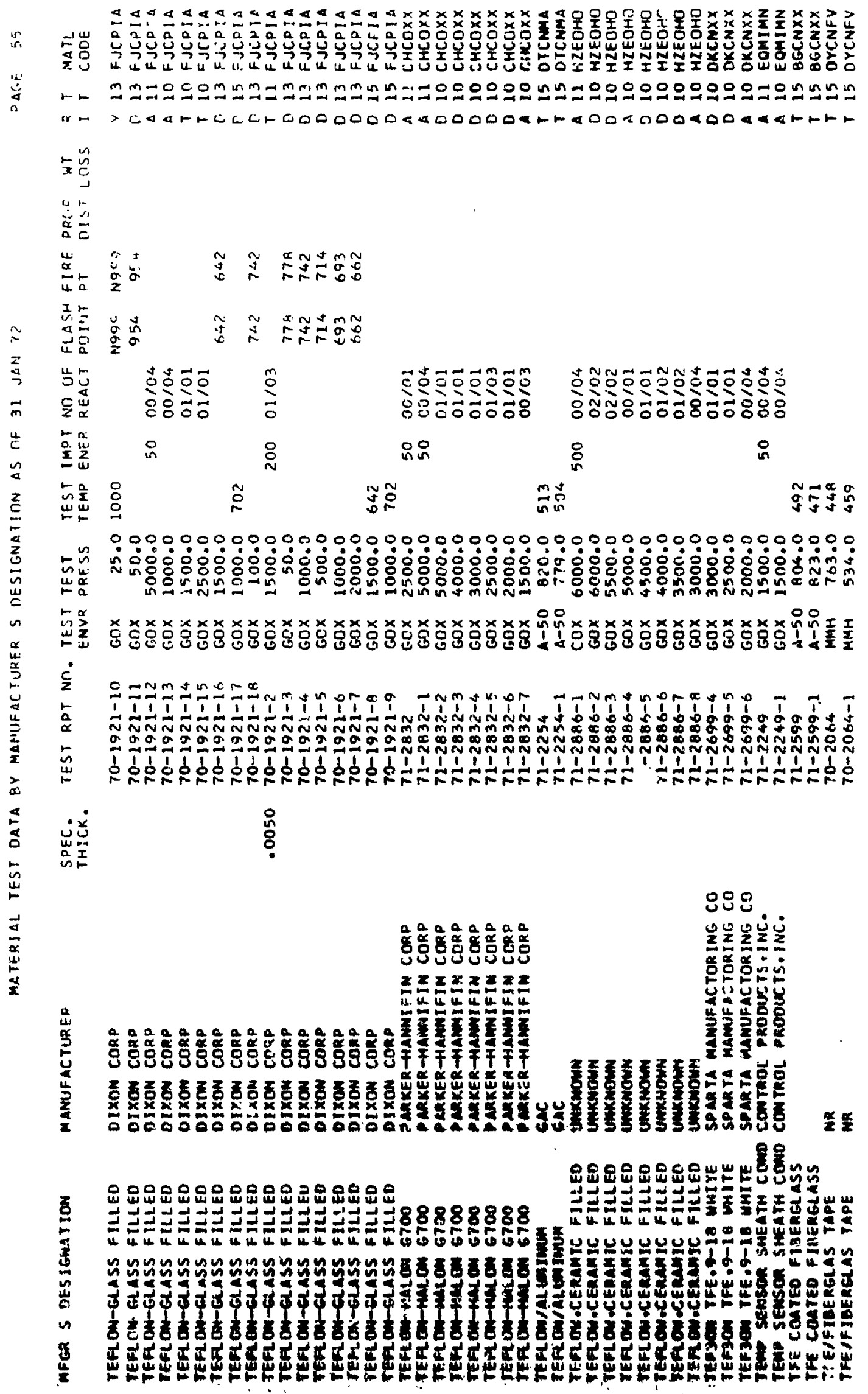




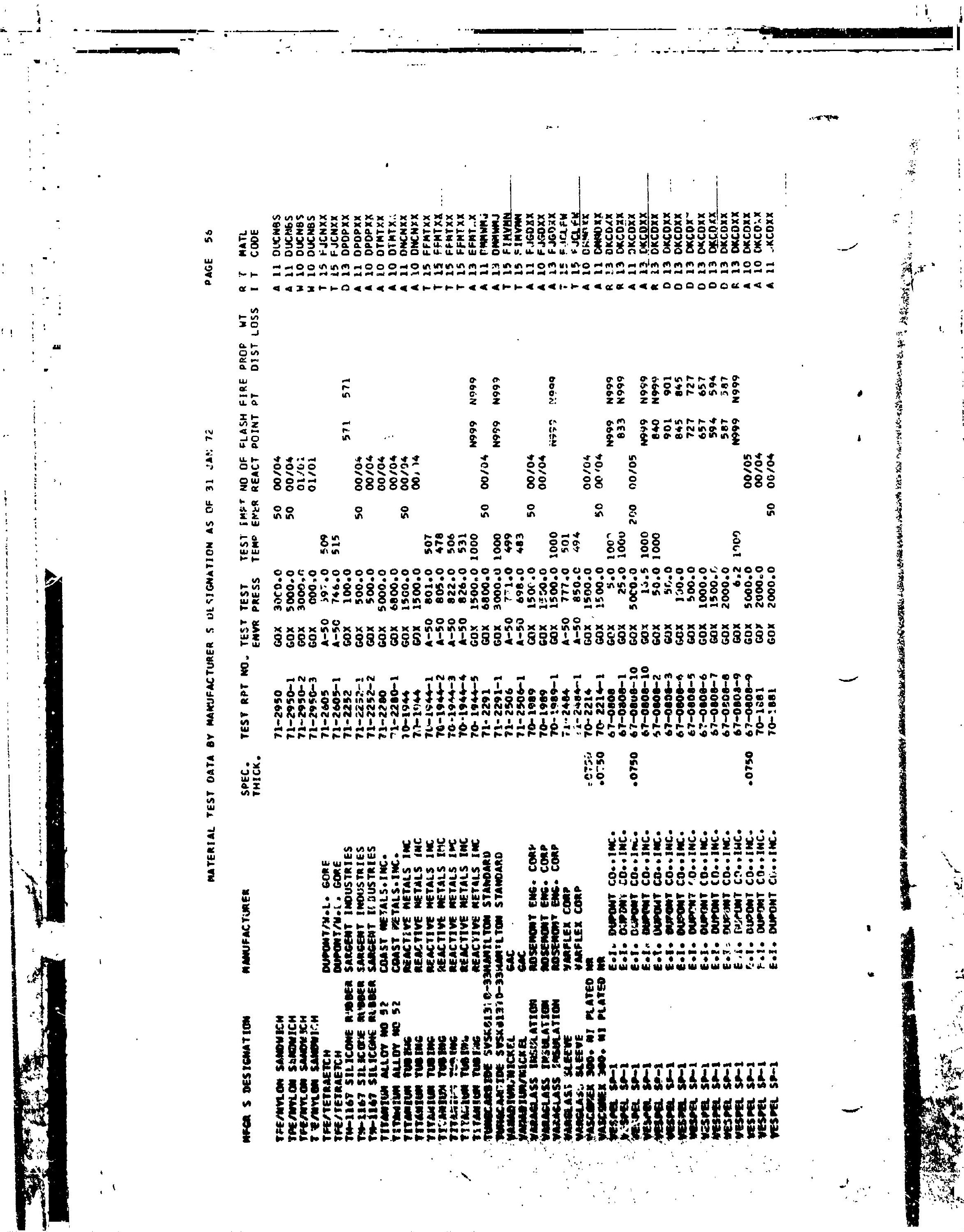



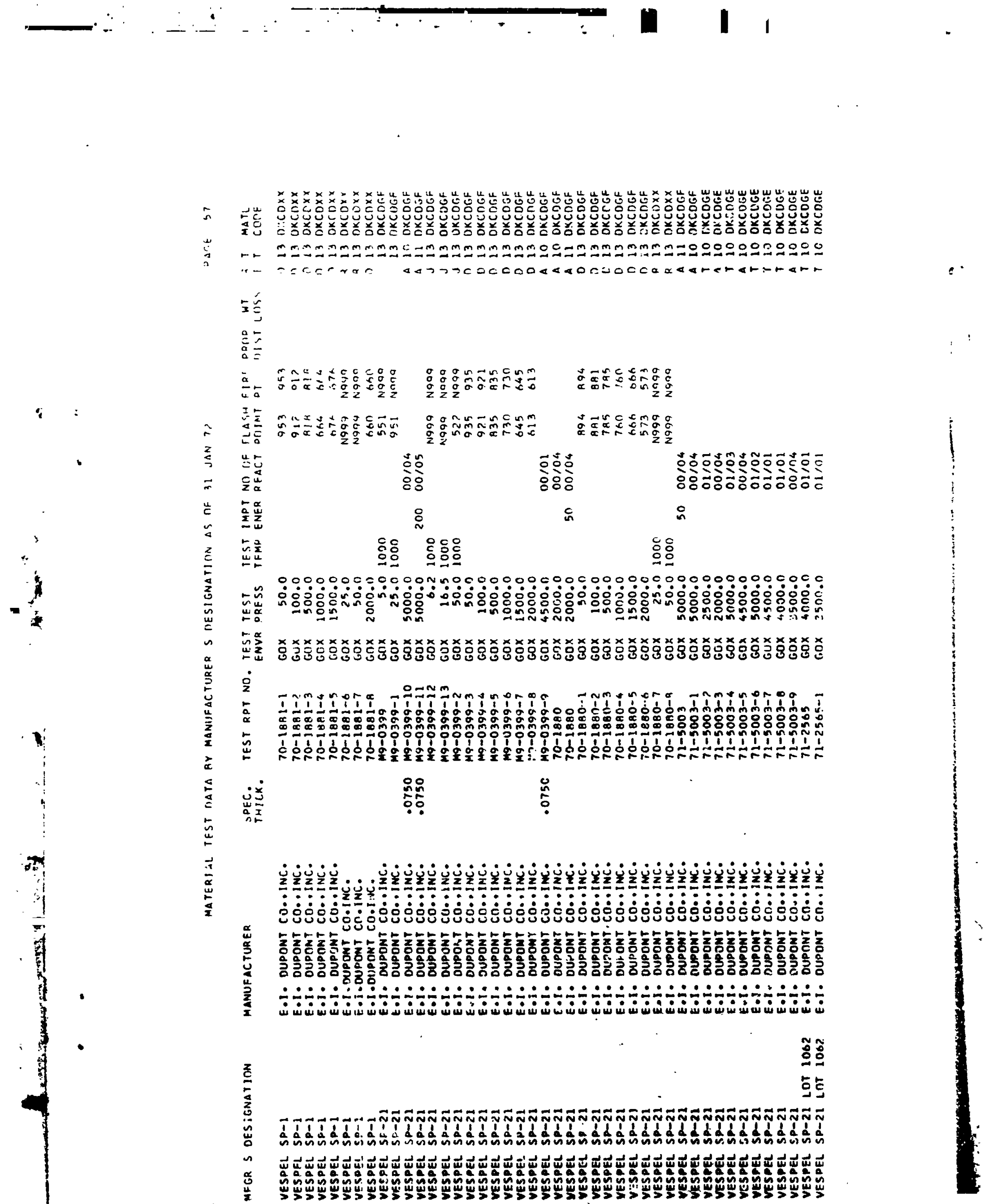

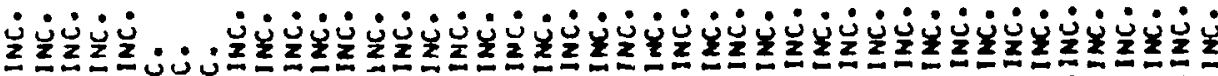

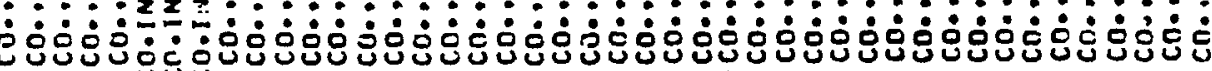

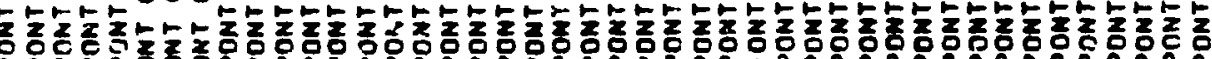

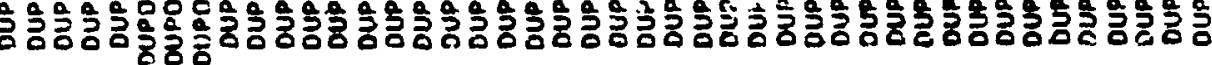

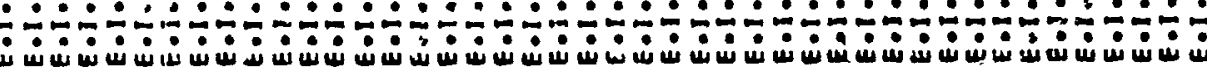

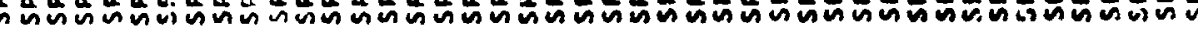

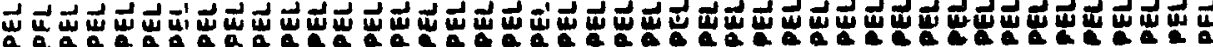

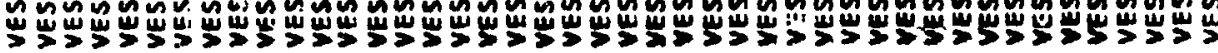




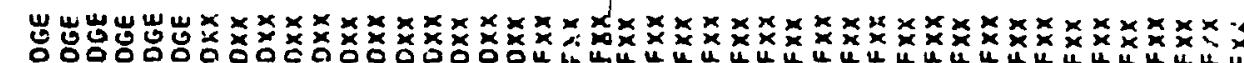

(r)

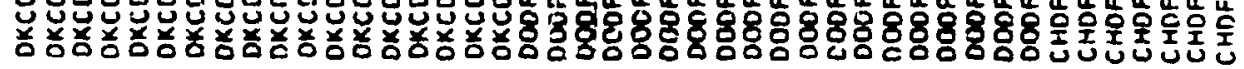

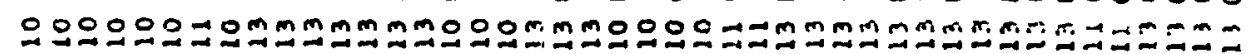

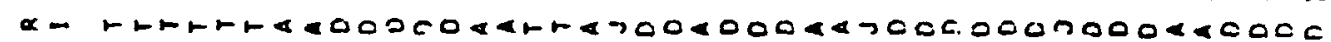

×

ç一

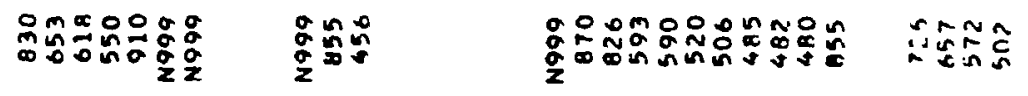

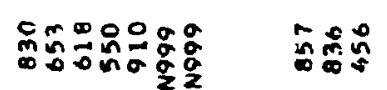

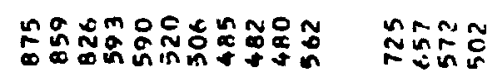

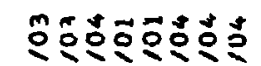

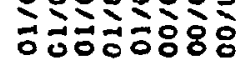
ํํㅇํำ

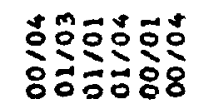

ำำ

은

요요

:

点离

잉요 : :

:

000000000000000000000040000 NM000000000000000

密

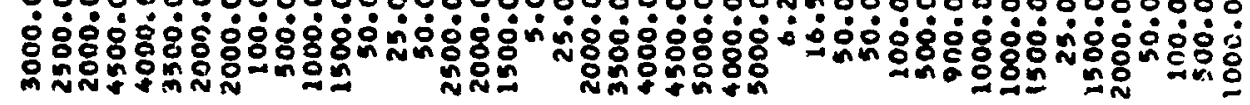

密妾

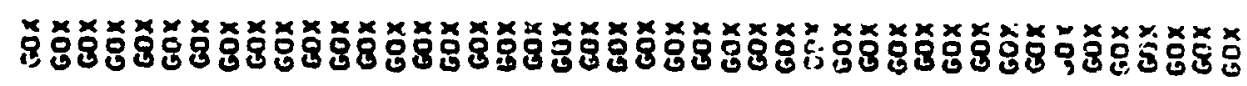

i

2

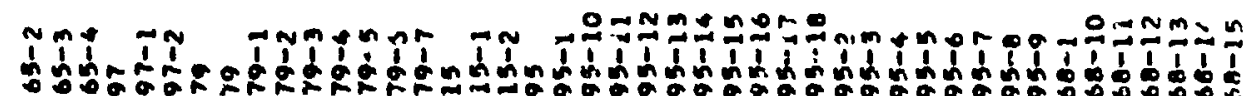

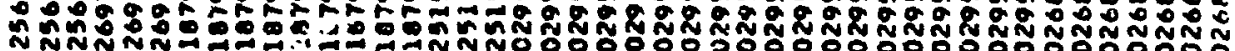

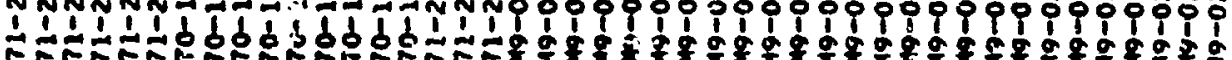

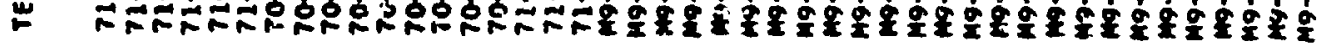

空总

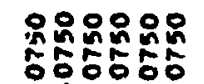

ㅇํำ:

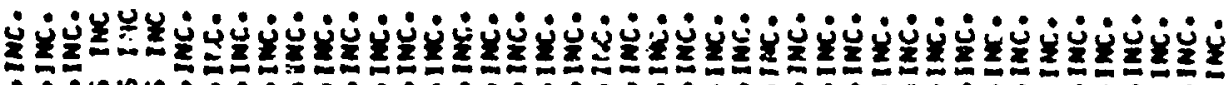

sơơ

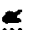

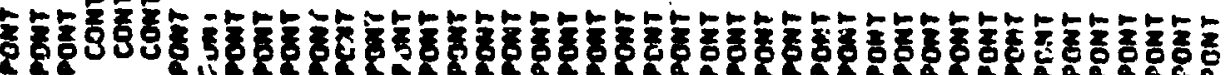

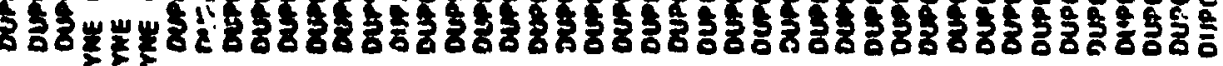

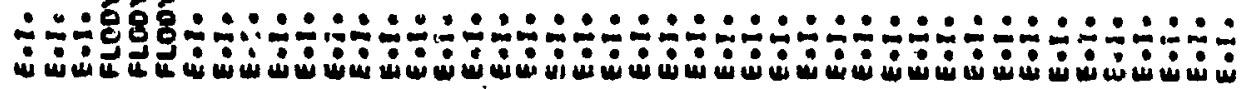

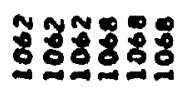

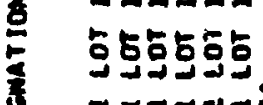

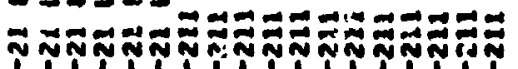

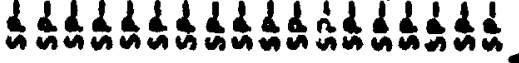

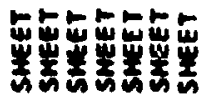

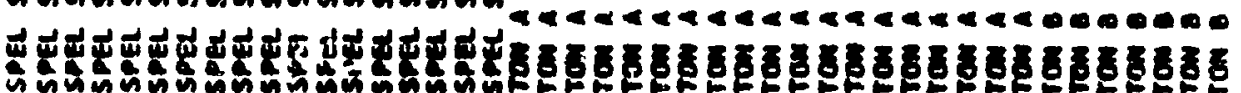




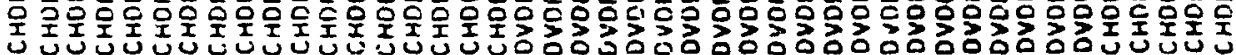
空

$\stackrel{s}{a}$

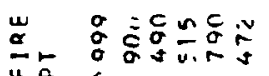

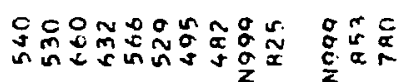

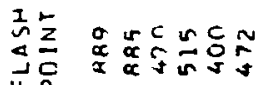

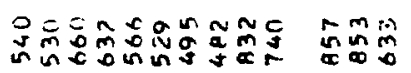

ֻ

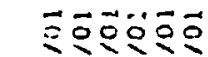

영용용

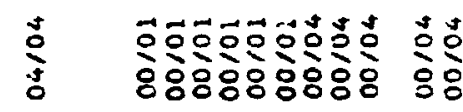

占竞

용

in

管品

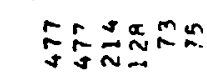

음

氙㐬

N nonco000000000m nnoc0000000000 Nno000000000000

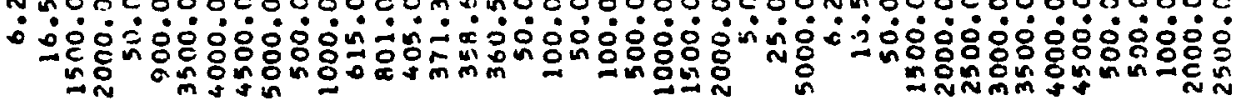

留竞 $\dot{0}$

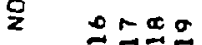

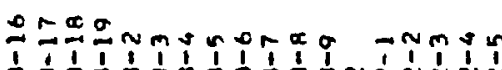
$O=N$

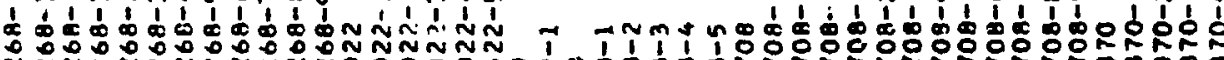

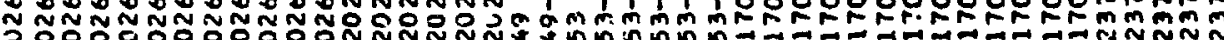

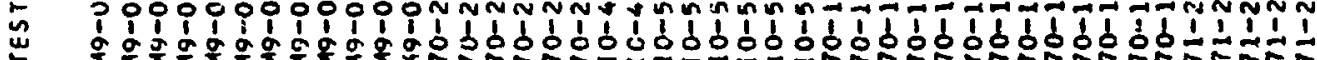

i

道完

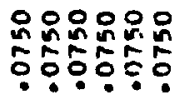

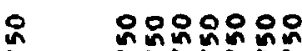

?

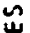

$\vec{a}$

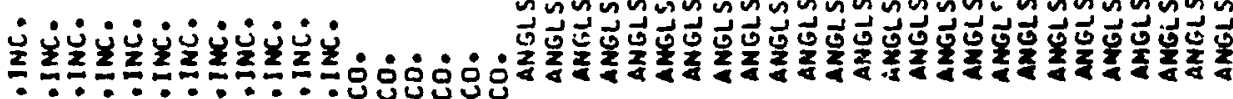

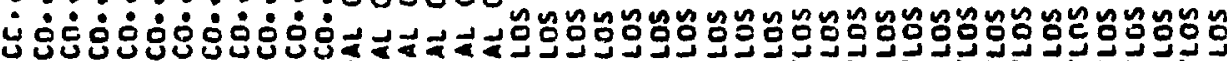

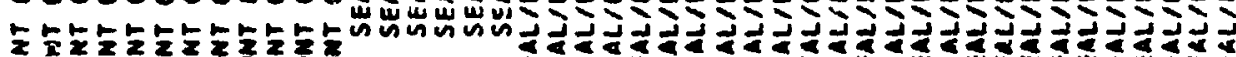

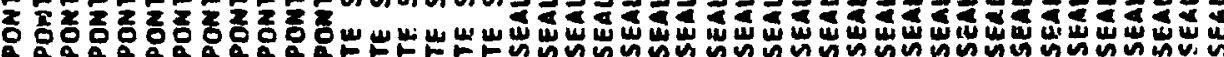

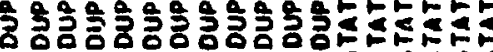

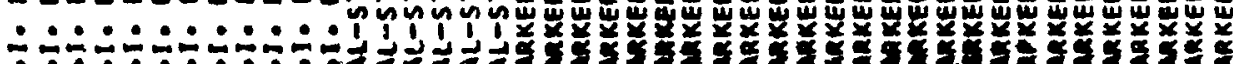

क्षि

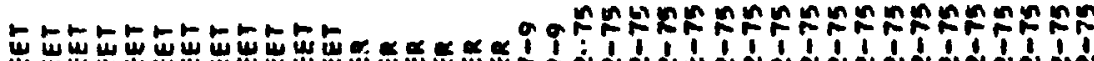

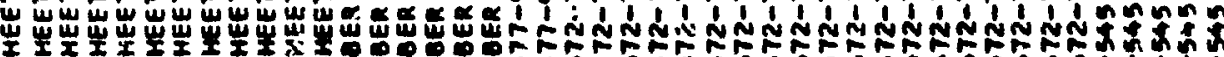

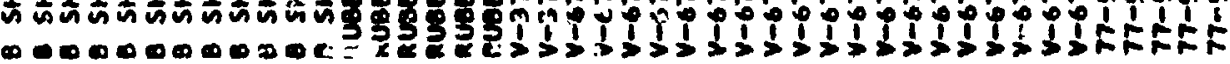

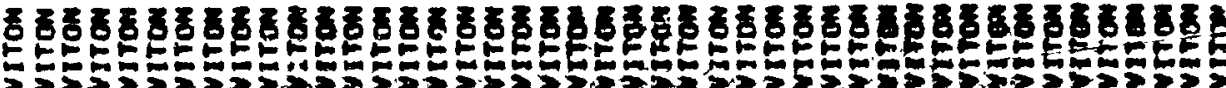




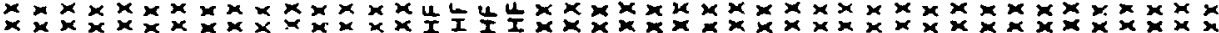

녕

เ

$\underline{x}$

cén

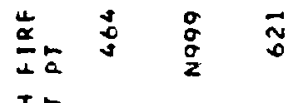

로요

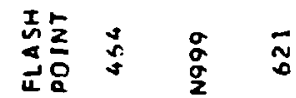

gog

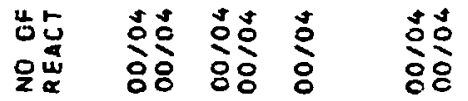

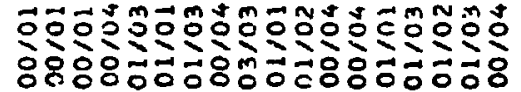

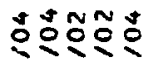
袈出 i in in

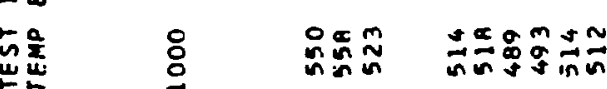

u 000000000000000010000000000000000000000000000 ヒй wa nun

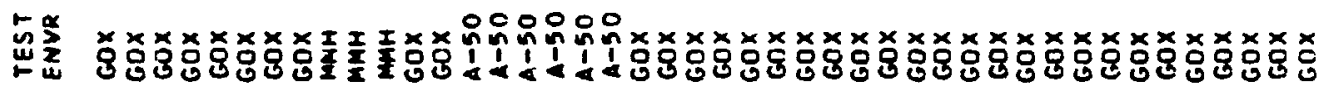
$\dot{0}$

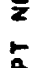

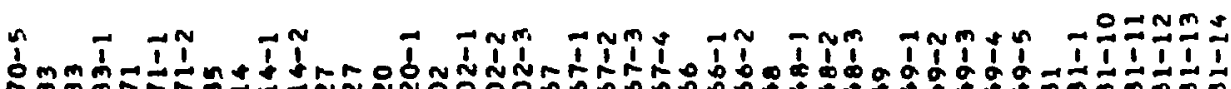
mogoTñ

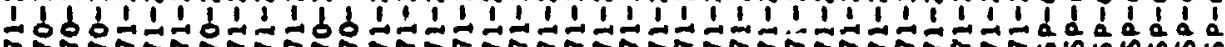

这这

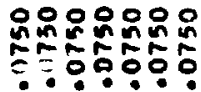

$\stackrel{2}{2}$

$\frac{1}{x}$

岇

(

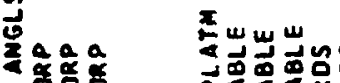

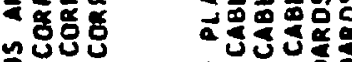

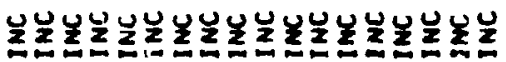

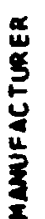
ड़ी

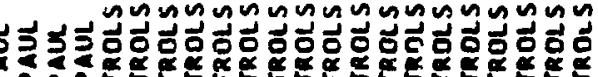

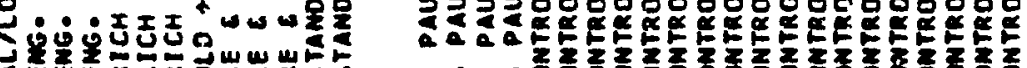

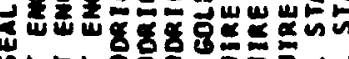

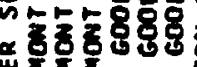

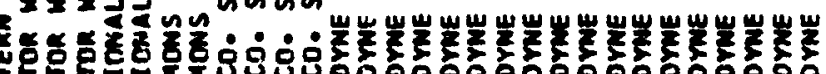

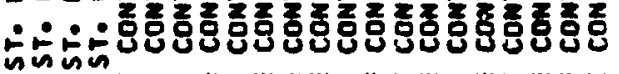
F

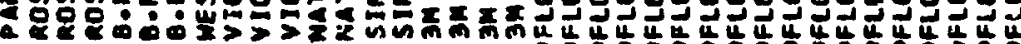

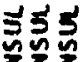

움 준홍

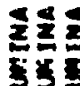

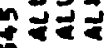

(2)

总总

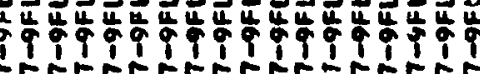

EFFEFFEFEREFEREFEF

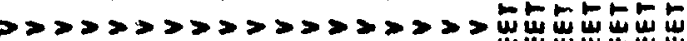

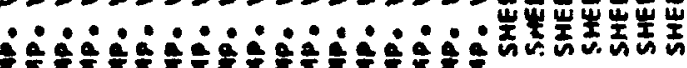

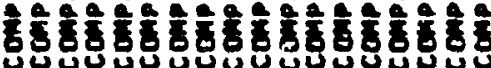

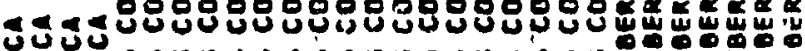

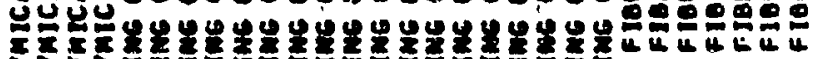

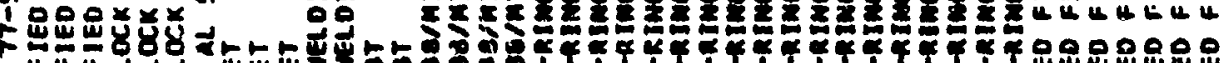

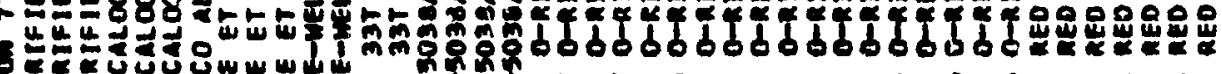

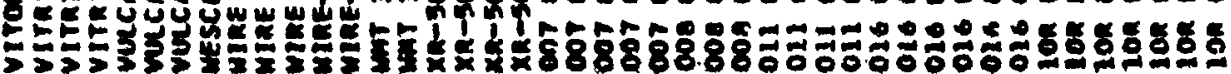




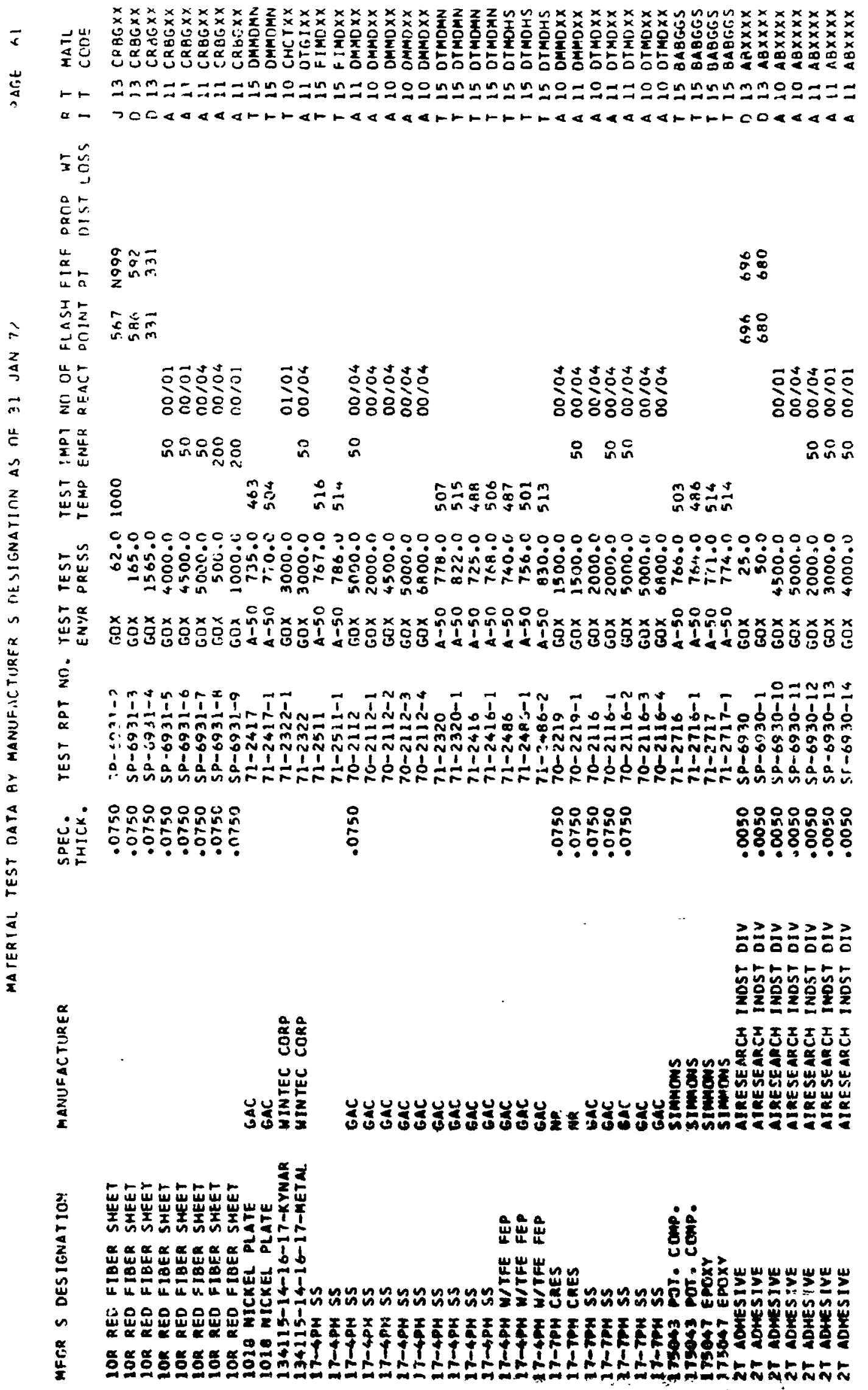




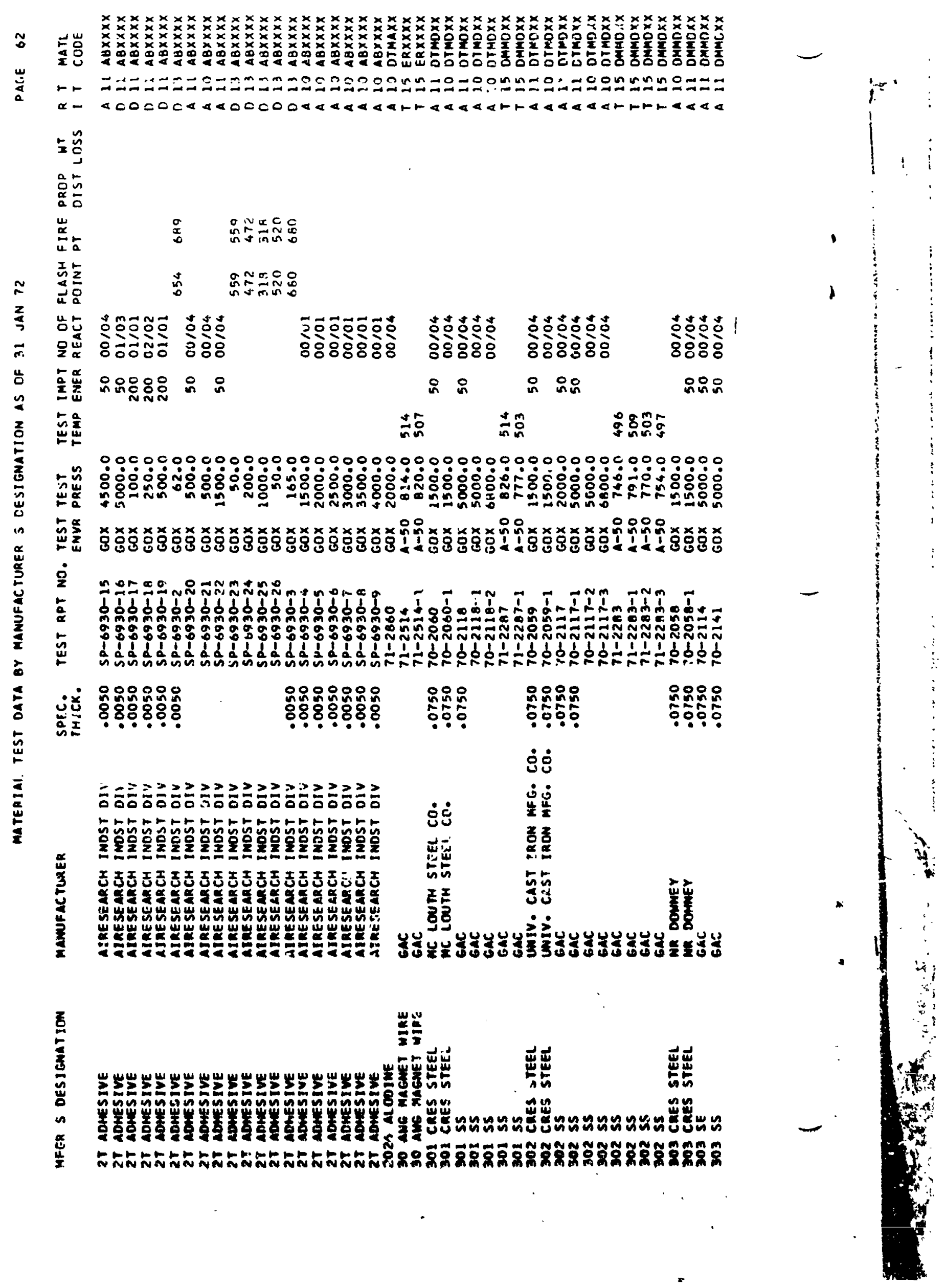




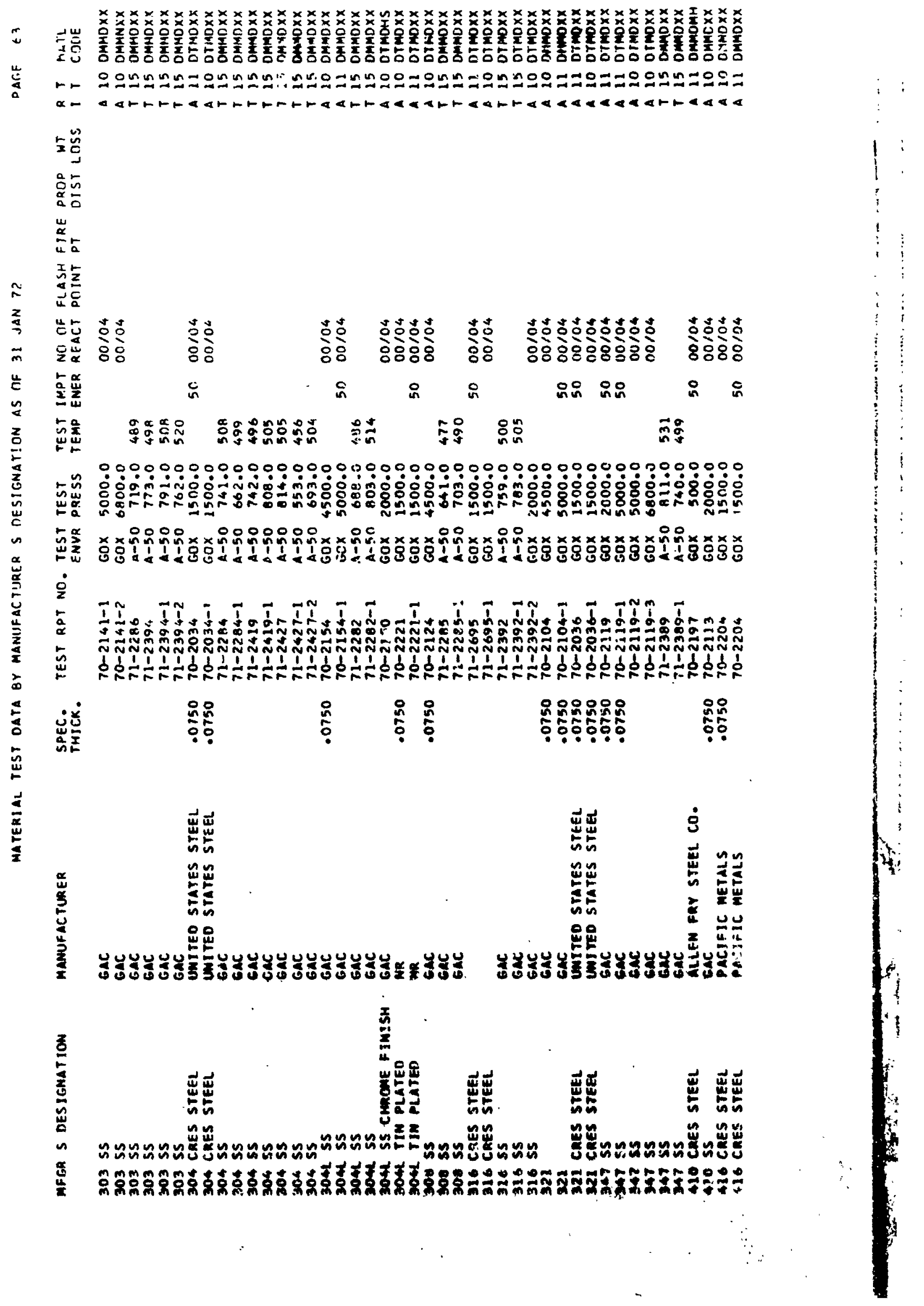




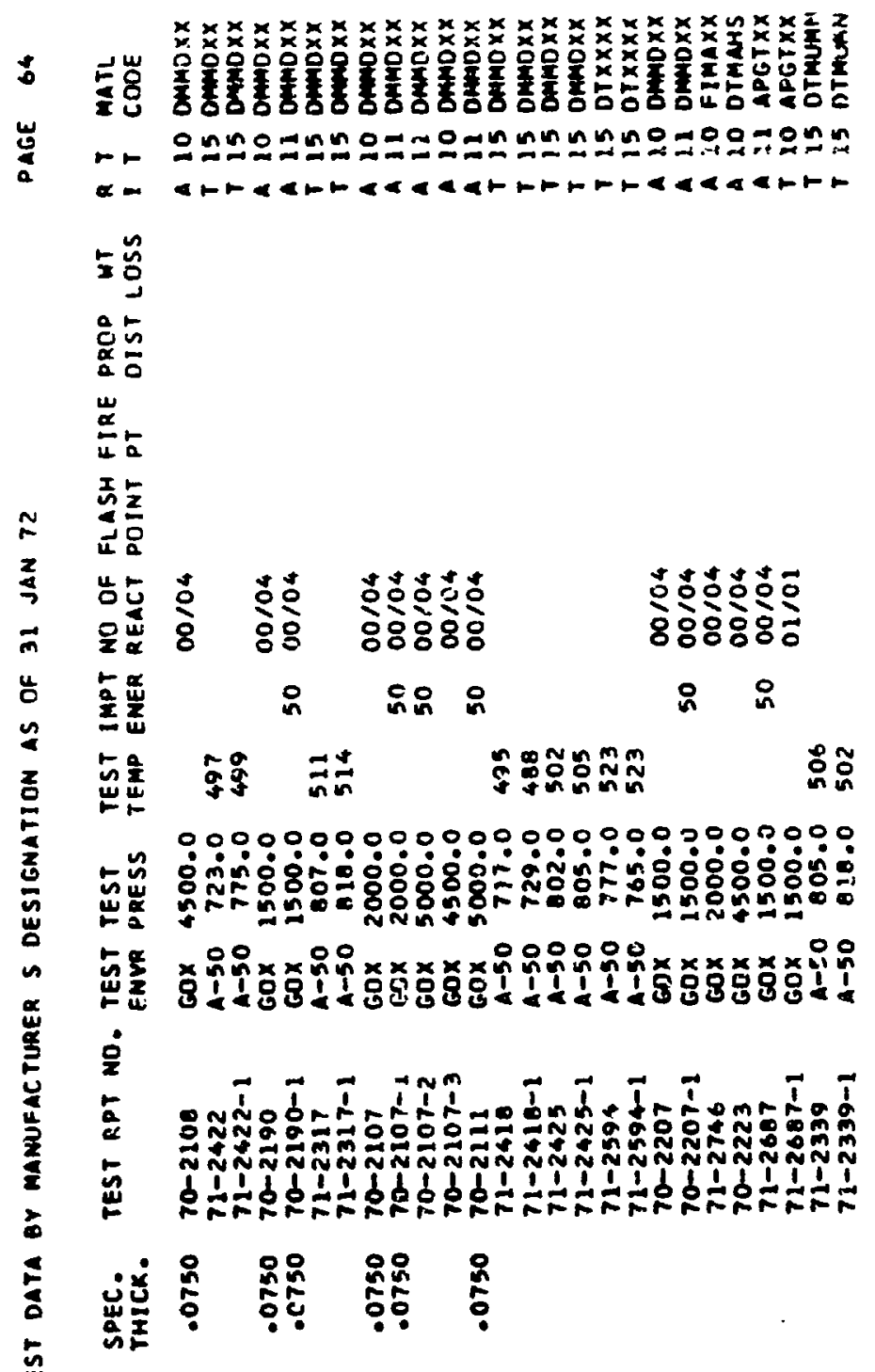

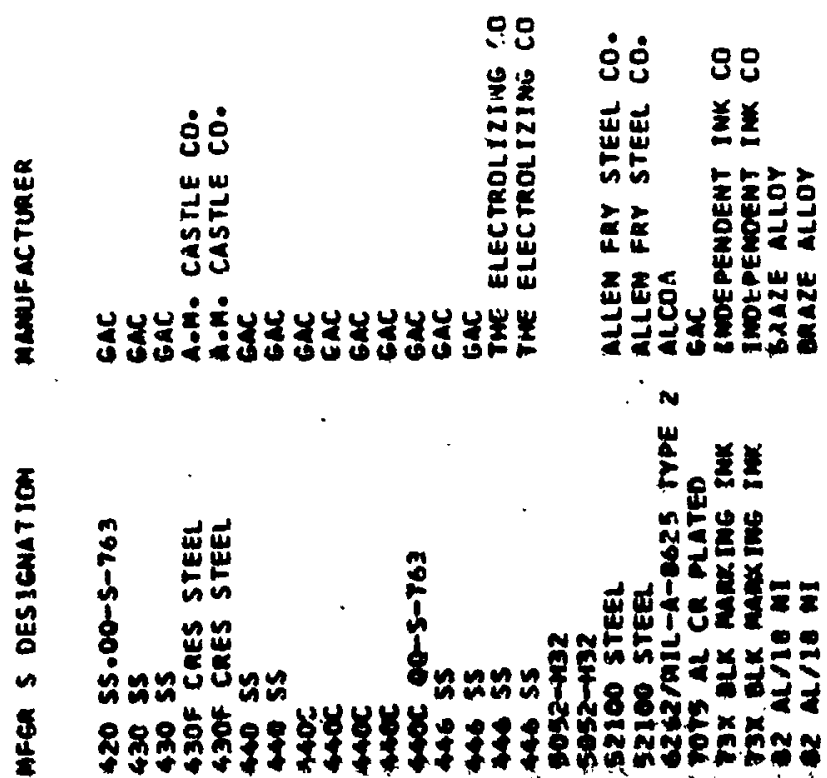


APPENDIX II - SELECTED SUMMARIES, CONCLUSIONS, AND RECOMMENDATIONS EXCERPTED FROM THE INDICATED REFERENCES. 
Attwood and Allen (1971)

\section{"CONCLUSIONS AND RECOMMENDATIONS}

(1) The dependence of the spontaneous ignition temperature, SIT, of a material on test techniques such as heating rate and gas flow rate, and on sample conditions such as nowder or block, new and clean or used and 'aged', has been demonstrated; but no consistent trends were apparent.

(2) Previnusly reported large decreases in SIT with increase in pressure above atmospheric are likely to have been partly caused by the change in test technique. With few exceptions the 'Pot' test gives higher SI'Ts than the 'Bomb' test, hence the use of the 'Pot' test alone, to assess the suitability of materials for use in oxygen, cannot be reco nmanded.

(3) Nylon is not recommended for use in high pressure oxygen. Even when new or unnsed its SIT can be below $300^{\circ} \mathrm{C}$, and wear and 'ageing' during use can apparently lower the SIT to $155^{\circ} \mathrm{C}$. The se could have been contributcry factors to the six fires from which this investigation stemmed.

(4) ZX32 a material suspected in one fire, did not ignite in any test.

(b. The SITs of several relatively new silicone materials have been measurent and generally increase with an increase in oxygen pressure. As this is the reverse of the behaviour of many non-silicone materials tested in 1950, silicone materials might well be used more widely in high pressure oxygen systems: Iivwever, only limited tests have been made so far: furthe: investigation would be necessary before any definite conclusions could be drawn.

(6) The need for a test or set of tests by which to define the compatibility of a material with oxygen has been discussed and a programme of work aimed at establishing such a test has been outlined. An interim atandard test has been proposed and a method of interpreting any spread of results suggested." 
Baum, Goobich, and Trainer (1962)

"Conclusions

1. Teflon and Kel-F are both compatible with high-pressure oxygen systems with regard to chemical reactivity, and they manifest a high degree of stability. Viton, however, shows questionable compatibility although an insufficient number of samples were tested in this program to draw firm conclusions. AiResearch also reports some failures with Viton $O-r i n g s$ but nevertheless they are using them as seals in the Mercury control equipment. In any case, neoprene seals were found to be incompatible with high-pressure oxygen.

Pure Teflon sufiers from certsin physical weaknesses. It tends to fold flow very easily, and because of its high ductility and lubricity, it is easily extruded out of shape when unconfined. Neither does a thin, unsupported Teflon disk have sufficient strength to prevent collapsa when high-pressure forces are applied.

Kel-F has sufficient strength an $\dot{i}$ rigidity to partially overcome the cold-flow problem for short periods and it can withstand instantaneous impacts frcm flov that would cause Teflon to collapse or extrude. However, Kel-F does not appear to be sufficiently ductile for seal use, nor does it provide the lubricity of Teflon. A possible solution, aside from the conventional compcunding of Teflon with ceramic, glass fiber, and asbestos cloth, is use of a new compound of Teflon and Kel-F. This compound consists of 80 parts Kel-F and 20 parts Teflon. According to the developer, Minnesota Mining and Manufacturing Corporation, it is sufficiently strong to resist cold flow, is more ductile than pure $\mathrm{Kel}-\mathrm{F}$, and retains the lubricity of Teflon. However, both Kel-F and Teflon should be employed as seals only when closely confined (like D-rings) to prevent possible collapse or cold flow.

2. Appziently the hydrcicarbon-oxygen mixture is a rathcr complex one in that merely mixing the two constituents does not appear to be the only thing necessary to initiate a chemical reaction. Case histories of storage vessels at 2000 psi or less suddenly exploding fcr no apparent reason seem to substantiate the suggestion that a third factor or sequence of events must be present. However, the triggering agent mas not be the same in all cases. The only method whereby the explosive nature of hydrocarbon-oxygen mixtures may be properly and more fully underotood is through an sxtensive series of carefully controlled deiberate explosicna. Studien of this type have been conducted, but never at pressures of 500 atmospheres.

On the basis of the data available from the present experiments, the following can be concluded:

(1) Below $400 \mathrm{~F}$ concentrations of 50 ppm of losa ar. act highly reactive and do not constitute a major danger.

(2) If a reaction did occur, it was either too sapid, too low, or too 3 ight. to be detected by visul readinge of the preasure gage or by temperature fluctuation recorded by the thermacoupla 
Baum, et al. (Continued)

(3) If a reaction did occur, it did not go to complation. This conclusicn is supported by the fact that traces of hydrocarbon were indicatiod in most gas analyses. The reaction may not have been sustained for two possible reasons: (1) because of the low concentration, the gas was too iinely diffused and could not surtain a flame front and (2) the total heat of reaction was small and was too quickly discipated to "set. off" the remaining unburned gases.

3. On the basis of the five evaluaticns just discussed, whe four metals considered can be rated in the following order in terms of their poseible application in high-pressure oxygen sysiems:

Stainless steel (Type 316) Goudt

Monel

Br28s

Pure copper
Good-

Poor to fair

Vexy poor
Shows sufficient strength and ductility for pressure-vessel use; has low oxidation $r$ ate and good erosion resistance

Is less ztrong but sufficient where weight is not a restricting factor; has lowest oxidation rate

Has insufficient strength ic: lightweight pressure-vessel application, but demonstrates good retention cf original physical properties; good oxidation resistance in dry atmospheres but poor resistance in moist atmospherea; has only fair eronion resiatance

Too weak to be used for pressure vessels; poor retention of physi. cal properties; has high autoignition temperature but also has high oxidation rate when exposed for long periode

The above rating is based on the inveatigation and analyais of only a amall. sampling of ench motal. More axtenuive and dotalled invantigations are required to determine quantitative reoulto. Qualltatively, on the basis of the experimente pexformed, only atalniese ateel and Monol aro scceptable alloys. Brass and pure copper, although poncenotng rome deatrable char astoriatice, ohould not be uned because of othex factore which cannot be aufuctenuly: coxupensated. 
Baun, et al. (Contisued)

4. It is evident on the basis of the data gathered that electrostatic charges due to high-pressure oxygen flow are not significant in themselves. How ever, some factors which arise because of the flow of gas must be seriously considered. One possible problem is ozone formation caused by the cooling of the gas and the presence of electrostatic chaxyes. The ozone molecule is much more active, chemically, than ordinary uxygen and therefore likely to lower the ignition temperature. A more imp'rtant factor is the presence of dust or liquid moisture in the gas stream. It has been shown that gases passed through a pin-hols orifice under a pressure head of 1800 psi invariably show a strong electrostatic charge only when either dust or liquid moistu-e is present in the gas stream. These charges may be sufficiently large to cause ignicion.

Ir the experiments performed at Battelle, some dust p.articles were present in the gas stream but probably they were not in sufficient quantity to increase the electrostatic charge greatly. Of course, the longest flow period was only 8 seconds ana the pressure w:as not cons'ant during the entire period.

Because the danger of detonation or chemical reaction being initiated by an electrostatic charge is potentially large, further investigations shouj be performed but with larger volumes which will perrait longer flow periods. Also, attempts should be made to control and measure the arnownt of dust of moisture in the stream to compare the effect on the charges generated. In general, however, regardiess of the negligible charge generated, equipment should be grounded wherever pussible.

5. Rapid heating due to gas surging into confined spaces $c$ an produce a majox hazard. During the experiments at Battelle, a pressure regulator failed and burned under surge conditiens. Also Aikesearch discovered that meny materials including neory ene and Viton reacted chemically when impacted by a surging gas at $8000 \mathrm{psi}$.

However, there is aloo evidence that at lower pressures, or when the receiver volure is comparatively large, the effect of surge compression is minor. This conclusion is supported by the results of the surge experiments' at Battelle and similar experiments performed at AiResearch.

On the basis of the experimental results and data available, it can be concluded that the rise in temperature due to adiabatic compression to 8000 psi is probably not aufficient to cause large masses of meral to ignite. However, the possibility of thin sectioned metal wire and of polymers such as neoprene igniting is great. Also the danger of organic or hydrocarbon contaminant chemically roacting is serious eince many of these have ignition temperatures below $500 \mathrm{~F}$, enpectally in hich-pronure ganeou ozygen. 
Baum, et al. (Continued)

6. Since the basic aims of the research were to evaluate the relative safety of 7500 -pei gaseous oxygen systems and to identify the hazards which $c$ an be

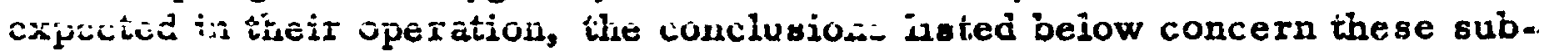
jecte specifically.

Although some of the research results indicate that:- lative safety $=a n$ be maintained apart from absolutely ideal conditions, it cannot be assumed that high standards of cleanliness and handling technique are not desirable. Whenever ideal conditions and procedures are possiblc, they must be insisted upon. However, although danger increases with less ideal conditions, certain compromises $\mathrm{c}$ an sometimes be tolerated. Only through continued research and through accumulated engineering experience $c$ an a more confident assessment of the extent of these allowable compromises be made. Until the tirne that further reseirch and engineering provides additional information for formulation of recommendations, the conclusions given below can be used as general guides:

(1) Contarninated oxygen gas at 7500 psi, as investigated in this program and under the environmental conditions imposed when considered inde pendently of the equipment or system employed, is relatively safa from spontaneous combustior. or dsconation.

(2) Hazardous chemical reactions of 7500-psi oxygen gas with foreign elemente seem to be dependent upon conditions other than simple mixing, proximity, or high-velocity flow. Temperature is believed to be the most aritical variable and the minimum temperature at which a reactios will occur is in turn dependent upon the existing pressure.

(3) Hazards and difficulties encuuntered in the operation of high-pressure gaseous oxygen systems seom to te attributable primarily to poo: system derign and to the use of pooxly designed equipment.

In addition to the general conclusions above the followiag more technical and specific conclusions have been drawn:

(1) Absolutel-: clean, dut-free atmosphezos are not essential to safe operation.

(2) Concentrutio se of hydrocarbons in the order of 50 ppm or less are not dangeroualy leactive.

(3) Electrostatic shargso caused by short flow periuds through a small orifice appear to bu segligible.

(4) Stainlen steel and Monel are accoptcble materiale cf conetruction.

(5) Uncoated or unplated copper appeare to oxddise too readily to be used extensivoly.

(6) Although casen of combueticn involving Tuflon and Kel-F bave been roported, the cxperimente conducted abow inst these are accerfable noumotallic saling matarieln. 
Baum, et al. (Continued)

\section{RE.COMMENDATIONS}

Iro primary recominteidatiuis have jec: formulated on the hasis of the conclusions presented above.

(i) A broader, more detailed study of materials compatibility with 7,00-psi oxygen gas should te pursued. This stury should be an atiempt to derive a more exact understanding of the conditions that initiate combustion. Extensive experimenti.tion vith stainless steel, Monel, anodized alurinum, Teflon compounds, KSel-F compounds, and varicus thread lubricants and sealarits shoula be conducted to permit a proper statistical analysis. These expe:iments should heve two objectives:

(a) Determination of the spontareous ignition temperature urder static conditions and after various periods of exposure.

(b) Determination of the spontaneous ignition tempexature during surge conditions and evaluation of the influence of the volume :o surface-area ratio.

(2) Because of the inadequacy of available equipment to provide reliable, long-time performar :e for absolutely leakproof operation, a development program should be initiated. This program should be planned to investigate $c_{2}$.tica-design criteria. The components that require further sicidy, in estimated order of priority, are:

- Fittings

- Valves, manual and remote

- Lightweight pressure vessels

- Regulators." 
Guter (1967)

"SUMIMARY AND DISCUSSION

Ignition temperaiures in high pressure gas were determined ising a stainless steel borm in which samples could be raised to the ignition temperatu:e in a few minutes. The effect on ignition temperature of changes in total pressure, rate of heating, "ageing", i.e. prolongad storage of material in oxygen under pressure, oxygen concentracion, and the physical strite of the sample were determined in the high pressure apparatus. A sinpler apparatus called the 'pot' ignition apparatus was developed for the rapid determination of ignition temperatures in oxygen at atmospheric pressurf.

The rrany mateitals examined have been classified in the following five groups:

1. Lubricants, including thread sealing compounds.

2. Natural and Synthetic Rubber Hose Materials.

3. Polymers.

4. Valve Seat materials.

5. Metals and Alloys.

The ignition temperatures of the materials in Class I were relatively unaffected by changes in oxygen pressure. The Aroclors (chlorinated diphenyls) were particularly resistant, and had ignition temperatures above $400^{\circ} \mathrm{C}$. If their other properties aze satisfactory they should prove suitable for use as lubricants and hydraulic fluide in oxygen systems. Acheson Grease 1.30 and the Ministry's anti-seize and sealing compound also had high ignition temperatures which were unaffected by pressure. For this reason they would be preferred to the silicone greases for use in oxygen.

The ignition temperatures of the rubber hoze materials in Class II were all cunsiderably reduced by increasing the oxygen pressure, except in the case of silicone rubler whicu ignited above $300^{\circ} \mathrm{C}$. The natural and synthetic rubbers, other than silicone, were found tc ignite at temperatures below $200^{\circ} \mathrm{C}$ in oxygen at pressures of 100 atmospheres or higher. The ignition temperatures were conaiderably rediced if traces of the fabric used as reinforcement in the completed hose were included with the sample. increases in heating rate led to significant reductions in the ignition temperatures of hycar, neoprene and BTR Hose (Specificaticn 1180). Provided certain precautions are strictly observed it is suggested that rubber hoses may be used with high pressure oxygen.

Included in Class III were Teflon, Kel-F and phowphorylated folyvinyl alcohol which were the most resintant non-metallic materials examined. They failed to ignite in oxygen at 250 atmospheres when heated to $350^{\circ} \mathrm{C}$. 
Guter (Continced)

In the 'pot' test they sornetimes ignited at temperatures above $500^{\circ} \mathrm{C}$. Increasing the oxygen pressure to 175 atmospheres reduced the ignition temperature of most of the other materials included in class iتj, Dui with polythene, nylon and perspex a further increase in pressure to 250 atmospheres caused only an insignjficant increase in the ignition temperatuse. Polyth ne, red vulcanised fibre and rosin bonded fabric were also examined in air; the ignition temperatures in air were found to be rather higher than in oxyger but no definite relationshif between the partial pressure of the oxygen and the ignition temperature oi these materials was obtained. Special areing experiments provided interesting results, but unfortunately did not yield general coliclusions.

The materials in Class IV with the exception of GACO seating materials had relatively low ignition temperatures. The much higher ignition temperatures obtained with some of the materials in Class III suggest that they may be preferred for making valve seats, provided their mechanical properties are satisfactory.

None of the metals and ailoys in Class $\mathrm{V}$ ignited in oxygen at 250 atmospheres when heateõ alone to $350^{\circ} \mathrm{C}$. Copfer, magnesium alloy and mild steel turnings ignited in the presence of a drop of oil if heated to about $200^{\circ} \mathrm{C}$ in oxygen at 250 atmospheres.

Changes in gas flowrate, oxygen concentration, heating rate and physical state had no marked effect on ignition temperature for most of the materials examired. Exceptions were some Class II materials which vere afferted by heating rate ard Bיna which in the form of shavings ignited at temperatures more than $100^{\circ}$ below the corsesponding ignition te:nperatures for samples in block form.

Materials in Classes II, III and IV worc examined by the 'pot' test. In general, it was found that the higher the 'po:' ignition temperature the hig'ser was the ignition temperature in high pressure oxygen. Unfortunately the. 'pot' ignition temperature gave no indication of the effect of pressure ir the range $50-250$ atmospheres on ignition temperature.

No attempt was made to examine the behavioux of the materials under actual working conditions at high pressure. It is not possible therefore to relate the ignition temperatures observed under controlled conditions to the hazards associated with the everyday use of combustible materials in high pressure oxygen. However as no materials ignited at a temperature belcw $100^{\circ} \mathrm{C}$ and $v \times r y$ few below $150^{\circ} \mathrm{C}$ in oxygen at pressures up to 250 atmospheres it seems highly probable that with careful selection a number of materials which are not entirely non-inflammable can be safeiy used in oxygen at high pressures. When using such materials it is important to avoid any sudden chinges in pressure or temperature, and to ensure the absence of any inflammable dust or other material more susceptible to ignition, which might initiate combustion. 
Guter (Continued)

The mssibility of fires in high pressure oxvgen systems would be largely avoided by measures that would prevent conversion of the free energy of the compressed gas into heat. If this could be acnieved in the design of equipment then the ignition characteristics of the materials that come into contact with the oxygen would be of secondary importance. Until this ideal is reached, safety in the use of high pressure uxygen will deperd not only on the selection of materials with a high ignition temperature, but on carefu' attention to the design of tine apparatus, and upon the observance of a number of elementary but essential precautions. As the starting-point of combustion will clearly be determined by the material of lowest ignition temperature which happens to be present, it is important to exclude carefuliy all traces or organic dust and oil. Particles of dust and fibre introduce a special hazard in connection with the temperatire rise which occurs on adiabatic compression in a closed tube. In this case the rise in temperature of the gas may be considerable, but its heat capacity is small. The gas is therefore unable to raise appreciably the temperature of any massive body with which it is in contact, and its heat is rapidly dissipated. A small particle of fibre in the gas stream, however, can be raised to a temperature approaching that of the $g a s$, and $c$ an the refore readily be ignited. When this occurs it will cause the ignition of any other inflammable materia' in its vicinity.

The work described ia this report does not provide a basis for shoice of materials for use in high pressure oxygen without regard to the circumstances of use, but it is hoped that it will serve as a useful guide for the selection of the best materials for a particular duty, and the range of conditions under which they can be safely used."

(Parts of the summary and discussion are omitted.) 
Juhnston (1970)

"CONCLUSIONS:

1. No great technology differences exist among the fields reviewed.

2. Breathing oxygen sysiems utilized today have been quite successfu: in meeting their intent. The maiority of the relatively few failuxes which have occurred have been traced to poor handling practices.

3. The success of today's designs has been the result of designing by experience, largely without thorough scientific understanding.

4. Improvement in and standardization of specifications and guidelines are seeded in the following areas:

a. Syotem design requirements as a function of pressure, and use.

b. Materials requirements and a suitable list of materials for specific applications.

c. Materials test methods which will verify suitability of materials for the given applications.

d. Accurate testing methods for determination of a given systems contamination level.

e. Allowable contamination levels and materials including particle sizes for the various system pressure levels." 
Kimzey (1970)

"CONCLUDING REMARKS

The literature available prior to the Apollo 13 incident indicates that little vurk has been performed on electrically induced ignition of metals. Much work has been done on impact ignition, particularily in LOX environments; however, much of the data are nnt direcily usable due to the wide variety of e:-perimental techniques employed. Sufficient work has been performed to permit the following observations:

1. The ignilion temperature of a metal in LOX is independent of pressure, convection, and oxygen percentage.

2. The effect of halogen impurities on the ignition temperature of metals cannot be determined from existing data.

3. Ignition temperatures, like boiling points, or melting points, appear to be depressed by the addition of impurities." 
Marzani (1968)

\section{"CONCLUSION}

The following conclusions are made with regard to material evaluation:

I rom a fire-resistance standpoint, TFE is superio: to the other materials tested.

- CTFE is nearly as high in fire resistance. Polyvinylidene fluoride and the polyimides are intermediate. Polyurethanes, ethylene-prcpylene rubbers and polyethylene are lowest.

- The inclision of fire-resistant materials in composites with less fire-resistant materials does not insure that the composite will have improved fire resistance.

- Of the parameters affecting combustion, pressure has the greatest effect on material ignition temperature. Sample size is important in determining the flammability limits. Sample geometsy can be an important factor in ignition temperature and reaction kinetics.

- Materials ignite more readily at lowex pressures in oxygen than in air. Above 2400 psig the difference disappears.

The following conclusions are made with regard to the method of study:

- The modified high-pressure bomb satisfactorily provided reproducible spontaneous-ignition data on small samples of solid materials in an oxygen atmosphere. Data indicace a favorable degree of correlation with published data.

- This test method should be considered in any effort to establish a siandardized test procedure for determining the spontaneous-ignition temperatures of solid materials at elevated pressures.

- A standardized test will not necessarily yield a result which will be applicable under every condition of material usage." 
Nihart and Smith (1964)

\section{"CONCLUSIONS}

The following conclusions are based upon the results of the present experimenta! test program and other daia referenced in this report.

1. The spontaneous ignition temperatures of the materials tested are essentially the same in $7500 \mathrm{psi}$ oxygen as in 2000 psi oxygen.

2. The relative resistance of metals and alloys to ignition and combustion in 7500 psi oxygen agrees in general with results obtained in earlier Linde test work at 2000 psi and with the results of Dean and Thompson (1961) except for aluminum.

3. Only three thread lubricants might have possible safe application in 7500 psi oxygen. These lubricants are Dixon's Flake Graphite No, 1, Burnil Brand Microplates, and Almasol Powder. Further information on their lubricating properties and the rmal stability would need to be known before a complete recommendation could be made. One drawback to this type of lubricant is that there is always a possibility of particulate matter inadvertently getting into the high pressure system.

4. The only thread sealant tested in this program which might be recommended for 7500 psi oxygen service would be 50-50 soft solder (which could be used in tinning threads). TFE tape is not recommended because of the possibility of pieces getting into the gas stream.

5. Recognizing that some type of packing is needed for static and dynamir seals, glass-filled TFE would be the only material presently recommended for use. Even its use presents a hazard and it should only be used when tightly confined.

6. Incinel alloy 600 , brass, Monel alloy 400 , and nickel are recommended for use in $7500 \mathrm{psi}$ oxygen. Other metals might be acceptable if plated with rickel, silver, or gold. Monel alloy K-500 might also be acceptable but it was not given the promoted ignition test in 7500 psi oxygen.

7. Of the materials tested, stainless steel and aluminum are the least satisfactory for use at oxygen pressures of 7500 psi.

8. Copper is not recommended becmuse of the results of Baum, Goobich, and Trainer (1962). Other copper alloys might be acceptable material but would need to be tested.

9. Electrostatic charges developed during the charging of a small high pressure receiver were found to be negligible.

10. The simulated system vas pressurised with oxygen to instantaneous pressures ranging from 665 to 7100 psi without incident. Pressurisation time varied from 0.5 to 0.21 eeconde. 
Nihart et al. (Continued)

The hazards considered to be most responsible for ignitions in oxygen systems are:

a. Adiabatic Compression - High temperatures may be produced when low pressure oxygen is suddenly bzought to a high fiz squre, such as when a valve is suddenly opened between a high press portion of the system. These temperatures cat be $r_{1}$. sh enough to ignite organic materials or small particles of metal.

b. Particulate Matter - Particles may be accelerated in a high velocity stream and impacted against organic materials or metallic burrs, projections, etc. Their energy is converted to high local temperatures by this impact with subsequent ignitioil of associated materials. Even the particles themselves might be ignited if they were either organic or metallic in nature.

These hazards may be substantially reduced by proper cleaning of the equipment initially, use of filters (especially ahead of regulators) minirnum use of organic material, and judicicus cperation of valves and regulators to prevent rapid increases in pressure.

There are other mechanisms by which ignition may occur but these have been well covered by Reynales (1959).

\section{RECOMMENDATIONS}

1. Further study should be made on the copper alloys to define more clearly their compatibility and applicability in 7500 psi systems.

2. More tests should be conducted on metals and alloys to determine the effect of geometric configuration on the relative ignition temperatures.

3. There is need for further investigation into thread lubricants and thread sealants. This study would need to cover their physical properties such as lubrication and sealing qualities as well as their compatibility with oxygen. Development of special lubricants and sealants might be required.

4. A program is needed to ievelop and build better hardware constructed of materials more compatible with high pressure oxygen. The program should fover any and all eqiuipment which would be used in a 7500 psi oxygen system." 
Ordin (1971)

\section{"SAFETI RECOMMENDATIONS}

Although the solution to many of the problems which caused the oxygen mishaps cannot be specifically prescribed withou. further researcal and development efforts, several practical safety regulations are recommended to increase the operalional safety. These recommendations based on specific mishaps include the following:

(a) Prevent the cross connecting of fuel, oxygen and purge lines by means of designs and permit no subsequent uncontroiled revisions by maintenance personnel.

(b) Suitably restrain all flexible ines at specific intervals.

(c) Prevent the verting and disposal of oxygen near eiectrical systems or other ignition sources capable of initiating and promoting fires.

(d) Provide controlled valve operation of oxygen valves to limit generation of heat due to ga.s compression.

(e) Lábel pressure lines with values of operational, prouf, and design burst pressure.

(f) Conduct pre-operational hazaxd analyses on liquid and gaseous pressure systems before checkout, operation or maintenance.

(g) Insure verification of pressure relief before liguid and gas lines are disconnected.

(h) Emphasize hazards of operations in oxygen systems through training. Many operating personnel are not fully aware of the hazards associated with oxygen systems.

(i) Maintain records of any rework on tanks, lines and related equipment. The operations performed should be available to evaluate continued use of equiprient.

(j) Fluids used should be identifled and environmental chamber operations include a verification of the composition of tho gas mixtures employed.

(k) Liquid oxygen loading rates should be established comniensurate with duct and equipment fatigue capacitins. Material failures have been induced by low tress, high frequency vibratione caused by excessive fill rates. Instrurnentation should be installod to measure and monitor induced vibration. 
Orain (Continued)

(1) Standards should be established interfacing the electrical systems to the oxygen systems. Problems of electrical arcing of interior lights anf fixtures should be resolved.

(m) Insure availability of recent information on results of testing and of field experiences on the compatibility of materials with oxygen." 
Schwinghamer (1971)

"CONCLUSTONS

Without a satisfactory solution to the problem of materials reaction sensitivity in LOX and GOX, highly reliable expendable launch vehicles and non-reusable spacecraft would not have been possible. The basic test method which accomplished this end was the ABMA and MSFC-SPEC-106B. As a result of the Apollo 13 incident, increased emphasis is being plared on materials compatibility in a high pressure GOX environment.

Besides impact sensitivity of materials, approximately adiabatic compression conditions can contrive to induc $\epsilon$ materials reacivity. Tests run at high pressure using the new MSFC tester have so far shown that:

1) The materials used in the tests cited in Table II showed an inverse relationship between thickness and impact sensitivity.

2) Of the materials tested to date, seve:ai tend to indicate that impact sus , itivity in GOX is more pressure dependent than in LOX.

3) The impact sensitivity of the materials tested to date in GOX at the preesures tested showed enhanced impact sensitivity with higher pressure.

4) The rank ordering of the materials tested 80 far in LOX up to 1000 psia $\left(6.8 \times 10^{6}\right.$ Newtons $\left./ \mathrm{m}^{2}\right)$ is the same as the rank ordering resuiting from tests in LOX at 14.7 psia $\left(9.5 \times 10^{4}\right.$ Newtons $\left./ \mathrm{m}^{2}\right)$.

While there is agreement on the syntactical basis of probability theory as it applies to LOX/GOX rompatibility tasting, there is indeed the danger of a disparity between the syntactice and the explanation a.d interpretation of these signs in terms of the real-world. Statistics can be 2 useful indicator if cautiously and correctly applied. There is the distinct danfier of a retreat to, or a preoccupation with, "cure all" test methods and techniques, $r$ eanwhile disregarding the necessity for hard data acquired from statistically meaning ful numbers of tests.

Future plans at MSFC include inveatigation and research on a variety of LOX/GOX sensitivity testing metk ids and techniques. It is expected that configuration testing will continue to be necessary in special situations.

In the final analysis, the many questions of materiale compatibility in LOX and GOX will undoubtedly continue to be crucial considerations to the aerospace designer concerned with our future spese volucles and spacecraft." 
White and Ward (1966)

\section{"SUMMARY AND CONCLUSIONS}

The ignition of netals in oxygen and oxygen atruospheres was reviewerd from the viewpoints of (a) metriods that have hoe's used to study behavior, (b) cxperimental values that have been obtained, and ( $c$; the status of theories that permir the calculation of ignition temperatures.

While no clearcut definition of ignition cemperature has been developed, it appears probable that a definite or an absolute ignition temperature does exist for a particular metal-oxygen system. In general ternis, if the energy input as converted to heat is greater than the heat dissipation, a temperature will be reached at which ignitior, of the motal will occur. Practically. this temperature appears dependenc on many factors some of which aru relatively static ( $\epsilon . g$. , atmosphere, composition, purity, metal surface area and condition, etc.) and others that may be dynamic (e.g., pressure, impact, impact velocity, vibration, etc.). No standard test procedures or methods have heen developed to evaluate the ignition temperatures of metals. The net result is that varying values have been reported for the same or similar metal-oxygen systems.

Despite these differences, the following generalizations can be offered on the basis of the experimental evaluations performed to date:

(1) All metals, with the possible exception of gold and platinum, can be expected to ignite in oxygen at scme elevated temperature.

(2) Alloys of several systems have been shown to ignite in oxygen systems at relatively low temperatures and some at LOX temperarures if sorne external zource of energy input is present. Generally, the presence of a fresh rietal surface is also necessary to cause ignition at these low temperatures. Theso ignition-sensitive alloy svstems include the alloys of titanium, zixconium, thorium, urenium, lead, tin, and magnesium.

(3) A number of secondaxy euergy input sources heve been shown to cause ignition of these sensitive alloys in oxygen yotems. The - souces also probably produç a fresh metal aurface and aro identified as follows:

In Gaseous Oxygen

Electric spark

Functure

Streas rupture

In Liquir Oxygen

Mechanical impact

Explosive shock.

Puncturo 


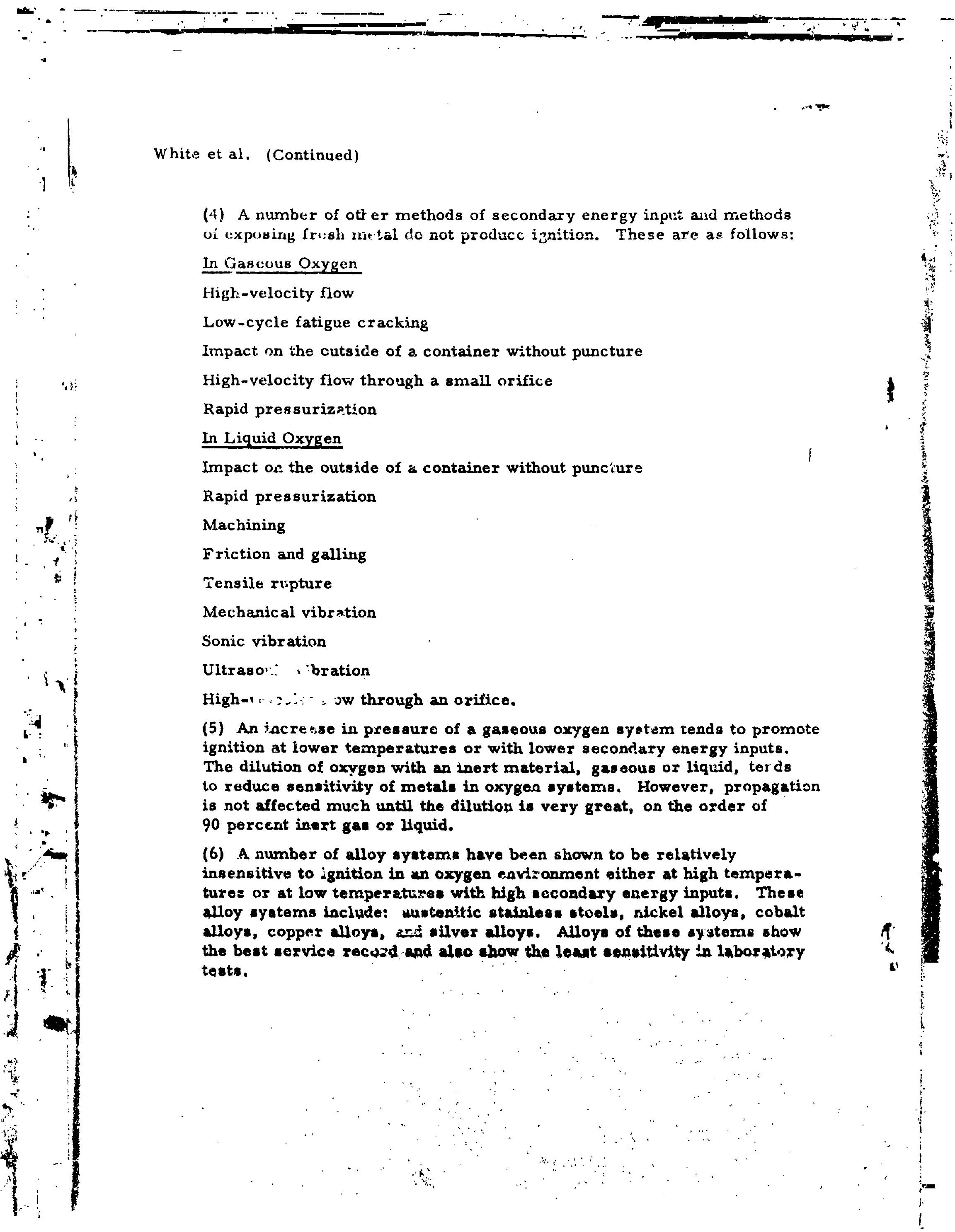


White at al. (Continued)

(7) Another sroup of alloys appears to be somewhat intermediate between thr sensitive and insensitive grcups cited in Items 2 and 6 . This group includes aluminum slloys, the 400 series siainless steels, and carbon and low-alloy high-strength steels. These materials would be expected to find imited use in relatively nonsensitive applications."

(R.maining ciscission has been omitted).

1.

$i$

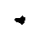

;

【

4 